\title{
AGR-1 Irradiated Test Train Preliminary Inspection and Disassembly First Look
}

Paul Demkowicz

Lance Cole Scott Ploger

Philip Winston

January 2011

The INL is a

U.S. Department of Energy

National Laboratory

operated by

Battelle Energy Alliance

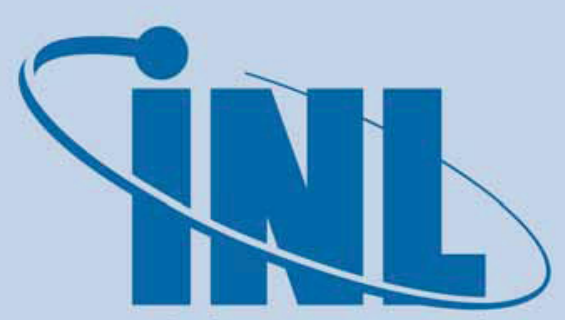

Idaho National Laboratory

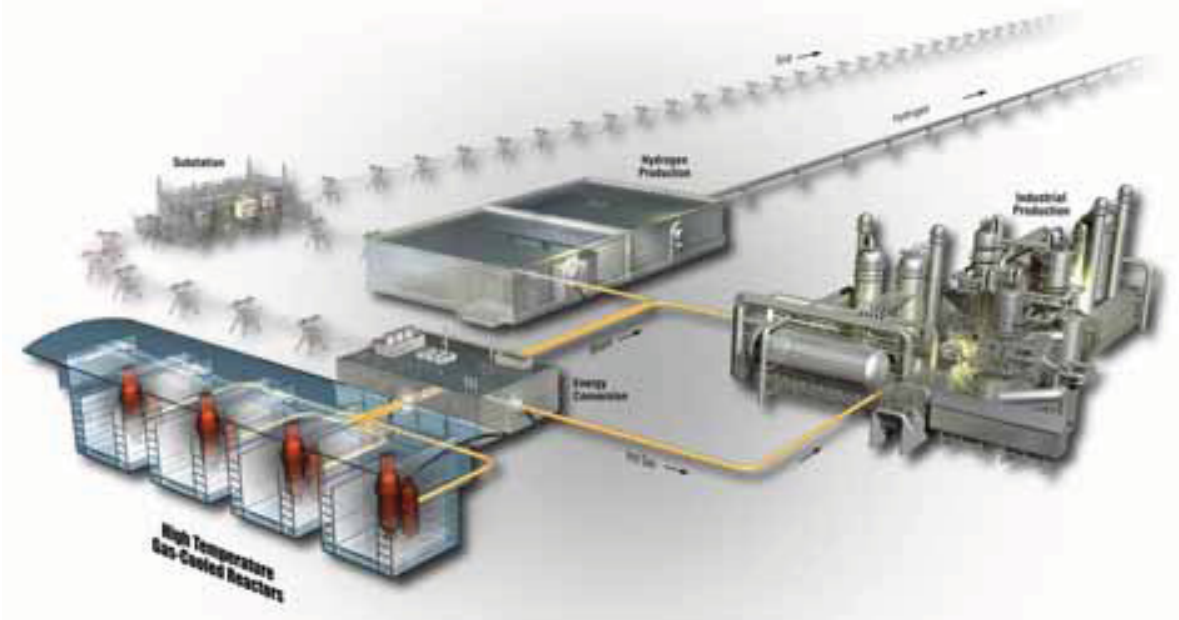




\section{DISCLAIMER}

This information was prepared as an account of work sponsored by an agency of the U.S. Government. Neither the U.S. Government nor any agency thereof, nor any of their employees, makes any warranty, expressed or implied, or assumes any legal liability or responsibility for the accuracy, completeness, or usefulness, of any information, apparatus, product, or process disclosed, or represents that its use would not infringe privately owned rights. References herein to any specific commercial product, process, or service by trade name, trade mark, manufacturer, or otherwise, does not necessarily constitute or imply its endorsement, recommendation, or favoring by the U.S. Government or any agency thereof. The views and opinions of authors expressed herein do not necessarily state or reflect those of the U.S. Government or any agency thereof. 


\title{
AGR-1 Irradiated Test Train Preliminary Inspection and Disassembly First Look
}

\author{
Paul Demkowicz, Lance Cole, Scott Ploger, Philip Winston
}

January 2011

Idaho National Laboratory

Next Generation Nuclear Plant Project

Idaho Falls, Idaho 83415

Prepared for the

U.S. Department of Energy

Office of Nuclear Energy

Under DOE Idaho Operations Office

Contract DE-AC07-05ID14517 



\section{Next Generation Nuclear Plant Project}

\section{AGR-1 Irradiated Test Train Preliminary Inspection and Disassembly First Look}

INL/EXT-10-20722

January 2011

Approved by:

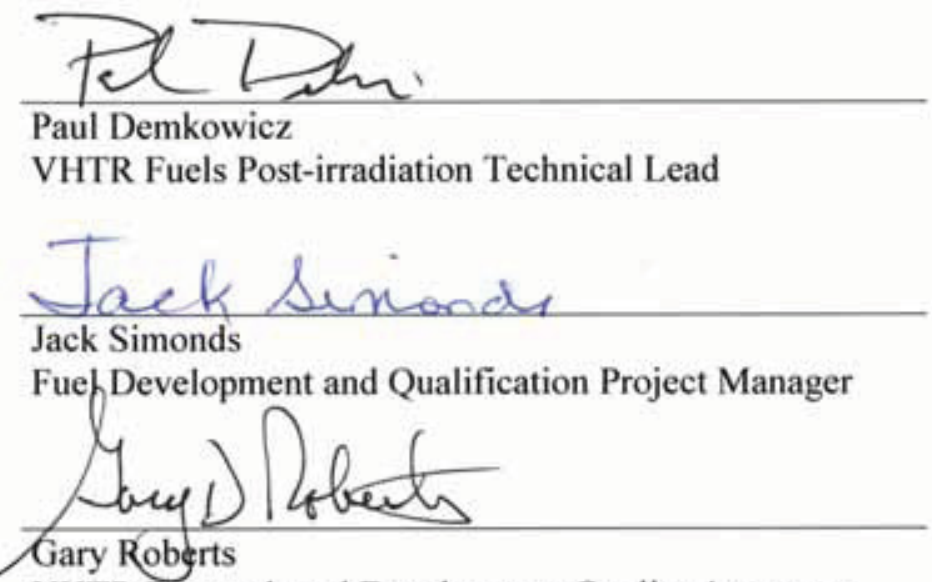

VHTR Research and Development Quality Assurance

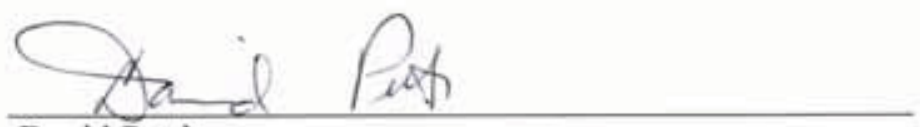

David Petti

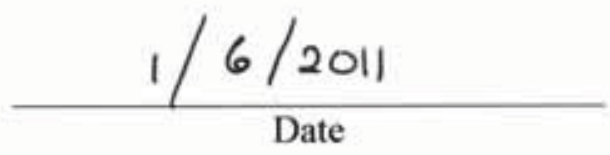

VHTR Research and Development Director
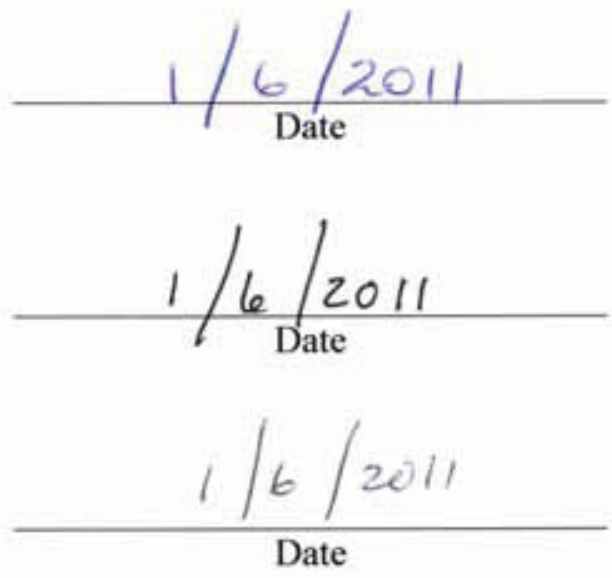



\section{Summary}

The AGR-1 irradiation experiment ended on November 6, 2009, after 620 effective full power days in the Advanced Test Reactor, achieving a peak burnup of $19.6 \%$ fissions per initial heavy metal atom. The test train was shipped to the Materials and Fuels Complex in March 2010 for post-irradiation examination (PIE). The first PIE activities included nondestructive examination of the test train, followed by disassembly of the test train and individual capsules and detailed inspection of the capsule contents, including the fuel compacts and the graphite fuel holders. Dimensional measurements of the compacts, graphite holders, and steel capsule shells were performed using a custom vision measurement system (for outer diameters and lengths) and conventional bore gauges (for inner diameters).

Gamma spectrometry of the intact test train gave a preliminary look at the condition of the interior components. No evidence of damage to compacts or graphite components was evident from the isotopic and gross gamma scans. Neutron radiography of the intact Capsule 2 showed a high degree of detail of interior components and confirmed the observation that there was no major damage to the capsule.

Disassembly of the capsules was initiated using procedures qualified during out-of-cell mockup testing. Difficulties were encountered during capsule disassembly because of irradiation-induced changes in some of the capsule components' properties, including embrittled niobium and molybdenum parts that were susceptible to fracture and swelling of the boronated graphite fuel holders that affected their removal from the capsule shells. This required various improvised modifications to the disassembly procedure to avoid damage to the fuel compacts. Ultimately, the capsule disassembly was successful and only one compact from Capsule 4 (out of 72 compacts in the test train) sustained damage during the disassembly process, along with the associated graphite holder.

The compacts were generally in very good condition upon removal. Only relatively minor damage or markings were visible using high resolution photographic inspection. Compact dimensional measurements indicated diametrical shrinkage of 0.9 to $1.4 \%$ and length shrinkage of 0.2 to $1.1 \%$. The shrinkage was somewhat dependent on compact location within each capsule and within the test train. Compacts exhibited a maximum diametrical shrinkage at a fast neutron fluence of approximately $3 \times 10^{21} \mathrm{n} / \mathrm{cm}^{2}$.

The boronated graphite holders were in good condition although some damage was sustained during disassembly, primarily attributed to swelling of the holders in Capsules 2-5 (holders initially contained nominally $7.0 \%$ boron carbide as a burnable poison). The diametrical swelling of the holders in Capsules $2-5$ was 0.7 to $2.1 \%$, and in some cases (particularly in Capsule 3) appear to have expanded sufficiently to contact the steel capsule liner, which complicated extraction from the capsules. By contrast, the graphite holders in Capsules 1 and 6 (containing nominally 5.5\% boron carbide) exhibited diametrical shrinkage of 0.4 to $0.9 \%$. The drastic difference in the dimensional change behavior of the two types of graphite is primarily attributed to the difference in $\mathrm{B}_{4} \mathrm{C}$ content and the different location in the test train (outer Capsules 1 and 6 received on average a fast fluence approximately 27\% lower than the other capsules).

One of the irradiated compacts (6-3-2) has been deconsolidated into individual particles and analyzed using the leach-burn-leach process. The deconsolidation process proceeded very well, with very little matrix material observed adhering to the separated particles. The leach-burn-leach results indicate a single particle with a defective $\mathrm{SiC}$ coating, detected during the post-burn leach step. A number of additional AGR-1 compacts will be analyzed in a similar manner as PIE proceeds. 
Continuing PIE of the fuel compacts and the irradiation capsule components is focused on assessing the performance of the multicapsule instrumented test train and components and evaluating the fuel performance during irradiation and during post-irradiation accident simulations. This includes high temperature safety testing in pure helium at temperatures up to $1800^{\circ} \mathrm{C}$. 


\section{CONTENTS}

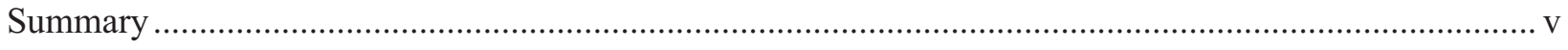

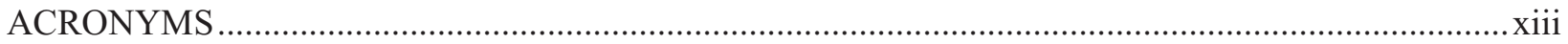

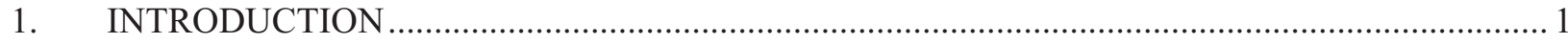

2. AGR-1 RECEIPT AND NONDESTRUCTIVE EXAMINATION .......................................... 3

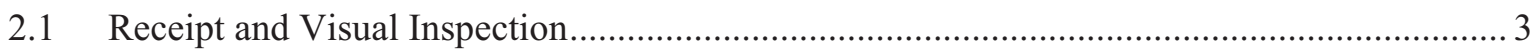

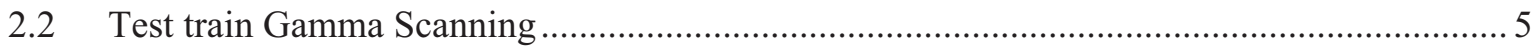

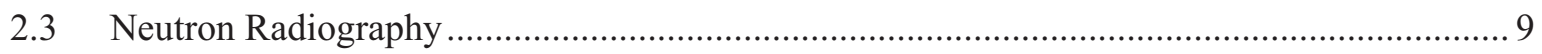

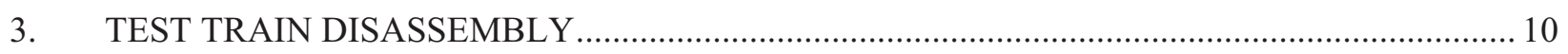

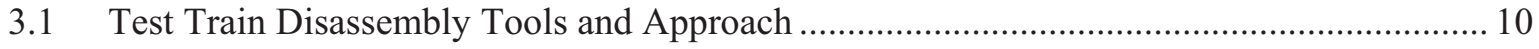

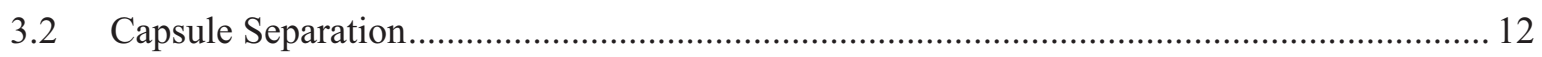

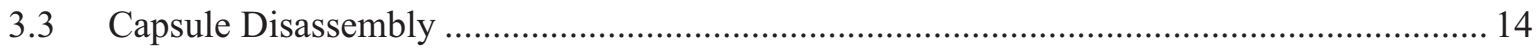

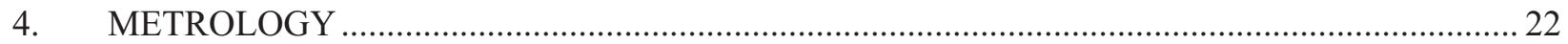

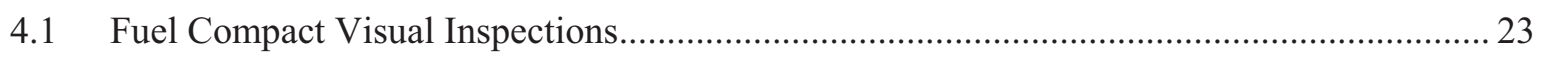

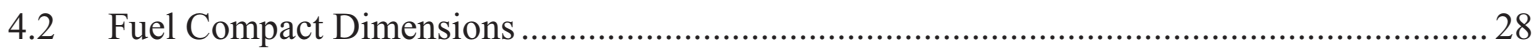

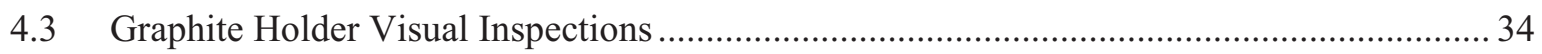

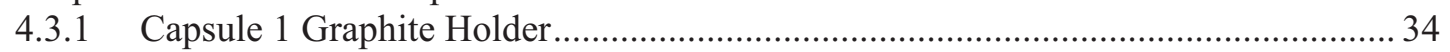

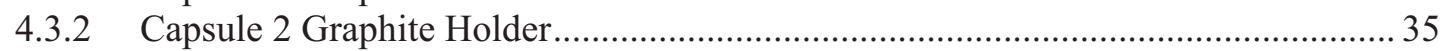

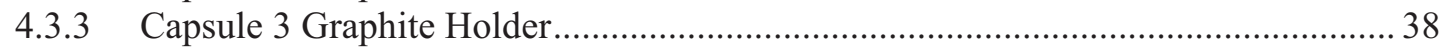

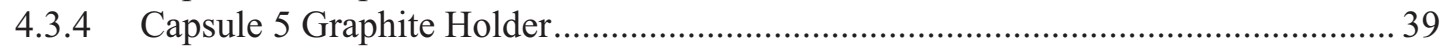

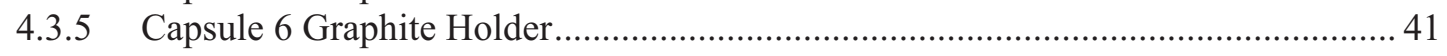

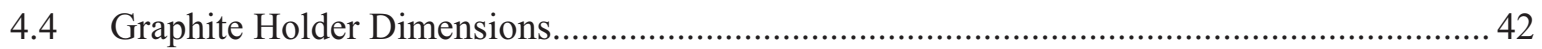

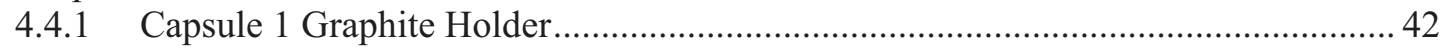

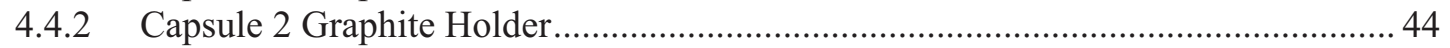

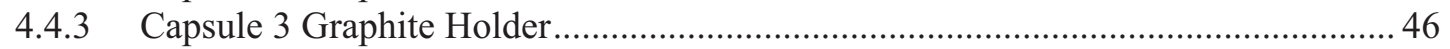

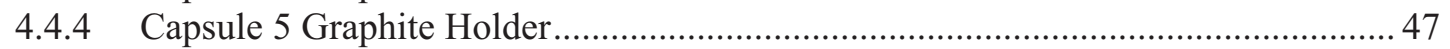

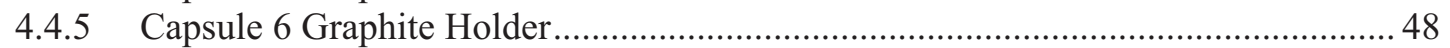

4.4.6 Graphite Holder Dimensions Summary and Discussion....................................... 49

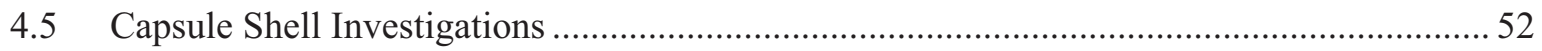

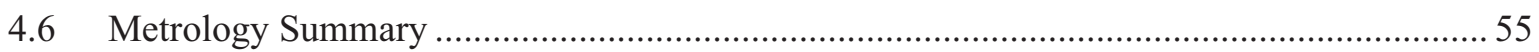

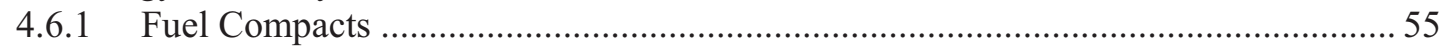

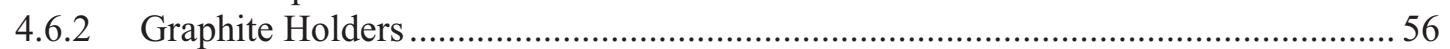

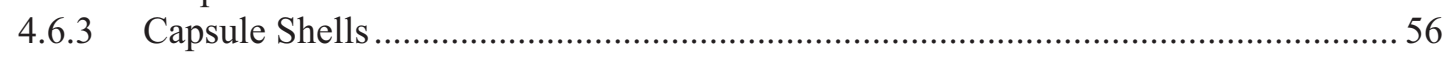

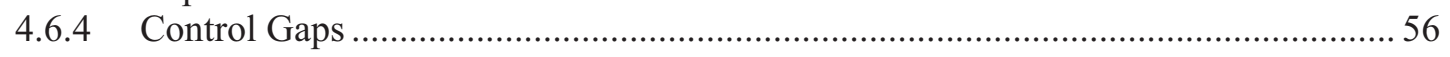

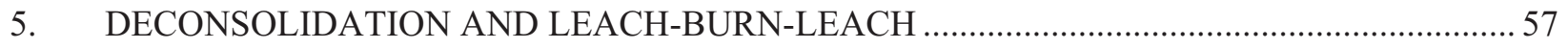

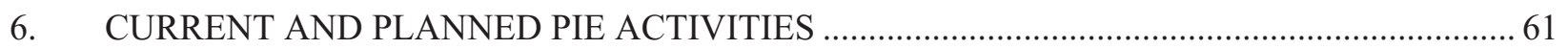

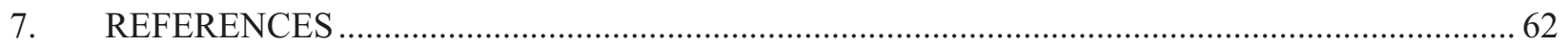

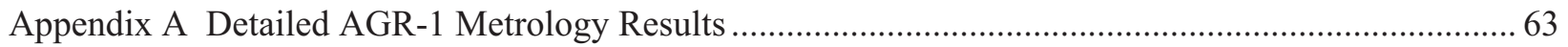




\section{FIGURES}

Figure 1. Photograph (left) and x-radiograph (right) of an unirradiated baseline AGR-1 fuel compact. Uranium oxycarbide kernels and nonfueled end caps are clearly visible in the $\mathrm{x}$-radiograph. 1

Figure 2. Numbering scheme for AGR-1 compacts. 3

Figure 3. GE-2000 shipping cask with AGR-1 test train backing into the HFEF facility for unloading. 4

Figure 4. Leadout cracking at the Capsule 6/leadout interface caused by the guillotine cut made to separate the main test train from the leadout. .5

Figure 5. Scratches on Capsule 6 caused by handling in the ATR reactor canal. 5

Figure 6. Test train holder (shown in the boxed region) used to mount the test train in the HFEF PGS positioning stage.

Figure 7. Cut-away top view of the test train gamma scanning geometry. The orientation shown is for scanning of Stack 2. 6

Figure 8. Gross gamma scan data for the individual fuel stacks of the AGR-1 test train......................... 7

Figure 9. Test train gross gamma scan detail for Capsule 2, Stack 1 ....................................................... 8

Figure 10. Selected isotopic gamma count data for Stack 1; Capsule 6 is at the top of the plot. ................ 8

Figure 11. Neutron radiograph of Capsule 2 taken prior to disassembly................................................. 9

Figure 12. A single AGR-1 capsule shown prior to irradiation. .................................................................. 10

Figure 13. Disassembly slide table with disassembly and metrology equipment..................................... 10

Figure 14. Some of the rail mounted capsule disassembly tools. ............................................................ 11

Figure 15. Capsule circumferential cuts made to separate and disassemble the capsule......................... 12

Figure 16. Compact push tool with force gauge measurement............................................................ 12

Figure 17. Aluminum storage container for irradiated compacts. ........................................................ 12

Figure 18. Tri-tool cutter set up to separate the leadout stub from the test train (image taken using a mirror).

Figure 19. Gas lines and thermocouple sheaths exposed as Capsule 6 is cut and pulled away from Capsule 5.

Figure 20. Shattered 3/32 inch molybdenum thermocouples (indicated by arrows) resulting from use of a guillotine cutter. 14

Figure 21. Through-tubes of Capsule 4 that broke near the capsule head. 15

Figure 22. Image showing location of through tube that pulled out of Capsule 2 head 16

Figure 23. Picture of vises and pry bar used to attempt to pull apart the cut Capsule 4 shell. 17

Figure 24. Cleaved end of Capsule 4 graphite holder. Bottom of the Level 2 compacts are visible. 17

Figure 25. Pry tool used to pry the floor section from Capsule 6. 18

Figure 26. Floor of Capsule 3 showing two through-tubes that broke instead of pulling out of the capsule floor. 
Figure 27. Capsule 5 graphite holder after capsule disassembly. .........................................................2 20

Figure 28. Graphite spacer (left) and Grafoil spacer (right) taken from Capsule 5 ................................ 20

Figure 29. AGR-1 noncontact metrology system during mockup qualification. ....................................2 23

Figure 30. Typical appearance of AGR-1 fuel compacts (1-1-1 at left, 2-3-3 at right)..........................24

Figure 31. Upper crack in Compact 4-1-3 and bottom notch in Compact 4-2-2, both from holder

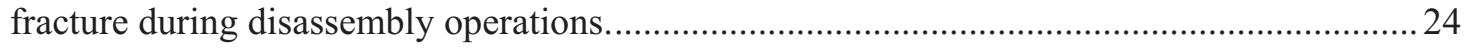

Figure 32. Shallow notches in end-cap corners of Compacts 6-3-2 (left) and 2-1-2 (right)....................25

Figure 33. Axially oriented lateral scratches on Compacts 6-4-1 (left) and 3-4-1 (right). .......................25

Figure 34. Broad marks from apparent abrasion on Compacts 5-4-1 (left) and 2-4-1 (right)...................26

Figure 35. Dark "scuff” marks on Compacts 4-3-2 (left) and 4-3-1 (right)...........................................26

Figure 36. Small rounded deposits on sides of Compact 4-4-1 (left) and Compact 4-4-2 (right). ............28

Figure 37. Average diameter changes of individual AGR-1 compacts..................................................2 29

Figure 38. Average length changes of individual AGR-1 compacts......................................................2 29

Figure 39. Diameter changes averaged for all fuel compacts in each AGR-1 capsule.............................. 30

Figure 40. Length changes averaged for all fuel compacts in each AGR-1 capsule.................................. 31

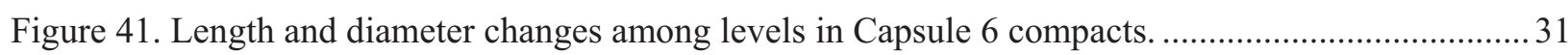

Figure 42. Length and diameter changes among levels in Capsule 1 compacts. ..................................... 32

Figure 43. Tapered diameter shrinkage in outermost Capsule 6 and Capsule 1 compacts......................... 32

Figure 44. Average diameter changes for all AGR 1 compacts as a function of calculated fast

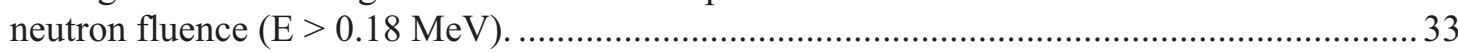

Figure 45. Average length changes for all AGR 1 compacts versus calculated fast neutron fluence

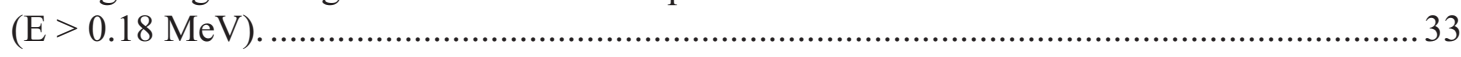

Figure 46. Relationship of graphite holder azimuths to in-pile orientation. ............................................ 34

Figure 47. Holder 1, top end left, 240-degree azimuth facing camera.................................................. 35

Figure 48. Images of bottom (left) and top (right) ends of Holder 1, 0-degree azimuth to right................ 35

Figure 49. Holder 2, bottom end left, 240-degree azimuth facing camera. .............................................. 36

Figure 50. Top end of Holder 2, 240-degree azimuth facing camera. ...................................................... 36

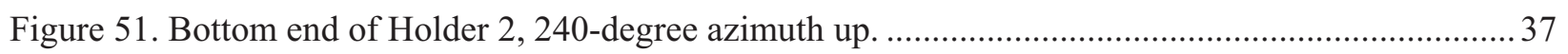

Figure 52. Bottom (a) and top (b) ends of Holder 2, both with 0-degree azimuth at right; top end

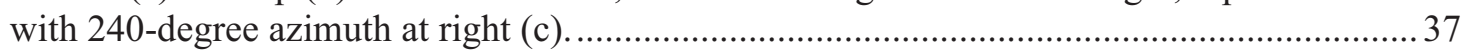

Figure 53. Holder 3, top end left, 0 -degree azimuth (marked by bright paint) facing camera.................... 38

Figure 54. Top of Holder 3 with 240-degree azimuth facing camera (Stack 3 hole opened by

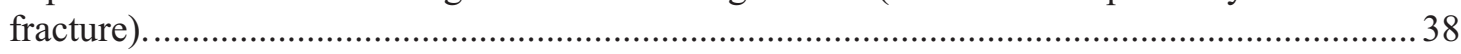

Figure 55. Views of bottom (left) and top (right) of Holder 3, 0-degree azimuth to right........................ 39

Figure 56. Holder 5, bottom end left, 240-degree azimuth facing camera. ............................................. 39

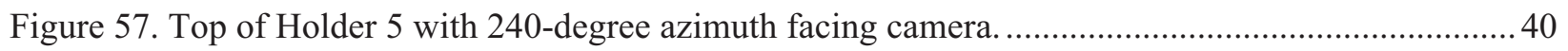


Figure 58. Holder 5 bottom end (left, 0 degrees to right) and top end (right, 240 degrees to right).......... 40

Figure 59. Holder 6, top end left, 240-degree azimuth facing camera................................................... 41

Figure 60. Reflective deposit and small crack on Holder 6 top, 120-degree azimuth facing camera.

Figure 61. Crack near Holder 6 bottom from through-tube removal, 0-degree azimuth toward camera 42

Figure 62. Relative changes in OD along the length of Holder 1 ...................................................... 43

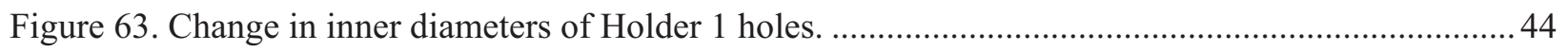

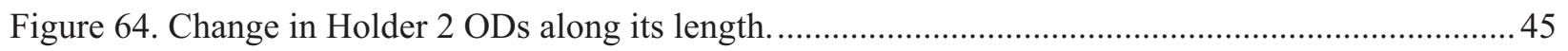

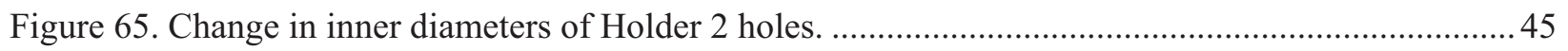

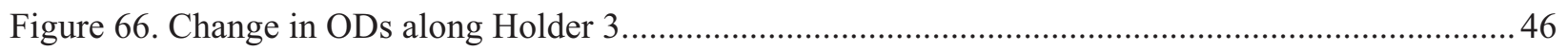

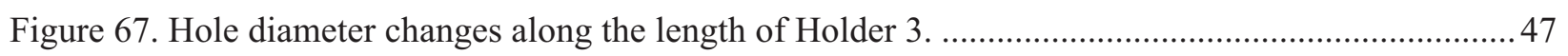

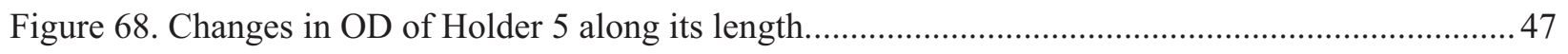

Figure 69. Hole diameter changes along the length of Holder 5 ......................................................... 48

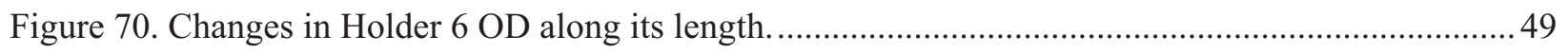

Figure 71. Hole diameter changes along the length of Holder 6 ........................................................... 49

Figure 72. Relative change in ODs of AGR-1 graphite holders. ...................................................... 50

Figure 73. Outer diameter averages for the five AGR-1 graphite holders measured................................51

Figure 74. Interiors of bottom of Shell 3 (left) and middle of Shell 4 (right) ...........................................53

Figure 75. Interior deposits near bottom of Shell 2 (left) and middle of Shell 5 (right)..........................54

Figure 76. Internal deposits near the top (left) and toward the bottom (right) of Shell 1 ........................54

Figure 77. Deposited material near the top (left) and middle (right) of Shell 6.......................................5

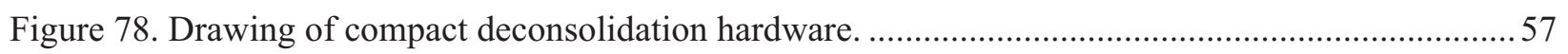

Figure 79. Deconsolidated particles with matrix debris (Compact 6-3-2) ............................................... 58

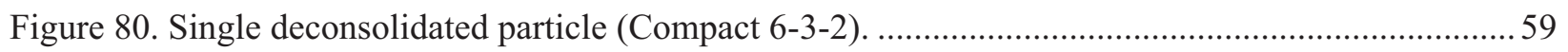

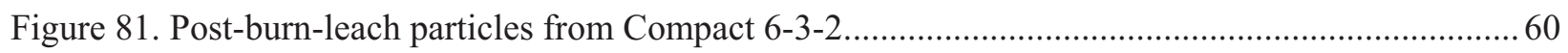

Figure A-1. Example of analyzed compact image (here Compact 5-3-3). ............................................. 64

Figure A-2. Compact backup metrology apparatus in use on an irradiated AGR-1 compact.................... 72

Figure A-3. Example of analyzed graphite holder composite (here Holder 6 at 0 degrees)..................... 74

Figure A-4. Bore gauge measurements of hole diameters in the Capsule 1 graphite holder..................... 75

Figure A-5. Backup metrology apparatus in use on Capsule 1 graphite holder....................................... 81 


\section{TABLES}

Table 1. Characteristics of the AGR-1 irradiated capsules. 15

Table 2. Cumulative lessons learned as the AGR-1 disassembly activities progressed............................2 21

Table 3. Number of fuel compacts showing various types of anomalies...................................................2 27

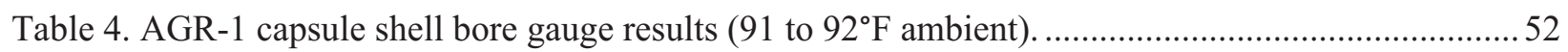

Table 5. Outer diameters of Capsule 5 shell, in inches $\left(86^{\circ} \mathrm{F}\right.$ ambient $)$................................................... 55

Table 6. Total uranium in deconsolidation and leach-burn-leach solutions for Compact 6-3-2..............60

Table A-1. Metrology results from AGR-1 Capsule 1 fuel compacts $\left(92^{\circ} \mathrm{F}\right.$ ambient $)$............................ 66

Table A-2. Metrology results from AGR-1 Capsule 2 fuel compacts $\left(93^{\circ} \mathrm{F}\right.$ ambient). .......................... 67

Table A-3. Metrology results from AGR-1 Capsule 3 fuel compacts $\left(93^{\circ} \mathrm{F}\right.$ ambient $)$............................ 68

Table A-4. Metrology results from AGR-1 Capsule 4 fuel compacts $\left(87^{\circ} \mathrm{F}\right.$ ambient). .......................... 69

Table A-5. Metrology results from AGR-1 Capsule 5 fuel compacts $\left(83^{\circ} \mathrm{F}\right.$ ambient $)$........................... 70

Table A-6. Metrology results from AGR-1 Capsule 6 fuel compacts $\left(84^{\circ} \mathrm{F}\right.$ ambient)........................... 71

Table A-7. Backup and image dimensions from select AGR-1 fuel compacts (in inches)......................73

Table A-8. Exterior metrology results from AGR-1 Capsule 1 graphite holder ( $93^{\circ} \mathrm{F}$ ambient)...............76

Table A-9. Hole diameter results from Capsule 1 graphite holder $\left(82^{\circ} \mathrm{F}\right.$ ambient $)$...............................76

Table A-10. Exterior metrology results from AGR-1 Capsule 2 graphite holder $\left(86^{\circ} \mathrm{F}\right.$ ambient $) \ldots \ldots \ldots \ldots . . . .77$

Table A-11. Hole diameter results from AGR-1 Capsule 2 graphite holder $\left(86^{\circ} \mathrm{F}\right.$ ambient $)$.................... 77

Table A-12. Exterior metrology results from AGR-1 Capsule 3 graphite holder $\left(92^{\circ} \mathrm{F}\right.$ ambient)............ 78

Table A-13. Hole diameter results from AGR-1 Capsule 3 graphite holder $\left(92^{\circ} \mathrm{F}\right.$ ambient $) \ldots \ldots \ldots \ldots \ldots \ldots \ldots . . . . . . . . .78$

Table A-14. Exterior metrology results from AGR-1 Capsule 5 graphite holder $\left(90^{\circ} \mathrm{F}\right.$ ambient)............. 79

Table A-15. Hole diameter results from AGR-1 Capsule 5 graphite holder $\left(92^{\circ} \mathrm{F}\right.$ ambient $) \ldots \ldots \ldots \ldots \ldots \ldots \ldots . . . . .79$

Table A-16. Exterior metrology results from AGR-1 Capsule 6 graphite holder $\left(86^{\circ} \mathrm{F}\right.$ ambient)............ 80

Table A-17. Hole diameter results from AGR-1 Capsule 6 graphite holder $\left(88^{\circ} \mathrm{F}\right.$ ambient $)$..................... 80 


\section{ACRONYMS}

AGR Advanced Gas Reactor

ATR Advanced Test Reactor

ECAR Engineering Calculation and Analysis Report

HFEF Hot Fuel Examination Facility

ID inner diameter

IMGA irradiated microsphere gamma analysis

INL Idaho National Laboratory

LED light-emitting diode

NGNP Next Generation Nuclear Plant

OD outer diameter

ORNL Oak Ridge National Laboratory

PGS precision gamma scanner

PIE post-irradiation examination

VHTR very high temperature reactor 


\section{AGR-1 Irradiated Test Train Preliminary Inspection and Disassembly First Look}

\section{INTRODUCTION}

The Next Generation Nuclear Plant (NGNP) Fuel Development and Qualification Program was established to perform the requisite research and development on tri-strucural isotropic coated particle fuel to support deployment of a very high temperature reactor (VHTR). The overarching goal of the program is to provide a baseline fuel qualification data set to support licensing and operation of a VHTR. To achieve these goals, the program includes the elements of fuel fabrication, irradiation, post-irradiation examination (PIE) and accident testing, fuel performance modeling, and fission product transport analysis [Petti 2010].

A series of fuel irradiation experiments are planned in the Advanced Test Reactor (ATR) at Idaho National Laboratory (INL). These experiments are intended to provide data on fuel performance under irradiation, support fuel process development, qualify the fuel for normal operating conditions, provide irradiated fuel for accident testing, and support the development of fuel performance and fission product transport models. The first of these irradiation tests, designated AGR-1, began in the ATR in December of 2006 and ended in November 2009. This experiment was primarily to act as a shakedown test of the multicapsule test train design and to provide early data on fuel performance that will be used in fuel fabrication process development. This test will also provide samples for post-irradiation accident testing, where fission product retention of the fuel at high temperatures will be experimentally measured. The capsule design and details of the irradiation experiment have been presented previously [Grover 2010; Pope 2010].

AGR-1 fuel particles consist of $350 \mu \mathrm{m}$ diameter uranium oxycarbide kernels coated with a pyrocarbon buffer $(100 \mu \mathrm{m})$, inner pyrolytic carbon $(40 \mu \mathrm{m})$, silicon carbide $(35 \mu \mathrm{m})$, and outer pyrolytic carbon $(40 \mu \mathrm{m})$ layers. Uranium enrichment in the kernels is $19.8 \%$ [Maki 2009]. The particles were pressed into right cylinderical compacts using a thermosetting carbonaceous material. The fuel compacts are nominally $25 \mathrm{~mm}$ in length and $12.3 \mathrm{~mm}$ in diameter and contain approximately 4,100 coated particles as shown in Figure 1.
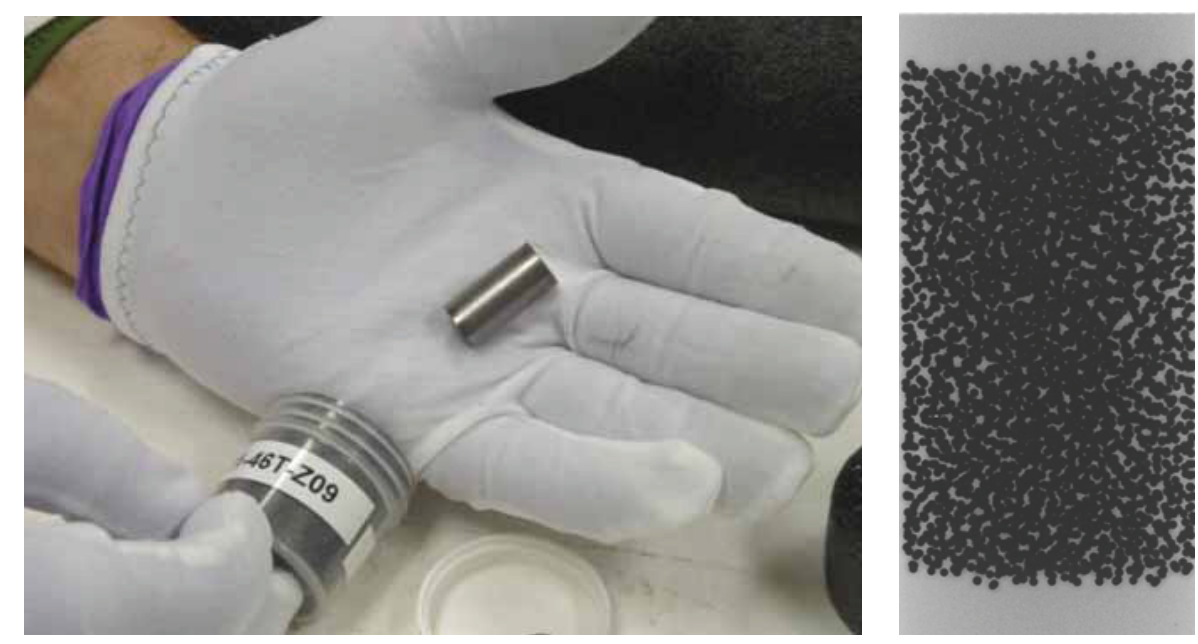

Figure 1. Photograph (left) and x-radiograph (right) of an unirradiated baseline AGR-1 fuel compact. Uranium oxycarbide kernels and nonfueled end caps are clearly visible in the x-radiograph. 
The compacts have $\sim 1.5 \mathrm{~mm}$ thick fuel-free end caps at the top and bottom, as shown in Figure 1. A baseline fuel type and 3 fuel variants were included in the AGR-1 irradiation, with each variant fabricated by varying one step of the coating process to produce slightly different inner pyrolytic carbon or $\mathrm{SiC}$ coating properties. One key goal of the experiment is to identify any fuel performance differences between the fuel types, either during the irradiation or during post-irradiation high temperature accident tests, in order to support optimization of the fuel fabrication process and eventual selection of a reference fuel for qualification.

A total of 72 compacts were irradiated in the AGR-1 experiment in six different capsules. The experiment completed 620 effective full power days in the reactor and achieved a calculated peak burnup of $19.6 \%$ fissions per initial heavy metal atom with zero particle failures observed based on the measured fission gas release-to-birth ratios [Pope 2010]. At completion of the irradiation, the test train was shipped to the Materials and Fuels Complex at the INL for post-irradiation examination.

The post-irradiation examination of coated particle fuel is focused primarily on verifying coating integrity and fission product retention of the fuel during normal irradiation conditions and during offnormal accident scenarios. As AGR-1 is the first irradiation of its kind in the NGNP program and involves a complex, multicapsule, instrumented lead experiment containing four different types of fuel, the PIE will also seek to investigate the performance of test train and components. The specific objectives and planned PIE activities for the AGR-1 experiment are presented in the AGR-1 PIE Plan [Demkowicz 2010].

This report presents the results of initial test train nondestructive examinations, capsule disassembly, visual inspection and dimensional measurements of compacts and graphite fuel holders, and preliminary results of compact deconsolidation/leach-burn-leach testing on one of the Capsule 6 compacts.

Throughout this report the fuel compacts are identified using a numbering system developed for the AGR-1 test train. This is based on the specific capsule, level, and stack number for each compact. Figure 2 identifies the stack and position (or level) numbers in a particular capsule. For example, Compact 6-4-1 refers to the compact in Capsule 6 at the top (Level 4) of Stack 1. 


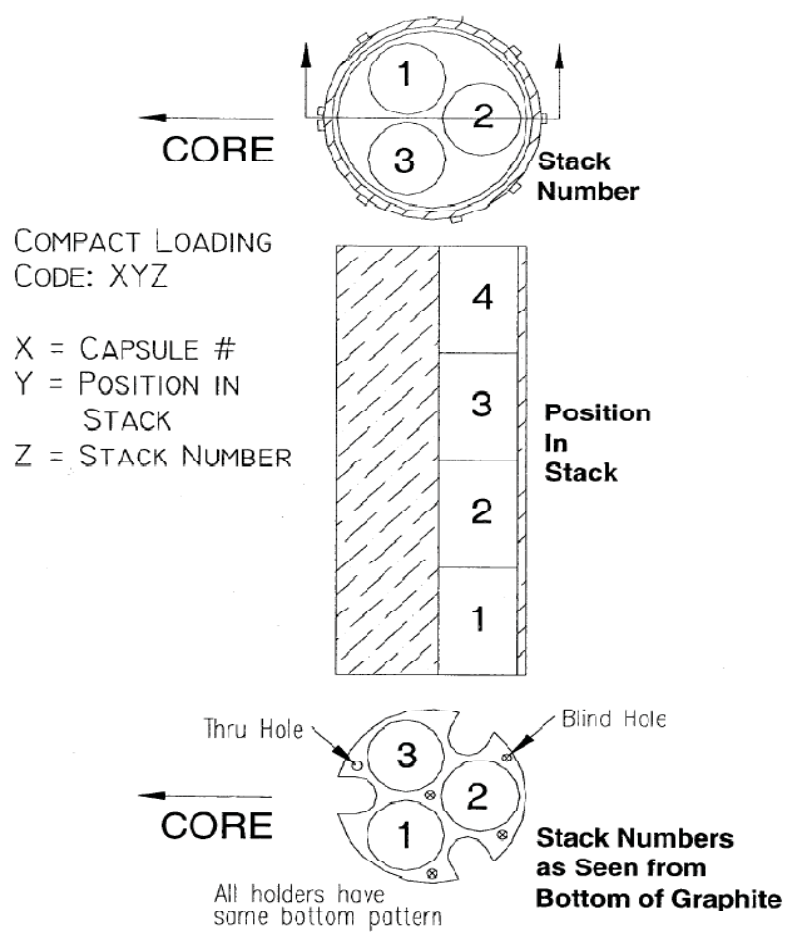

Figure 2. Numbering scheme for AGR-1 compacts.

\section{AGR-1 RECEIPT AND NONDESTRUCTIVE EXAMINATION 2.1 Receipt and Visual Inspection}

The AGR-1 test train was transported from the INL ATR to the INL Hot Fuel Examination Facility (HFEF) in a GE-2000 shipping cask on March 25, 2010 (see Figure 3). Cask cavity height limitations necessitated cutting the test train. The test train was cut approximately 1 inch above the top of Capsule 6 with a remotely operated guillotine type cutter in the Dry Transfer Cubicle of the ATR. This resulted in the 43-inch-long test section (containing all six capsules) that was shipped to HFEF. ATR Operators also cut and saved approximately 40 inches of the test train leadout (located immediately above the test capsules) for future shipment to HFEF where the exhaust lines from the six capsules will be examined and analyzed for radioisotopes that may have plated onto the tube walls. 


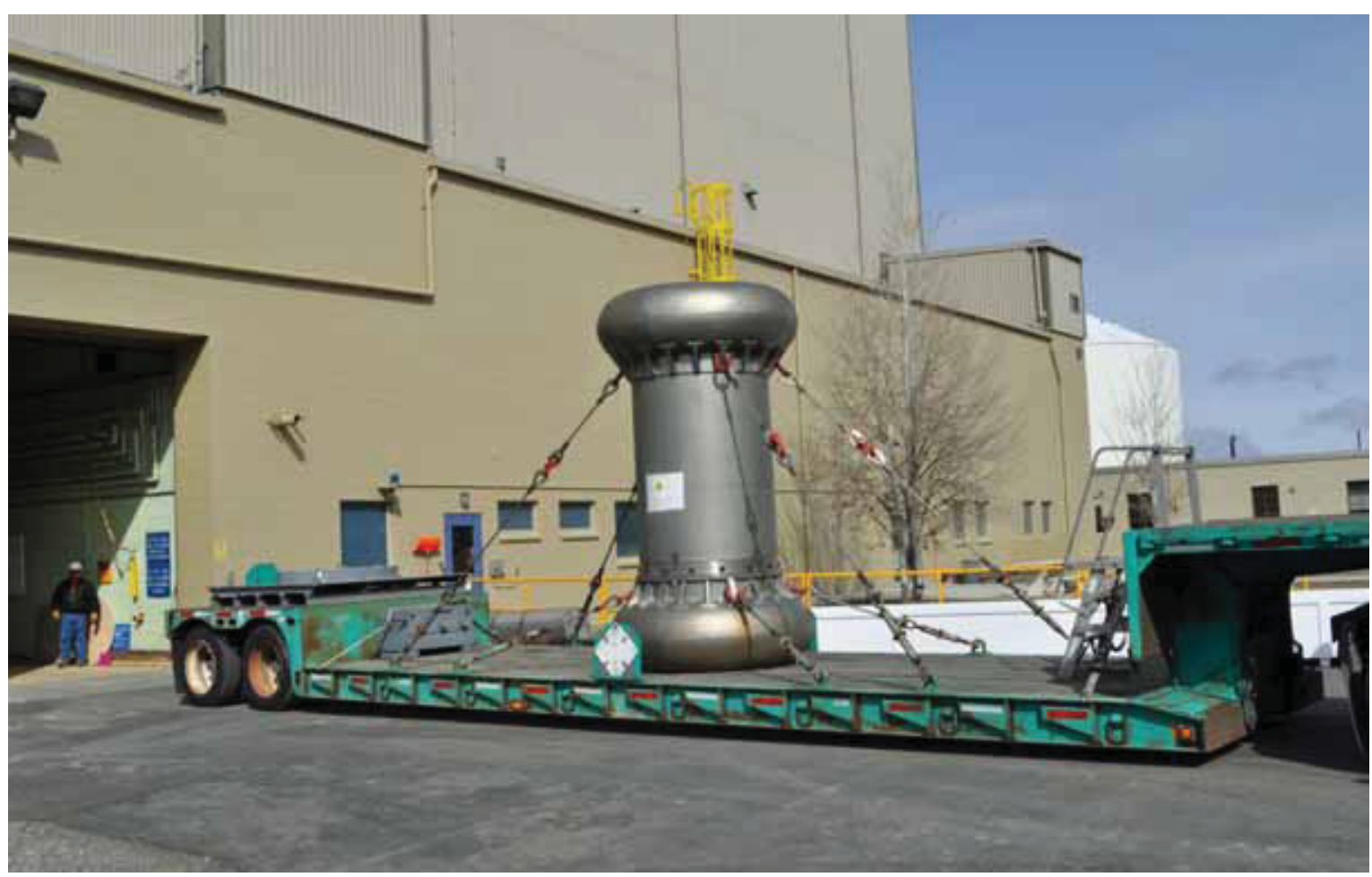

Figure 3. GE-2000 shipping cask with AGR-1 test train backing into the HFEF facility for unloading.

The test train was received at the HFEF hot cell and visually inspected on March 29, 2010. The inspection found no evidence of weld deterioration or other serious flaws on the test train exterior. It was noted that the guillotine cut made above the Capsule 6 head caused cracking of the leadout in the area immediately above Capsule 6 as shown in Figure 4. The integrity of Capsule 6 was not compromised by this cracking. This type of cracking was not observed with a mockup assembly of unirradiated stainless steel. The cracking was believed to be an indication of the expected stainless steel embrittlement caused by the high neutron fluence experienced by the test train.

Capsule 6 had radial scratches in the top $25 \%$ of the capsule, primarily on one side of the test train. Some of these scratches are shown in Figure 5. Longitudinal scratches were also present along the length of the test train with the most evident scratches being on Capsules 2 and 3. The scratches are attributed to the efforts required to remove the test train and leadout assembly from the ATR reactor through the under water reactor channel chute. Metal structure in the passage way interfered with the test train during the removal process, making it difficult to remove the test train from the reactor. Operators had to twist, turn, and pull the unit to get through the passage. 


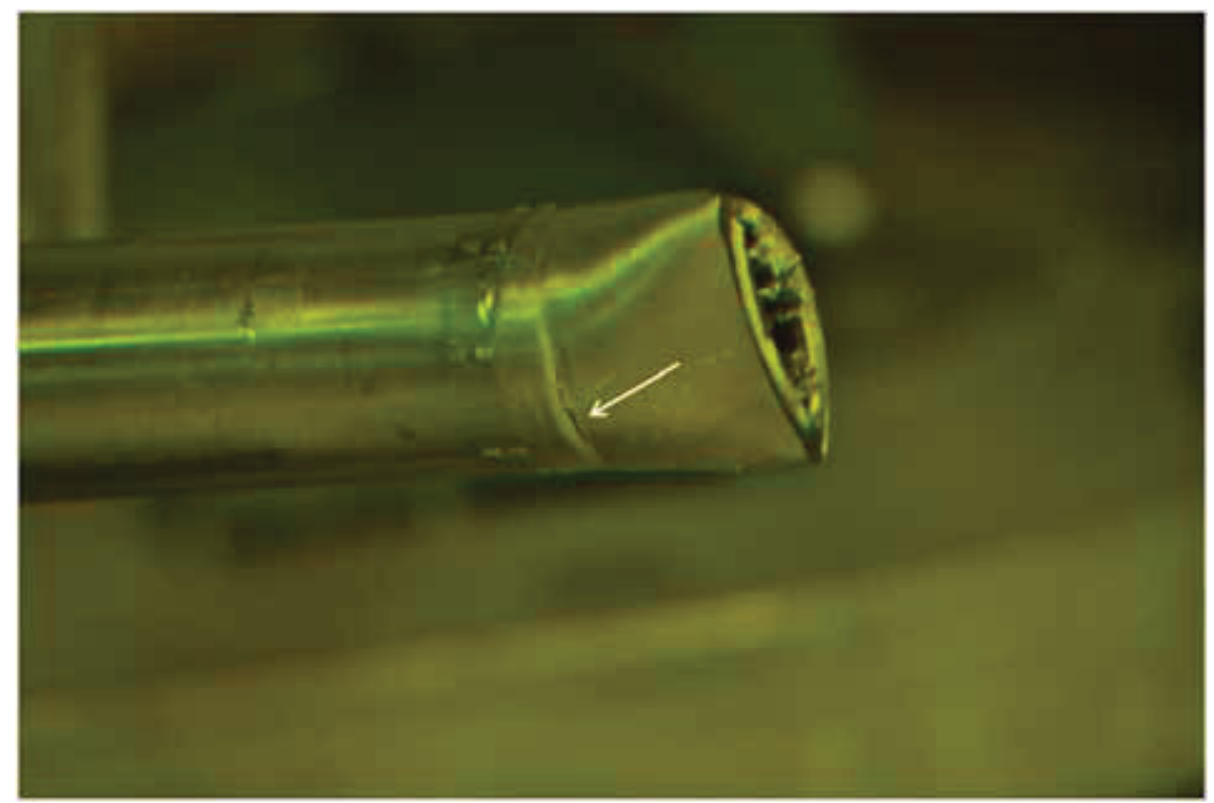

Figure 4. Leadout cracking at the Capsule 6/leadout interface caused by the guillotine cut made to separate the main test train from the leadout.

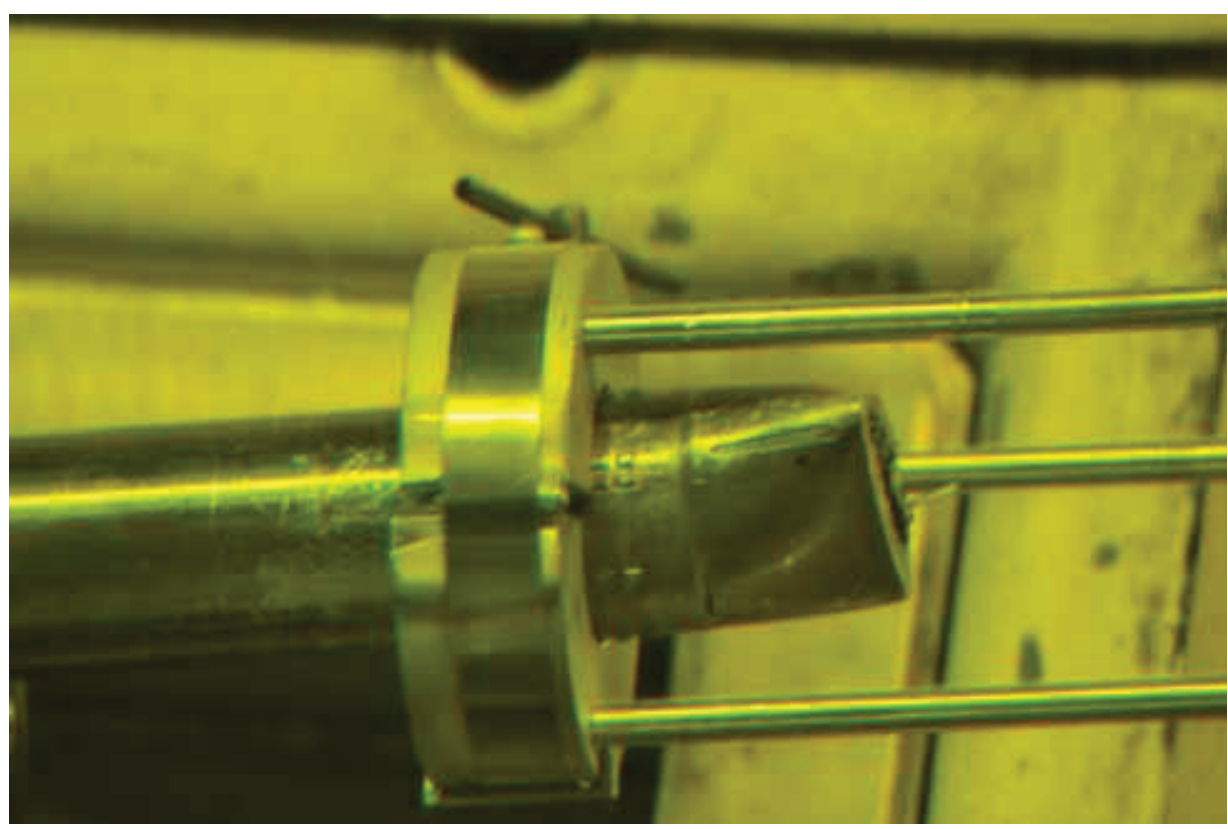

Figure 5. Scratches on Capsule 6 caused by handling in the ATR reactor canal.

\subsection{Test train Gamma Scanning}

Gamma scanning of the test train using the HFEF Precision Gamma Scanner (PGS) was performed following the visual examination. The holder shown in Figure 6 was used to attach the test train to the PGS positioning stage. This holder held the test train within roughly 0.09 to 0.15 inch of vertical (depending on the orientation) along the three foot long fueled portion. Gamma scanning of the AGR-1 test train was initiated on April 2, 2010. 
Complete axial scans of each compact stack were performed, collecting both gross and isotopic data. The test train was positioned vertically in front of the PGS collimator so that each compact stack was counted separately, which required a portion of the stacks toward the radial center of the capsules to be uncounted due to the slight overlap of the compacts (Figure 7). The scans were performed using a collimator slit 7/8-inch wide (horizontal direction) and 0.05 -inch tall (vertical direction), moving in 0.05 -inch steps. The entire fueled length of the test train was scanned using this approach.

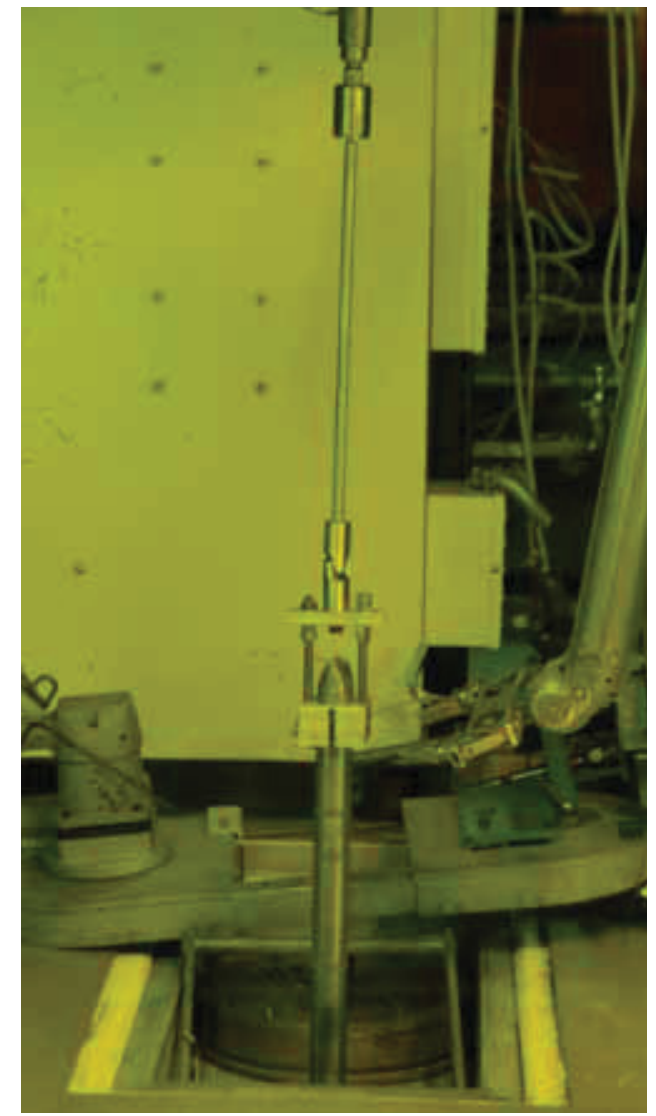

Figure 6. Test train holder (shown in the boxed region) used to mount the test train in the HFEF PGS positioning stage.

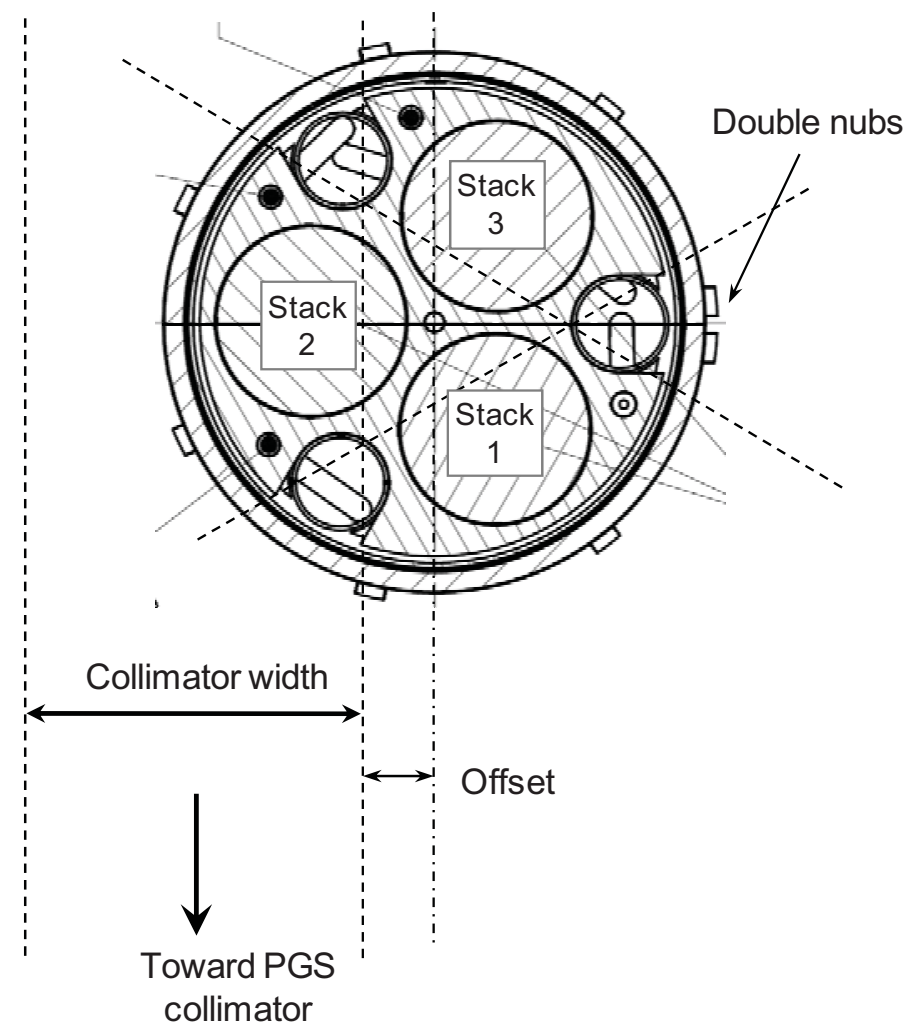

Figure 7. Cut-away top view of the test train gamma scanning geometry. The orientation shown is for scanning of Stack 2.

The fuel compacts and interior components of the test train (e.g., capsule heads, niobium gas lines, hafnium shrouds, compact end caps) could be easily resolved from the gross and isotopic data. Figure 8 shows the gross gamma scans from each of the three vertical scans covering the three fuel stacks. The results from all three stacks were very similar. Figure 9 shows a detail scan for Capsule 2, Stack 1 . The fuel compacts, nonfueled compact end caps, and steel components of the test train are clearly visible. Evidence of the thin hafnium shroud in each capsule is also visible in the gross gamma scans and even more apparent in the isotopic data. Figure 10 shows isotopic data for selected radioisotopes for the Stack 1 scan. Capsule steel components, notably the capsule head and capsule floor, are evident in the Co-60 scan. The Hf-181 count data are dominated by the Hf shrouds around the fueled portions of the capsules, but also contain a contribution from the $\mathrm{HfO} 2$ insulation in the experimental Mo-Nb thermocouples. The location and depth of thermocouples in each capsule are confirmed by the Hf- 181 count data. The fuel compacts are evident from the Cs-137 and Zr-95 scan data. Note that anomalously low readings near the top of Capsule 6 were due to gamma ray attenuation by the fixture used to secure the test train to the PGS positioning stage. 

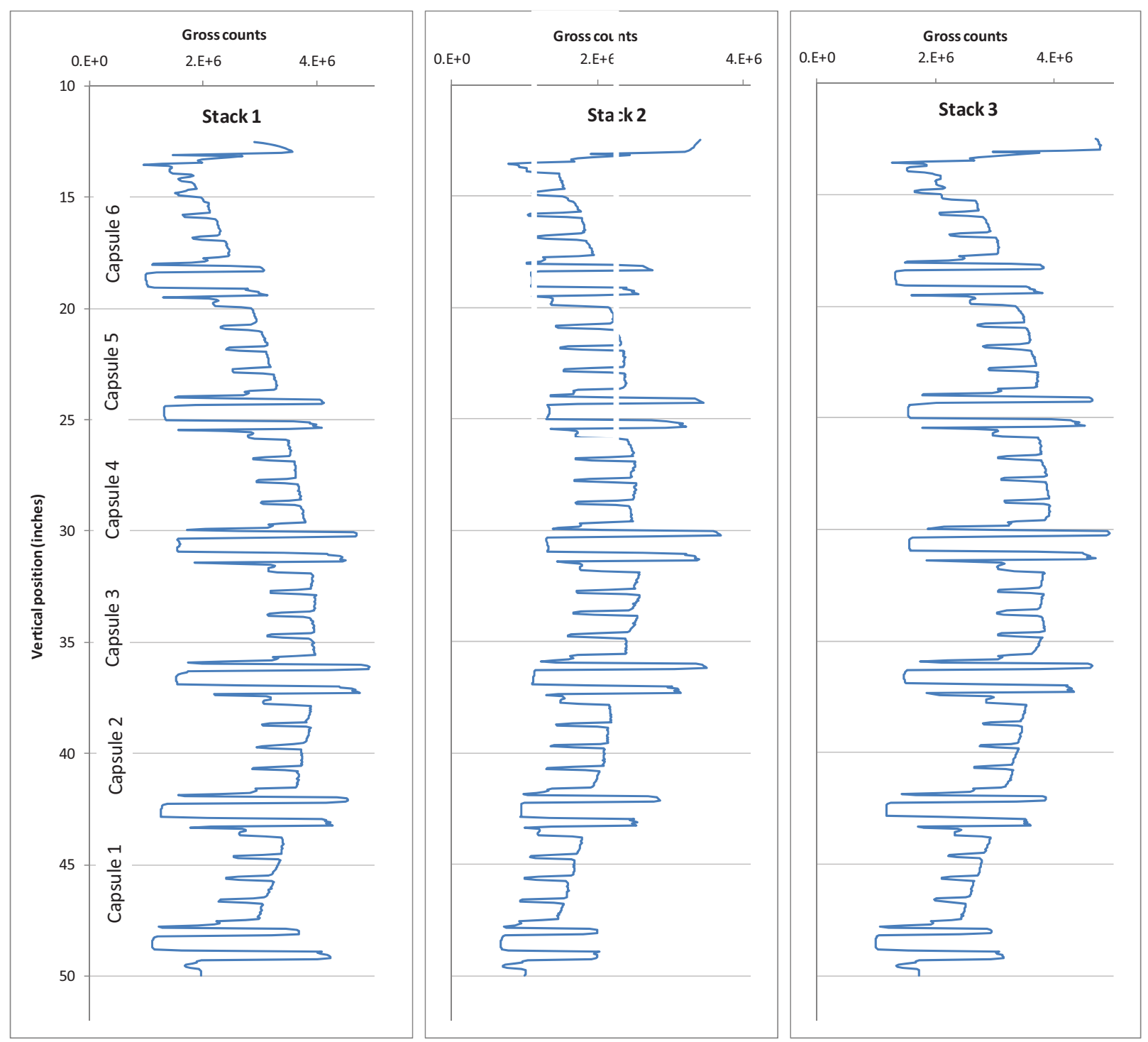

Figure 8. Gross gamma scan data for the individual fuel stacks of the AGR-1 test train. 


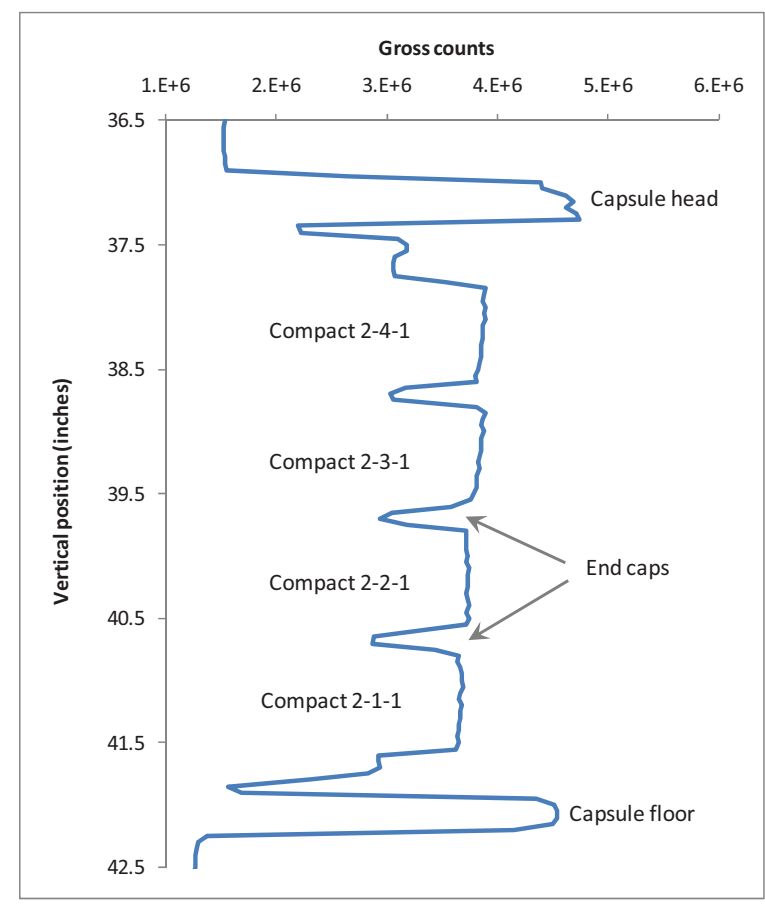

Figure 9. Test train gross gamma scan detail for Capsule 2, Stack 1.

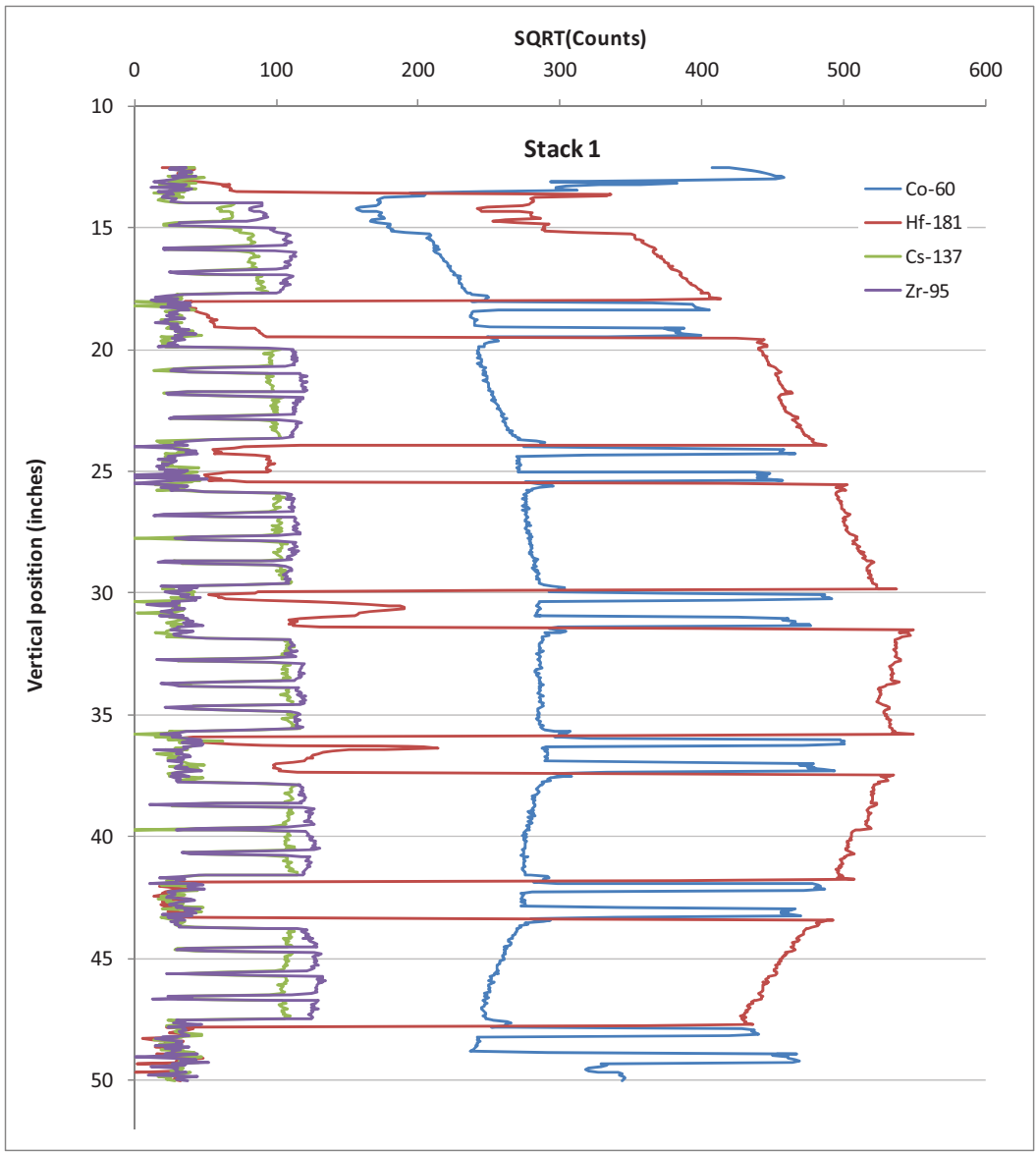

Figure 10. Selected isotopic gamma count data for Stack 1; Capsule 6 is at the top of the plot. 
The data revealed that no axial displacement of the compacts had taken place (within the linear resolution of the method). In addition, the nonfueled gap immediately above the Capsule 4 graphite holder and fuel compacts was examined in detail with long count times ( 1 to 2 hours) in an attempt to observe fission products that might have migrated from the fuel (e.g., Cs-137, Ag-110m). No fission products were observed in this region above the level of background. It is evident that more sensitive methods of analysis on the graphite capsule components, including gamma counting them after removal from the large count-rate metallic capsule components, will be needed to detect and quantify fission products in these parts.

\subsection{Neutron Radiography}

The capability for neutron radiography of the entire intact test train was not available when the test train was first received at HFEF because of an upgrade to the neutron radiography reactor that was in progress. It was decided to perform neutron radiography on one of the intact capsules after sectioning the test train into separate intact capsules but prior to capsule disassembly (discussed in Section 3.3). This was done once the neutron radiography reactor was functional in order to assess the usefulness of this method for nondestructive analysis on future irradiated advanced gas reactor (AGR) test trains.

Figure 11 shows a radiograph taken of intact Capsule 2. The top of the capsule is at the top of the figure. This scan was taken with the double nubs (oriented toward the ATR core center during irradiation) facing the viewer in the image. The radiograph provides some detail of the condition of the capsule components. Note that the Grafoil spacers are slightly bowed on each end of the capsule. Based on the level of detail observed in the Capsule 2 radiographs, it appears that this technique will be useful for assessing the condition of interior components in future irradiated AGR test trains.

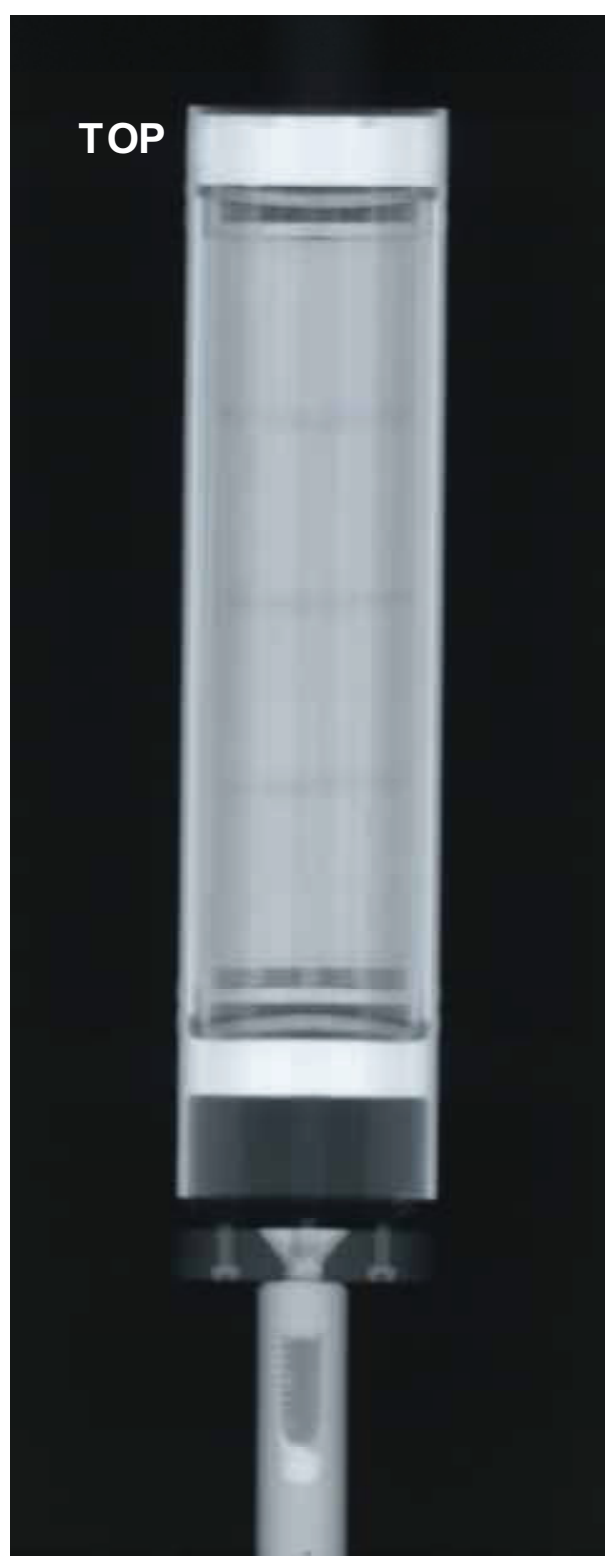

Figure 11. Neutron radiograph of Capsule 2 taken prior to disassembly. 


\section{TEST TRAIN DISASSEMBLY}

\subsection{Test Train Disassembly Tools and Approach}

After gamma scanning was complete, the test train was separated into individual capsules (shown in Figure 12). The capsules were then disassembled and the irradiated fuel compacts and other capsule components were retrieved for testing and analysis. Custom remotely operated tools were used to make the required circumferential cuts on the outer shell of the capsules (stainless steel tubing plus liners). The tool used to separate the capsules and cut the individual capsule shells was a modified Tri-Tool Model 572AC Server Master portable tubing lathe mounted on the rails of a slide table as shown in Figure 13. Rail mounted remote handling tools such as the clamp vises and support cradle (shown in Figure 14) were used to handle the test train and its components during the capsule shell removal process. The clamp vises were used as the support and movement mechanism for other handling tools used during the disassembly and metrology operations.

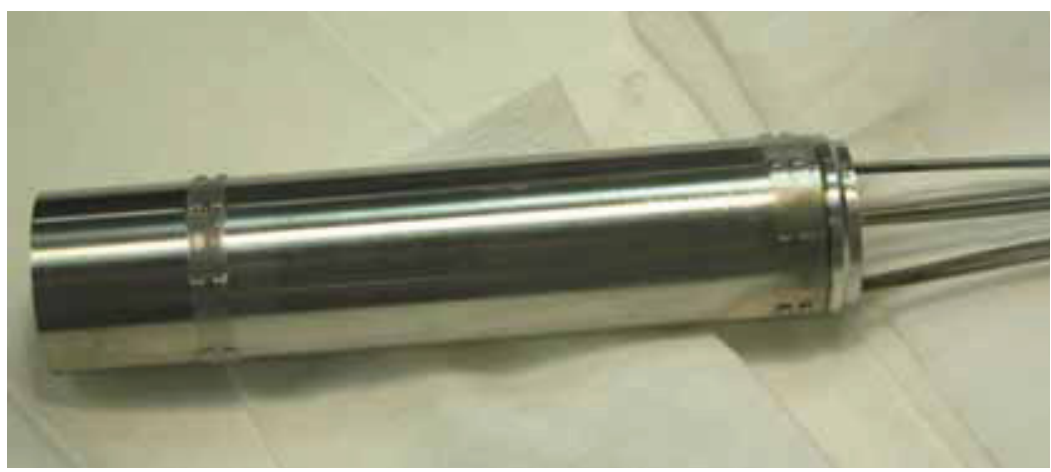

Figure 12. A single AGR-1 capsule shown prior to irradiation.

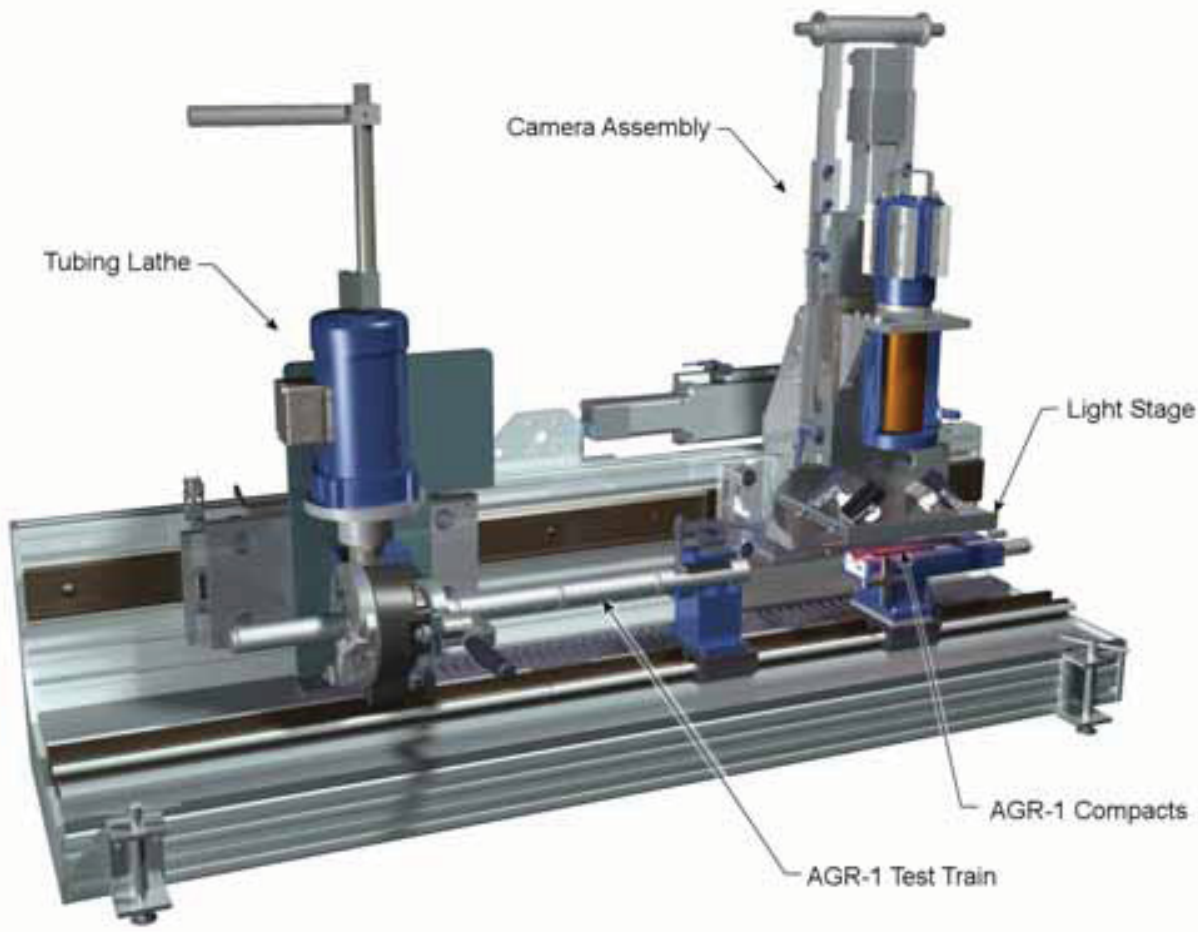

Figure 13. Disassembly slide table with disassembly and metrology equipment. 


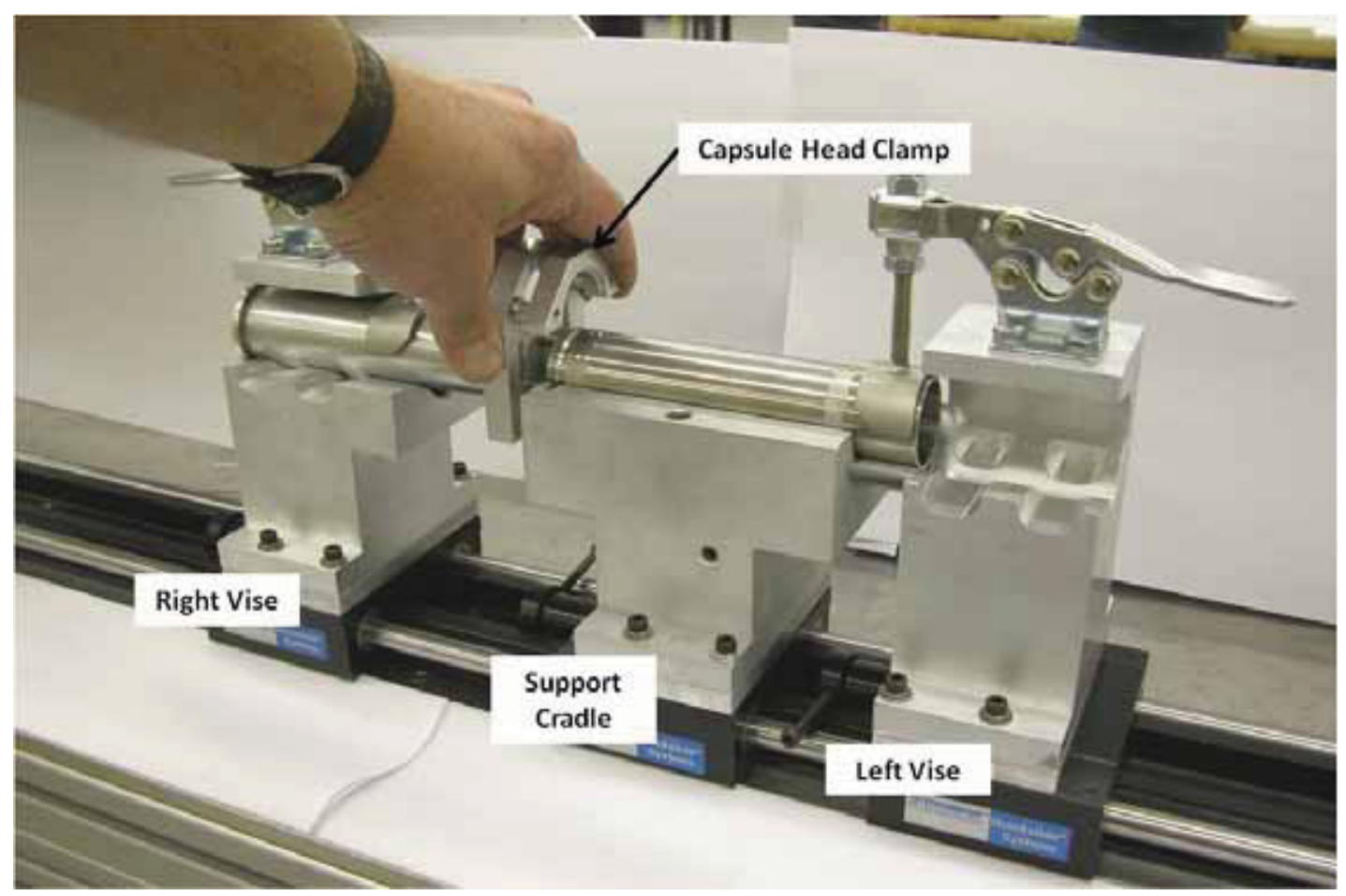

Figure 14. Some of the rail mounted capsule disassembly tools.

The approach for test train disassembly involved making a single circumferential cut near the capsule head to separate the capsules. As each capsule is separated from the test train, the thermocouple leads attached to the capsule head (see Figure 12) were cut and discarded and the exhaust gas lines from each capsule cut, labeled, and saved in designated containers for analytical activities to assess fission product migration behavior.

The initial approach adopted to disassemble the capsules was to make a circumferential cut at the head and then to pull the capsule head, through-tubes, and graphite holder from the capsule shell. Figure 15 shows where this circumferential head cut was made on the capsule shell to separate the test train into its individual capsule components and where the capsule shell was cut to allow disassembly of the capsule. Note that the figure shows circumferential cuts to remove the shell at both the head and floor of the capsule shell. The floor cut was added based on experience gained from disassembly of several capsules, as explained in Section 3.3.

The graphite holder could then be removed from the through-tube assembly and the compacts pushed out of the holder using a tool with a force gauge attached as shown in Figure 16, photographed, and placed in the individual storage containers shown in Figure 17. This disassembly sequence had to be altered several times during AGR-1 disassembly activities, as discussed in Section 3.3, as test train components behaved differently than expected because of deformation during irradiation.

Flux wires, melt wires, and niobium thermocouple sleeves inserted in the graphite holders have not been removed at the time of this writing but will be removed for analysis after in-cell gamma counting activities on the graphite holders have been completed. Removal of these items will involve coring, cutting, or breaking up the graphite holder to free them from the graphite holder assembly.

All capsule components are given unique identifiers and cataloged to preserve the identity of the component and the location within the test train from which the component was removed. For example, the capsule number, level, and stack number (as in Figure 2) were recorded for each fuel compact. 


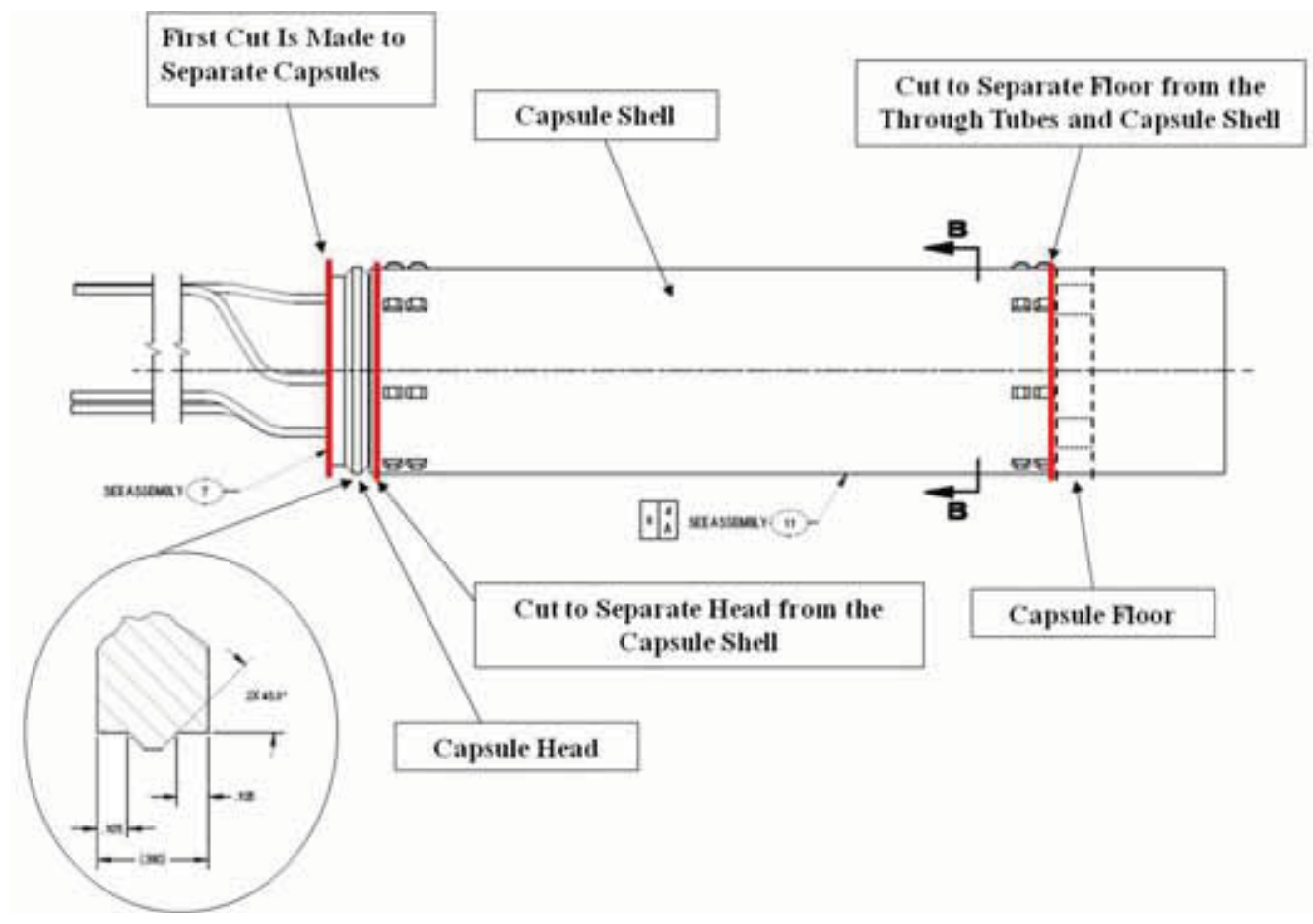

Figure 15. Capsule circumferential cuts made to separate and disassemble the capsule.
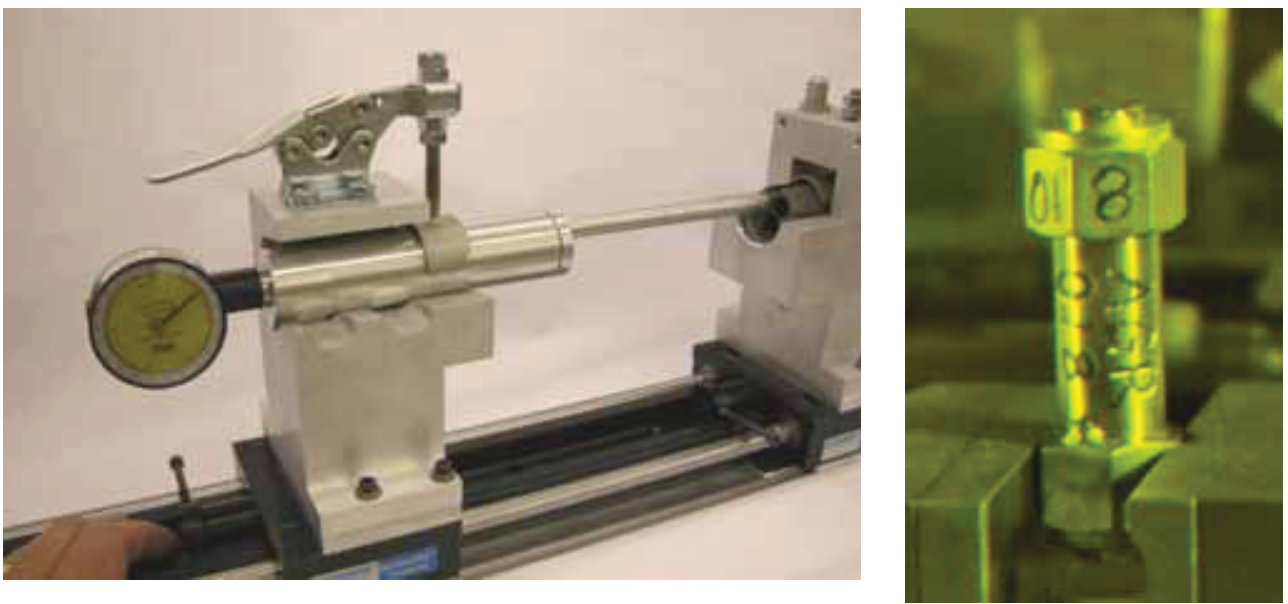

Figure 16. Compact push tool with force gauge

Figure 17. Aluminum storage container for measurement. irradiated compacts.

\subsection{Capsule Separation}

Activities were initiated on April 13, 2010, to separate each of the six capsules from the welded test train assembly. The contact exposure rate of the test train was in excess of $100,000 \mathrm{R} / \mathrm{hr}$ and 3 - $\mathrm{ft}$ rates were approximately $1,000 \mathrm{R} / \mathrm{hr}$. The modified tri-tool pipe cutter assembly (which utilizes a lathe-type cutter bit) that was used to separate the test train capsules and leadout stub is shown in Figure 18.

Figure 18 also shows how the test train and cutter were configured to cut the leadout stub (approximately 1 inch long) from the test train assembly. The six capsules were then successfully separated using the remotely operated cutter. 


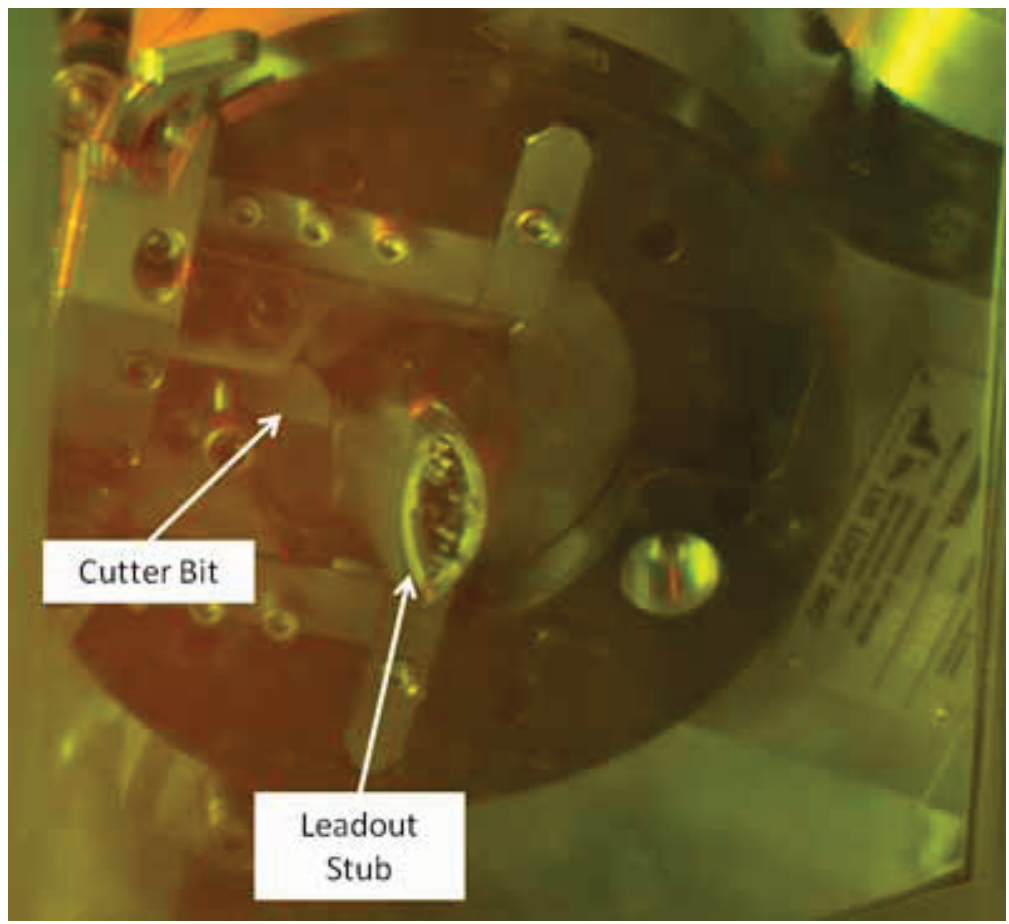

Figure 18. Tri-tool cutter set up to separate the leadout stub from the test train (image taken using a mirror).

As each test train capsule was removed, the metallic gas lines and thermocouple sheaths from the capsules below (routed within the through-tubes of the capsules) became accessible as shown in Figure 19. As each capsule was removed, the exposed portion of the remaining gas lines was progressively longer. The gas lines and the thermocouples attached to the exposed capsule head were removed and identified based on position in the capsule head and physical inspection. The exhaust gas lines were placed in storage containers for further examination and the inlet gas lines and thermocouple sheaths discarded.

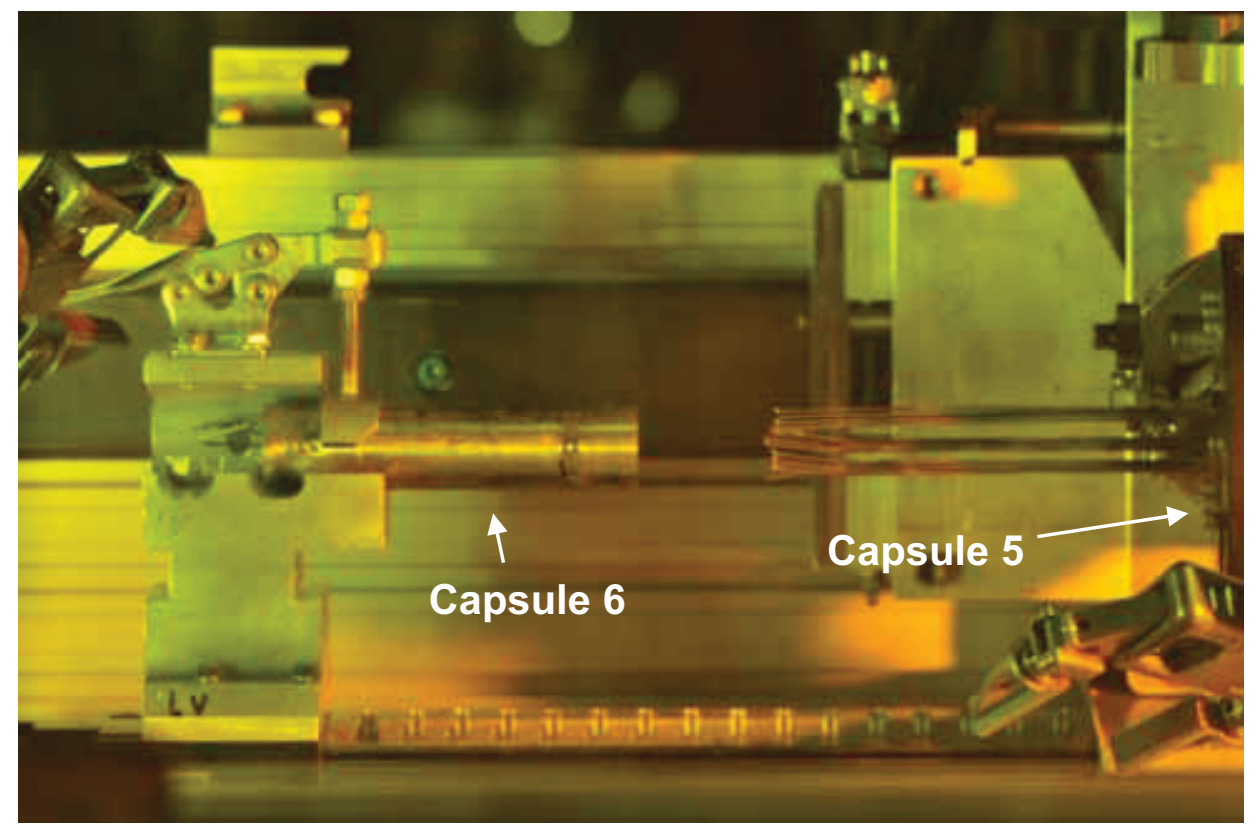

Figure 19. Gas lines and thermocouple sheaths exposed as Capsule 6 is cut and pulled away from Capsule 5. 
The gas lines and thermocouple sheaths were found to be embrittled (due to neutron fluence) and very fragile. The niobium gas lines fractured easily by simply bending them to approximately 90 degrees with manipulators. The molybdenum-sheathed thermocouples also showed evidence of embrittlement as demonstrated by the shattered appearance of the metal sheath where the guillotine cut was made as shown in Figure 20. The figure also shows chunks out of the molybdenum sheath of the visibly larger 3/32 inch diameter Type $\mathrm{N}$ thermocouple sheaths used only in Capsule 6.

The six capsules were successfully separated and placed in 2-gallon paint can storage containers. These cans provided easy manipulator access and room to store removed components from the capsule, as needed, during the disassembly process.

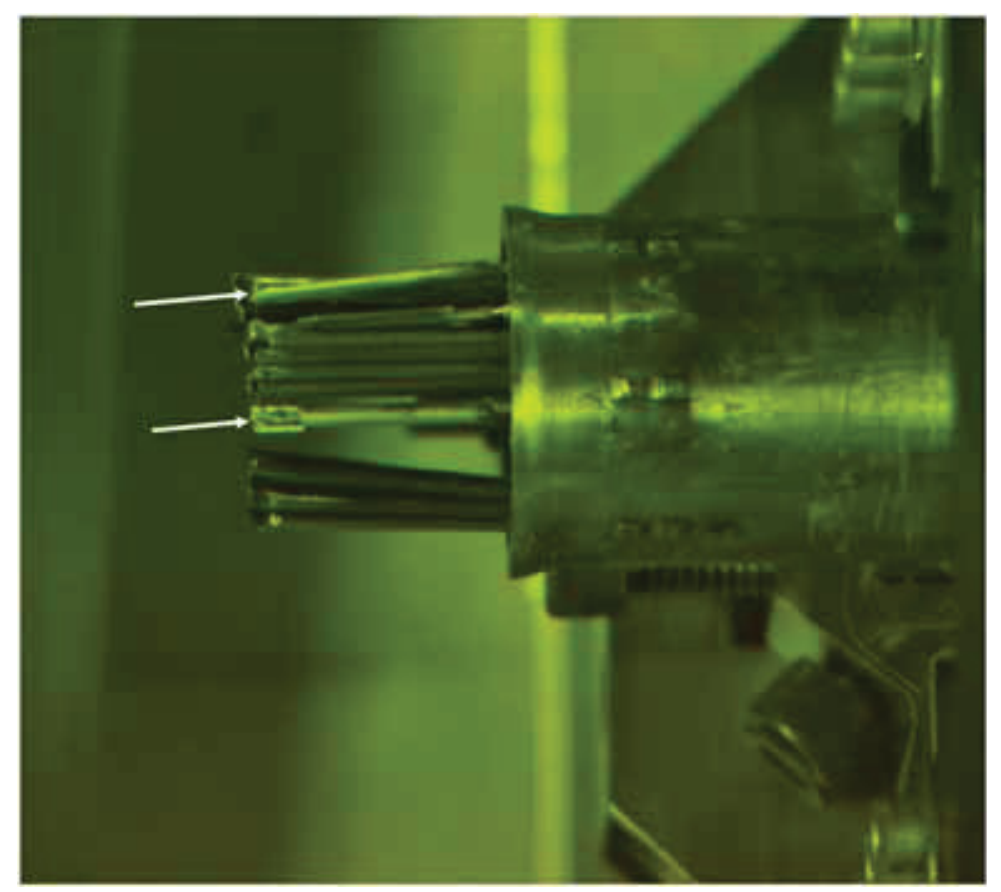

\section{Figure 20. Shattered 3/32 inch molybdenum thermocouples (indicated by arrows) resulting from use of a guillotine cutter.}

\subsection{Capsule Disassembly}

After the capsules were separated, each of the six capsules was disassembled in order to remove their contents. While some minor difficulties were encountered, disassembly activities became more efficient for the last few capsules. This section summarizes the disassembly experiences for each capsule and shares the lessons learned during the AGR-1 test train disassembly activities.

The order of disassembly was established with regard to the relative importance of the capsule compacts to planned analysis activities and variations in the capsule characteristics. Some of the characteristics are shown in Table 1.

Disassembly of the AGR-1 capsules was conducted in the following order: Capsules 1, 4, 6, 3, 5, and 2 (Capsule 6 was initially first in the order, but problems in disassembly resulted in a switch to Capsule 1). Capsules 1 and 6 were considered the best candidates for "shakedown" of disassembly methods since they contain the same fuel type as Capsules 4 (Variant 3) and 3 (Baseline), but achieved lower burnup and fast fluence. 
Table 1. Characteristics of the AGR-1 irradiated capsules.

\begin{tabular}{|c|c|c|c|c|}
\hline Capsule & Fuel Type & $\begin{array}{c}\text { Graphite Holder } \\
\text { Boron Carbide } \\
\text { Content } \\
(\%)\end{array}$ & $\begin{array}{c}\text { Average Fast } \\
\text { Neutron Fluence } \\
(\mathrm{E}>0.18 \mathrm{MeV}) \times 10^{21} \\
\left(\mathrm{n} / \mathrm{cm}^{2}\right)^{\mathrm{a}}\end{array}$ & $\begin{array}{c}\text { Preirradiation } \\
\text { Radial Clearance } \\
\text { Between Shell Liner } \\
\text { and Graphite Holder } \\
\text { (in) }\end{array}$ \\
\hline 1 & Variant 3 & 5.5 & 3.06 & 0.019 \\
\hline 2 & Variant 2 & 7.0 & 3.85 & 0.011 \\
\hline 3 & Baseline & 7.0 & 4.18 & 0.010 \\
\hline 4 & Variant 3 & 7.0 & 4.09 & 0.010 \\
\hline 5 & Variant 1 & 7.0 & 3.61 & 0.014 \\
\hline 6 & Baseline & 5.5 & 2.71 & 0.029 \\
\hline
\end{tabular}

a. Pope 2010 .

Note that the preirradiation, as-fabricated radial clearances between the graphite holder and the capsule shell for each capsule is also listed in Table 1. These gaps were determined specifically for each capsule in order to provide optimal temperature control. As discussed later in this report, the postirradiation gaps proved to be an important factor in disassembling the capsules, since these gaps changed substantially over the course of the experiment's irradiation graphite holder dimensional changes.

In addition to the niobium gas lines and niobium and molybdenum thermocouple sheaths, the molybdenum through-tubes were also significantly embrittled during irradiation and could be broken relatively easily. The tubes tended to crumble if they were subjected to crushing loads such as use of pliers and were relatively easy to break under tension loads when applying force to pull the head from the shell. Figure 21 shows three through-tubes that were broken when the Capsule 4 head was separated by pulling the capsule apart.

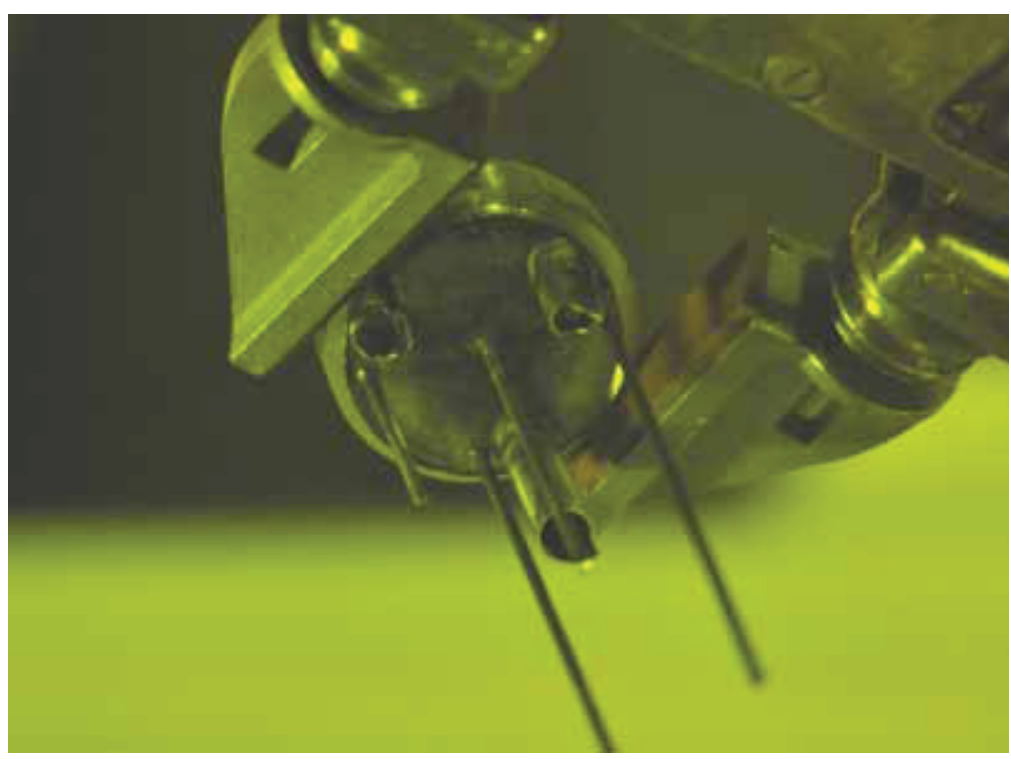

Figure 21. Through-tubes of Capsule 4 that broke near the capsule head.

Over the course of the disassembly operations, $22 \%$ of the capsule through-tubes pulled out of the capsule head when force was applied to pull the capsule apart. In these cases, the brazes securing the through-tubes to the head did not hold as the capsule was pulled apart (see Figure 22). It is estimated that 
approximately $50 \%$ of the gold in the braze material (comprised of $80 \%$ gold and $20 \%$ nickel) transmuted to mercury during irradiation. It is believed that degradation of the braze alloy due to this transmutation may be the cause of the unexpected separation of some of the through-tubes when applying tension to separate the capsule head from the capsule shell.

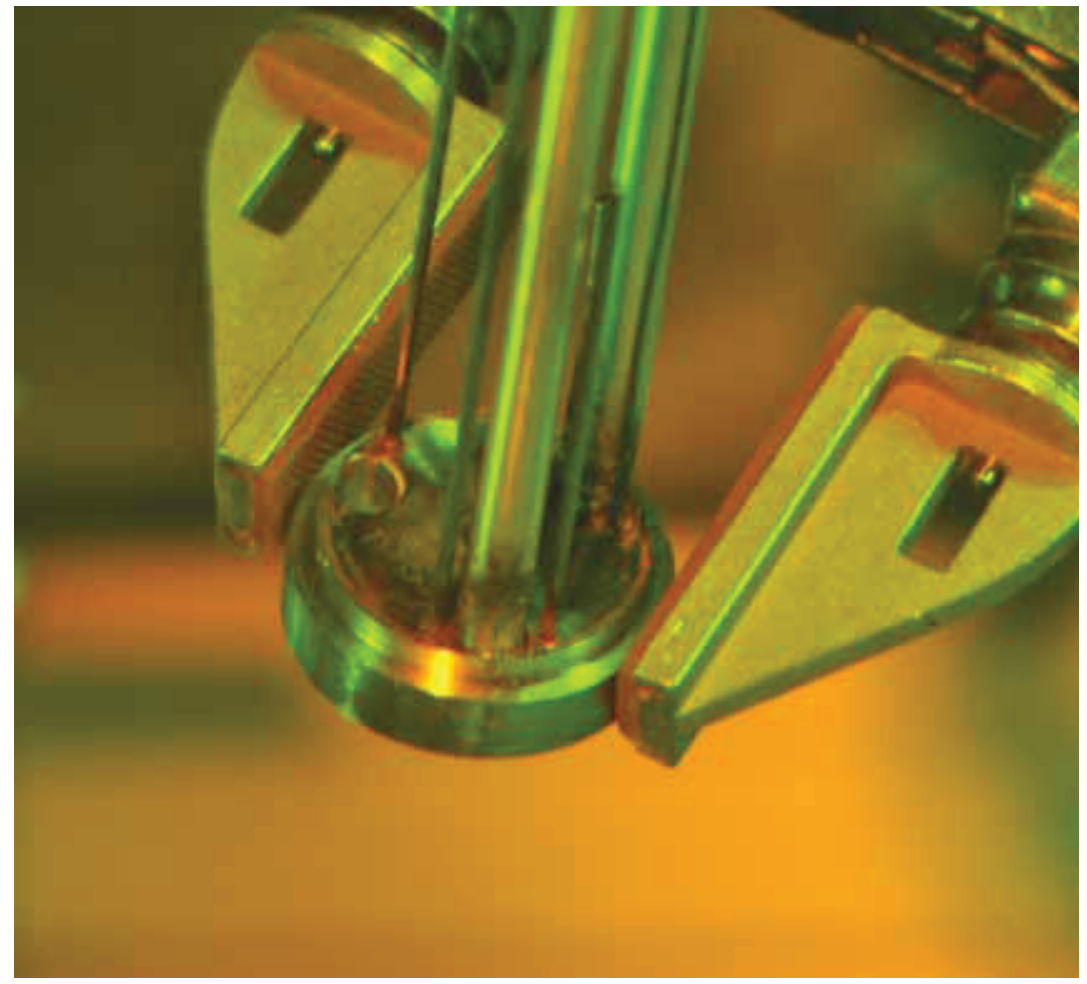

Figure 22. Image showing location of through tube that pulled out of Capsule 2 head.

Capsule 1 was successfully disassembled with only minor difficulty. All three through-tubes pulled out of the head. The cause of this is tentatively attributed to degradation of the braze alloy as discussed above. A force of $21 \mathrm{lb}_{\mathrm{f}}$ was required to push one of the fuel stacks out. The other two stacks could not be pushed out initially with $21 \mathrm{lb}_{\mathrm{f}}$, but were removed with little resistance after several days of being left undisturbed. The cause for the change in force required to push out the compacts is not known.

Capsule 4 proved to be more difficult to disassemble. From the beginning, Capsule 4 behaved differently than Capsule 1. After making a head cut, the capsule shell was pulled in an attempt to separate it from the capsule head and the graphite holder. All three through-tubes broke near the head, allowing removal of the head but the graphite holder remained inside the capsule shell. With the floor still intact at the bottom of the capsule, no access was available to attempt to push out the graphite holder or compacts.

A second cut was made three-quarters of the way down the capsule shell in hopes that the floor section of the capsule could be removed from the graphite holder, giving access to the compacts and pushing the graphite holder from the shell. After the cut was made, the floor section of the capsule could still not be removed (using disassembly vises and a pry bar tool as shown in Figure 23). The cut section of the shell appeared to be crimped to the graphite holder by the lip created when the shell was cut. This binding was not expected since the preirradiation radial clearance between the capsule shell liner and the graphite holder was 0.010 inch (see Table 1) and it was anticipated that the graphite holder would shrink (as was observed on initial inspection of the Capsule 1 graphite holder, see Section 4.4.1) giving additional clearance. 


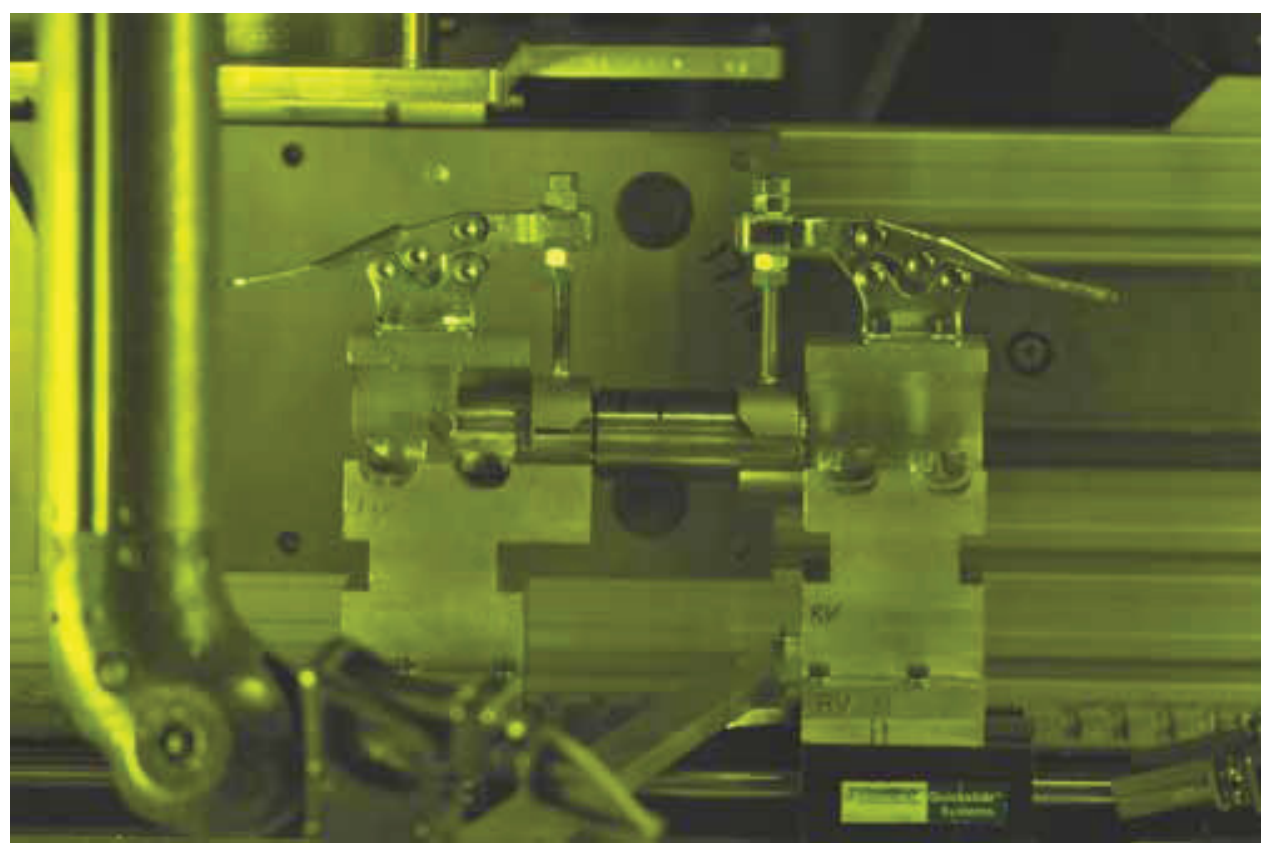

Figure 23. Picture of vises and pry bar used to attempt to pull apart the cut Capsule 4 shell.

As more force was applied to separate the Capsule 4 floor section, the through-tubes broke and graphite holder cleaved separating the capsule into two sections, both still bound within the capsule shell. The cleaved end of the larger top section of the capsule (containing the top three levels of compacts in each stack) is shown in Figure 24. This left the larger section in a configuration that allowed the compacts to be pushed out of the graphite holder.

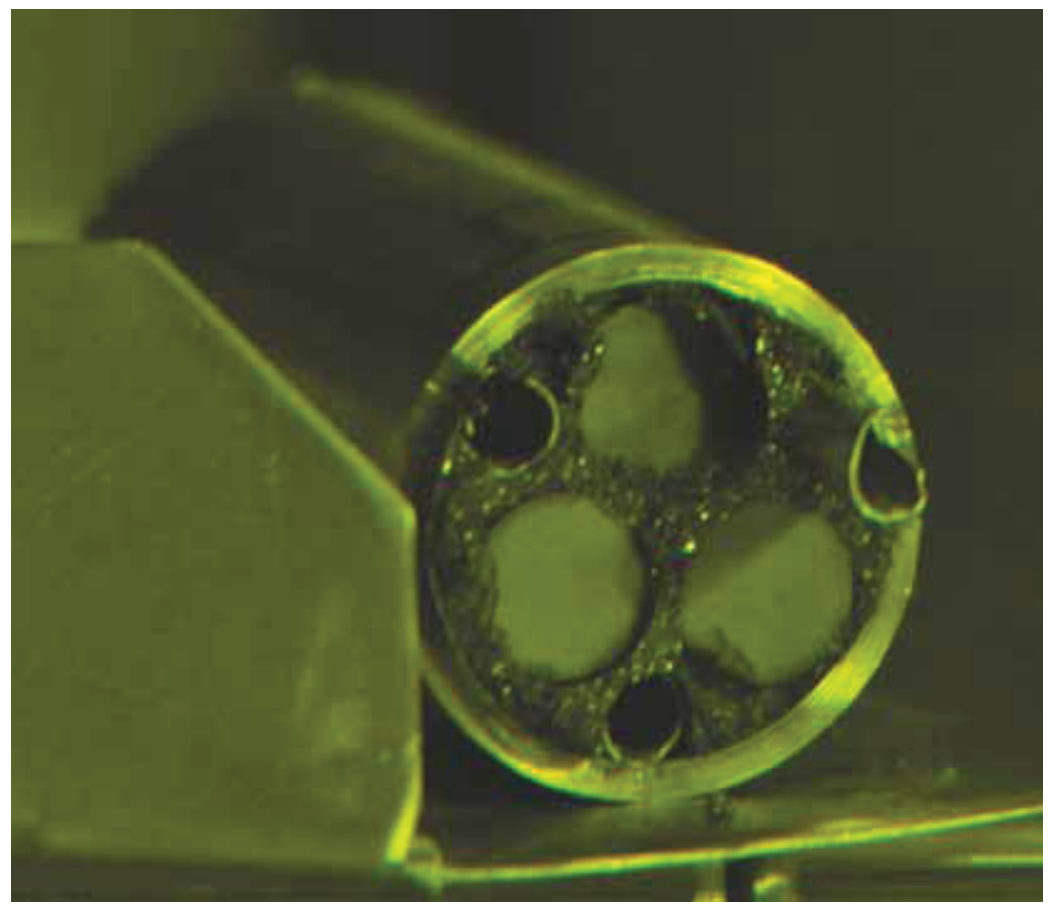

Figure 24. Cleaved end of Capsule 4 graphite holder. Bottom of the Level 2 compacts are visible. 
The lower section still had the stainless steel floor present, allowing access to only one end of the compacts. Two of the three compacts easily slid out of the holder and were recovered without damage, but compact 4-1-3 was stuck in the lower section of the graphite holder and without access to both ends it could not be dislodged. The graphite holder had to be broken in order to remove the compact. After removal by breaking up the holder, the compact was examined and found to have a small crack and one of the compact end caps had damaged edges (photograph of Compact 4-1-3 is presented in Section 4.1). It is believed that all of this damage was due to the extraction process. The upper portion of the graphite holder was still securely bound inside the capsule shell (discovered on subsequent capsules to be the result of significant diametrical swelling of the holder) and had to be broken in order to remove it.

Initially no need was anticipated to make a floor cut (at location shown in Figure 15) because the through-tubes of each capsule were designed to be free-floating with a diametrical clearance of 0.0003 to 0.0007 inch to their floor hole. The capsule was designed to allow through-tube movement in the floor holes to avoid stresses induced by differential thermal expansion of capsule components during the test train irradiation. However, it was found that the through tubes were typically stuck securely in the capsule floor. Evaluation of the failure to retrieve the Capsule 4 graphite holder intact resulted in a modified disassembly procedure that involved carefully making cuts both at the capsule floor and capsule head and removing the floor before removing the head. Pry and wedge tools were also fabricated to give more mechanical advantage when trying to pull the capsule apart. The pry tool used is shown in Figure 25 . The removal of the major resistance of the through-tubes stuck in the capsule floor made pulling the head from the shell a relatively easy task.

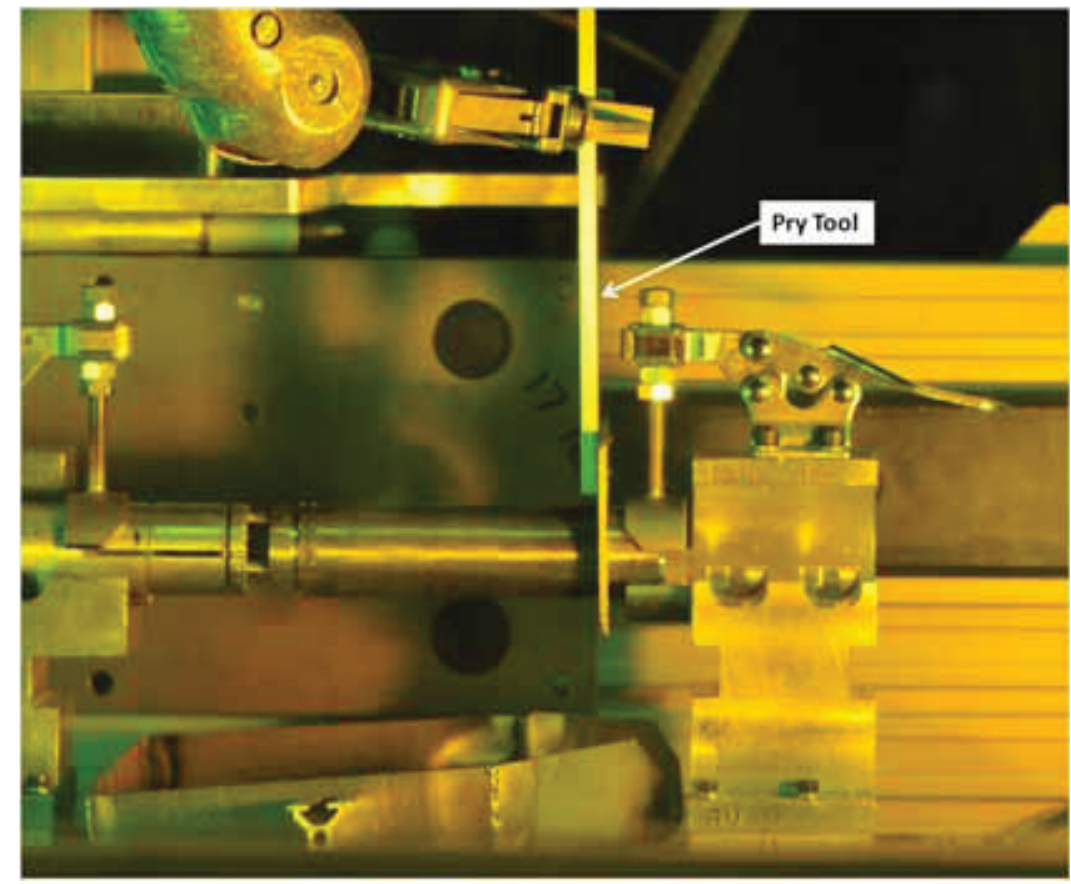

Figure 25. Pry tool used to pry the floor section from Capsule 6.

The new capsule disassembly approach was used in the disassembly of Capsule 6 and the capsule came apart relatively easily. However, both a head cut and a floor cut were made before trying to pull the capsule apart. This worked but it was deemed to be a mistake to make both cuts before trying to pull the capsule apart because this made it more difficult to use pry tools. The floor section was successfully removed but the thermocouples and gas line were all broken from the head while prying the capsule apart. This led to the plan for future capsules to make the floor cut first and pry the floor off before making the head cut. 
The improved disassembly approach was used on Capsule 3 and the floor was successfully removed before making the head cut. Figure 26 shows the Capsule 3 floor with two broken through-tubes. Having the major resistance of the bound floor tubes removed, it was relatively easy to make the head cut and remove the capsule shell and graphite holder. The Capsule 3 graphite holder was retrieved intact. However the graphite holder would not fit into its aluminum storage container because the diameter was too large. Dimensional measurements confirmed that this graphite holder had indeed grown in diameter and length (see Section 4.4.3). Evaluation suggested that this was related to the different boron content in the Capsule 3 holder compared to Capsules 1 and 6 (see Table 1), as discussed further in Section 4.4.

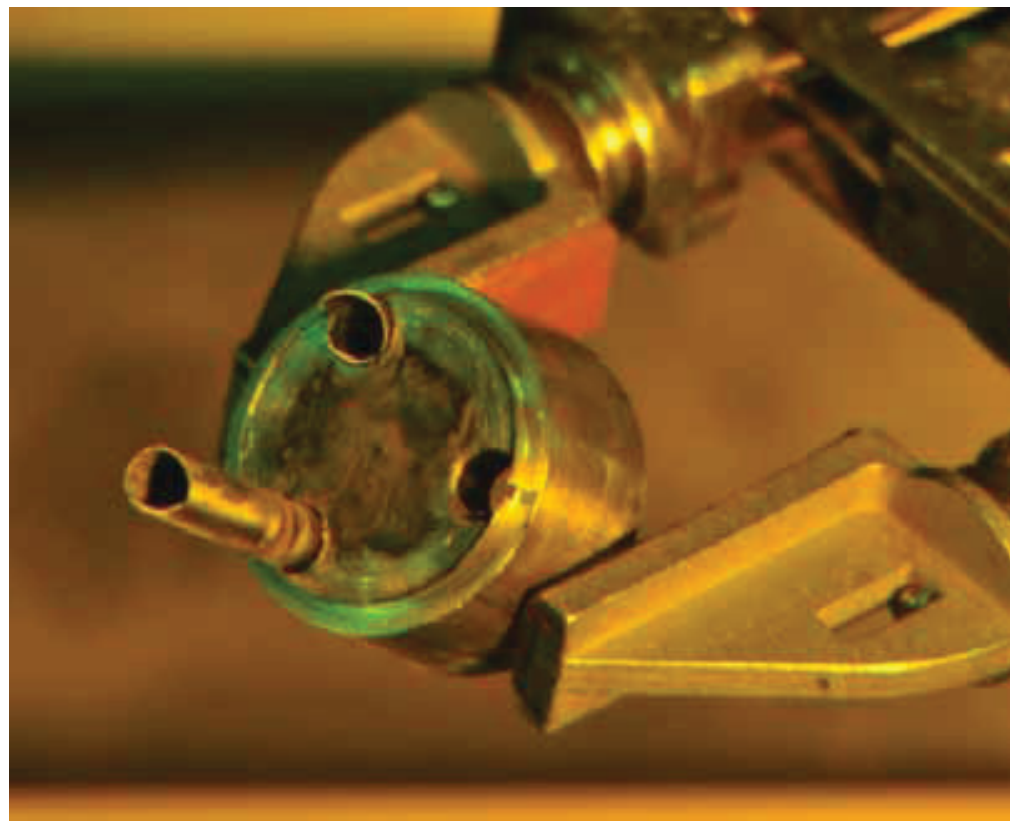

Figure 26. Floor of Capsule 3 showing two through-tubes that broke instead of pulling out of the capsule floor.

After the graphite holder swelling behavior was better understood and the tendency of the throughtubes to stick in the shell floor was known, the disassembly technique was clearly dictated:

1. Use extreme care not to create any burrs during cutting that extend beyond the shell liner inner diameter (ID).

2. Cut and remove the shell floor before attempting to cut and remove the head from the capsule shell.

3. Use high leverage tools to pull with sufficient force to break the embrittled though tubes, if necessary, to separate the floor and head from the shell body.

Utilizing these techniques Capsules 5 and 2 came apart quickly and with little difficulty. Dimensional measurements confirmed that the graphite holders of these two capsules also swelled as experienced in the Capsule 4 and 3 graphite holders having 7.0\% boron carbide content. Figure 27 shows the graphite holder from Capsule 5. Careful examination of the holder photograph reveals that the graphite holder expanded diametrically more on the ends than in the middle, giving it a slight hourglass shape. In addition, the through-tube channels (one of them facing the camera in Figure 27) were distorted with a slight bridging across the top of the channel, which impacted disassembly operations in certain cases. These changes were verified by dimensional measurements and are discussed in more detail in Sections 4.3 and 4.4. 
The graphite holders, graphite spacers, and Grafoil spacers of all six capsules appeared to maintain their physical integrity during irradiation. Figure 28 shows a graphite spacer and a Grafoil spacer taken from Capsule 5.

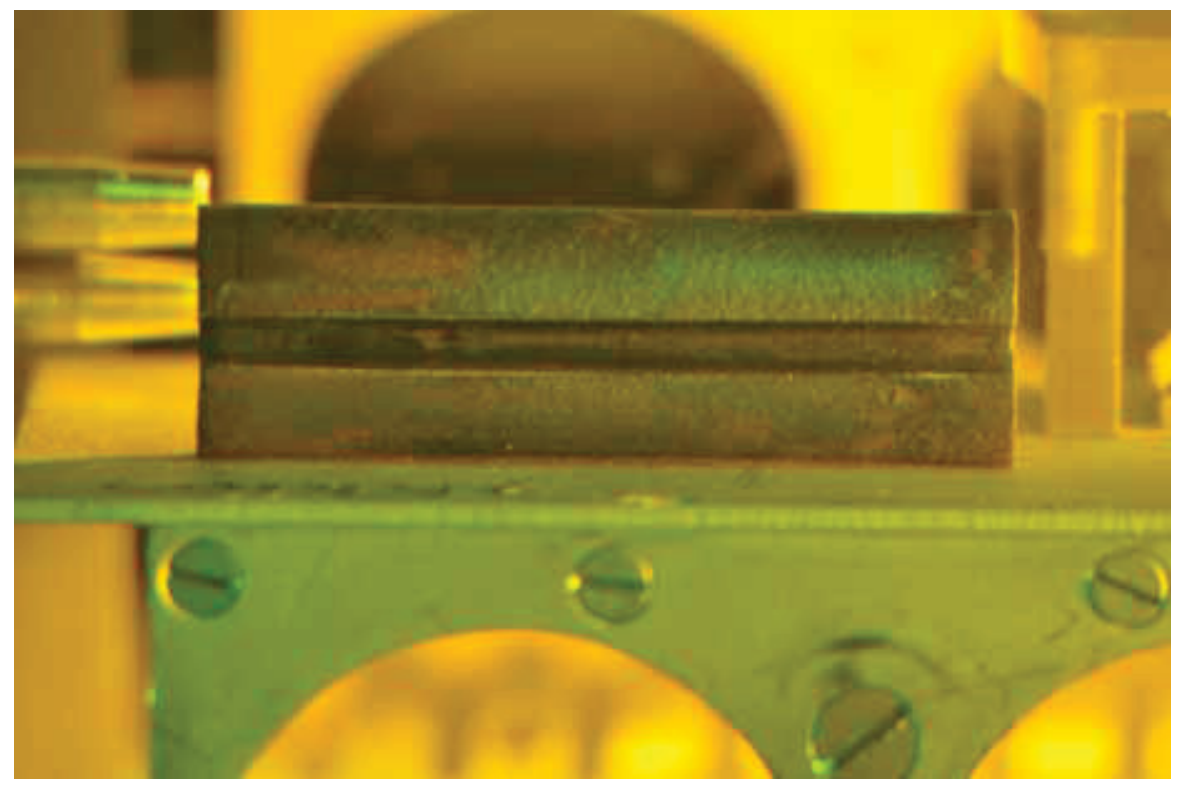

Figure 27. Capsule 5 graphite holder after capsule disassembly.
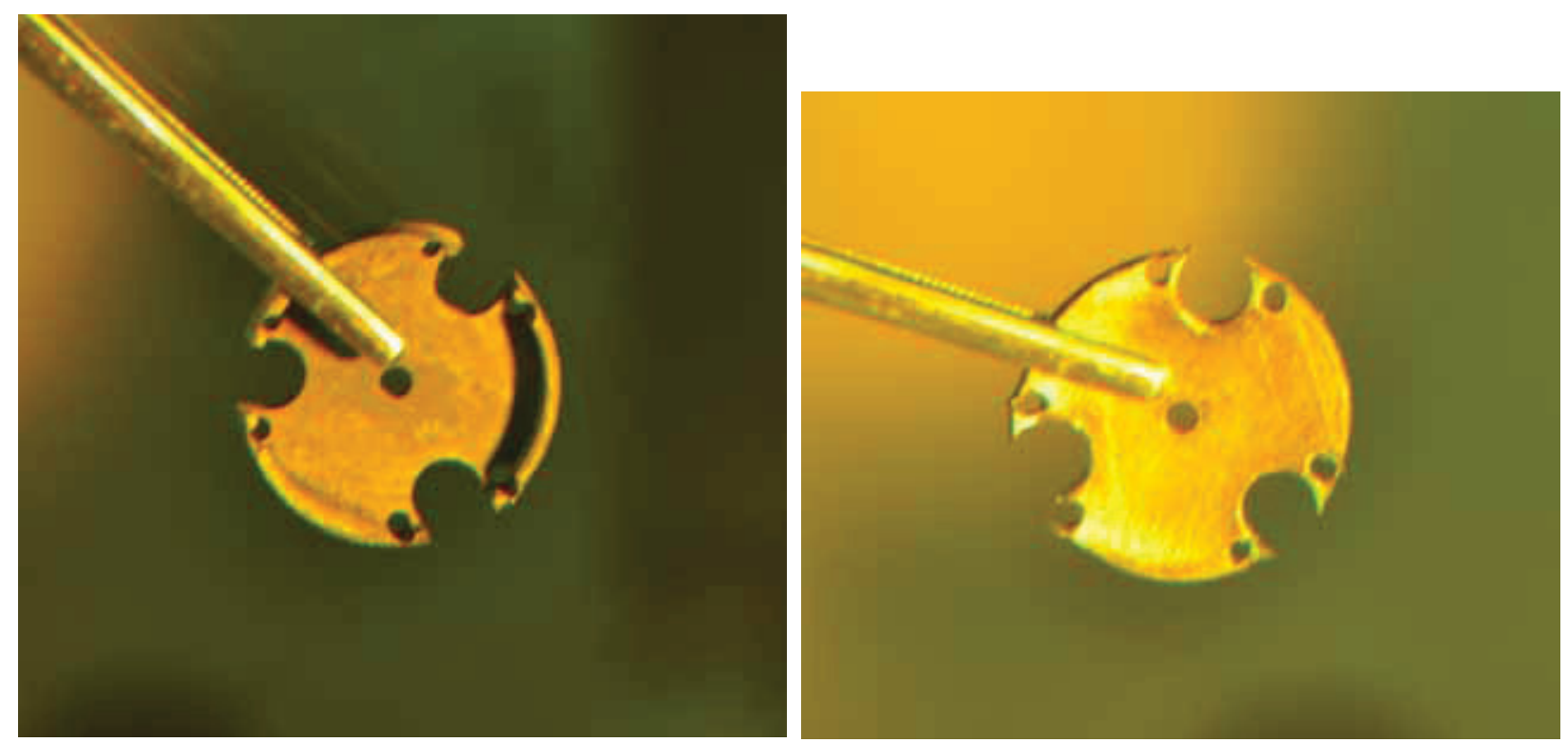

\section{Figure 28. Graphite spacer (left) and Grafoil spacer (right) taken from Capsule 5.}

Inspection of the metallic capsule shells, after the disassembly was completed, revealed that the internal surfaces of the shells contained varying amounts of deposited material. This is discussed further in Section 4.5 in conjunction with measurements of capsule shell inner diameters.

The primary lessons learned during the capsule disassembly activities are summarized in Table 2 . 
Table 2. Cumulative lessons learned as the AGR-1 disassembly activities progressed.

\begin{tabular}{|c|c|}
\hline Capsule & Lessons Learned \\
\hline 1 & $\begin{array}{l}\text { The three head brazes came loose when the head was pulled with sufficient force to accomplish the } \\
\text { separation, potentially because of transmutation of the gold (used in the head brazes) to mercury. }\end{array}$ \\
\hline \multirow[t]{2}{*}{4} & $\begin{array}{l}\text { All three through-tubes stuck in the floor; two tubes broke near the capsule head and one pulled out. } \\
\text { This demonstrated the issue with through-tubes binding in the floor, posing a major resistance to } \\
\text { disassembly. }\end{array}$ \\
\hline & $\begin{array}{l}\text { Difficulties removing the shell from the graphite holder after the capsule head was removed gave } \\
\text { evidence that radial clearance between the graphite holder and the capsule shell was smaller than } \\
\text { expected. }\end{array}$ \\
\hline 6 & $\begin{array}{l}\text { Both a floor cut and head cut were made and the capsule was successfully disassembled but the capsule } \\
\text { thermocouples and gas line were damaged in the prying process. It was resolved for future capsules to } \\
\text { make the floor cut first and pry the floor off before making a head cut. }\end{array}$ \\
\hline \multirow[t]{5}{*}{3} & $\begin{array}{l}\text { Making a floor cut on the capsule and removing the floor before attempting to remove the capsule head } \\
\text { eliminated the major obstacle to capsule disassembly and is the easiest way to take the capsule apart. }\end{array}$ \\
\hline & $\begin{array}{l}\text { Pry and wedge tools were needed to break the floor loose since floor removal typically requires } \\
\text { breaking the embrittled through-tubes which are often firmly stuck in the capsule floor. }\end{array}$ \\
\hline & After removing the floor, the head can be easily separated. \\
\hline & $\begin{array}{l}\text { The graphite holder was firmly affixed to the through-tubes, later determined to be because the through } \\
\text { tube channels had narrowed slightly during irradiation. Prying the tubes upward resulted in minor } \\
\text { damage to the holder (see Section 4.3). }\end{array}$ \\
\hline & The graphite holder would not fit in its storage container, indicating that it had swelled significantly. \\
\hline \multirow[t]{3}{*}{5} & $\begin{array}{l}\text { Confirmed that the through-tubes were sticking in the capsule floor. A floor cut proved useful in } \\
\text { eliminating this major resistance to disassembly as a first activity. }\end{array}$ \\
\hline & Confirmed that the graphite holder had swelled since it would not fit in its storage container. \\
\hline & Confirmed the usefulness of pry tools to removing the floor from the capsule. \\
\hline \multirow[t]{3}{*}{2} & $\begin{array}{l}\text { Confirmed again that the through-tubes were sticking in the capsule floor. A floor cut proved useful in } \\
\text { eliminating this major resistance to disassembly as a first activity. }\end{array}$ \\
\hline & Confirmed again that the graphite holder had swelled since it would not fit in its storage container. \\
\hline & Confirmed the usefulness of pry tools to removing the floor from the capsule. \\
\hline \multirow[t]{5}{*}{ All } & $\begin{array}{l}\text { The } 5.5 \% \text { and } 7.0 \% \text { boron carbide graphite behave differently under irradiation. The outside diameter } \\
\text { of the } 5.5 \% \text { boron carbide graphite holders and the diameter of the fuel holes both decreased. These } \\
\text { dimensions increased in the } 7.0 \% \text { boron carbide holders. }\end{array}$ \\
\hline & $\begin{array}{l}\text { It was observed that when the graphite holder expanded to the full diameter of the inside of the capsule } \\
\text { shell and liner, the holder then swelled to distort the through tube grooves and partially constrains the } \\
\text { through-tubes. }\end{array}$ \\
\hline & $\begin{array}{l}\text { The deposits vary on the walls of the various capsule shells. Some deposits are smooth and thin while } \\
\text { others are rough in texture and thicker. }\end{array}$ \\
\hline & $\begin{array}{l}\text { The graphite holders, graphite spacers, and Grafoil spacers all appeared to maintain their physical } \\
\text { integrity and did not show any apparent signs of breakage or crumbling from the neutron fluence } \\
\text { experienced during the irradiation. }\end{array}$ \\
\hline & $\begin{array}{l}\text { The compacts all appeared to maintain their integrity and did not show any apparent signs of significant } \\
\text { deterioration from the neutron fluence experienced during the irradiation. }\end{array}$ \\
\hline
\end{tabular}




\section{METROLOGY}

Measuring the dimensional changes of the AGR-1 fuel and capsule components is of considerable importance, primarily because of the potential changes in thermal gaps caused by irradiation-induced dimensional change of the components and the effect this may have on the calculated thermal history of the fuel. The two gaps of most interest are the radial gaps between fuel compacts and the graphite fuel holders and between the graphite fuel holders and the steel capsule shell. Consequently, the outer diameter (OD) of the fuel compacts and graphite holders and the inner diameter of the graphite holder fuel holes and the capsule shell were measured. In addition, the length of the compacts and graphite holders was also measured.

A noncontact approach was taken for measuring lengths and diameters of AGR-1 fuel compacts and their graphite holders during PIE. The primary reason was to obtain external dimensions on these potentially fragile components without risk of damage from probe pressure and without additional handling steps thought likely for contact measurements. A customized system based on vision measurement/machine vision principles was selected to meet dimensional requirements $(\leq 0.0005$-inch resolution, $\leq 0.001$-inch combined standard uncertainty) and also to obtain high resolution inspection images as AGR-1 capsules were disassembled.

Major components of the noncontact metrology system are displayed in Figure 29. A shielded 6.6-megapixel camera and shielded telecentric lens were vertically oriented on a radiation-resistant stage assembly. Upper illumination for fuel compacts and graphite holders was provided by three high intensity light-emitting diodes (LEDs). Holders were supported on a rotating fixture for viewing at three azimuths 120 degrees apart. To enhance contrast along their edges, holders were positioned above an aluminum imaging backdrop, which also had a 45-degree mirror for end views. Compacts were unloaded from holders onto a roller table for imaging at multiple azimuths. The roller table included an LED light pipe for backlighting compact ends.

The LEDs provided sufficient monochromatic illumination to minimize the aperture on the lens and maximize its depth of focus, which was sufficient to cover the upper half of a graphite holder. The lens field of view is 1.33 inches, which converts to a camera pixel width of approximately 0.00045 inch. The field of view was large enough to cover compact lengths and holder diameters within a single image but not the 4-inch length of holders. Six images were consequently taken along the length of each holder and stitched into composites with image processing software, which was also used to extract dimensions. Examples of analyzed compact and holder images are presented in Appendix A. Pixel size was calibrated to images taken of a NIST-traceable chrome grid lithographed onto a glass substrate. The glass had a low thermal expansion coefficient to minimize effects of changing ambient temperature in the hot cell, which can vary from 80 to $100^{\circ} \mathrm{F}$. Performance was checked on steel standards before and after components from each capsule were imaged.

Commercial bore gauges, in conjunction with appropriate support/alignment fixtures and ring gauge standards, were used to measure the inner diameters of graphite holders (after removal of fuel compacts) and the inside of stainless steel capsule shells. The bore gauges are described in Appendix A.

Performance of the entire AGR-1 metrology system (camera-based noncontact equipment for external measurements and bore gauges for inner diameter measurements) was rigorously demonstrated as meeting design requirements per NQA-1 protocol during remote qualification. The demonstration of noncontact equipment utilized steel standards carefully fabricated to resemble both AGR-1 fuel compacts and AGR-1 graphite holders. The reference dimensions of these standards were established at the MFC Precision Laboratory with NIST-traceable measurement methods. Performance of bore gauges was established using commercial ring gauge standards certified at the INL Standards and Calibration Laboratory. Calibration techniques and qualification results are comprehensively reported in Engineering 
Calculations and Analysis Report ECAR-900 [Ploger 2010], along with detailed analysis of measurement uncertainties.

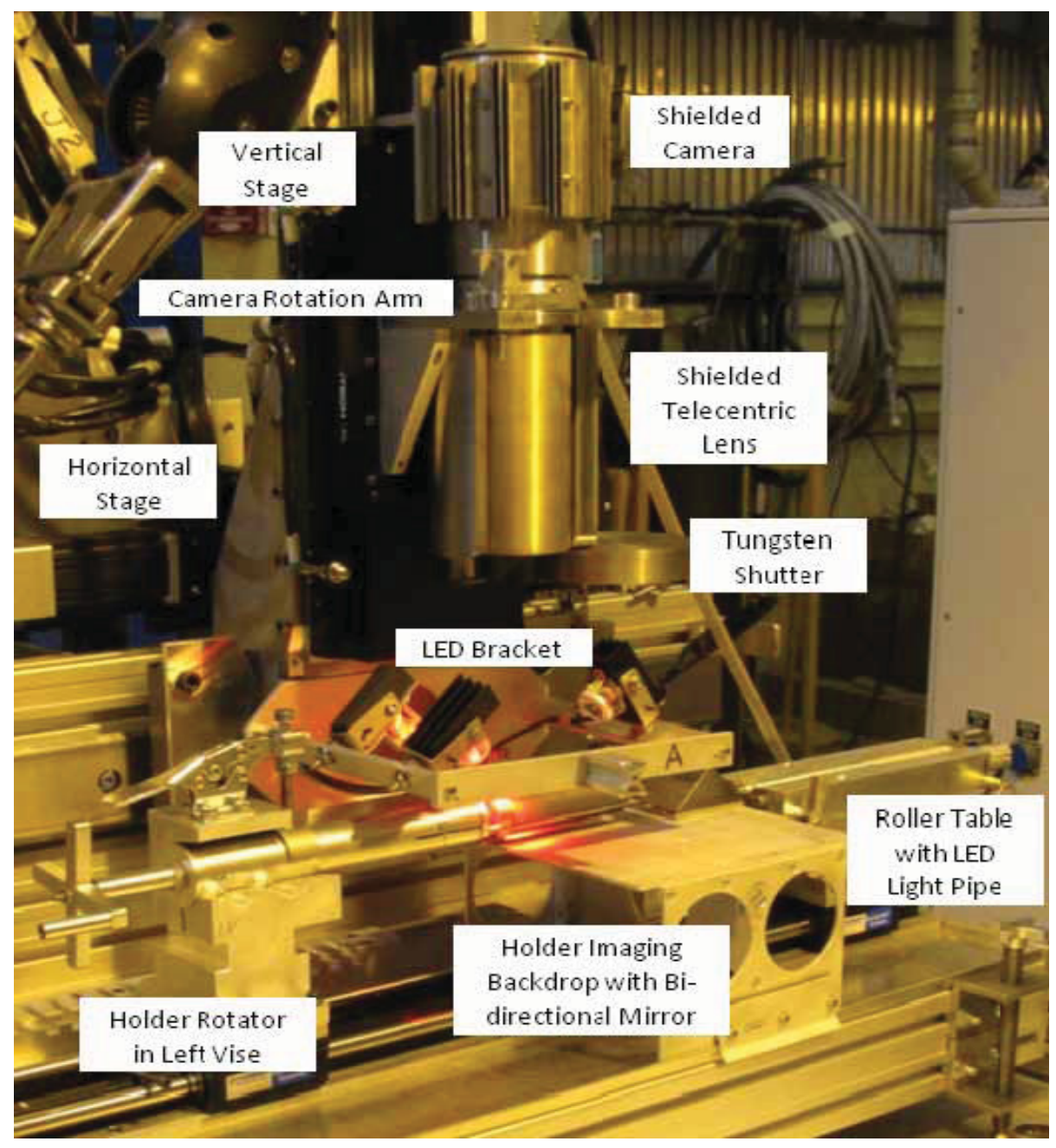

Figure 29. AGR-1 noncontact metrology system during mockup qualification.

\subsection{Fuel Compact Visual Inspections}

All AGR-1 fuel compacts were extracted intact. No structural defects related to irradiation were observed, no free fuel particles were detected as compacts were unloaded from the holders, and no cavities were found on compact surfaces from which fuel particles could have been dislodged. Many compact images revealed no conspicuous damage from remote disassembly. Two representative examples of undamaged compacts are presented in Figure 30, where compact sides are brightly lit for contrast when measuring diameters.

Damage tentatively associated with disassembly occurred in a variety of forms. Most forms of disassembly damage were superficial. The only serious effects of disassembly occurred on two Capsule 4 compacts on either side of the transverse fracture induced in the graphite holder to enable compact removal (discussed in Section 3.3). This fracture occurred between the lower two rows of compacts (between Levels 1 and 2). Figure 31 shows a crack through the upper end-cap on Compact 4-1-3 and a relatively deep notch in the bottom end-cap on Compact 4-2-2. The fact that no fuel particles were released in these extreme circumstances illustrates the structural strength of the AGR-1 fuel compacts. 
Notches in end-cap corners also were observed in three compacts from other AGR-1 capsules. However, they typically were shallow, as indicated in Figure 32.

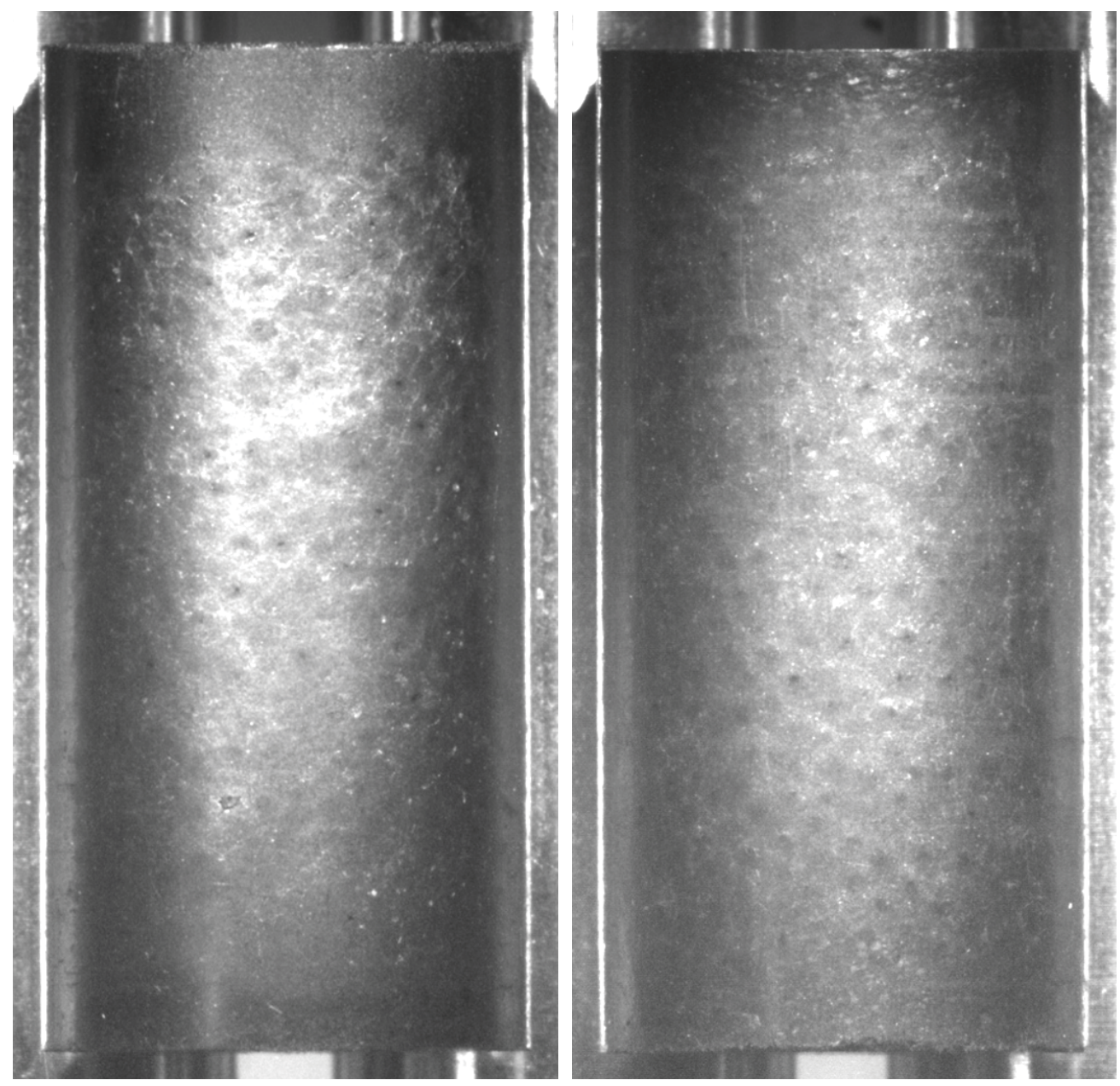

Figure 30. Typical appearance of AGR-1 fuel compacts (1-1-1 at left, 2-3-3 at right).
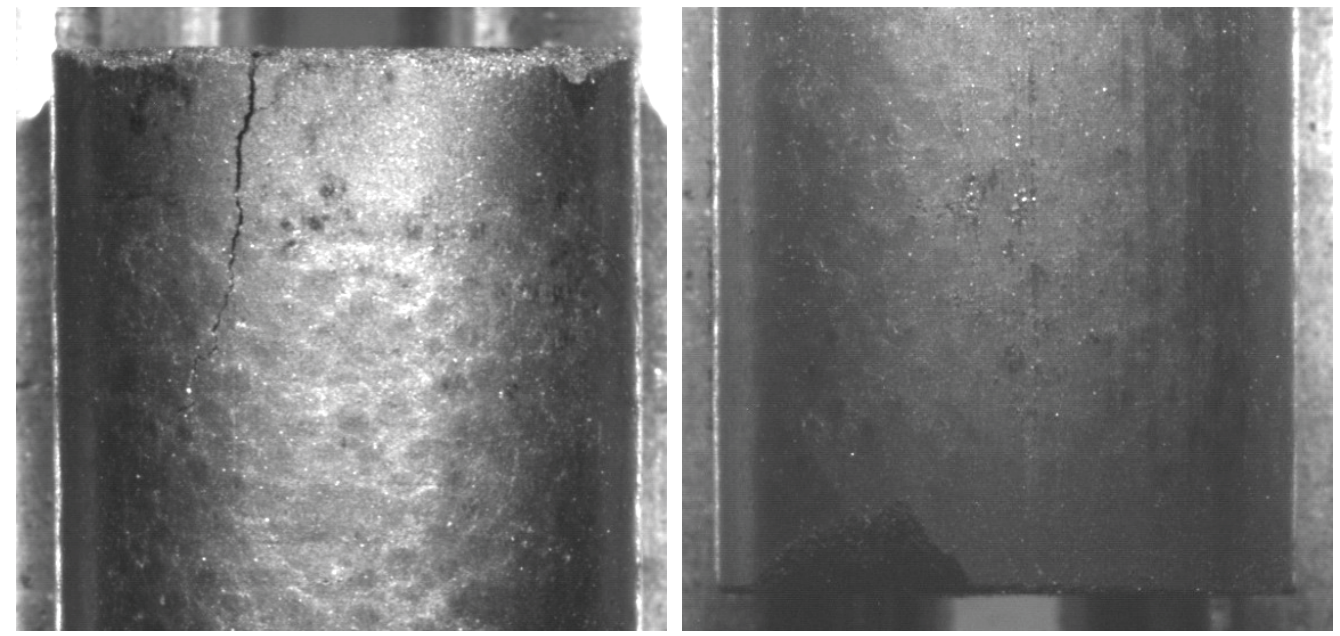

Figure 31. Upper crack in Compact 4-1-3 and bottom notch in Compact 4-2-2, both from holder fracture during disassembly operations. 

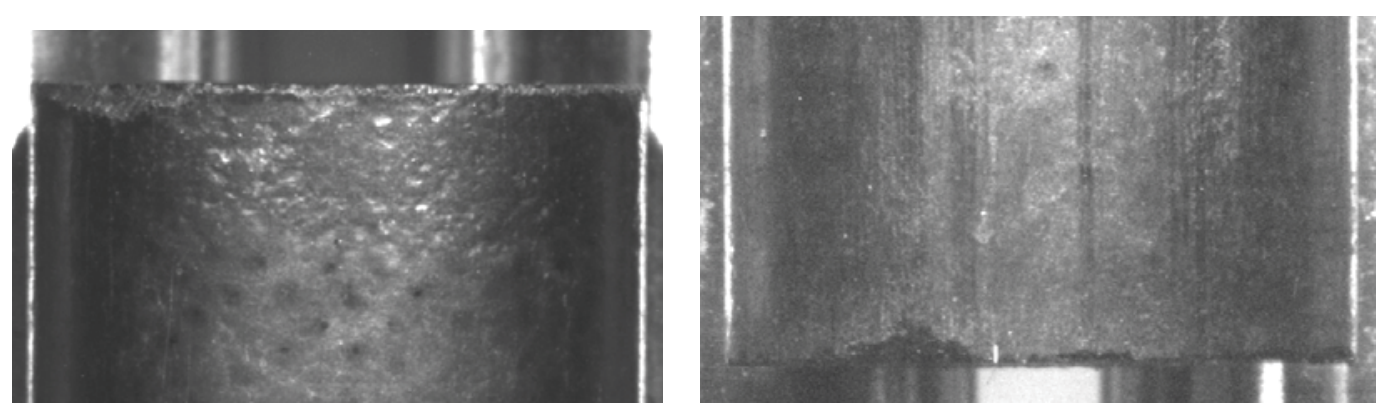

Figure 32. Shallow notches in end-cap corners of Compacts 6-3-2 (left) and 2-1-2 (right).

Some AGR-1 compacts were apparently scratched during removal from their graphite holders. The scratches were always axially oriented and tended to be found in all compacts from a particular stack. This suggests that abrasive material may have been present in some holes in graphite holders, although it is not certain whether the abrasive material was introduced during disassembly. Two examples of such axial scratches are provided in Figure 33.
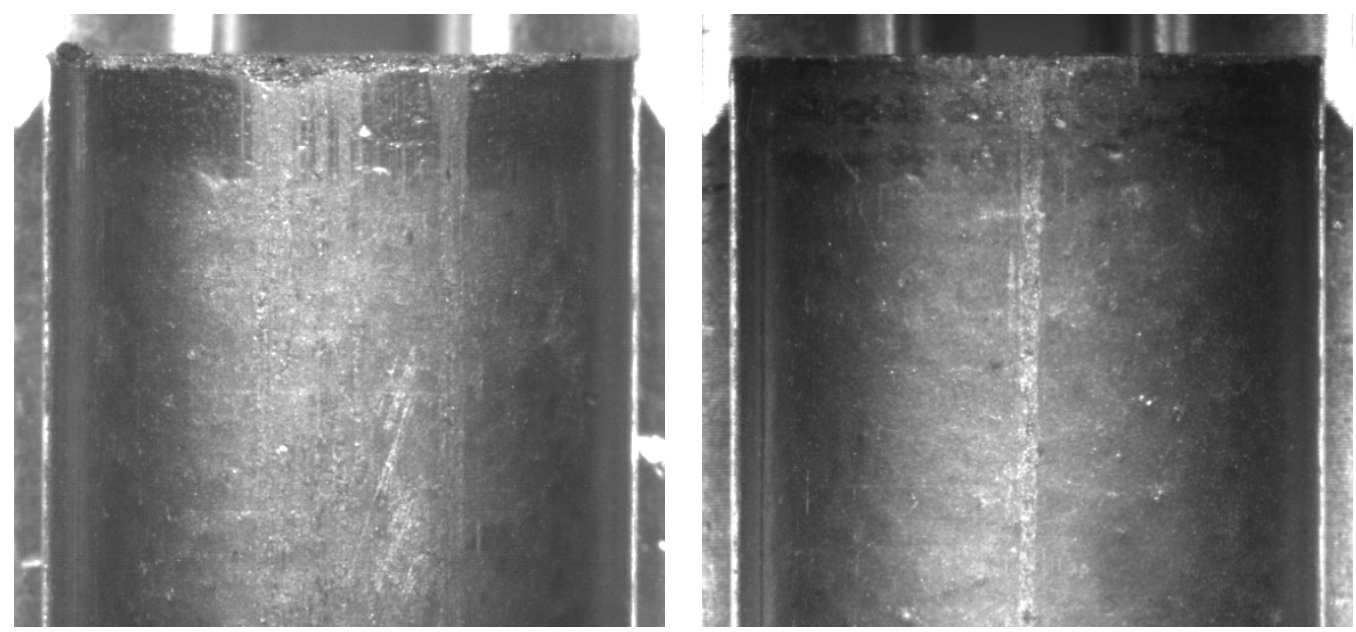

Figure 33. Axially oriented lateral scratches on Compacts 6-4-1 (left) and 3-4-1 (right).

Broad superficial blemishes were found on a few AGR-1 compacts, which also may be from abrasion during extraction from their graphite holders. The two most prominent features of this type are displayed in Figure 34.

Another type of axial mark was found on most AGR-1 compacts from Capsule 4. As illustrated in Figure 35, these marks appear darker and do not scatter light in the same manner as surface features that are more clearly related to abrasion. They have been tentatively identified as scuff marks caused by rubbing against the graphite holder during compact extraction. However, because nearly all of the Capsule 4 compacts were expelled across the fracture surface on the graphite holder, the rubbing also could have occurred against graphite fines resulting from the fracture. 

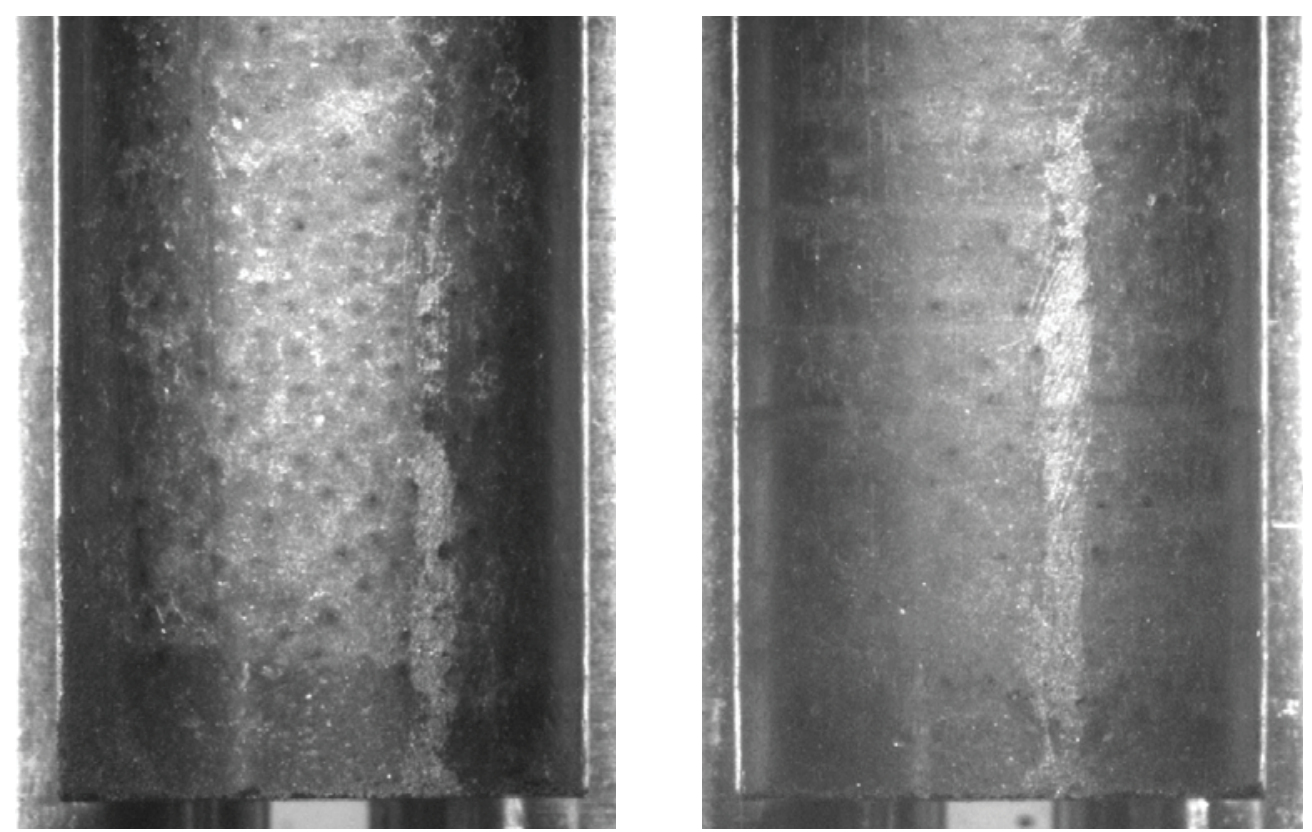

Figure 34. Broad marks from apparent abrasion on Compacts 5-4-1 (left) and 2-4-1 (right).
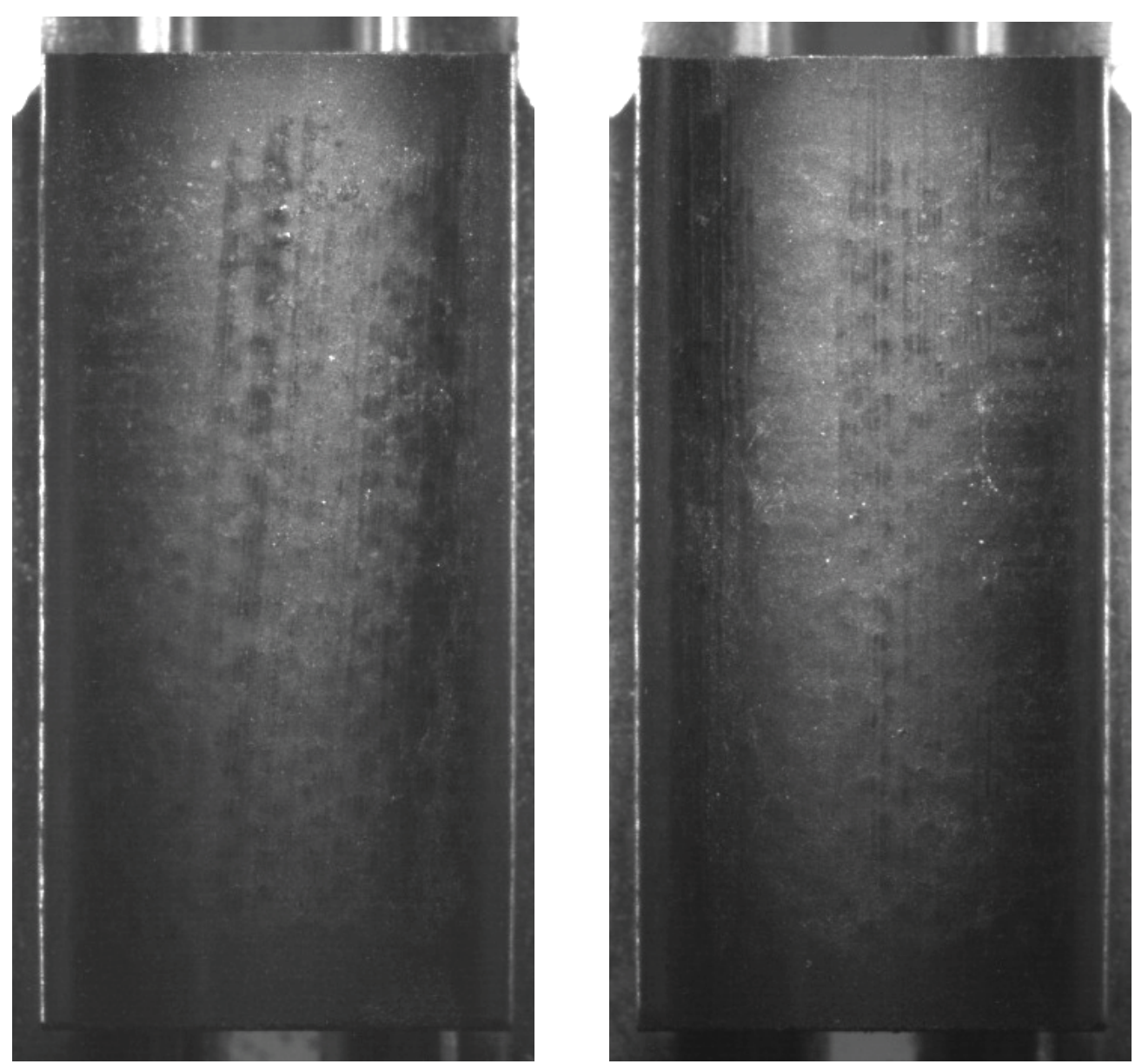

Figure 35. Dark "scuff" marks on Compacts 4-3-2 (left) and 4-3-1 (right). 
The frequency of occurrence of these compact anomalies is given in Table 3 in terms of the number of compacts from each AGR-1 capsule for which a particular type of anomaly was detected. Thirty-four of 72 compacts (47\%) exhibited no unusual features. End-cap notches range from the shallow ones displayed in Figure 32 to the deepest one in Figure 31. No more than one end-cap notch was found on a given compact. Axial scratches are the most common type of anomaly, although many of the compacts tallied in Table 3 were less severely scratched than indicated in Figure 33; some are barely distinguishable. As indicated in Table 3, scratched compacts tend to be clustered in stacks, suggesting that they were abraded by the same material when extracted from their holders. Bright marks tallied in Table 3 typically cover less surface area than those depicted in Figure 34. The dark marks were detected on compacts from all three stacks and are likely from extraction across the fracture surface of the Capsule 4 graphite holder. Only one crack was found in an AGR-1 compact, and it is almost certainly associated with fracturing of the Capsule 4 graphite holder during disassembly. With the possible exception of this single crack, none of these anomalies are expected to have any influence on subsequent PIEs.

Table 3. Number of fuel compacts showing various types of anomalies.

\begin{tabular}{|c|c|c|c|c|c|c|}
\hline $\begin{array}{c}\text { AGR-1 } \\
\text { Capsule }\end{array}$ & $\begin{array}{c}\text { No } \\
\text { Anomalies }\end{array}$ & $\begin{array}{c}\text { End-Cap } \\
\text { Notches }\end{array}$ & Scratches & $\begin{array}{c}\text { Bright } \\
\text { Marks }\end{array}$ & $\begin{array}{c}\text { Dark "Scuff" } \\
\text { Marks }\end{array}$ & Crack \\
\hline 1 & 12 & - & - & - & - & - \\
\hline 2 & 5 & 1 & $5(4$ in Stack 2$)$ & 4 & - & - \\
\hline 3 & 5 & 1 & $6(4$ in Stack 1$)$ & - & - & - \\
\hline 4 & 2 & 4 & 3 & - & 8 & 1 \\
\hline 5 & 4 & - & $\begin{array}{c}8(4 \text { each in } \\
\text { Stacks 1 and 3) }\end{array}$ & 2 & - & - \\
\hline 6 & 6 & 2 & $4(3$ in Stack 1) & - & - & - \\
\hline
\end{tabular}

A different type of anomaly, which probably existed prior to disassembly, was detected on three Capsule 4 compacts. Figure 36 shows small deposits of as-yet unidentified material on two of the upper Level 4 compacts. The bead-like shapes appear to protrude from compact sides and are aligned axially. The round deposits are currently thought to be braze alloy that relocated downward from the upper head. A small sample was scraped from the Compact 4-4-1 exterior with a special remote fixture designed to prevent damage to the compact body. Analytical results from the scraping are not yet available. 

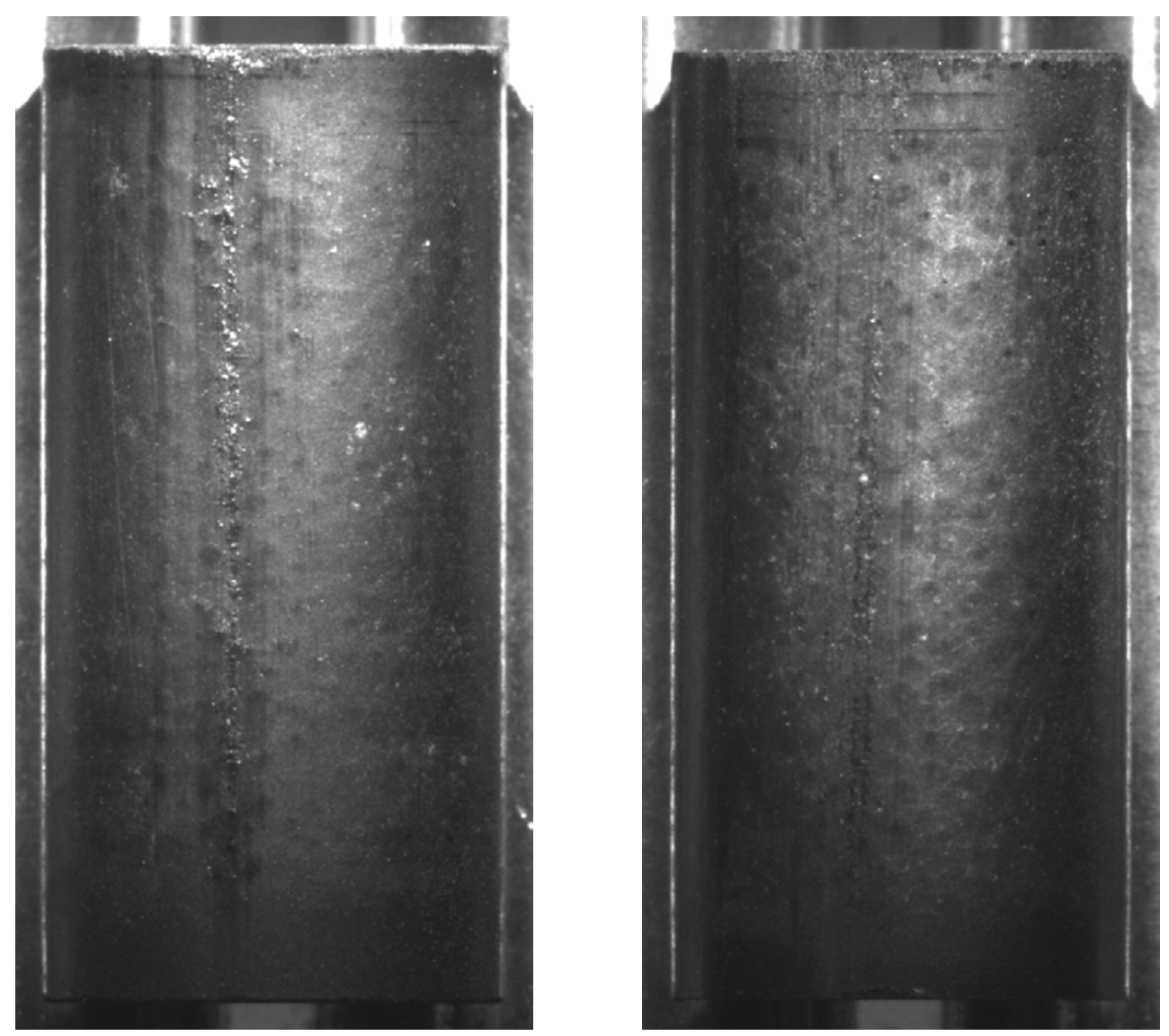

Figure 36. Small rounded deposits on sides of Compact 4-4-1 (left) and Compact 4-4-2 (right).

\subsection{Fuel Compact Dimensions}

This section presents results extracted from AGR-1 fuel compact metrology data detailed in Section 1 of Appendix A. Appendix A provides an example of an analyzed compact image to illustrate where measurements were made at three azimuths 120 degrees apart. As discussed in Appendix A, compact results are given as relative changes from as-fabricated values during irradiation. As-fabricated compact dimensions were extracted from Oak Ridge National Laboratory (ORNL) compact lot data compilations for the Baseline (Capsules 3 and 6; Hunn 2006a), Variant 1 (Capsule 5; Hunn 2006b), Variant 2 (Capsule 2; Hunn 2006c), and Variant 3 (Capsules 1 and 4; Hunn 2006d) fuel. Appendix A explains how error bars were estimated as combined standard uncertainties for data points in certain plots shown below.

Figure 37 shows relative diameter changes for all 72 AGR-1 compacts where each data point represents an average of 45 measurements (15 spaced along the fuel-bearing length at each azimuth). Figure 38 shows relative length changes on AGR-1 compacts, where each data point represents an average of 12 measurements (four per azimuthal image). The data are arranged according to vertical position from the top of the test train (Capsule 6, Level 4, at the left) to the bottom (Capsule 1, Level 1, at the right). The approximately 2 -inch gap between graphite holders in adjacent capsules has been omitted. 


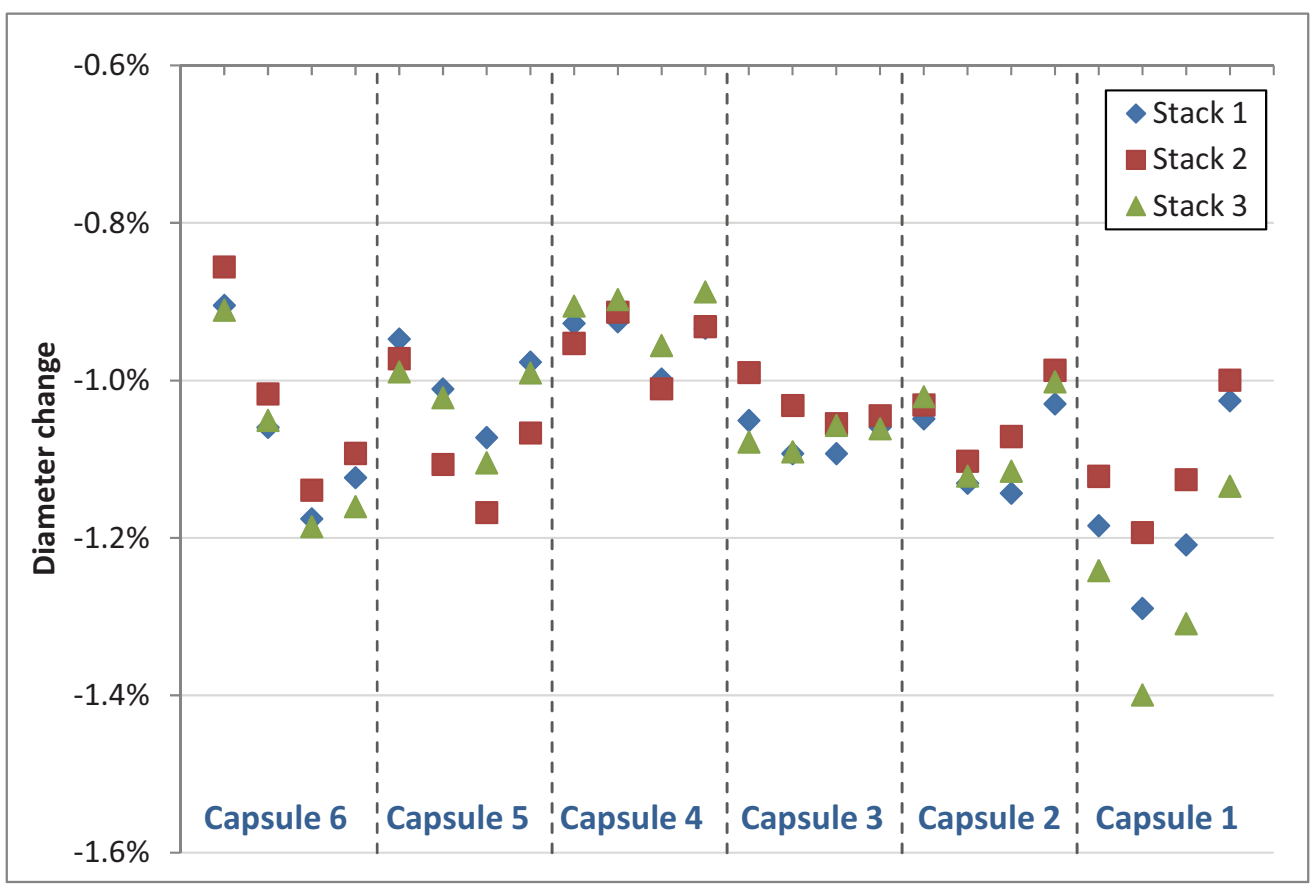

Figure 37. Average diameter changes of individual AGR-1 compacts.

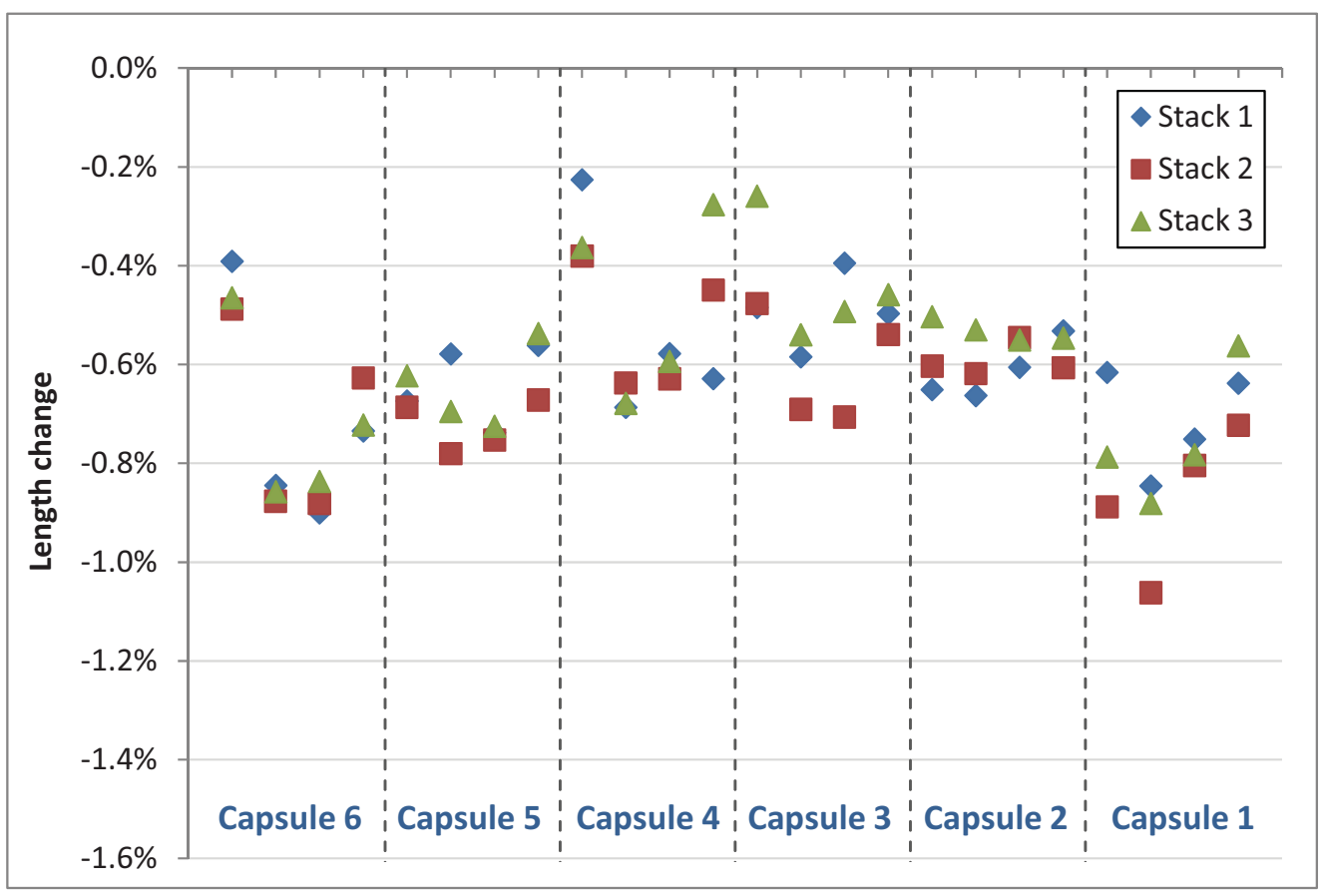

Figure 38. Average length changes of individual AGR-1 compacts. 
All values plotted in Figure 37 and Figure 38 are negative, which indicates consistent shrinkage during irradiation. Figure 37 and Figure 38 both show a strong dependence on the compact level in Capsules 6 and 1, which is addressed in detail later (see Figure 41 and Figure 42). Other candidate influences appear spurious because they only appear in one of these figures. For example, Figure 37 suggests there may have been more diameter shrinkage at inner Levels 2 and 3 than at outer Levels 1 and 4 within Capsules 2 and 5, but this is not supported by a corresponding length change pattern in Figure 38. Similarly, Figure 38 suggests less length change for outer levels in Capsule 4 compacts, but this possibility is not confirmed by Capsule 4 diameter changes in Figure 37. Stack number has no obvious influence in either figure.

Compact dimensional changes were averaged for each AGR-1 capsule. Capsule-averaged diameter change results are presented with error bars in Figure 39 and capsule-averaged length changes are displayed with error bars in Figure 40. (See Appendix A for values combined into averages and for discussion on error bar estimation.) These figures clearly demonstrate that AGR-1 fuel compacts shrank both radially and axially during irradiation by amounts that far exceed uncertainty. On a percentage basis, compact diameters consistently decreased more than lengths. In addition, despite the uncertainty bands, both figures suggest that slightly more dimensional change occurred toward the ends of the AGR-1 test train, especially near the bottom. No definite dependence on fuel variants can be discerned. For example, Variant 3 compacts in Capsules 1 and 4 exhibit both the greatest and least dimensional changes, respectively.

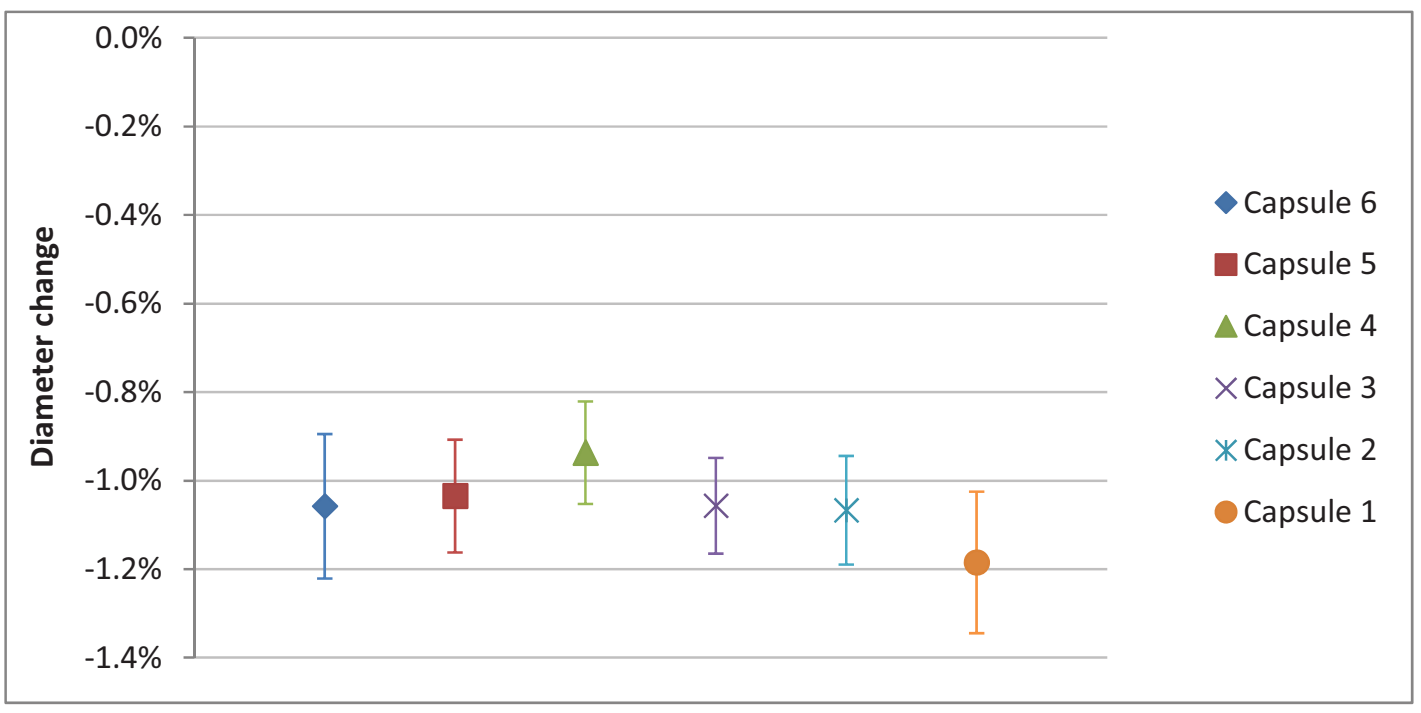

Figure 39. Diameter changes averaged for all fuel compacts in each AGR-1 capsule. 


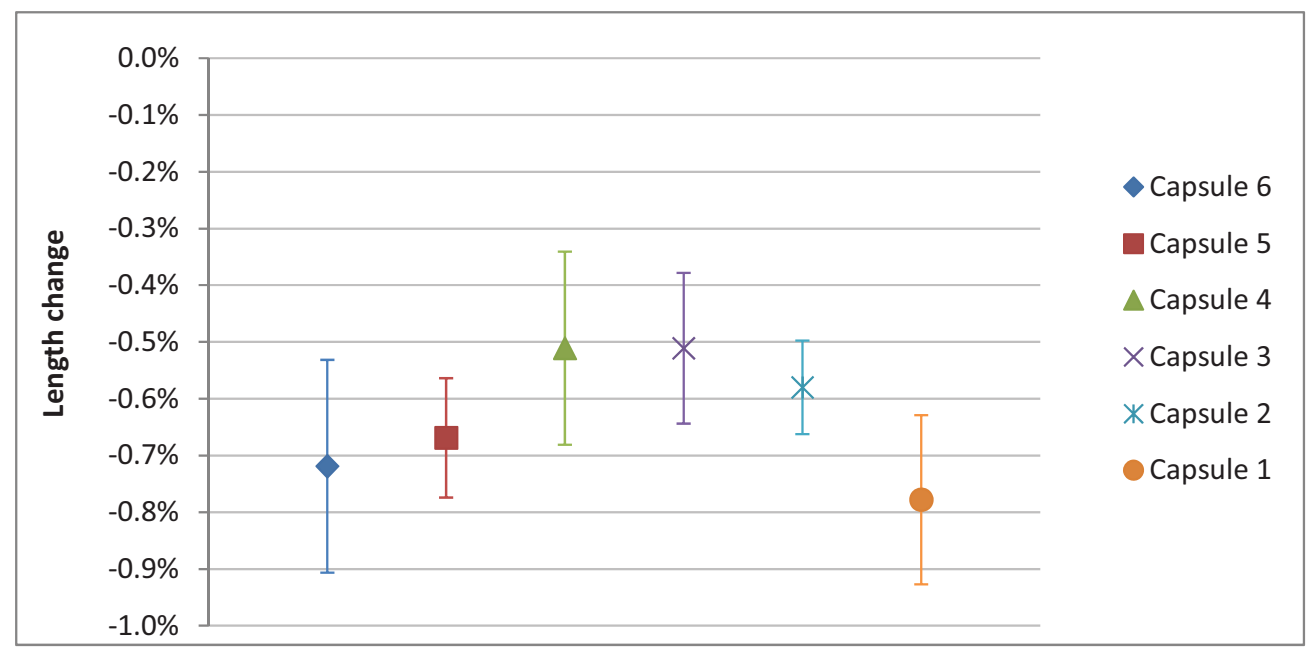

Figure 40. Length changes averaged for all fuel compacts in each AGR-1 capsule.

As noted above, Figure 37 and Figure 38 suggest that shrinkage varies by level in Capsule 6 and Capsule 1 compacts. This level influence is explored further in Figure 41 and Figure 42 where compact dimensional changes are averaged by level for Capsules 6 and 1, respectively. Each diameter change data point in these figures is the average of all diameter measurements for the compact (135 measurements) and each length change data point is the average of all length measurements for the compact (36 measurements). Figure 41 and Figure 42 suggest that compact shrinkage was at a maximum at level 3 in Capsule 6 and at Level 2 in Capsule 1. Figure 41 reveals substantially less length shrinkage for Level 4 compacts in Capsule 6 and Figure 42 shows appreciably less length shrinkage for Level 1 compacts in Capsule 1-the compacts near the top and bottom of the AGR-1 test train, respectively. A similar trend is seen in diameter changes, despite the overlapping error bars. Without the relatively low shrinkage in the outermost compacts, the capsule-averaged shrinkage in Figure 39 and Figure 40 for Capsule 1 and Capsule 6 compacts would have been even greater. Low shrinkage in the outermost compacts is primarily responsible for the larger error bars for Capsule 6 and Capsule 1 compacts in Figure 39 and Figure 40.
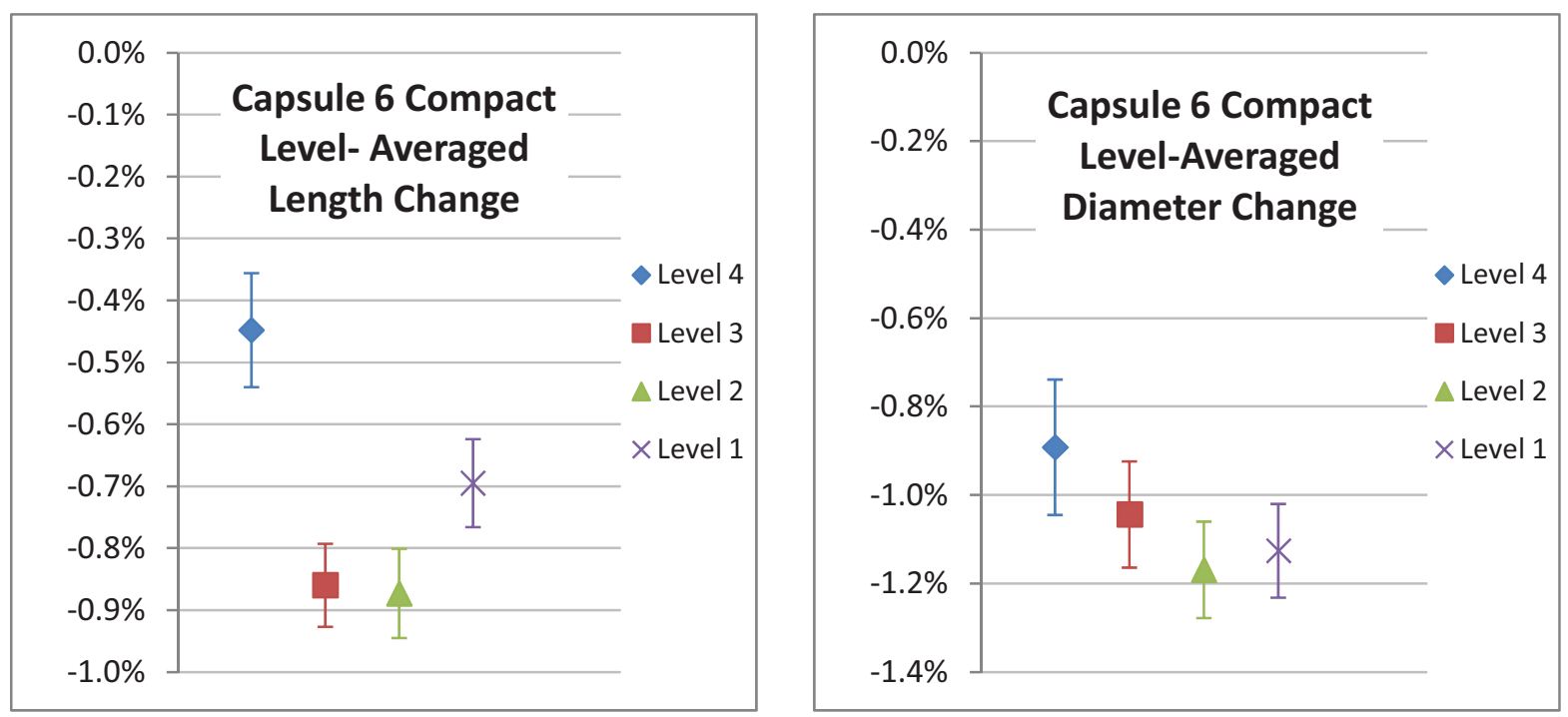

Figure 41. Length and diameter changes among levels in Capsule 6 compacts. 

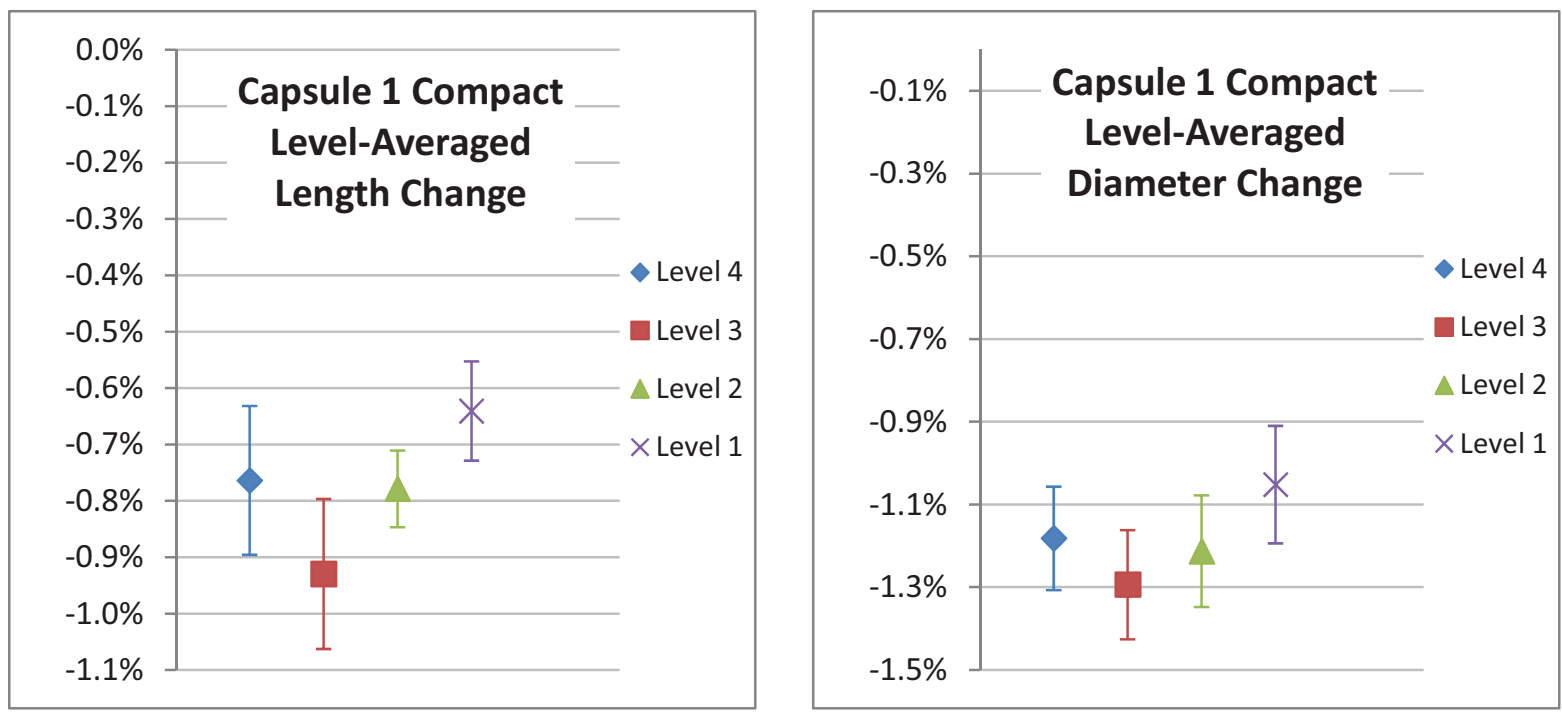

Figure 42. Length and diameter changes among levels in Capsule 1 compacts.

A strong effect of test train elevation was also noticed in diameter changes along the Level 4 compacts in Capsule 6 and Level 1 compacts in Capsule 1. All six of these outermost compacts showed pronounced tapers, which are displayed in Figure 43. As indicated, all six compacts shrank less toward their outer ends. These tapers (typically $0.3 \%$ ) greatly exceed the taper in as-fabricated diameter measurements on these compacts, which ranged from 0 to approximately $0.08 \%$. Approximately one-half as much taper was observed on Level 3 compacts in Capsule 6 and Level 2 compacts in Capsule 1 (slopes in same direction as in Figure 43 for outermost compacts). The smaller tapers found after irradiation on most other AGR-1 compacts could not be clearly distinguished from as-fabricated tapers.

While this report has focused on the compact average shrinkage values, the individual data points as presented in Figure 43 and the profiles along compacts will be examined further in future analyses, which will investigate potential influences at ends of capsules as well as near both ends of the AGR-1 test train.
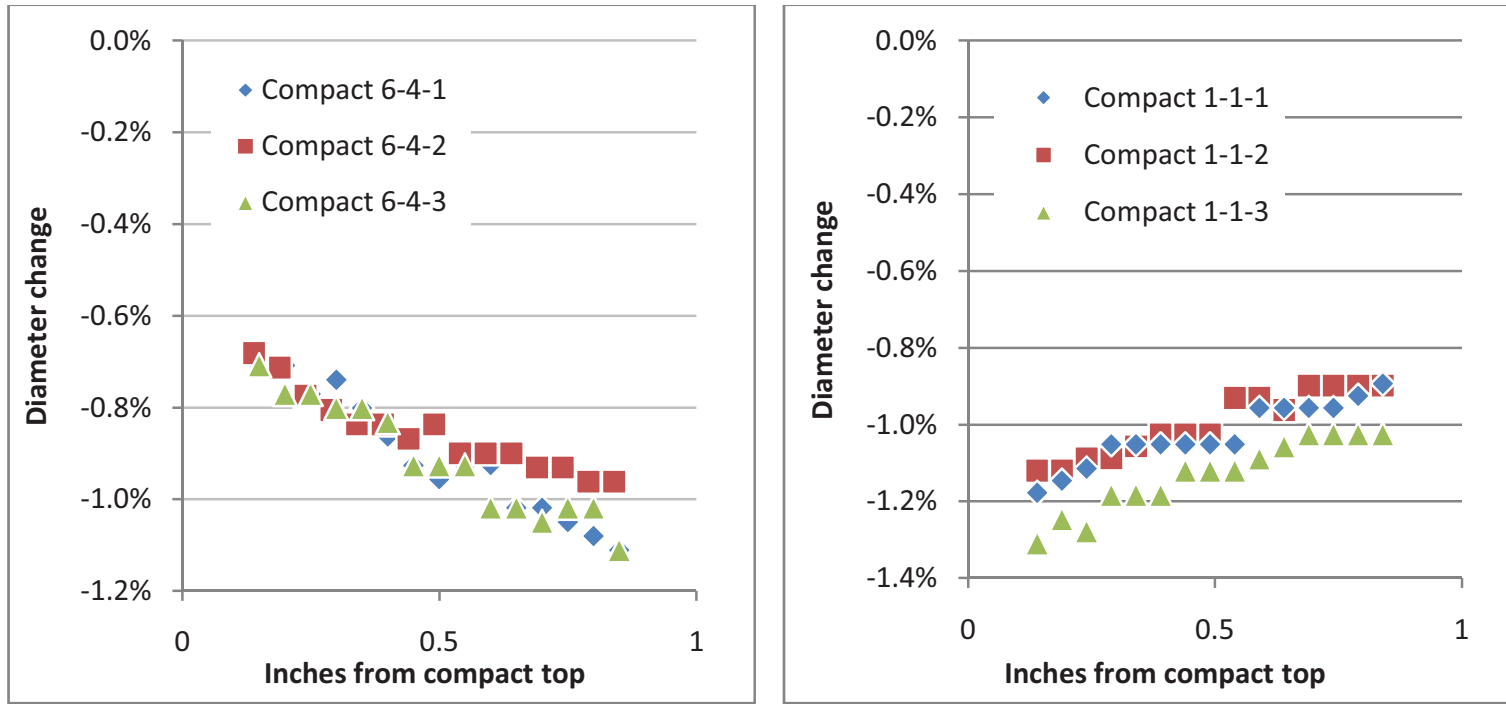

Figure 43. Tapered diameter shrinkage in outermost Capsule 6 and Capsule 1 compacts. 
Potential dependence on fast neutron fluence $(\mathrm{E}>0.18 \mathrm{MeV})$ is investigated for diameter change in Figure 44 and for length change in Figure 45. A downward slope can be discerned on the left portion of Figure 44 (below approximately $3 \times 10^{21}$ neutrons $/ \mathrm{cm}^{2}$ ), and there also may be a downward trend amongst the data scatter on the left portion of Figure 45. Meanwhile, the slope flattens in both figures above $3 \mathrm{x}$ $10^{21}$ neutrons $/ \mathrm{cm}^{2}$ and perhaps begins an upward trend. Thus, Figure 44 and and Figure 45 jointly suggest that shrinkage in AGR-1 compacts is a nonlinear function of fast neutron fluence. Refined analyses are planned to further investigate shrinkage dependence on fast fluence and other candidate factors such as compact temperature.

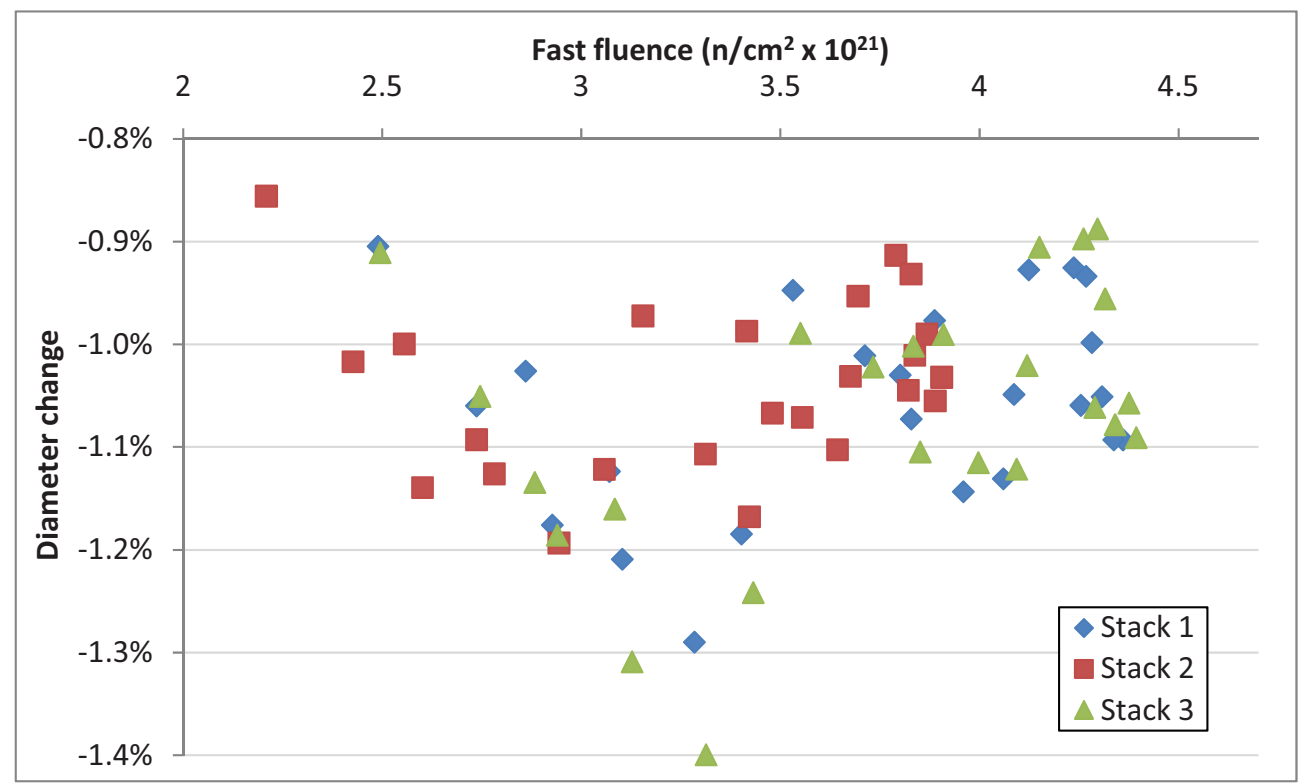

Figure 44. Average diameter changes for all AGR 1 compacts as a function of calculated fast neutron fluence (E > $0.18 \mathrm{MeV})$.

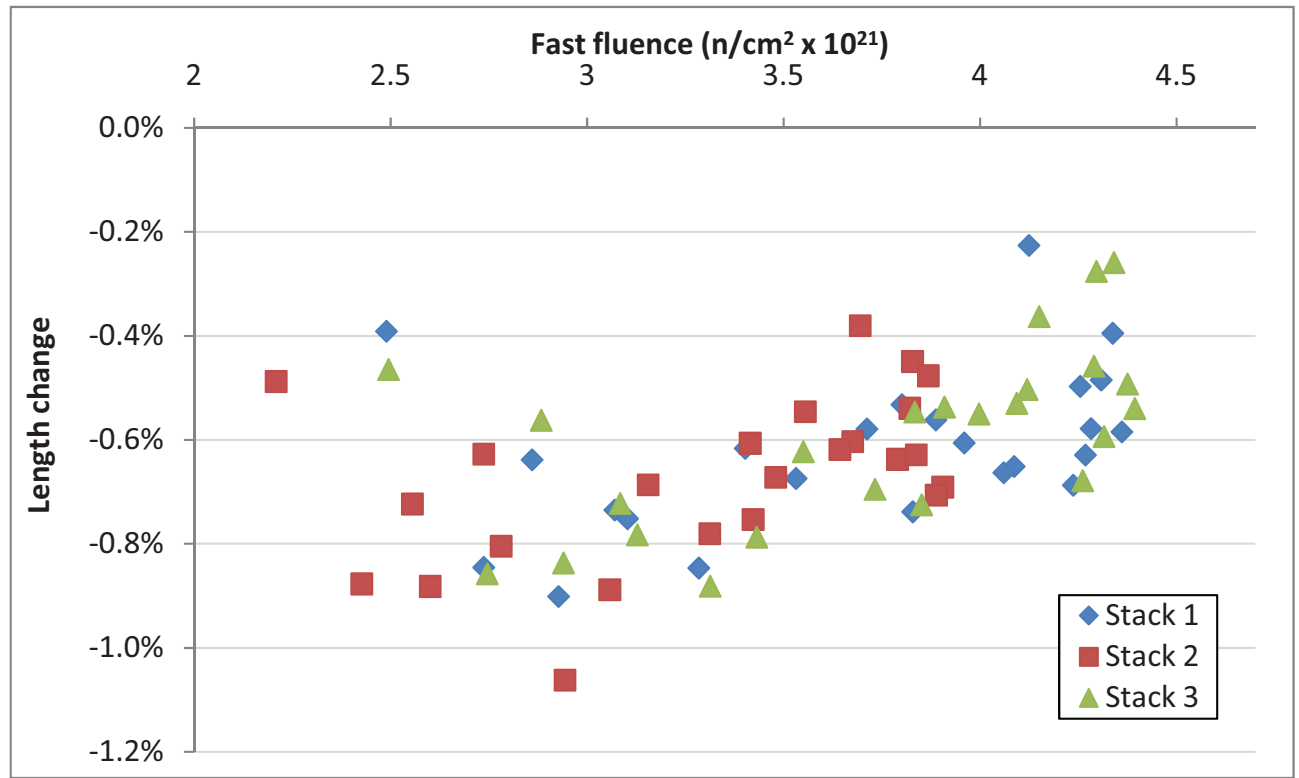

Figure 45. Average length changes for all AGR 1 compacts versus calculated fast neutron fluence $(E>0.18$ $\mathrm{MeV})$. 


\subsection{Graphite Holder Visual Inspections}

All AGR-1 graphite holders were supported during photographic inspection by a fixture that inserted a prong into each of the three through-tube grooves. Three azimuths 120 degrees apart were inspected for full coverage of the lateral surface. Inspection and imaging began at the 0-degree azimuth that faced the center of the ATR core. As indicated in Figure 46, each holder was then rotated clockwise 120 degrees (when viewed from the bottom) to the next azimuth. This section summarizes the results of visual inspection of the graphite holders. Section 4.4 presents the results of dimensional analyses.

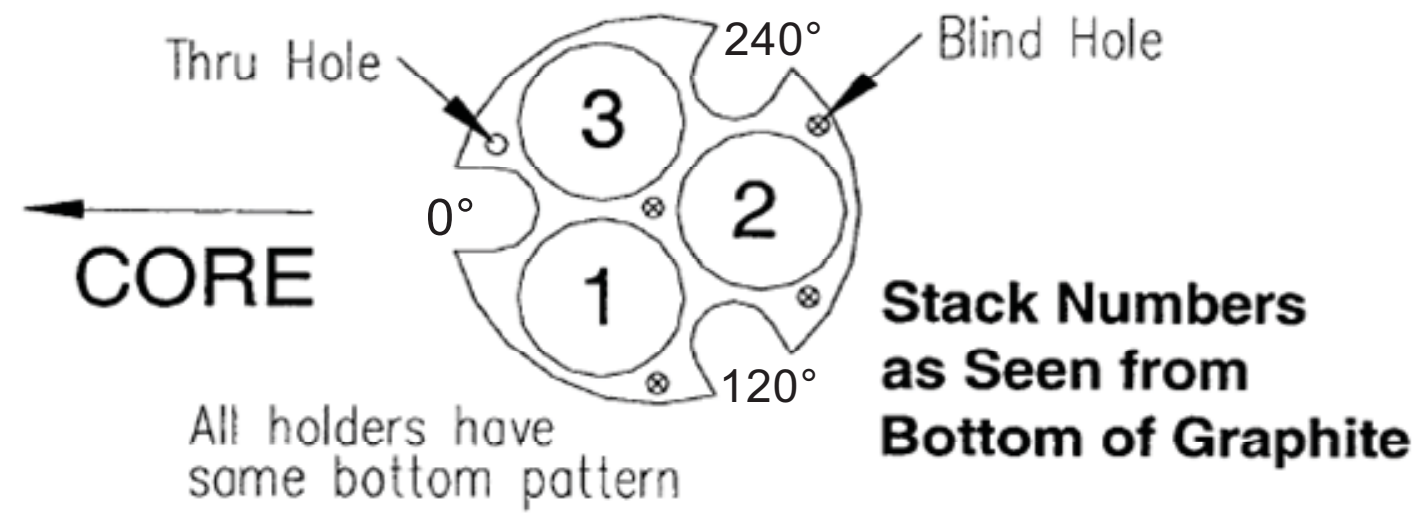

Figure 46. Relationship of graphite holder azimuths to in-pile orientation.

\subsubsection{Capsule 1 Graphite Holder}

A stitched composite image of the Capsule 1 graphite holder (Holder 1) is displayed at one azimuthal orientation in Figure 47 where overlapped regions between the six images appear slightly darker. No deleterious effects of irradiation were observed. No significant damage occurred during disassembly, although some axial rubbing marks evidently were caused by removal of the capsule shell. Its most noteworthy feature is the presence of small pits concentrated midway along the upper axial portion, which may be associated with boron carbide particles (5.5\% initial loading). The bottom of Holder 1 has a reflective band around its circumference, but the cause of this shiny surface is not currently known.

Views of both ends taken with a 45-degree mirror are presented in Figure 48. Neither image shows any damage from irradiation or disassembly. A circular mark can be distinguished on the bottom end. A diameter measurement on this image yielded 1.1783 inches, which is close to the nominal as-fabricated 1.180-inch diameter of the adjacent graphite spacer. 


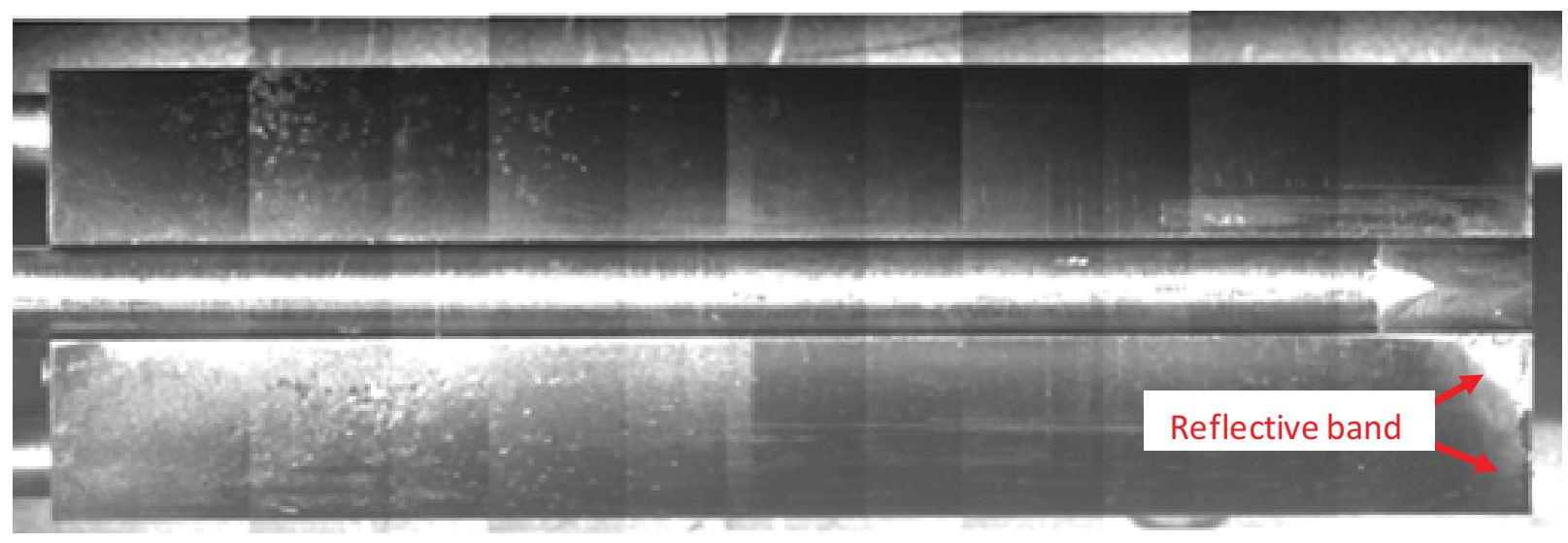

Figure 47. Holder 1, top end left, 240-degree azimuth facing camera.
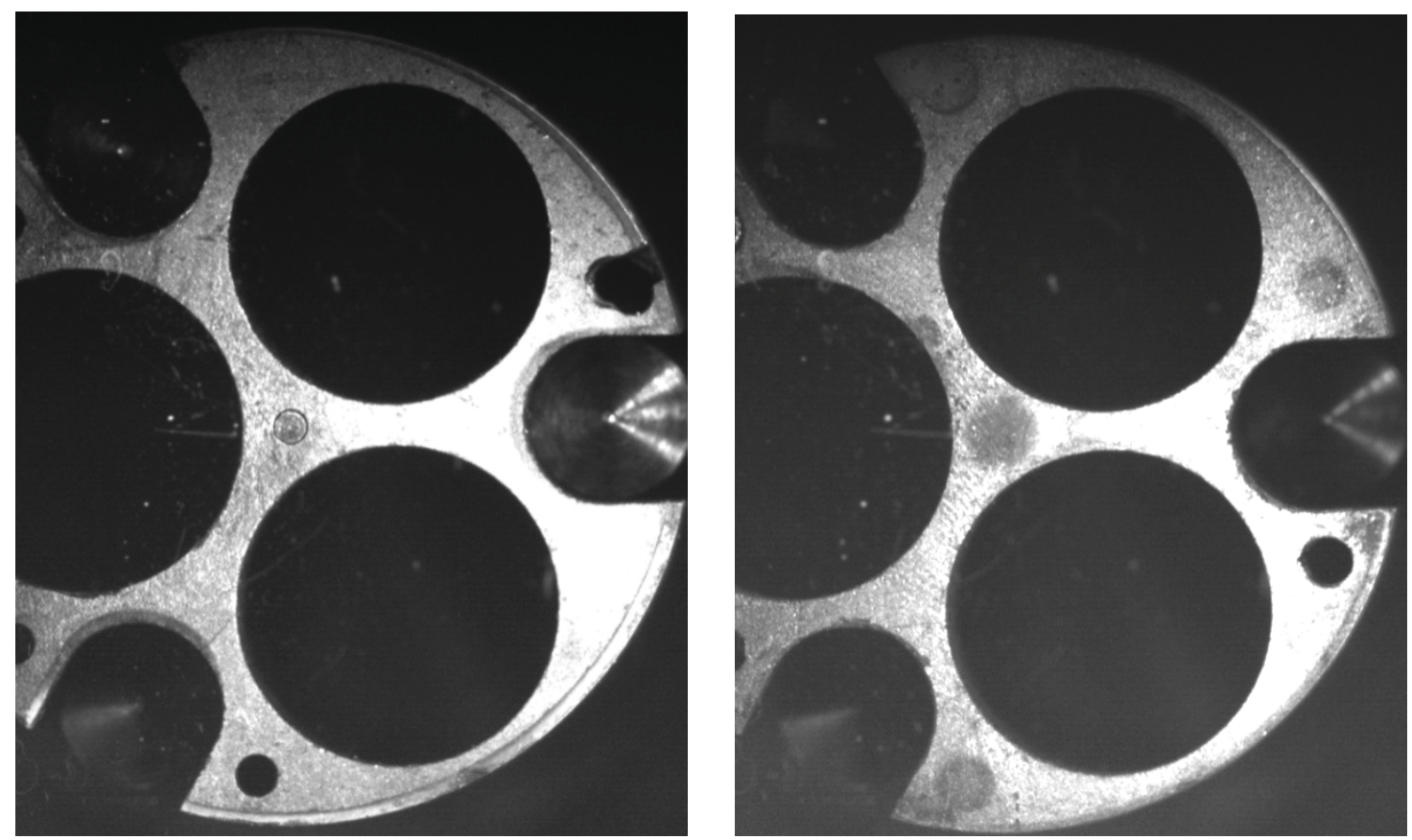

Figure 48. Images of bottom (left) and top (right) ends of Holder 1, 0-degree azimuth to right.

\subsubsection{Capsule 2 Graphite Holder}

The Capsule 2 graphite holder (Holder 2), which was loaded with 7.0\% boron carbide, is shown in Figure 49. No structural damage is apparent from either irradiation or disassembly. However, several types of nonuniform deformation can be discerned. The diameter is tapered outward toward both ends (see next section for dimensional results), and both ends have a slight dish shape. In addition, the throughtube groove appears to narrow near both ends. The pointed support fixture prongs (same diameter as through-tubes) could only be inserted a short distance into the grooves, unlike Holder 1. Faint axial marks along the bottom end may be from rubbing against the capsule shell liner during extraction because local OD measurements indicate that radial growth of Holder 2 was sufficient at both ends to locally contact the capsule shell liner. 


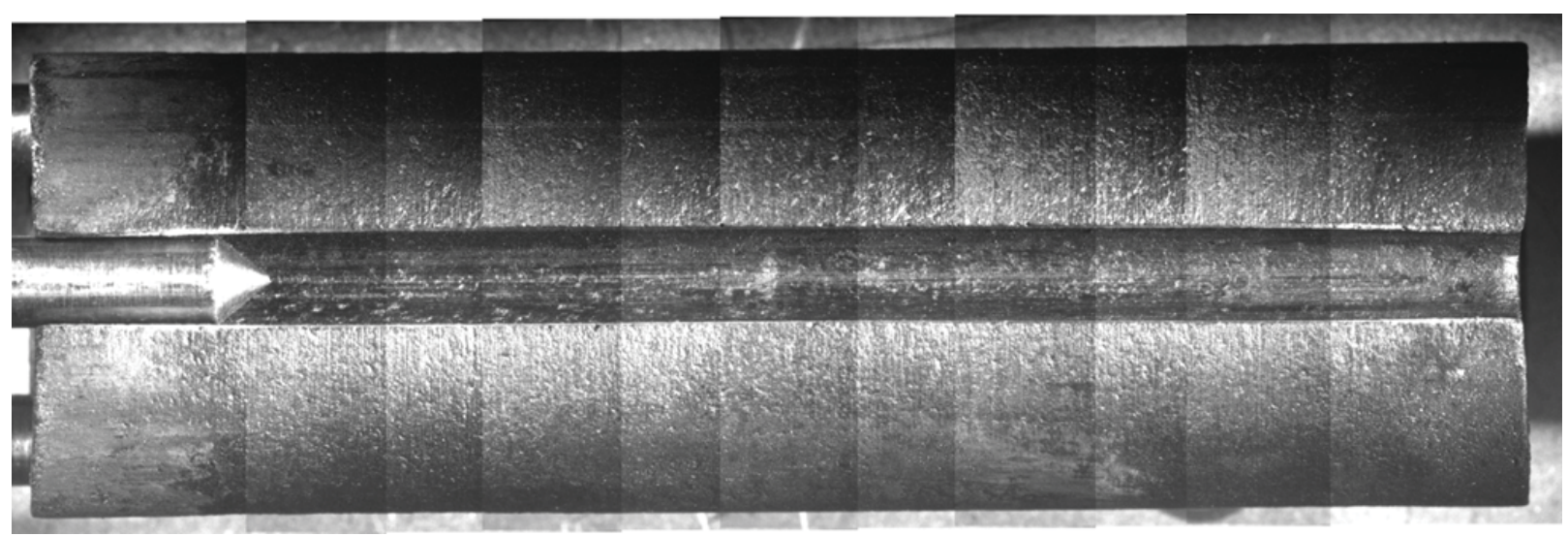

Figure 49. Holder 2, bottom end left, 240-degree azimuth facing camera.

The top and bottom of Holder 2 (sides of Figure 49) are examined at higher magnification in Figure 50 and Figure 51. These figures jointly indicate that the dish shape of Holder 2 ends is related to the shorter holder length near through-tube azimuths than away from them. The base of the through-tube groove in Figure 50 is recessed downward (also in 0-degree and 120-degree grooves), which indicates that the top end of Holder 2 developed a concave shape during irradiation.

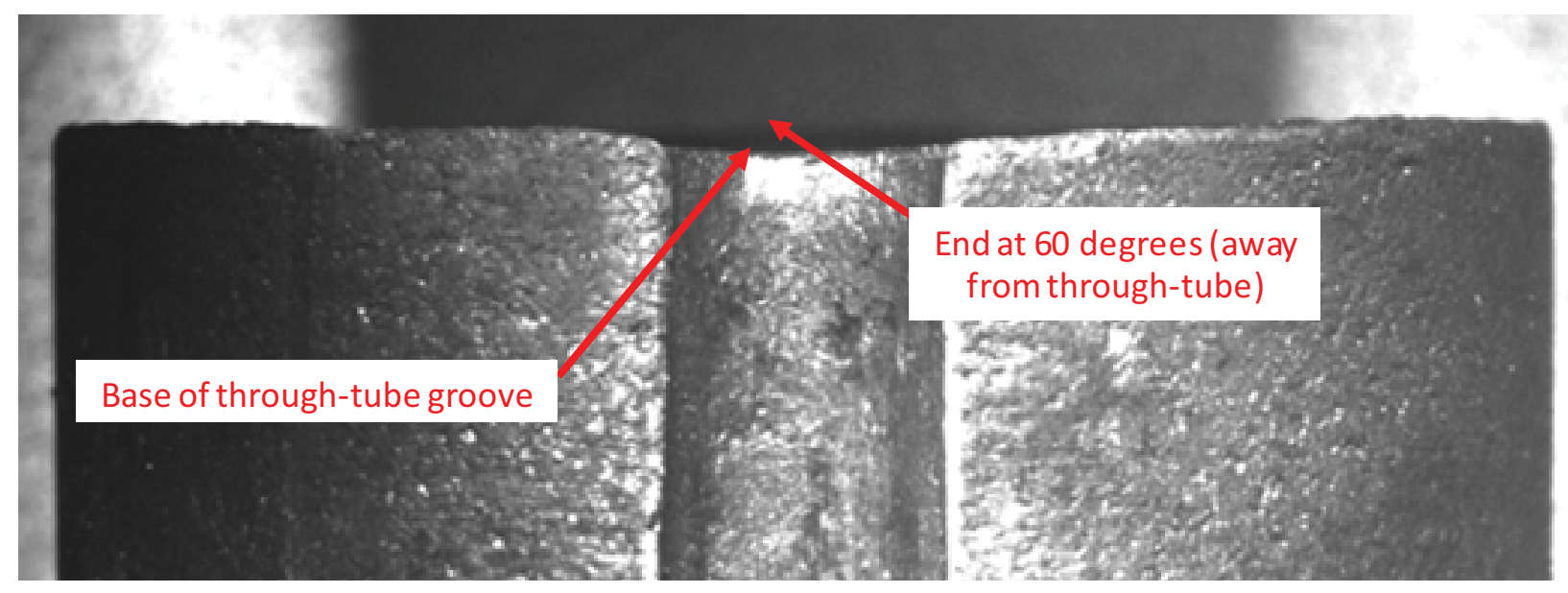

Figure 50. Top end of Holder 2, 240-degree azimuth facing camera. 


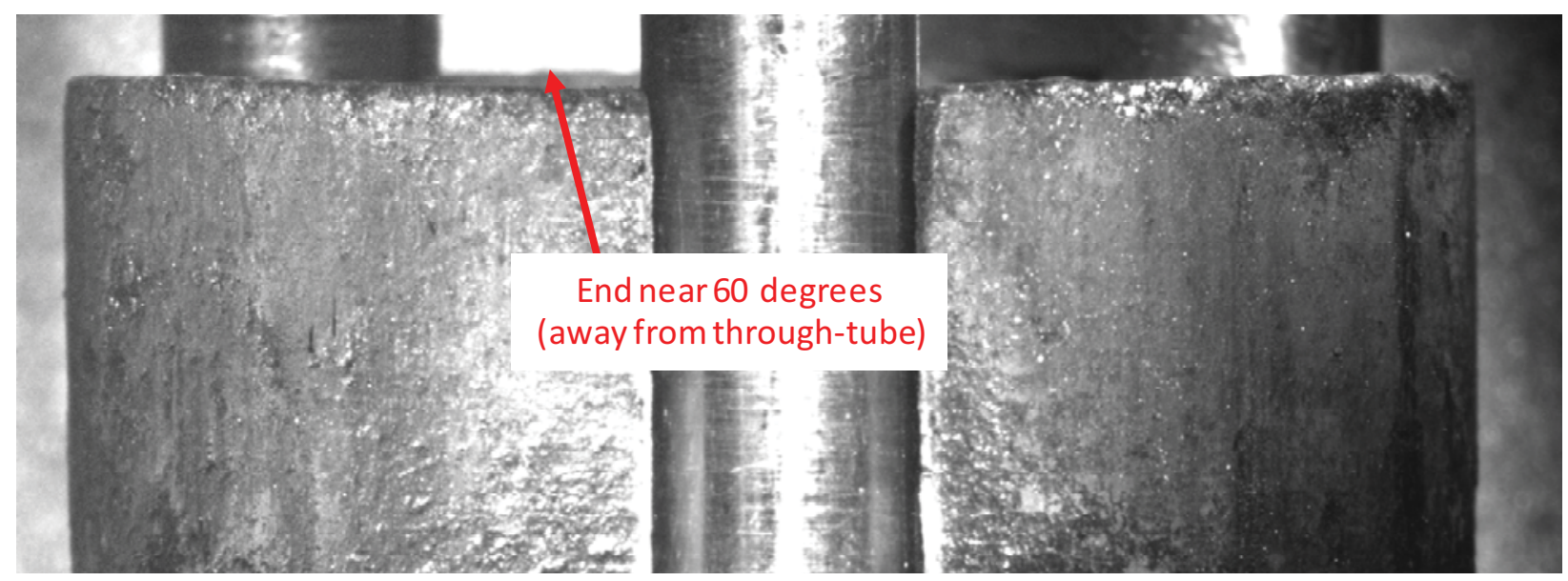

Figure 51. Bottom end of Holder 2, 240-degree azimuth up.

Views of Holder 2 ends are provided in Figure 52. A circular mark inward of the Holder 2 periphery is distinct on the top surface (Figure $52 \mathrm{~b}$ and c), but not on the bottom end. A measurement of the mark diameter yielded a value of 1.1816 inches, very close to the nominal 1.180 -inch as-fabricated diameter of the adjacent graphite spacer.

Figure 52 shows horseshoe shapes in some through-tube grooves where peripheral graphite partially bridged across the through-tube exteriors during irradiation. These distorted grooves are very different from the parallel groove sides of Holder 1 in Figure 48. This distortion explains the apparent narrowing of the through-tube grooves at both ends of Holder 2 in Figure 49, plus why it was difficult to remove the through-tubes during disassembly. This distortion was only found where Holder 2 contacted the shell liner, so this tangential growth may have been a consequence of constraint on radial growth.
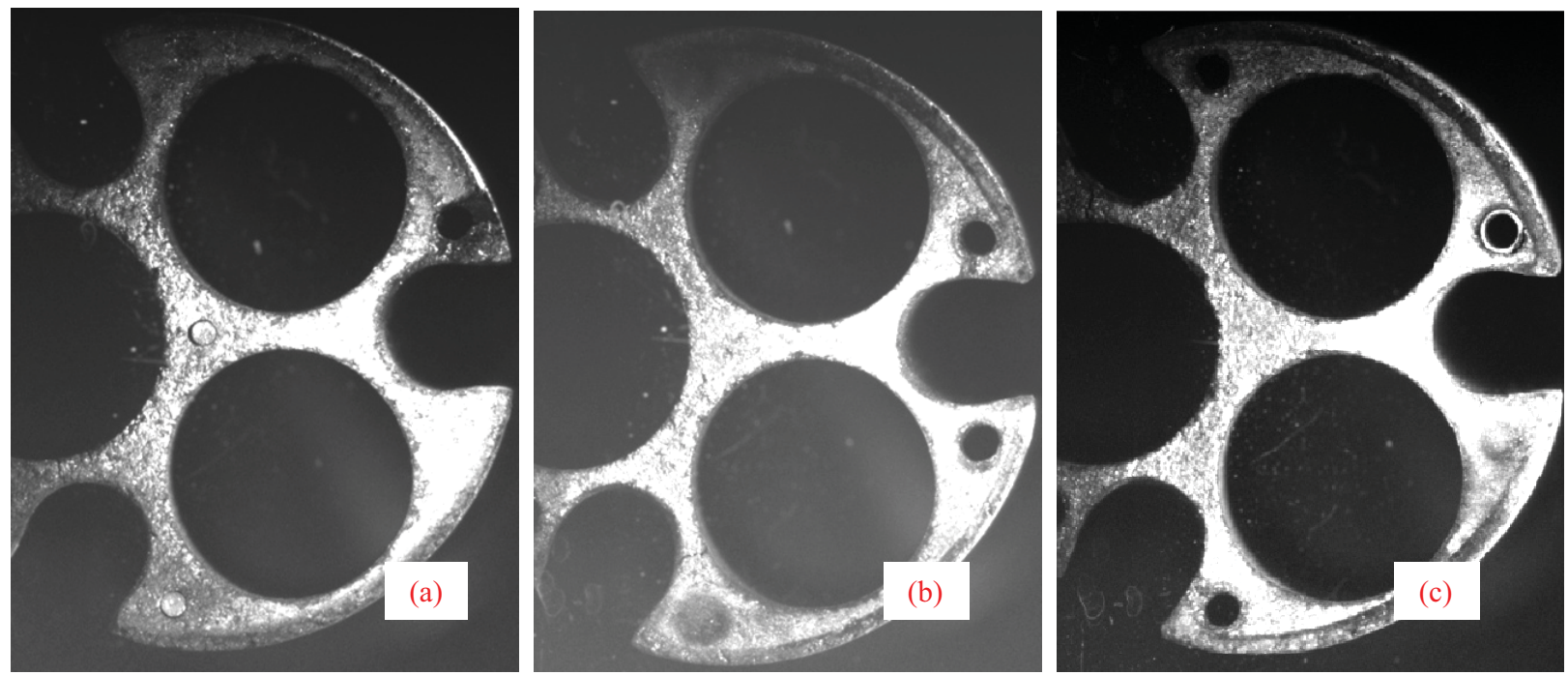

Figure 52. Bottom (a) and top (b) ends of Holder 2, both with 0-degree azimuth at right; top end with 240-degree azimuth at right (c). 


\subsubsection{Capsule 3 Graphite Holder}

The Capsule 3 graphite holder (Holder 3, 7.0\% boron carbide loading) is shown in Figure 53. As with Holder 2, fixture support prongs could only be inserted a short distance into through-tube grooves. Disassembly damage is apparent at the upper left of Figure 53 where a piece broke during separation of the upper head assembly. On the right half, graphite along the through-tube groove broke off when a through-tube was pried loose, exposing the hole for the gas inlet line. This fracture almost certainly resulted from tangential bridging of graphite (horseshoe-shaped groove) and associated pinching of the through-tube. Figure 53 indicates that tangential bridging of graphite occurred along the full length of the 0 -degree groove, with the greatest narrowing near the axial middle of the holder. Through-tube grooves were narrower near the ends on Holder 3 at 120-degree and 240-degree azimuths.

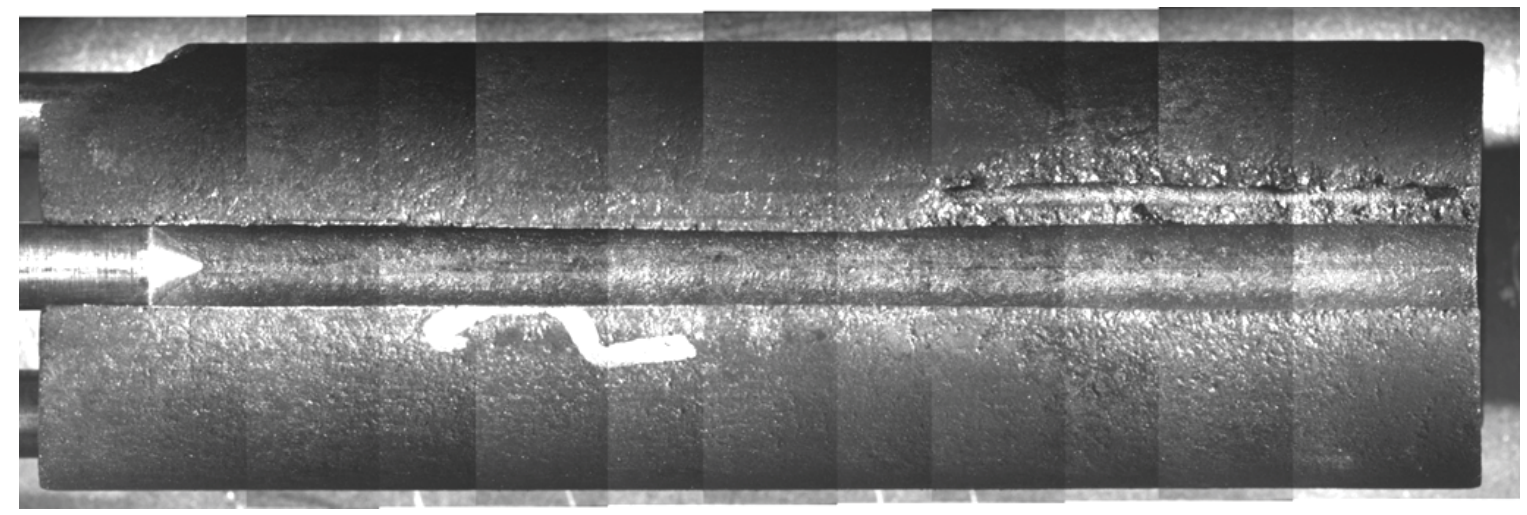

Figure 53. Holder 3, top end left, 0 -degree azimuth (marked by bright paint) facing camera.

As with Holder 2, the ends of Holder 3 appear dished because Holder 3 is slightly shorter near through-tube azimuths than away from them. Further evidence of this uneven deformation is shown in Figure 54, where the fracture opening makes it clear that the length of Holder 3 is greater along the periphery than near the radial center, indicating a concave surface at the top end. Although not shown here, the bases of the through-tube grooves were recessed at the bottom of Holder 3 at all three azimuths, also indicating a concavity at the bottom end of Holder 3 .

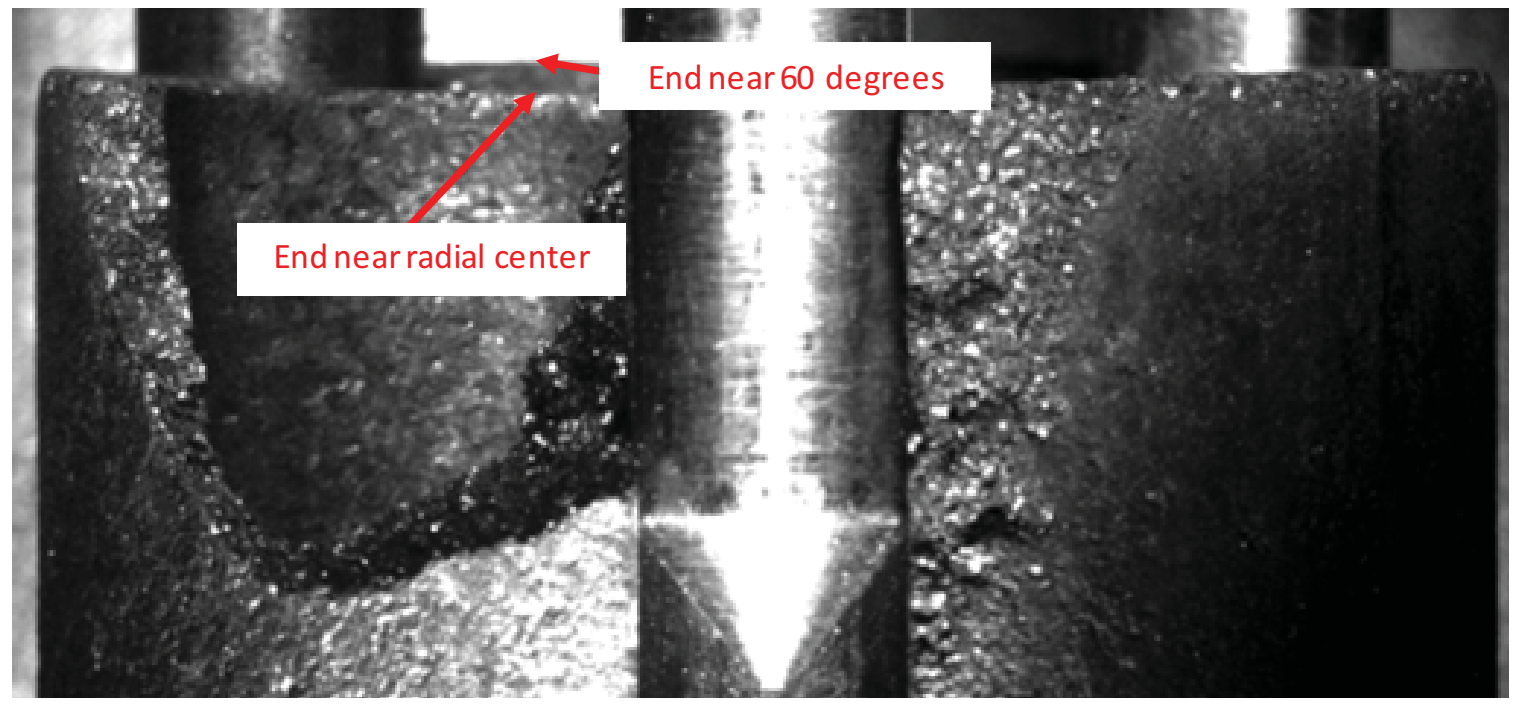

Figure 54. Top of Holder 3 with 240-degree azimuth facing camera (Stack 3 hole opened by fracture). 
Views of Holder 3 ends are shown in Figure 55. Two small cracks on the top surface probably occurred during disassembly. Horseshoe-shaped through-tube grooves are very conspicuous in Figure 55, except where fractured off along the lower axial portion of 0-degree groove during disassembly.
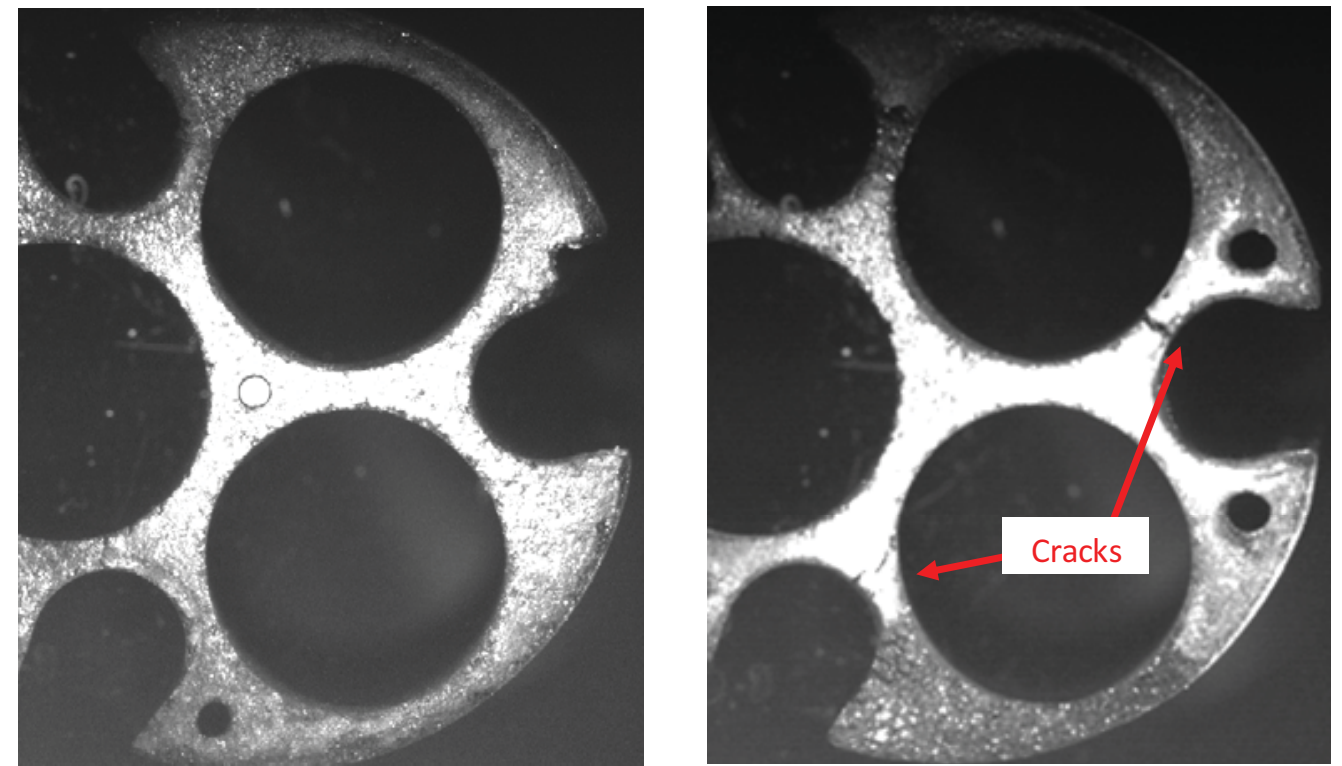

Figure 55. Views of bottom (left) and top (right) of Holder 3, 0-degree azimuth to right.

\subsubsection{Capsule 5 Graphite Holder}

The Capsule 5 graphite holder (Holder 5, 7.0\% boron carbide loading) is displayed in Figure 56. A small piece broke off at each end during disassembly. As with Holder 2, the diameter is larger toward both ends (see Section 4.4 for details) and both ends have a slight dish shape. Partial bridging occurred over the through-tubes near the top end, but support fixture prongs were able to penetrate farther into the grooves on the bottom end than was possible with Holders 2 and 3. Faint axial marks near the top end are probably from rubbing against the capsule shell liner during disassembly, since local OD measurements confirm that the top of Holder 5 swelled radially to contact the shell liner.

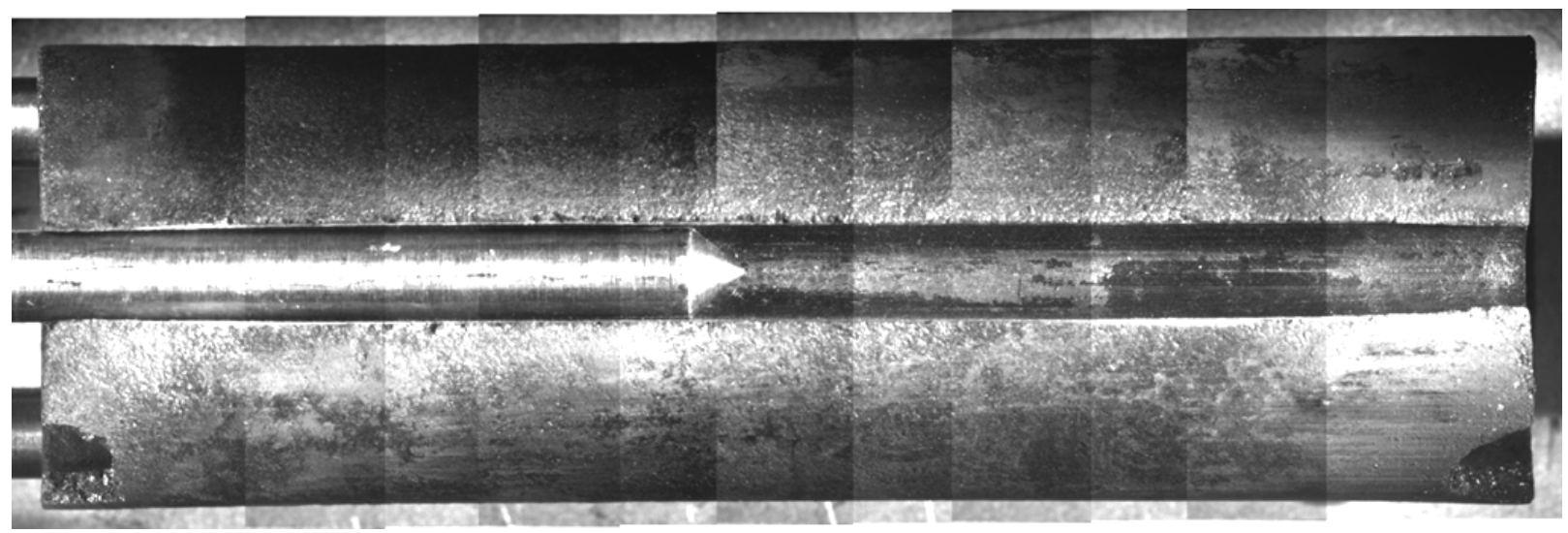

Figure 56. Holder 5, bottom end left, 240 -degree azimuth facing camera.

The axial rubbing marks are shown at higher magnification in Figure 57, which also illustrates the outward taper in the Holder 5 OD approaching the top end. As with Holder 2 and Holder 3, the length of 
Holder 5 is greater away from through-tube positions. The base of the through-tube groove is recessed downward in Figure 57, indicating a concavity at the top end. Similar recesses were observed at the top of the 0 -degree and 120-degree through-tube grooves.

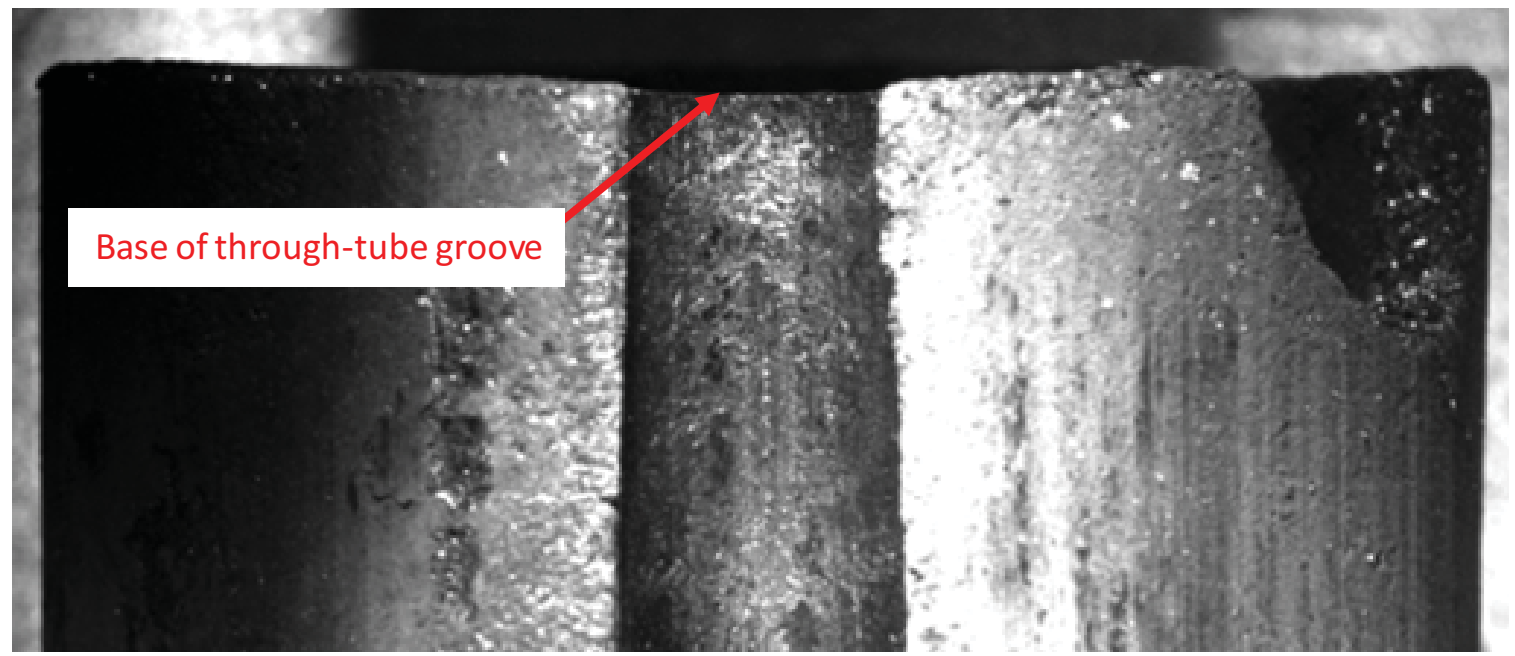

Figure 57. Top of Holder 5 with 240-degree azimuth facing camera.

Views of Holder 5 ends are provided in Figure 58. Although tangential graphite growth (bridging across through-tube grooves) is conspicuous at the top of Holder 5, the horseshoe shape is barely distinguishable at the bottom end, which is why the support fixture prongs were able to penetrate so far. This subdued tangential growth may be related to the measurement result that radial growth near the bottom was not quite sufficient to reach the capsule shell liner (see Section 4.4). Meanwhile, radial growth was constrained by liner contact at the top of Holder 5 , which apparently encouraged tangential growth across the top of through-tube grooves at that end.
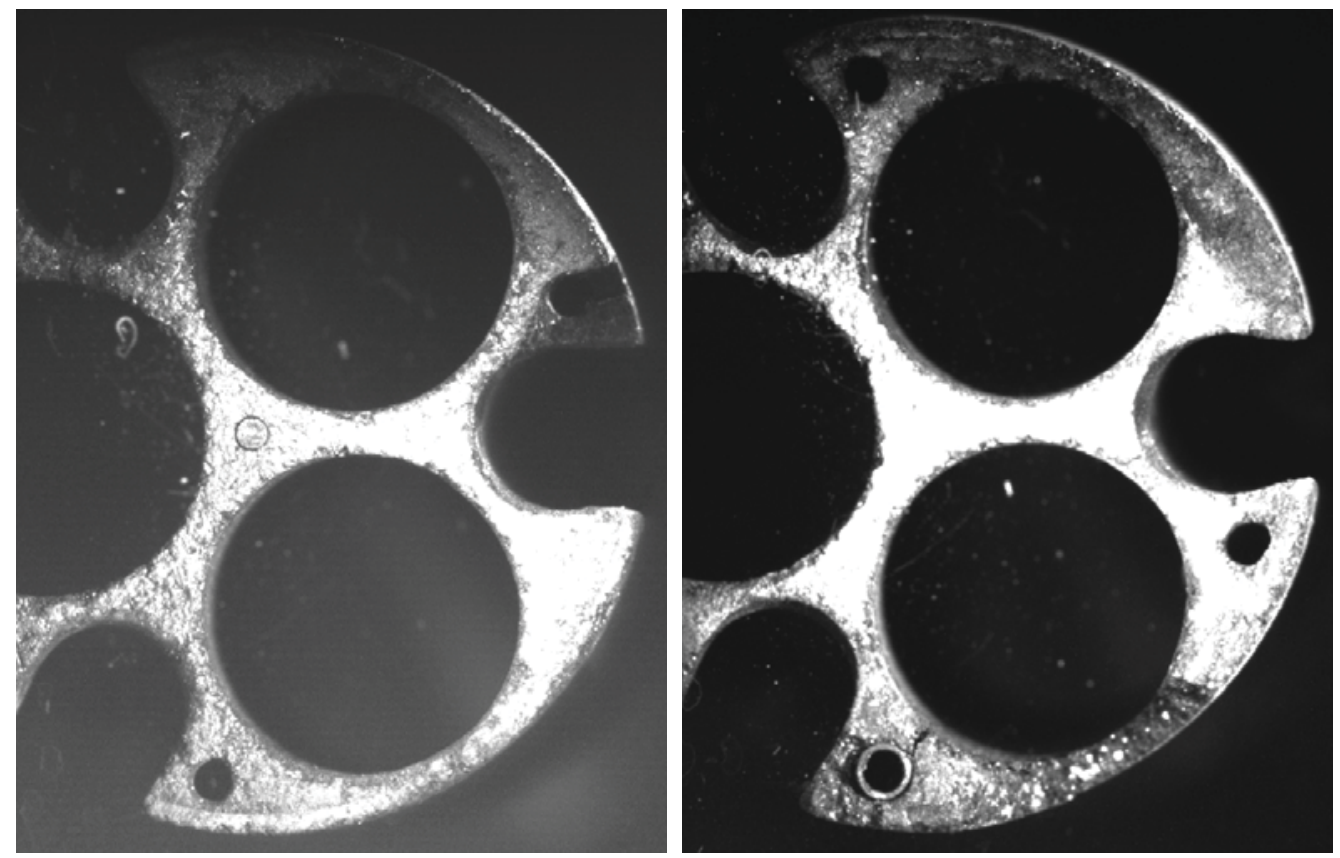

Figure 58. Holder 5 bottom end (left, 0 degrees to right) and top end (right, 240 degrees to right). 


\subsubsection{Capsule 6 Graphite Holder}

The Capsule 6 graphite holder (Holder 6, 5.5\% boron carbide loading) is presented in Figure 59. Corners are sharp and square and there are no obvious signs of concave ends. A large piece is missing at the lower right of this composite image, which was broken off during disassembly. Few pits can be distinguished along the sides of Holder 6, unlike in Figure 47 for Holder 1. A reflective deposit of unknown origin is located near the top end, similar in appearance to the shiny substance found near the bottom of Holder 1 (Figure 47). The shiny deposit is displayed at higher magnification in Figure 60. This figure also reveals a short crack next to a thermocouple, which was induced during separation of the upper head assembly on this capsule.

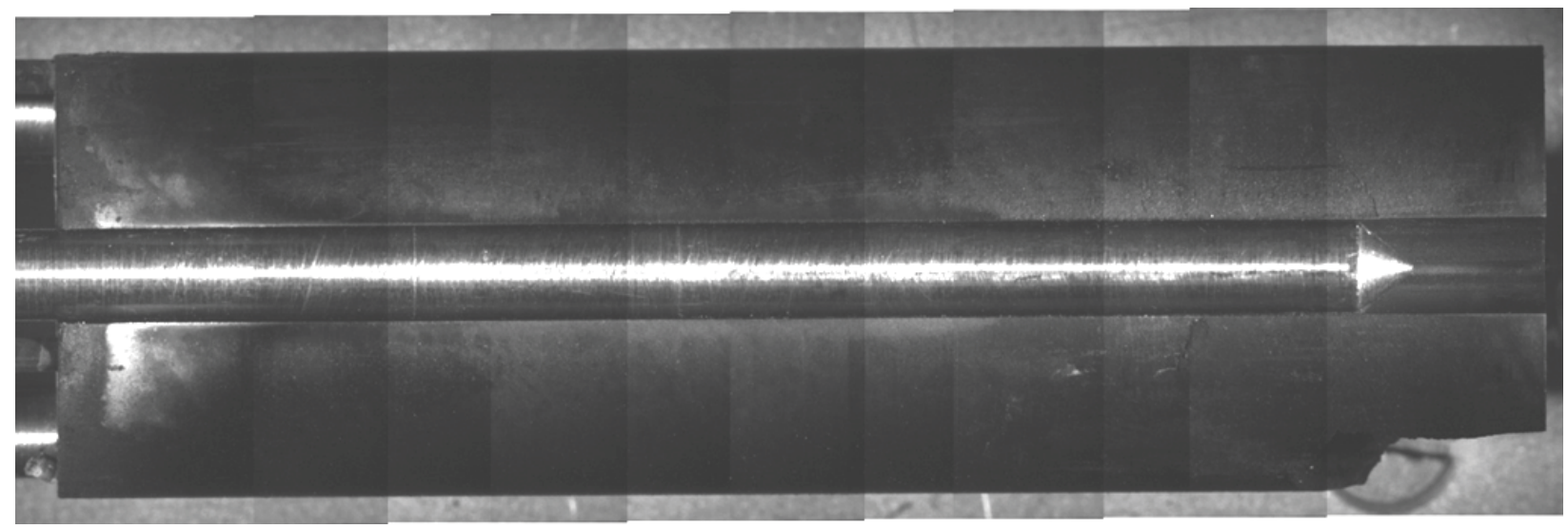

Figure 59. Holder 6, top end left, 240-degree azimuth facing camera.

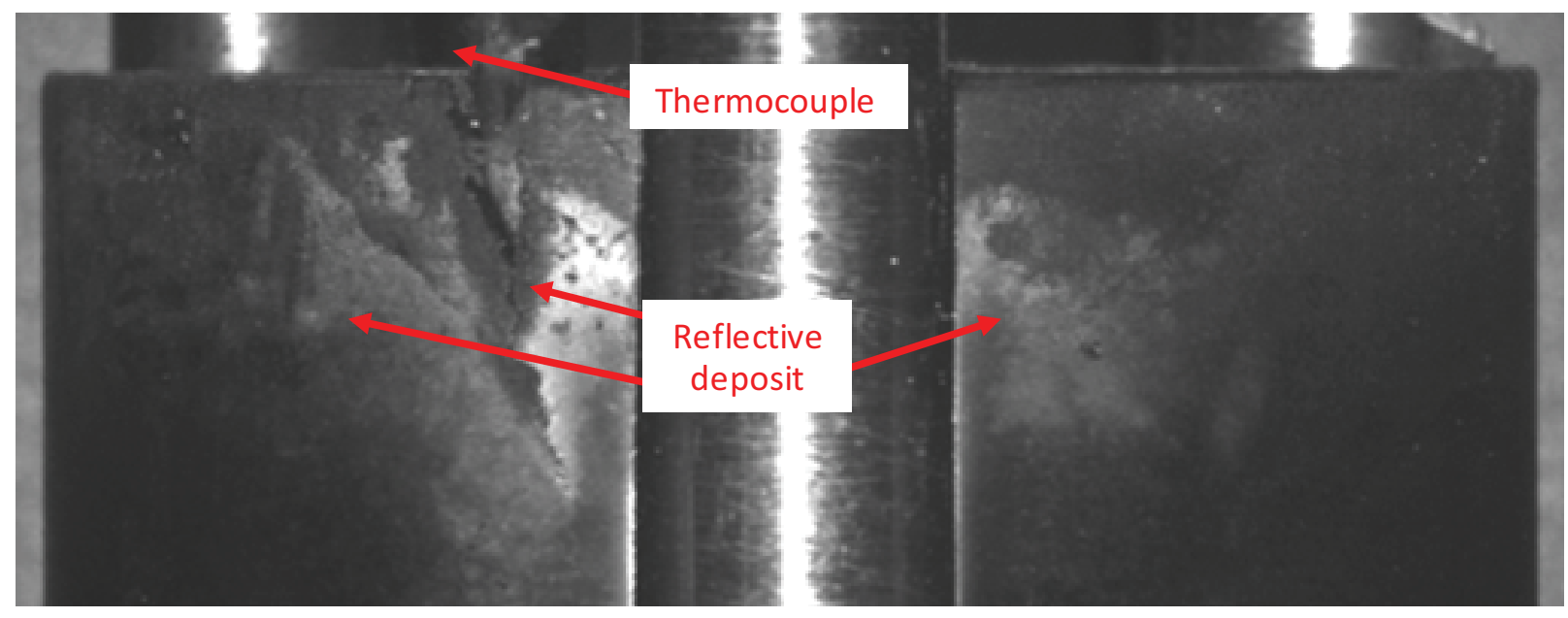

Figure 60. Reflective deposit and small crack on Holder 6 top, 120-degree azimuth facing camera.

The missing piece in Figure 59 was still attached when inspection of Holder 6 began. It broke off when this holder was rotated to the next azimuth along a crack shown in Figure 61, which propagated from a notch at the bottom end. This crack was induced during through-tube removal where a small piece of graphite at the groove base adhered to the molybdenum through-tube. 


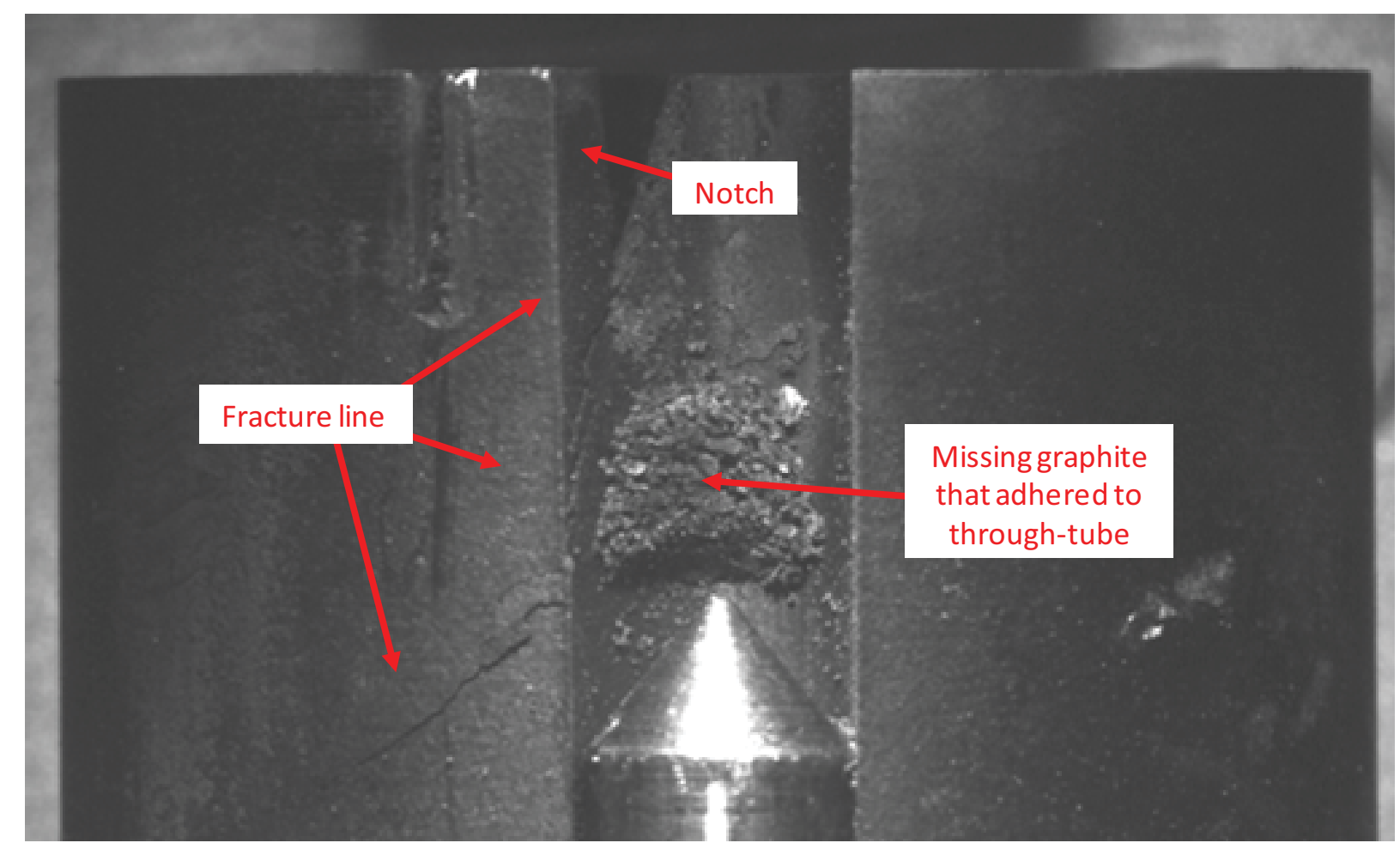

Figure 61. Crack near Holder 6 bottom from through-tube removal, 0 -degree azimuth toward camera.

\subsection{Graphite Holder Dimensions}

This section presents results extracted from graphite holder metrology data detailed in Section 2 of Appendix A, which also provides an example of an analyzed composite image of an AGR-1 holder to illustrate locations and frequencies of measurements. Appendix A provides further information on how error bars in certain plots below were estimated as combined standard uncertainties. Appendix A also includes additional description of the bore gauge measurements of inner diameters of the graphite holder holes that contained AGR-1 fuel compacts.

\subsubsection{Capsule 1 Graphite Holder}

Outer diameter changes (relative to the 1.219-inch as-fabricated diameter) are plotted by axial position for each azimuth of Holder 1 in Figure 62. Note that each azimuth listed is the orientation facing the camera, so diameters were measured between azimuths \pm 90 degrees from the listed azimuth. (For example, at the 0-degree azimuth, diameters were measured between the 90- and 270-degree sides.) Each data point in Figure 62 was derived from an average of five diameters measured over an axial region approximately 0.25 inch long, where individual measurements were spaced approximately 0.05 inch apart. As discussed in Appendix A, error bars were estimated by root-sum-squaring the standard deviations in the regional averages and one pixel width and then normalizing the result to the asfabricated diameter.

Negative values in Figure 62 reveal that Holder 1 shrank during irradiation along its entire length. The greatest shrinkage occurred at the bottom, near the lower end of AGR-1 test train. However, substantially more shrinkage was also measured near the top than along the middle. Error bars are slightly larger near the ends, which reflect larger standard deviations there from regional tapers. Holder 1 exhibits 
a small amount of ovality, especially near the middle where 240-degree diameters are lower than at the other two azimuths.

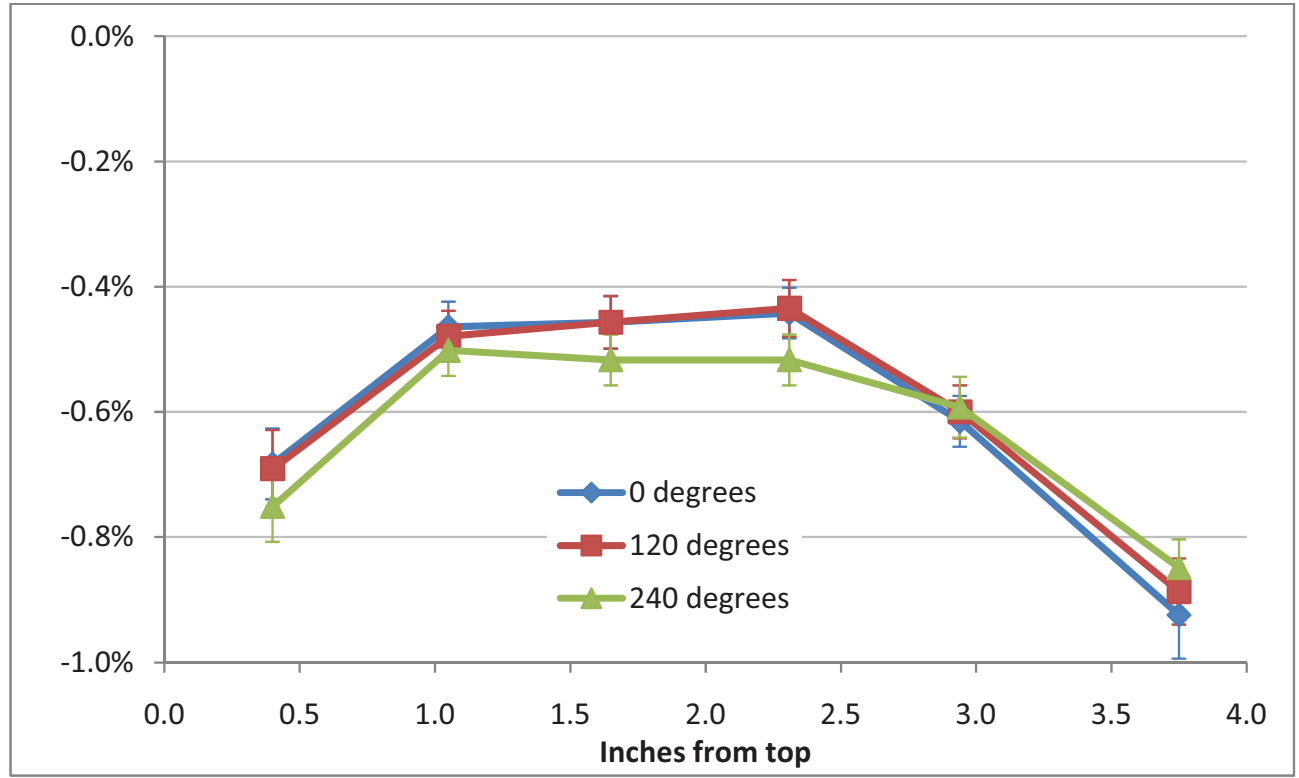

Figure 62. Relative changes in OD along the length of Holder 1.

As reported in Table A-8, Holder 1 also shrank axially during irradiation. The average length reduction was 0.0182 inch (-0.46\% relative to the 4.004 -inch as-fabricated length). Axial shrinkage amounts varied somewhat around the circumference, ranging from 0.0162 inch $(-0.40 \%)$ at the 150-degree azimuth to 0.0217 inch $(-0.54 \%)$ at 30 degrees.

Results from bore gauge measurements in Holder 1 holes (after removal of compacts) are displayed in Figure 63 . All values are relative to the 0.4903 -inch average hole diameter measured in Holder 1 before irradiation. Each data point represents a single measurement. Each error bar reflects a 0.0063 inch combined standard uncertainty for this bore gauge determined in ECAR-900 [Ploger 2010] in conjunction with a ring gauge standard. Although this size of error bar may not adequately represent local diameter variability in an actual holder, no better estimate is available without repeat measurements. Repeat measurements on AGR-1 holders were not performed in order to minimize the possibility of gouging interior surfaces with probe anvils. Similarly, the single as-fabricated diameter measurement within each hole prevents estimating preirradiation variability. Negative values in Figure 63 indicate that all three hole diameters shrank during irradiation. A trend is evident for slightly more shrinkage near the ends of Holder 1, which follows the pattern in OD shrinkage seen in Figure 62. 


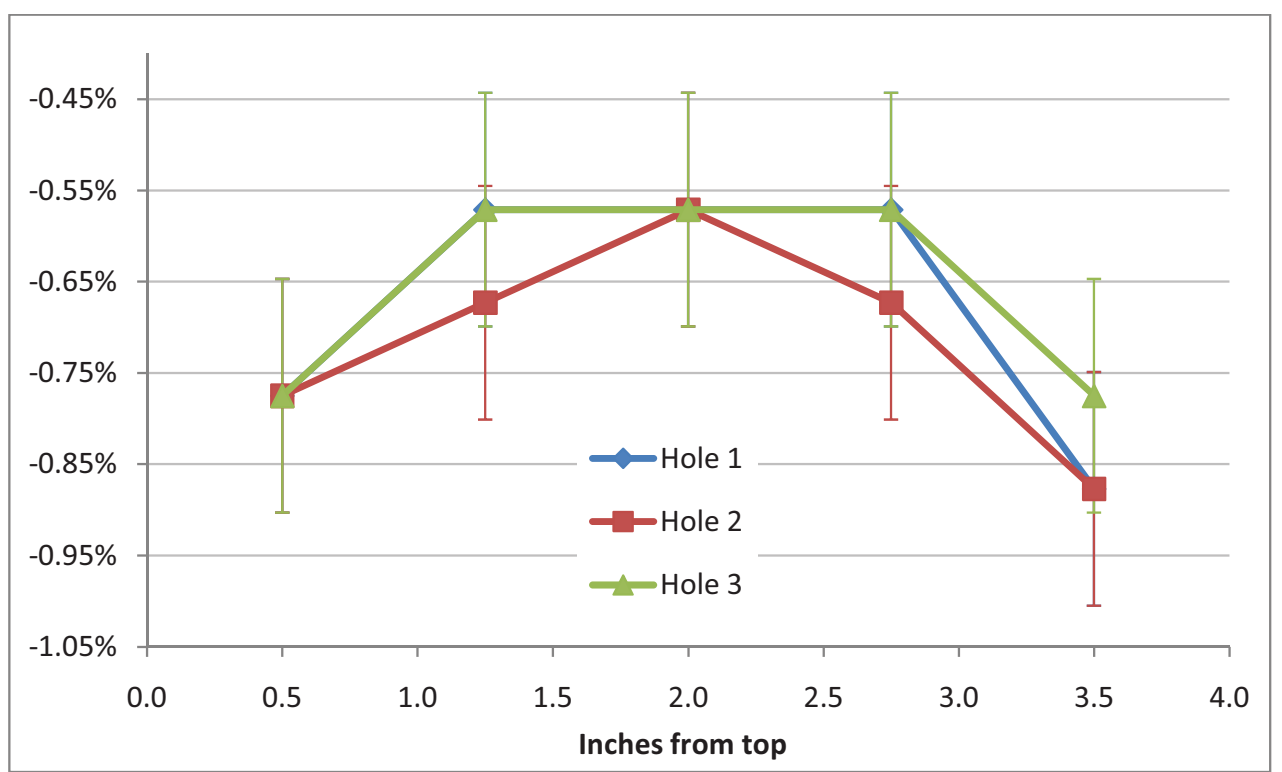

Figure 63. Change in inner diameters of Holder 1 holes.

\subsubsection{Capsule 2 Graphite Holder}

Figure 64 shows Holder 2 diameter change relative to the 1.234-inch as-fabricated diameter. Positive values indicate that Holder 2 grew radially during irradiation at all axial regions. Holder 2 tapers inward from the top to a neck near the 3-inch region followed by an outward flare near the bottom. Larger error bars near the ends reflect appreciable taper over these regions. Individual diameter measurements toward both ends indicate that Holder 2 was in contact with the inner liner of the Capsule 2 shell at the 0 - and 120-degree azimuths. A small amount of ovality is evident at the 1.0-, 2.3-, and 3.0-inch regions where differences between two azimuths are outside error bars.

As reported in Table A10, Holder 2 grew axially during irradiation. The average length increase was 0.0433 inch $(+1.08 \%$ relative to the 4.007 -inch as-fabricated length). Axial growth varied considerably around the circumference, ranging from 0.0406 inch $(+1.01 \%)$ at the 30-degree azimuth to 0.0472 inch $(+1.18 \%)$ at 210 degrees. Length measurements had to be made at peripheral positions, and more axial growth was observed away from through-tube positions than near them (see discussion in Section 4.3). The holder inspection section also described a concavity at the top end of Holder 2, so somewhat less axial growth occurred inside the periphery than indicated above. 


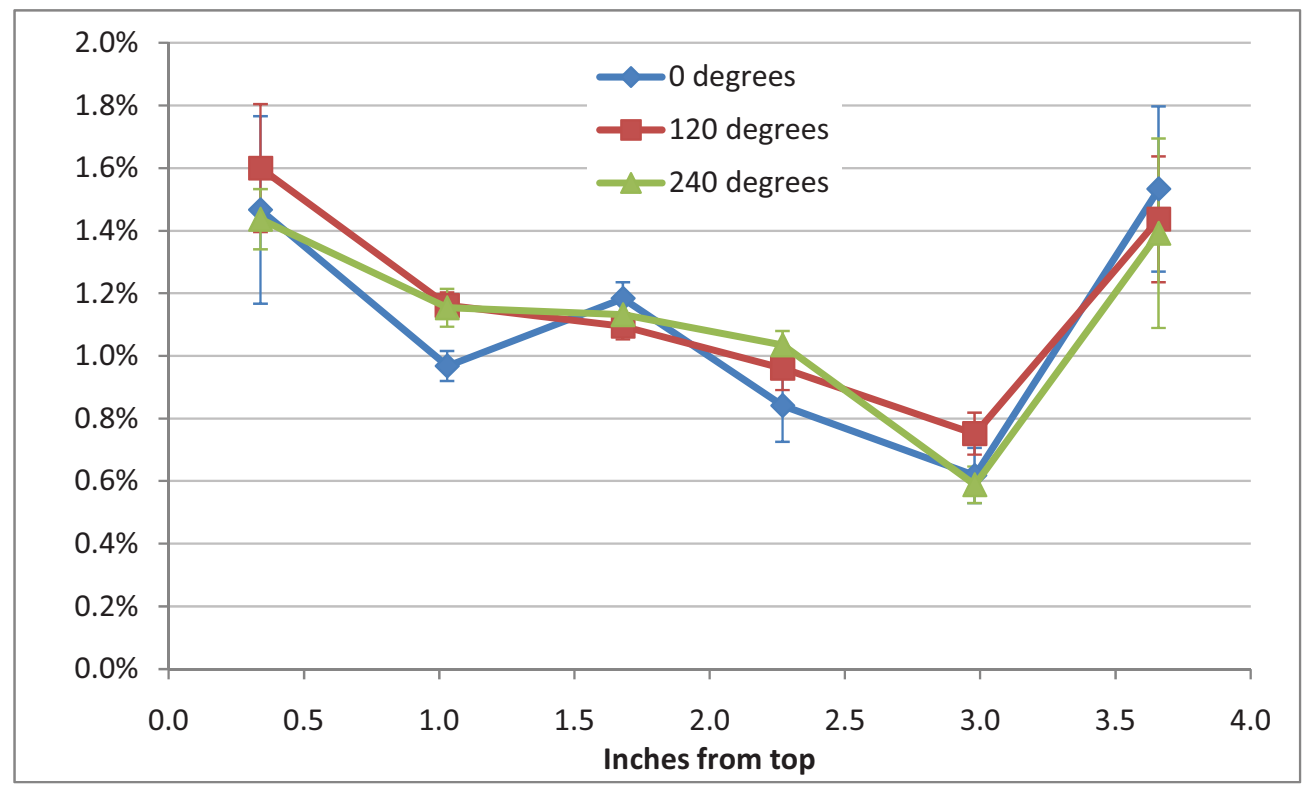

Figure 64. Change in Holder 2 ODs along its length.

Results from bore gauge measurements in Holder 2 holes are given in Figure 65. All values are relative to the 0.490 -inch diameter measured in all holes before irradiation. Positive and negative hole diameter changes in Figure 65 represent growth and shrinkage of holes during irradiation, respectively. Inner diameters of Holes 1 and 3 consistently increased along with Holder 2 ODs. Less diameter change occurred in Hole 2, which was oriented away from the ATR core center.

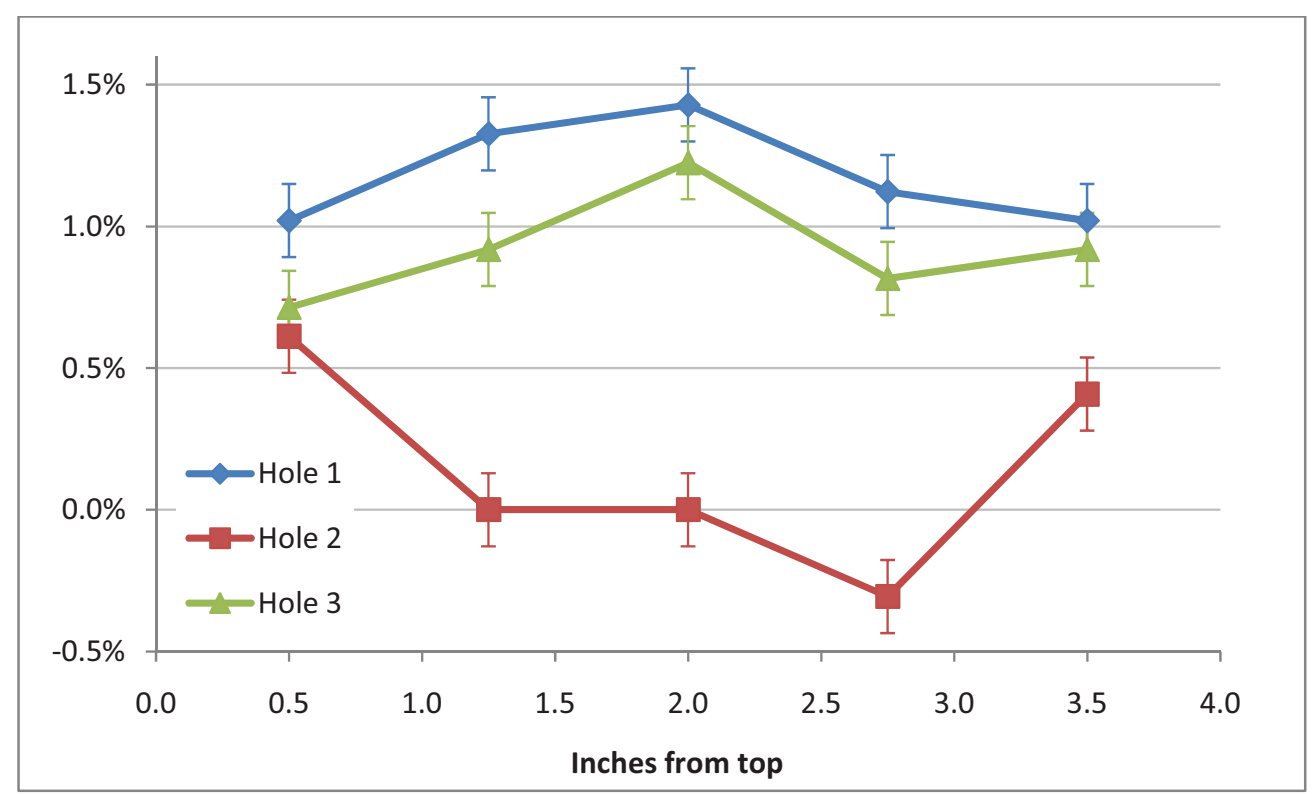

Figure 65. Change in inner diameters of Holder 2 holes. 


\subsubsection{Capsule 3 Graphite Holder}

Change in Holder 3 OD relative to the as-fabricated measurement (1.2375 inches) is shown in Figure 66. Positive values indicate radial growth, which was essentially uniform within error bars along the length of Holder 3. Individual diameter measurements indicate that the inner liner of the Capsule 3 shell was contacted locally at one or more azimuths at all axial positions excepting near 3 inches. Some ovality is evident among azimuths at most positions so Figure 66 suggests that the liner was not contacted around the entire circumference at any region (assuming that the liner retained a circular configuration).

As detailed in Table A12, substantial axial growth of Holder 3 occurred during irradiation. The average length increase was 0.0512 inch $(+1.28 \%$ relative to the 4.0043 -inch as-fabricated length). Axial growth varied considerably around the circumference, ranging from 0.0479 inch $(+1.20 \%)$ at 90 degrees to 0.0541 inch $(+1.35 \%)$ at 150 degrees. As discussed in the previous section, both ends of this holder exhibited concave surfaces, so less axial growth occurred radially inward on Holder 3 than is indicated by the axial growth values above.

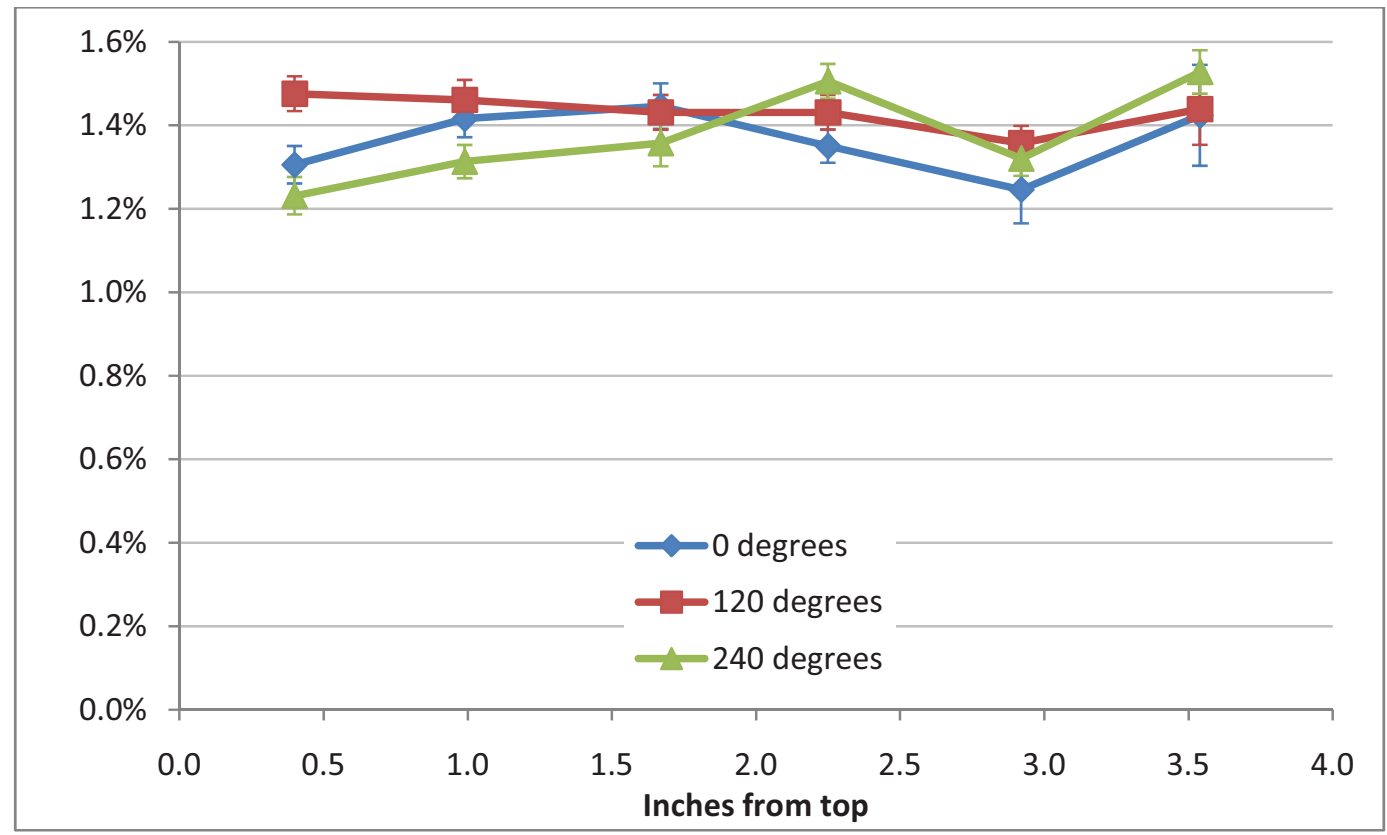

Figure 66. Change in ODs along Holder 3.

Results from bore gauge measurements in Holder 3 holes are given in Figure 67. All values are relative to the 0.490 -inch diameter measured in all holes before irradiation. Positive values in Figure 67 indicate that hole diameters enlarged during irradiation along with the OD of Holder 3. However, less growth was measured in Hole 2, which was oriented away from the ATR core center. 


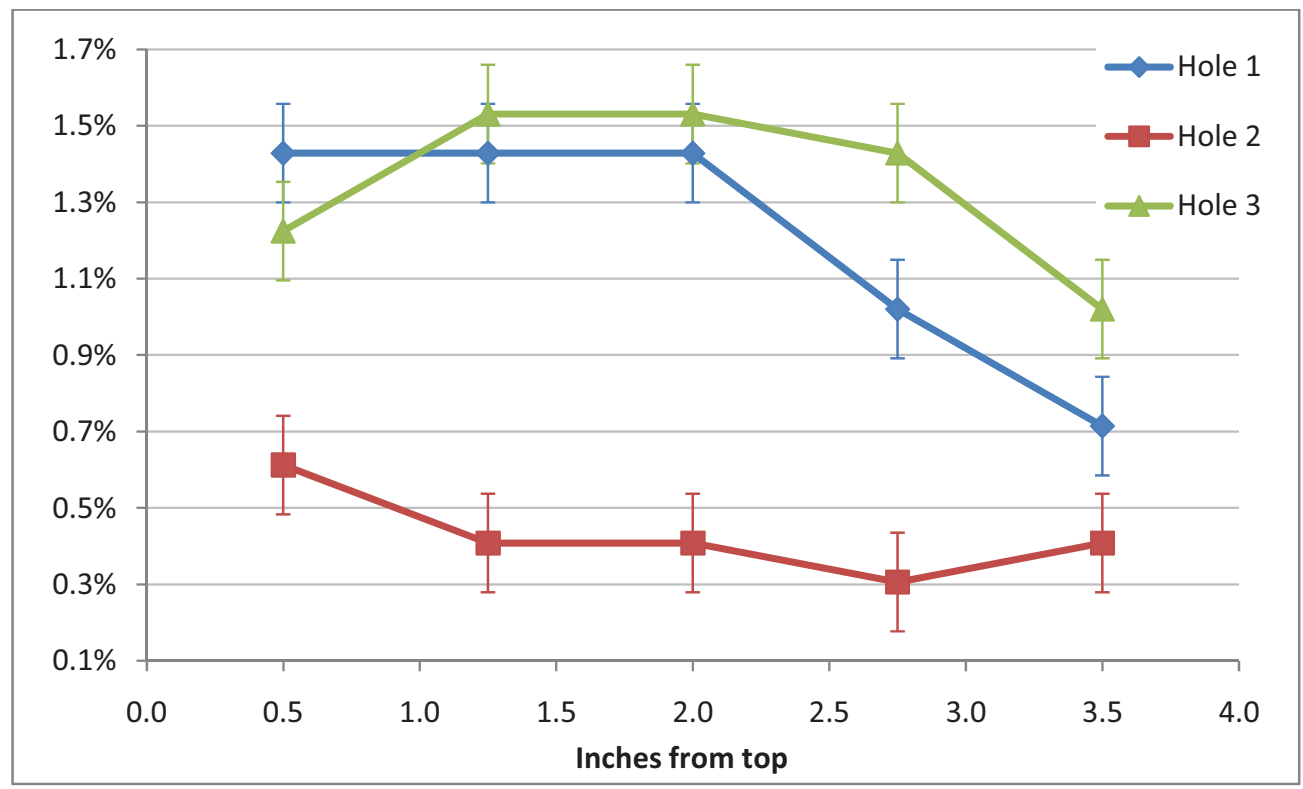

Figure 67. Hole diameter changes along the length of Holder 3.

\subsubsection{Capsule 5 Graphite Holder}

Change in Holder 5 diameter relative to the 1.228-inch as-fabricated diameter is presented in Figure 68. Positive values indicate that Holder 5 grew radially at all axial regions. The diameter of Holder 5 tapers inward from the top to a neck near 3 inches, then sharply increases near the bottom. This axial pattern is similar to that found for Holder 2, but the Holder 5 neck is twice as narrow. Larger error bars near the bottom end indicate considerable local taper there. Individual diameter measurements near the top suggest that Holder 5 contacted the inner liner of the Capsule 5 shell at all three azimuths.

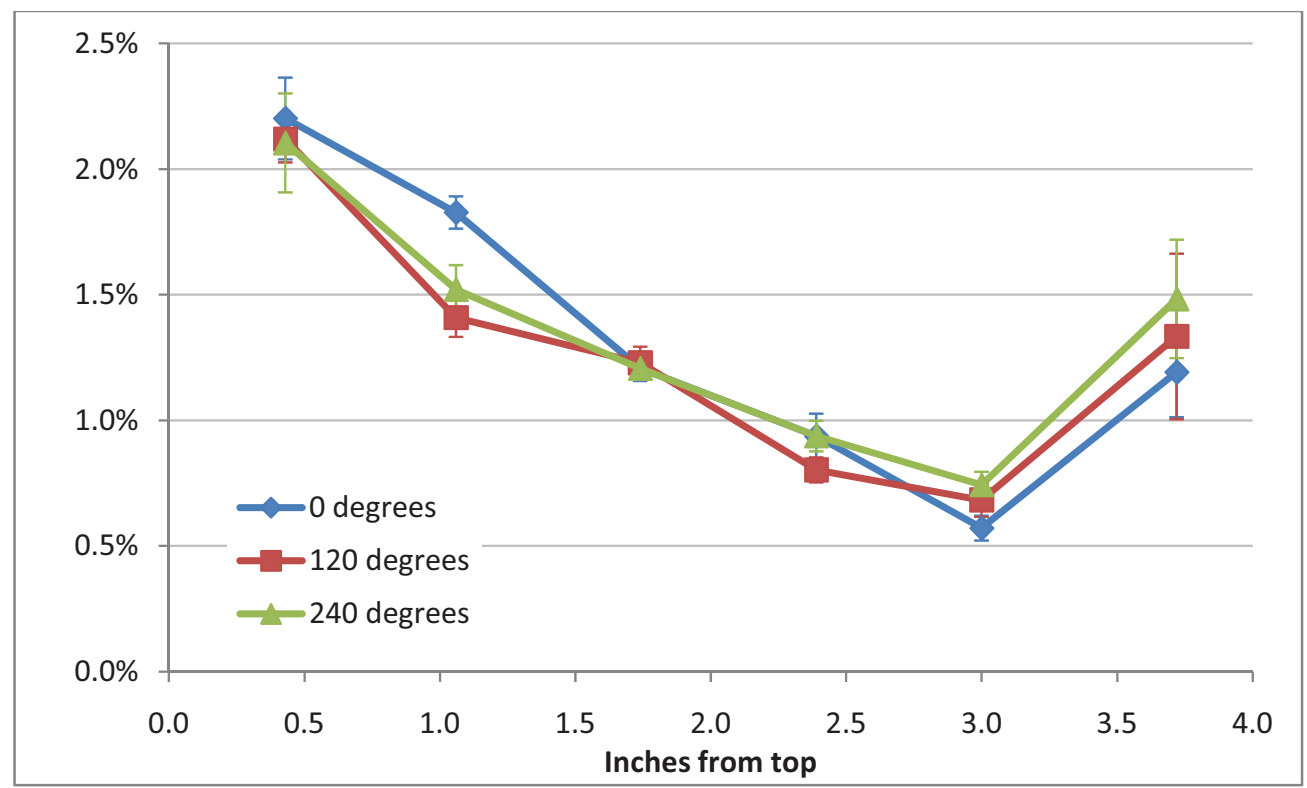

Figure 68. Changes in OD of Holder 5 along its length. 
Detailed length results from Holder 5 are presented in Table A14, where axial growth is shown comparable to Holders 2 and 3. The average length increase was 0.0504 inch $(+1.26 \%$ relative to the 4.002-inch as-fabricated length). Axial growth varied around the circumference by the largest amount among AGR-1 holders, from 0.0437 inch $(+1.09 \%)$ at 150 degrees to 0.0557 inch $(+1.39 \%)$ at 270 degrees. Length variability appears related to irregular axial growth around the periphery, depending on proximity to through-tube positions, as discussed in the holder inspection section. A concave surface was found at one end of Holder 5 during inspections, so portions near the radial center had less axial growth than indicated above.

Holder 5 bore gauge results are displayed in Figure 69. All values are relative to the 0.490 -inch diameter measured in all holes before irradiation. All hole diameters increased during irradiation along with the OD of Holder 5, but very little growth was measured away from the ends in Hole 2 (facing away from the ATR core center).

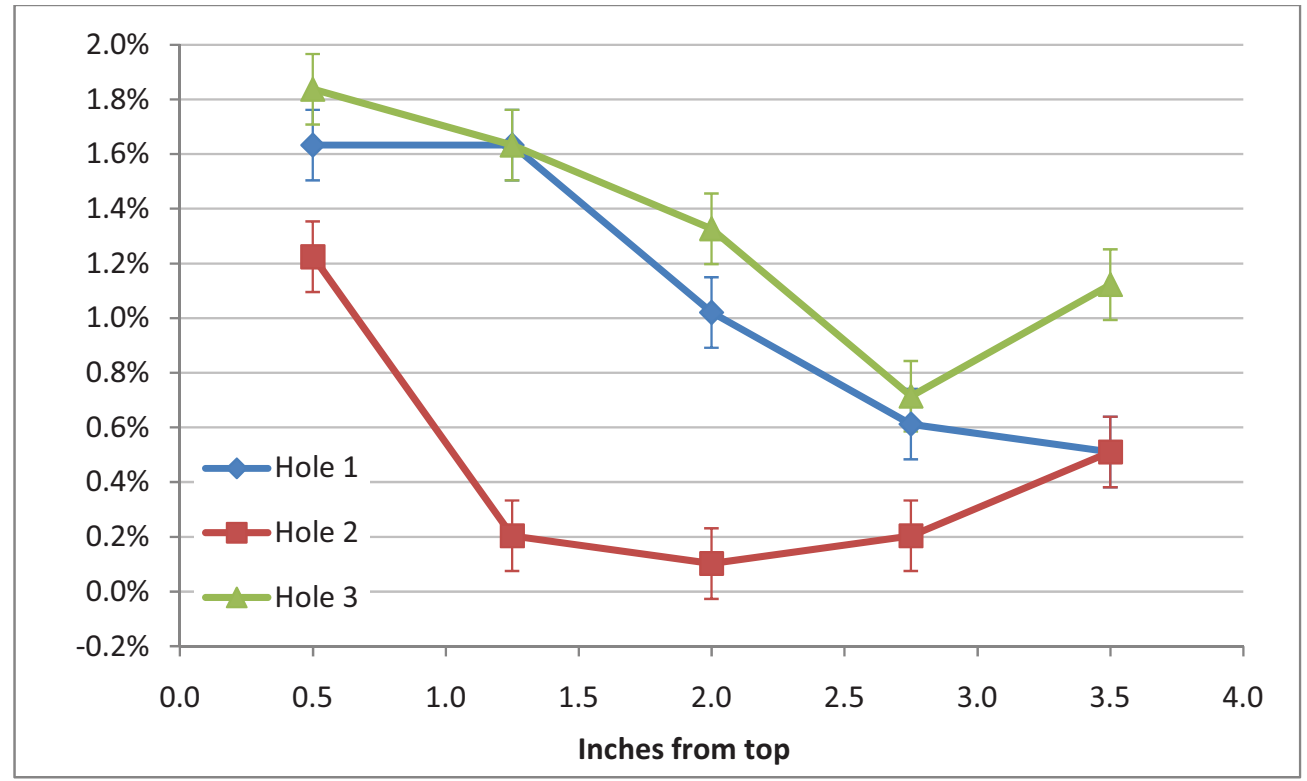

Figure 69. Hole diameter changes along the length of Holder 5.

\subsubsection{Capsule 6 Graphite Holder}

Change in Holder 6 OD relative to the 1.199-inch as-fabricated measurement is presented in Figure 70. Negative values indicate Holder 6 shrank radially during irradiation at all axial regions with additional shrinkage near the top. Metrology results from Holder 6 are thus similar to those from Holder 1. However, unlike Holder 1, there is little additional shrinkage at the opposite end. A 240-degree diameter could not be measured near the bottom because a small piece was broken off during disassembly.

As reported in Table A16, Holder 6 also shrank axially but by a smaller amount than Holder 1 . The average length reduction was 0.0085 inch $(-0.21 \%$ relative to the 4.0014 -inch as-fabricated length). Unlike Holder 1, virtually no difference was measured around the circumference of Holder 6. 


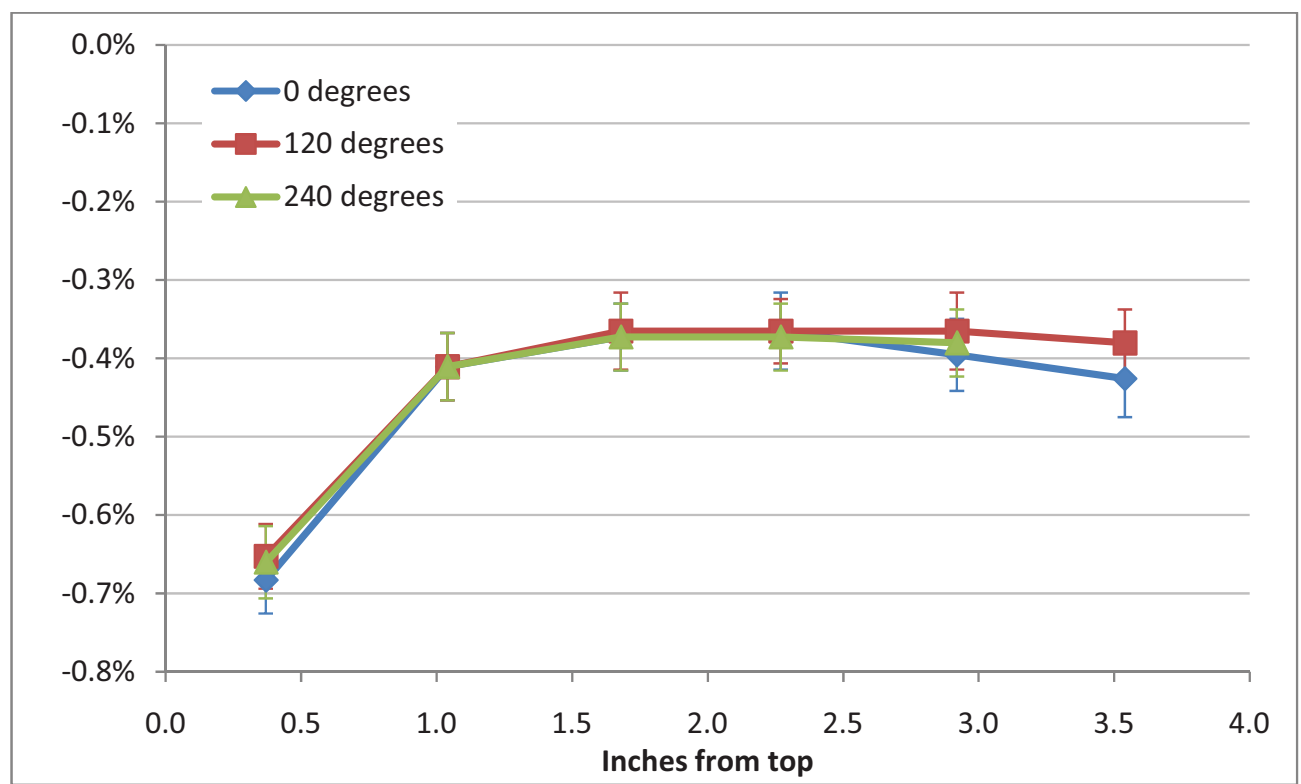

Figure 70. Changes in Holder 6 OD along its length.

Holder 6 bore gauge results are displayed in Figure 71 relative to the 0.4907 -inch average hole diameter measured before irradiation. Negative values indicate that all three hole diameters shrank. Slightly more hole shrinkage is evident near the top of Holder 6, following the same pattern as OD. Slightly less shrinkage is found in Hole 2, which was oriented away from the ATR core center.

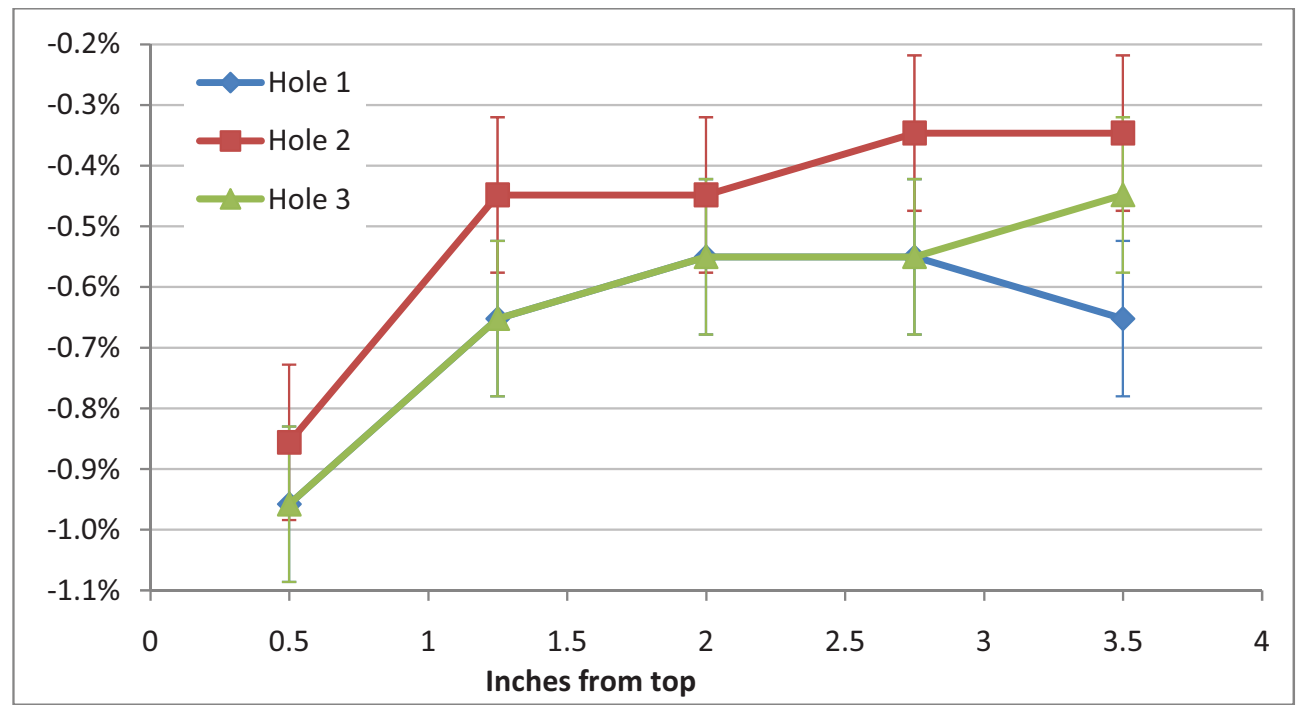

Figure 71. Hole diameter changes along the length of Holder 6.

\subsubsection{Graphite Holder Dimensions Summary and Discussion}

Relative changes in OD for Holders 6, 5, 3, 2, and 1 are respectively displayed left to right in Figure 72 according to their positions in the AGR-1 test train (2-inch gaps between holders included). No data are provided for Holder 4 because it had to be broken into pieces before images could be obtained. 
Graphite holders initially loaded with $5.5 \%$ boron carbide (Holders 1 and 6 ) shrank radially during irradiation while holders loaded with $7.0 \%$ boron carbide (Holders 2, 3, and 5) swelled radially. Figure 72 indicates that relative shrinkages in Holder 1 and Holder 6 ODs were nearly identical away from their ends. On a relative basis, radial swelling of Holder 3 and the ends of Holder 2 are very close. Figure 72 further highlights that the shapes of Holders 2 and 5 are not mirror images of each other; axially symmetrical configurations would have been expected if neutron fluence were the primary factor behind their profiles.

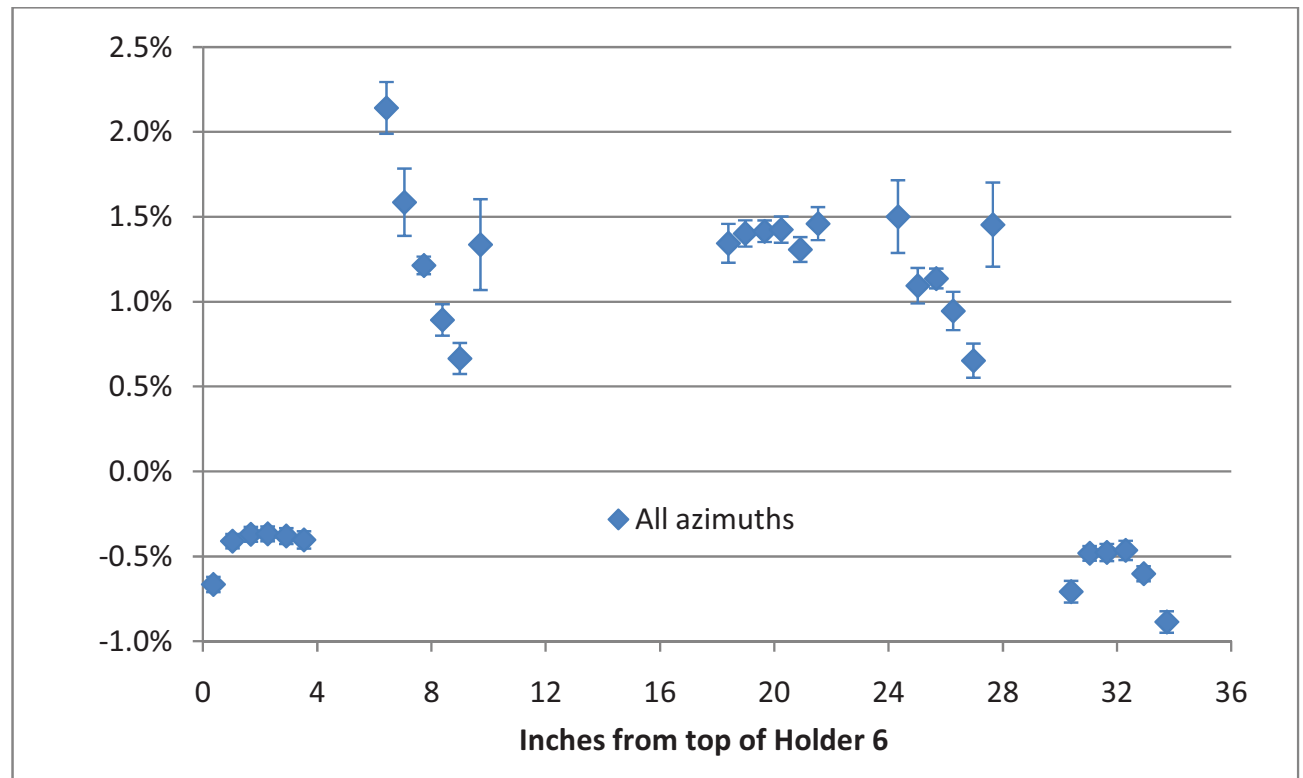

Figure 72. Relative change in ODs of AGR-1 graphite holders.

Outer diameter results from the five graphite holders are shown in Figure 73 according to their relative positions within the AGR-1 test train. Figure 73 reveals that the uppermost average diameter of Holder 2, most Holder 3 average diameters, and the end average diameters of Holder 5 are nearly equal to the inner diameter of the shell liners (approximately 1.256 inches), which is shown as the dashed red line. (Some individual diameter measurements in these averages were equal to the liner diameters.) More radial growth might have been possible at these regions of the $7.0 \%$ boron carbide holders without the shell liner constraint. Liner constraint on radial swelling may explain why relative changes for Holder 3 and the ends of Holder 2 are so close in Figure 72, since the as-fabricated diameters (1.2375 and 1.234 inches, respectively) were very similar. Meanwhile, the smaller 1.228-inch initial diameter of Holder 2 allowed it to expand more on a relative basis (shown in Figure 72) before contacting the shell liner. 


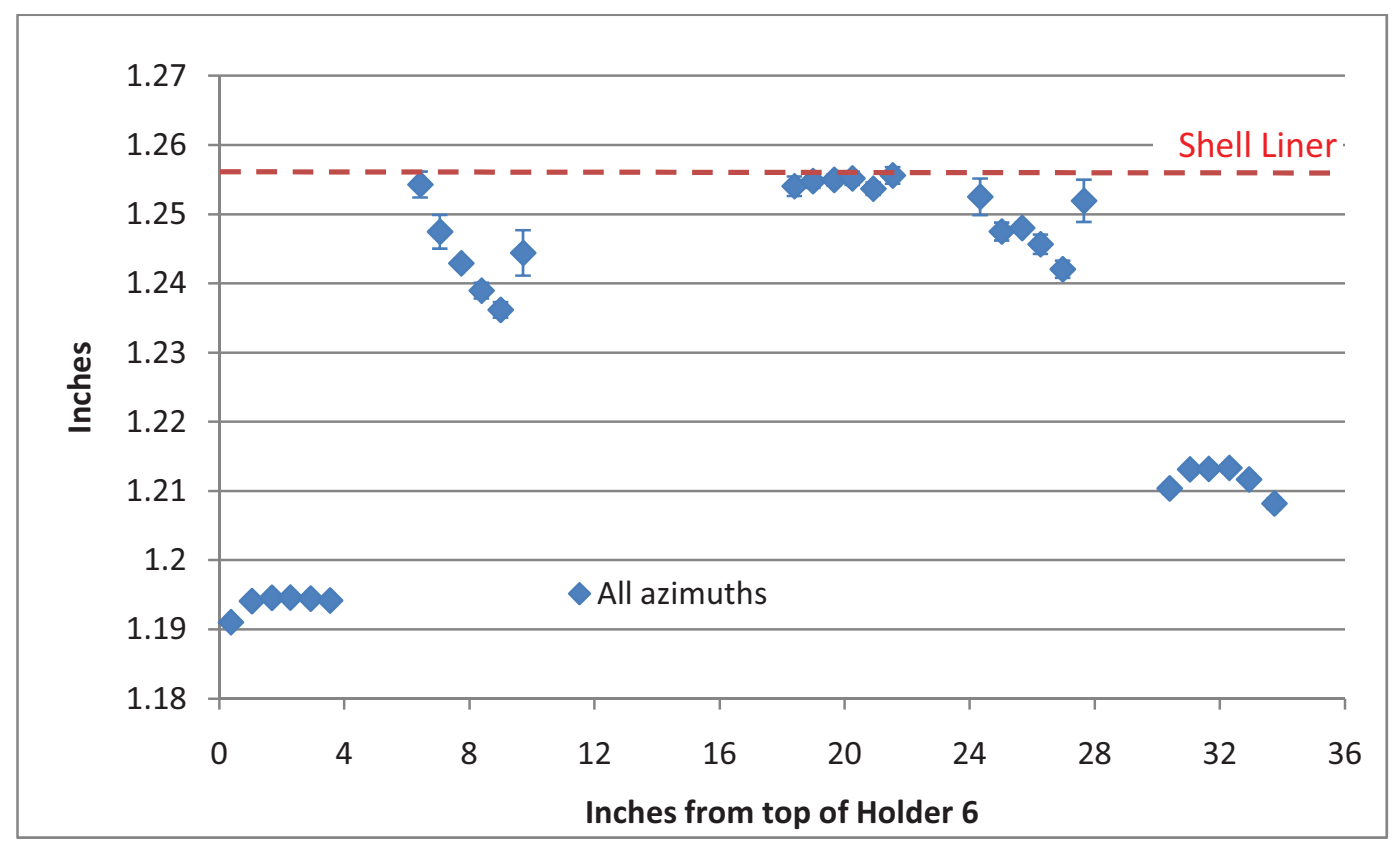

Figure 73. Outer diameter averages for the five AGR-1 graphite holders measured.

Both the thermal and fast neutron fluence are expected to play an important role in the graphite dimensional change behavior. The fast fluence for the AGR-1 test train in the ATR reactor follows a roughly parabolic profile that peaks at Capsules 3 and 4, near the axial core center [Pope 2010]. Previous work [Davidson 1966] has established that thermal neutron fluence is the primary factor contributing to radiation damage and dimensional change in boronated graphite due to the ${ }^{10} \mathrm{~B}(n, \alpha)^{7} \mathrm{Li}$ reaction and the very energetic helium and lithium ions produced. An analysis of the boron depletion calculations for the graphite holders indicates that the boron content was $>99 \%$ burned between cycles 8 and 11 for all of the holders. Since Capsules 1 and 6 had lower boron carbide content than the other capsules $(5.5 \%$ compared to $7.0 \%$ ), they would have received less radiation damage as a result of the boron capture reaction. In addition, since they were at the ends of the test train they also received a lower fast neutron fluence (Capsules 1 and 6 received on average 27\% less fast fluence than the other 4 capsules). The microstructure of the two types of graphite $\left(5.5 \%\right.$ and $\left.7.0 \% \mathrm{~B}_{4} \mathrm{C}\right)$ may also have played a role in the irradiation shrinkage/swelling behavior, but was not explored in detail as part of this experiment. Finally, temperature is expected to affect radiation shrinkage/swelling behavior, but since the measurements reported here will affect the calculated temperature values for the test train, and reanalysis of capsule temperatures with more realistic gas gaps is needed before looking at temperature effects in detail.

Ultimately it is not known how large a role these different parameters played in determining the final dimensional changes of the graphite holders. Further complicating analysis is the fact that almost the entire axial length of the Capsule 3 holder and portions of the Capsule 2 and 5 holders appear to have contacted their capsule shells which would have inhibited further diametrical expansion. Although Holder 5 experienced the largest local relative diametrical expansion ( $2.1 \%$ at the top of the holder), the data in Figure 72 and Figure 73 suggest that Holder 3, in the middle of the test train, experienced the greatest amount of irradiation-induced diametrical expansion as it essentially grew to contact the capsule shell at all axial locations, at which point further swelling would be inhibited. Holder 5, on the other hand, experienced less relative expansion in the middle, and was not constrained by the shell liner except possibly at the top location. This observation suggests that fast fluence did play a significant role in the behavior, since Holder 3 (along with Holder 4, for which no data are available) received the largest fast fluence. 


\subsection{Capsule Shell Investigations}

Inner diameters of capsule shells (actual measurement is made on the interiors of their stainless steel liners) were measured with a three-anvil, self-centering bore gauge similar to the bore gauge shown in Figure A4, but with a larger diameter head. The bore gauge was checked on a 1.2600-inch diameter ring gauge standard before and after each shell was measured. The probe was inserted into each shell according to fiducial marks on the bore gauge shaft. Depths were chosen in an attempt to match the $1 / 2$-inch, 2 -inch, and 31/2-inch axial positions of bore gauge measurements in graphite holders. However, multiple cuts were needed to separate several shells from their upper heads and the final cut location was not consistent from one capsule to the next, so it is difficult to accurately relate depths in shells to depths in holders. Also, the bottoms of Shells 3 and 4 were cut off during earlier disassembly activities, so bore gauge measurements were not possible there. Results of the bore gauge measurements of AGR-1 shells are presented in Table 4, wherein as-fabricated inner diameter values are averages of three measurements made by a hand-held 3-point inner micrometer. Each bore gauge entry represents a single measurement. Negative values indicate reduction from as-fabricated inner diameters.

Table 4. AGR-1 capsule shell bore gauge results ( 91 to $92^{\circ} \mathrm{F}$ ambient).

\begin{tabular}{|l|c|c|l|}
\hline \multirow{2}{*}{$\begin{array}{l}\text { Shell Number/As- } \\
\text { Fabricated Inner } \\
\text { Diameter (inches) }\end{array}$} & \multicolumn{3}{|c|}{$\begin{array}{c}\text { Inner Diameter Measurements } \\
\text { Absolute Change, inches (Relative Change, \%) }\end{array}$} \\
\cline { 2 - 4 } Shell 1/1.2564 & \multicolumn{3}{|c|}{ Bore Gauge Probe Depth from Upper Cut Surface (inches) } \\
\hline Shell $2 / 1.2561$ & $1.2500 /-0.0064(-0.51 \%)$ & $1.2450 /-0.0114(-0.91 \%)$ & $1.2500 /-0.0064(-0.51 \%)$ \\
\hline Shell 3/1.2565 & $1.2545 /-0.0016(-0.13 \%)$ & $1.2515 /-0.0046(-0.37 \%)$ & $1.2535 /-0.0026(-0.21 \%)$ \\
\hline Shell 4/1.2567 & $1.2560 /-0.0007(-0.06 \%)$ & $1.2565 /-0.0002(-0.02 \%)$ & Cut off \\
\hline Shell 5/1.2562 & $1.2545 /-0.0017(-0.14 \%)$ & $1.2520 /-0.0042(-0.33 \%)$ & $1.2565 /+0.0003(+0.02 \%)$ \\
\hline Shell 6/1.2563 & $1.2420 /-0.0143(-1.14 \%)$ & $1.2395 /-0.0168(-1.34 \%)$ & $1.2505 /-0.0058(-0.46 \%)$ \\
\hline
\end{tabular}

Table 4 reveals that inner diameters of Shell 3 and Shell 4 are close to as-fabricated dimensions, along with 0.9- and 3.9-inch depths for Shell 2 and Shell 5, which indicates that the shell liners did not buckle inward or otherwise deform during irradiation. The 2.4-inch depths inside Shells 2 and 5 show diameter reductions greater than the approximately 0.002 -inch uncertainty estimated for diameter changes (differences between pre- and post-irradiation measurements). Inner diameters inside Shell 1 and Shell 6 show even larger reductions, especially at 2.4 -inch depths. However, these results do not appear to indicate shrinkage of the AGR-1 capsule shells or buckling of the liner. Instead, photography through the hot cell window indicates that the apparent diameter reductions are primarily due to accumulated deposits of unknown material that vary in thickness, including within individual shells.

The interiors of Shell 3 and Shell 4 (after sectioning near mid-length with a tubing cutter) are shown in Figure 74. The deposits inside Shells 3 and 4 are thin and should perhaps be described as a film. Outlines of the through-tube grooves in the graphite holders can be discerned as parallel stripes. 


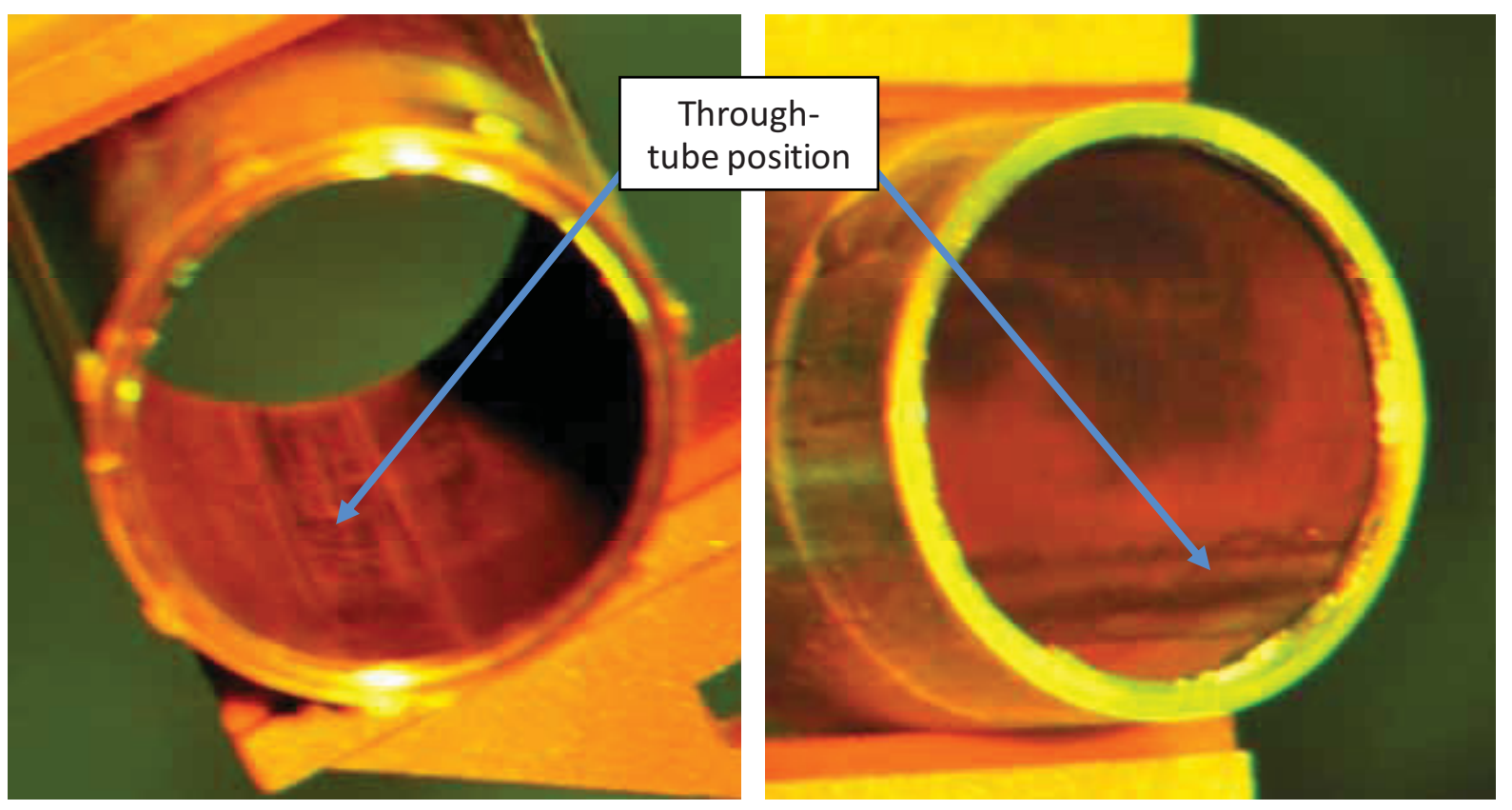

Figure 74. Interiors of bottom of Shell 3 (left) and middle of Shell 4 (right).

Interior views of Shells 2 and 5 are shown in Figure 75. Through-tube positions are less distinct than inside Shells 3 and 4, and deposits seem somewhat thicker in Figure 75 than in Figure 74 judging by layer depths adjacent to through-tube positions. Because both ends of Holder 2 and the top end of Holder 5 grew radially to locally contact the liner, the larger deposit pieces may have been scraped together during extraction of the holders. Deposits near the middle of Shells 2 and 5 typically appeared thicker than at their ends (in agreements with bore gauge measurements), perhaps because only small radial gaps were available for deposition near the ends.

Two views of relatively thick deposits inside Shell 1 are displayed in Figure 76. Some of the deposited material near the top evidently became dislodged from the liner interior during holder removal or bore gauge measurements. The deposit near the bottom of Shell 1 appears thicker and rougher below the elevation of the graphite holder.

Interior views of Shell 6 shown in Figure 77 are where bore gauge measurements in Table 4 indicated the largest diameter reductions. Thicker deposits here may be related to the relatively small as-fabricated diameter of Holder 6. Larger pieces near the top probably detached from the liner during removal of the graphite holder. Deposits still attached to the walls appear as plateau-like patches.

The nature of the deposits will be explored further when performing tests to determine the inventory of fission products on the capsule shells. The deposits will be removed and analyzed chemically to determine their composition.

One investigation was conducted to determine whether AGR-1 capsule shells might have deformed during irradiation. Images of the Capsule 5 shell exterior were captured before disassembly at four azimuths 45 degrees apart at upper and middle axial positions. Azimuths facing the camera were visually estimated to within \pm 10 degrees using binoculars. A new fixture was built for this purpose where Shell 5 was supported crosswise above the roller table used primarily for compact imaging. In this manner, shell sides could be backlit by the light pipe. Outer diameters were then extracted from the eight sets of images. Results are presented in Table 5, where each entry represents a single measurement. 


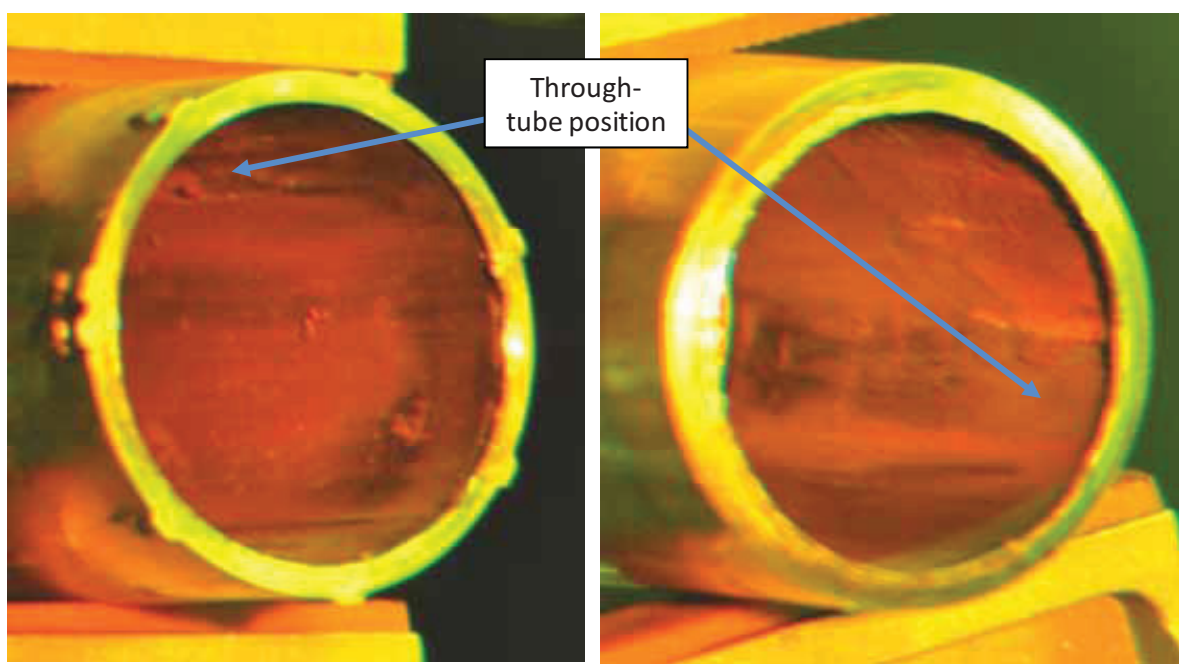

Figure 75. Interior deposits near bottom of Shell 2 (left) and middle of Shell 5 (right).
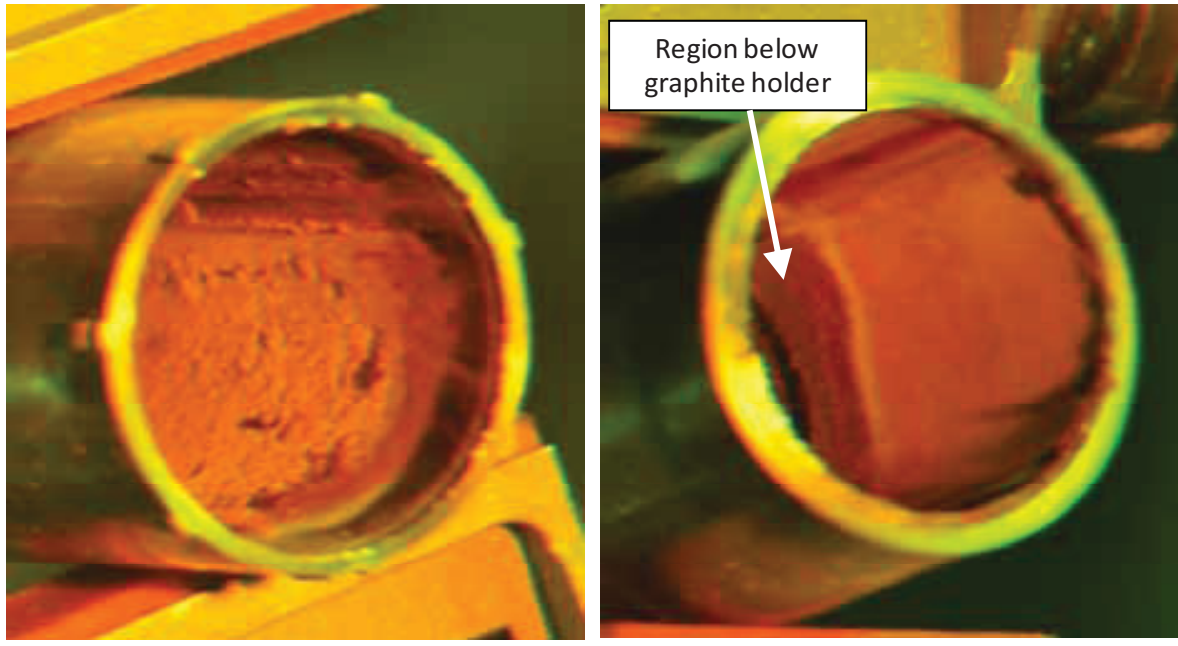

Figure 76. Internal deposits near the top (left) and toward the bottom (right) of Shell 1.
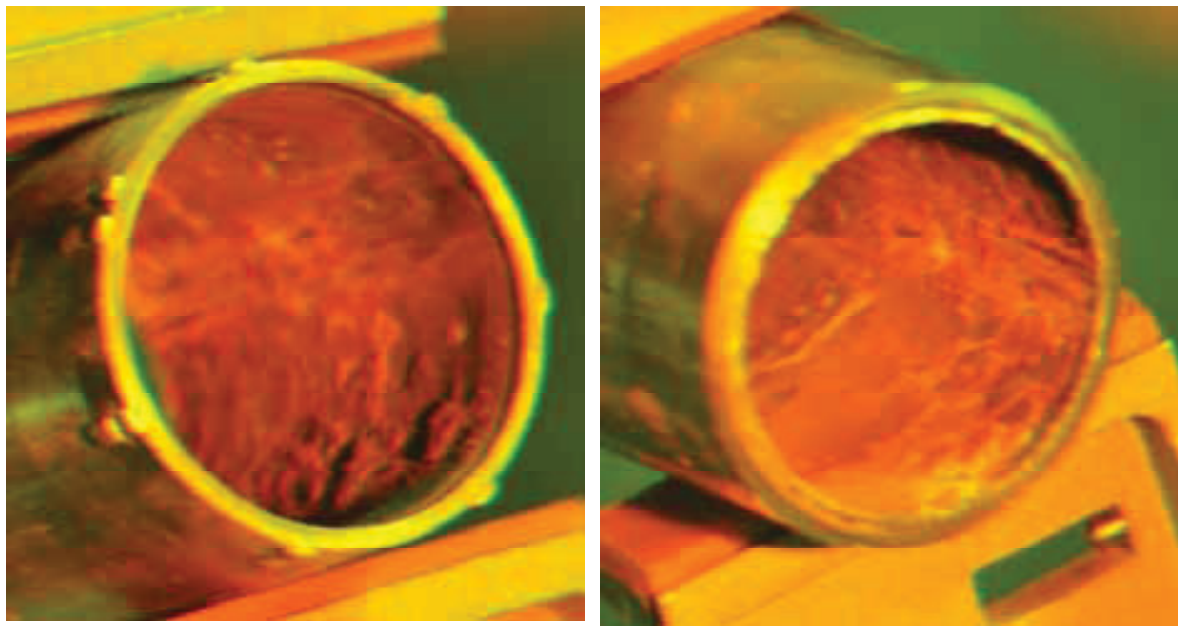

Figure 77. Deposited material near the top (left) and middle (right) of Shell 6. 
Table 5. Outer diameters of Capsule 5 shell, in inches $\left(86^{\circ} \mathrm{F}\right.$ ambient).

\begin{tabular}{|c|c|c|}
\hline Approximate Azimuth & $\begin{array}{c}\text { Top } \\
\text { (just inward of upper head) }\end{array}$ & $\begin{array}{c}\text { Middle } \\
\text { (midpoint of fueled region) }\end{array}$ \\
\hline 5 degrees & 1.40525 & 1.40525 \\
\hline 50 degrees & 1.40570 & 1.40525 \\
\hline 95 degrees & 1.40707 & 1.40616 \\
\hline 140 degrees & 1.40389 & 1.40525 \\
\hline
\end{tabular}

Image quality from the camera used for these measurements had deteriorated from radiation damage, and it was replaced shortly afterwards. It was not replaced before these measurements due to the heavy gamma dose anticipated from Co-60 activation product in the stainless steel. As a consequence, the uncertainty in the Table 5 measurements is estimated at $0.002 \mathrm{inch}$. The design range for as-fabricated shell diameters is between 1.404 and 1.406 inches. All Table 5 values are within the combined range of measurement uncertainty and fabrication tolerance. Thus, there is no obvious indication of any deformation of the Capsule 5 shell during irradiation.

These data confirm that the capsule shells experienced negligible dimensional change during irradiation, and that apparent reductions in inner diameters appear to result primarily from the presence of deposits, which will be analyzed at a later date.

\subsection{Metrology Summary}

The key findings from visual inspection and dimensional measurements of the fuel compacts, graphite holders, and capsule shells are summarized in this section. The lessons learned from these PIE activities will be used to modify and improve the design of future irradiation test trains.

\subsubsection{Fuel Compacts}

- All AGR-1 fuel compacts were extracted intact with no structural defects attributable to irradiation. One crack was induced during disassembly, along with minor scratches, abrasion marks, and end-cap notches on some of the compacts.

- Diameters and lengths of all AGR-1 fuel compacts decreased during irradiation by amounts that far exceeded measurement uncertainty.

- More net shrinkage was observed on average in compacts from Capsules 1 and 6, despite relatively low shrinkage in the outermost compacts in these capsules. Outermost compacts also exhibited a strong taper with less diameter shrinkage toward the top and bottom of the AGR-1 test train.

- Diameter changes measured among compacts from Capsules 2, 3, 4, and 5 are similar within measurement uncertainty, but smaller length changes were found on compacts from Capsules 3 and 4 than on compacts from Capsules 2 and 5.

- Fuel compact shrinkage increased with fast fluence $(\mathrm{E}>0.18 \mathrm{MeV})$ to approximately $3 \times 10^{21}$ neutrons $/ \mathrm{cm}^{2}$. Above this fluence value the trend reverses and shrinkage appears to decrease with increasing fluence, indicating that compact shrinkage is not a linear function of fast neutron fluence (see Figure 44 and Figure 45). 


\subsubsection{Graphite Holders}

- Graphite holders were in good condition after irradiation. All damage found on them after extraction from capsule shells was traceable to disassembly. The holder from Capsule 4 was completely destroyed during capsule disassembly.

- Diameters and lengths of graphite holders loaded with 5.5\% boron carbide (Capsules 1 and 6 at ends of AGR-1 test train) decreased during irradiation while diameters and lengths increased on the holders loaded with $7.0 \%$ boron carbide (interior capsules). These dimensional changes were far beyond measurement uncertainty.

- Diameter growth approached the shell liner along the entire Capsule 3 holder and near the ends of holders from Capsules 2 and 5. Local contact with the liner may have prevented further radial growth at these positions.

- Length measurements on holders from Capsules 2, 3, and 5 were influenced by exaggerated axial growth at their peripheries, which resulted in concave shapes at their ends.

- Changes in hole diameters within graphite holders almost always exhibited the same trend as changes in OD. Holes generally expanded in holders from Capsules 2, 3, and 5, while holes shrank in holders from Capsules 1 and 6. Axial profiles in hole diameters tended to follow axial profiles of ODs, particularly for Stack 1 and Stack 3 holes.

- Smaller change was generally measured in the diameter of Hole 2 (away from the ATR core center) than in Holes 1 and 3.

\subsubsection{Capsule Shells}

- $\quad$ Bore gauge measurements inside shells from Capsules 3 and 4 and near the ends of Capsule 2 and 5 shells are close to as-fabricated dimensions, suggesting that no detectable inward deformation (such as liner buckling) occurred on capsule shells during irradiation.

- Bore gauge measurements revealed significant inner diameter reductions on the middle of shells from Capsules 2 and 5 and considerably greater reductions throughout the interiors of shells from Capsules 1 and 6.

- Photo-visual examinations showed that substantial thicknesses of unknown material had accumulated on shell liners within Capsules 1, 2, 5, and 6. Although deposit layers were probably perturbed during removal of graphite holders, deposits appear much thicker in Capsule 1 and Capsule 6 shells. These larger deposit thicknesses are likely related to the larger gaps between graphite holders and shell liners in these capsules.

- Exterior measurements of the Capsule 5 shell found no significant evidence of radial growth, shrinkage, or ovality.

- These observations suggest that the inner diameter reductions measured in various capsule shells were in fact caused by the accumulated deposits, and not shrinkage of the steel shells themselves.

\subsubsection{Control Gaps}

The dimensional changes in fuel compacts and capsule components discussed in detail in this report affect the thermal control gas gaps within the capsules. A detailed analysis of the gaps is beyond the scope of this report, but the basic implications for dimensional change for the gaps are summarized below.

- All compact-holder gaps increased (all compacts shrank; some holder holes expanded while others shrank, but hole shrinkage was always less than compact shrinkage). 
- Graphite-shell gaps of Capsules 1 and 6 increased (the graphite holders shrank while the capsule shells remained at close to as-fabricated diameters). However, accumulated deposits inside the capsule shells appear to have filled part of the gap.

- Graphite-shell gaps of Capsules 2 through 5 decreased nonuniformly (all holders swelled diametrically, often nonuniformly along the holder length). In some cases the gap appears to have completely disappeared at room temperature. Deposits were also found within these capsule shells.

\section{DECONSOLIDATION AND LEACH-BURN-LEACH}

The post-irradiation examination of the AGR-1 fuel calls for deconsolidation of selected compacts to obtain individual fuel particles for subsequent analysis, and as an initial step in the leach-burn-leach analysis [Demkowicz 2010]. Particle analyses include visual inspection, gamma counting, and radiochemical analysis of kernels to support burnup determination and fission product inventory measurements.

The basic electrochemical process for decomposing the compact matrix uses a nitric acid electrolyte solution through which an electric current is passed. The glassware configuration used by INL supports the compact inside a $28 \mathrm{~mm}$ OD $(24 \mathrm{~mm}$ ID) fused silica deconsolidation tube on a plate with $3 \mathrm{~mm}$ perforations on a $4 \mathrm{~mm}$ pitch located approximately $25 \mathrm{~mm}$ from the bottom of the tube. The deconsolidation tube is contained in a 30 $\mathrm{mm}$ ID Soxhlet thimble that has a porous bottom that uses a \#2 (medium) silica frit. The electrolytic contacts are maintained by a $10 \mathrm{~mm}$ OD silica tube with an expanded $20 \mathrm{~mm}$ "elephant foot" lower end through which a 28 -gauge platinum-rhodium anode wire is threaded and formed into a spiral coil at the lower end where it makes contact with the $12.4 \mathrm{~mm}$ diameter compact. The entire assembly is lowered into a tall-form beaker filled with $150 \mathrm{ml}$ of $4 \mathrm{M}$ nitric acid, such that approximately $5 \mathrm{~mm}$ of the compact is immersed in the acid. The cathode is another platinumrhodium wire that is lowered into the solution between the thimble and the tallform beaker. The entire experimental setup is shown in Figure 78. The electrodes are connected to a power supply that can be controlled by current or voltage to maintain total wattage. The electrolyte solution is sampled to determine the concentration of actinides and fission products prior to initiating the leach and burn steps.

Subsequent acid leaching of the deconsolidated material (particles and

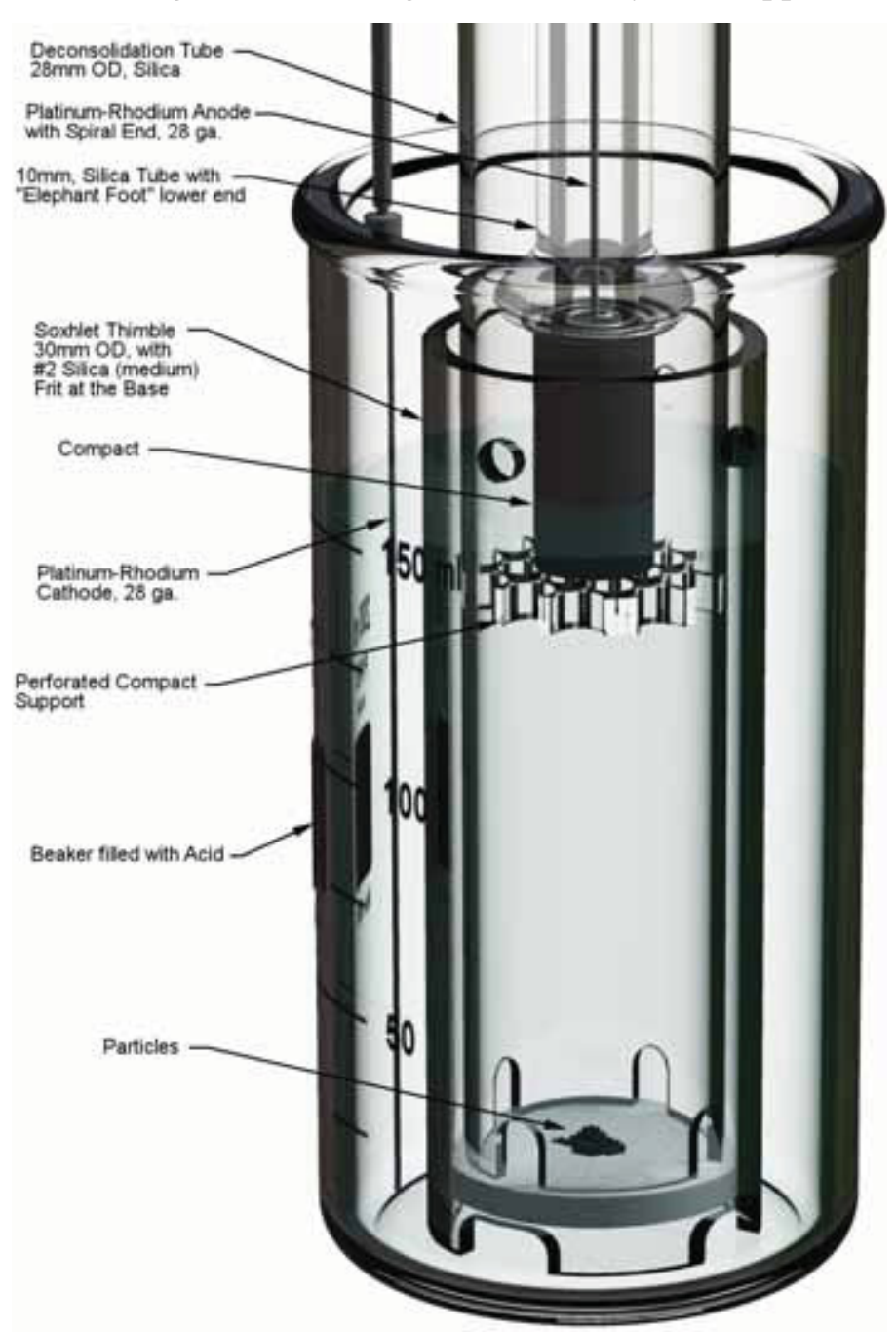

Figure 78. Drawing of compact deconsolidation hardware. 
matrix debris) is performed in $16 \mathrm{M}$ nitric acid using a Soxhlet extraction apparatus. Two 24-hour leaches are performed and both the leach solutions are assayed for actinides and fission products. The particles are then heated in air at $750^{\circ} \mathrm{C}$ for 72 hours to remove all exposed carbon. A second set of two 24-hour post-burn acid leaches (16M nitric acid) are then performed identical to preburn leaching. The deconsolidation and leaching hardware is located in the INL Analytical Laboratory hot cells.

Compact 6-3-2 was deconsolidated in approximately 70 minutes with an average power of $7.7 \mathrm{~W}$. Figure 79 shows a sample of deconsolidated material taken prior to the first preburn leach. The resulting particles were free of agglomerates and appeared to be uniformly separated, with no identified examples of matrix retention. A single particle from Compact 6-3-2 being examined on a vacuum needle is shown in Figure 80. No exposed kernels were noted in the deconsolidation based on the uranium concentration.

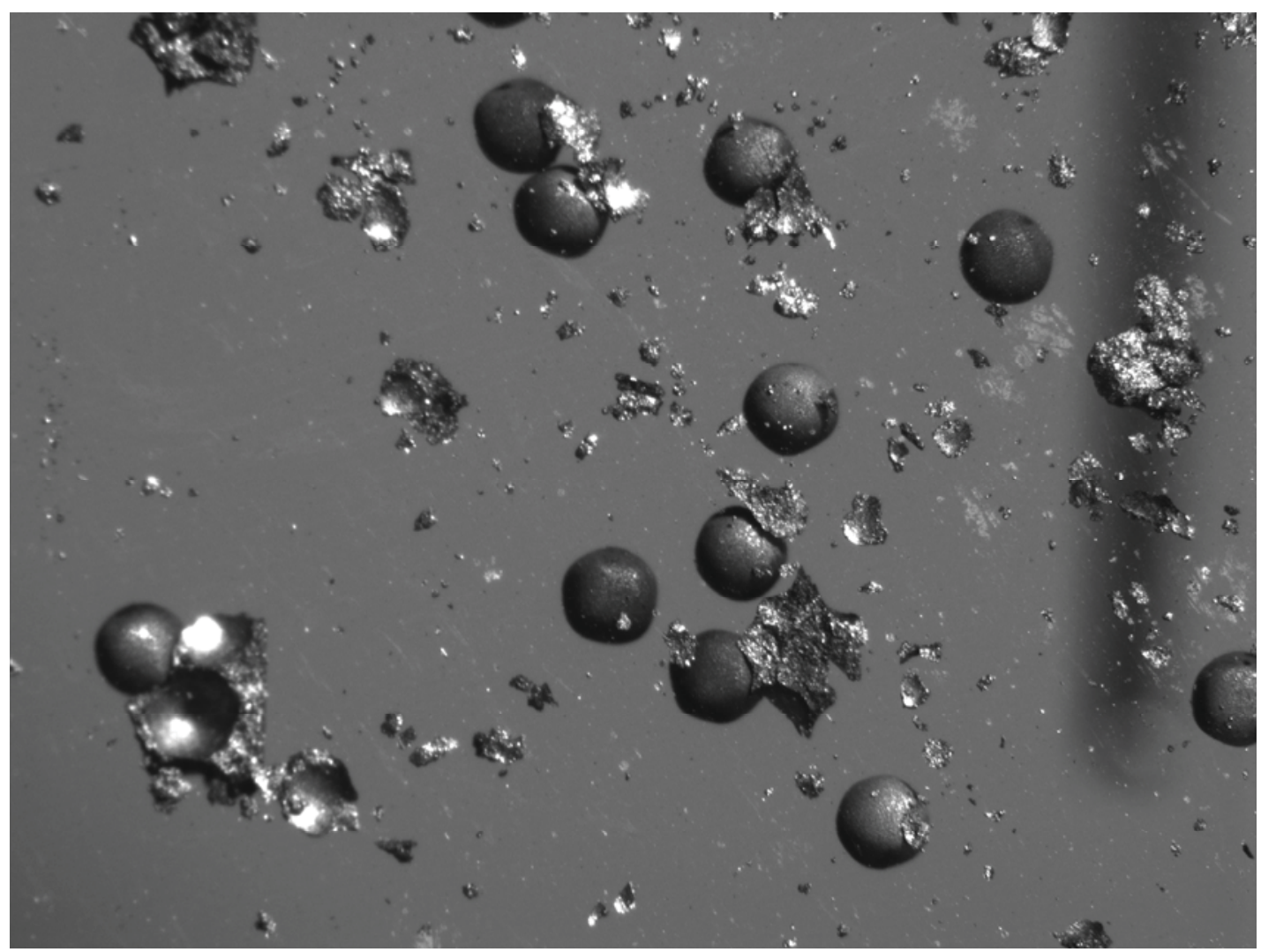

Figure 79. Deconsolidated particles with matrix debris (Compact 6-3-2). 


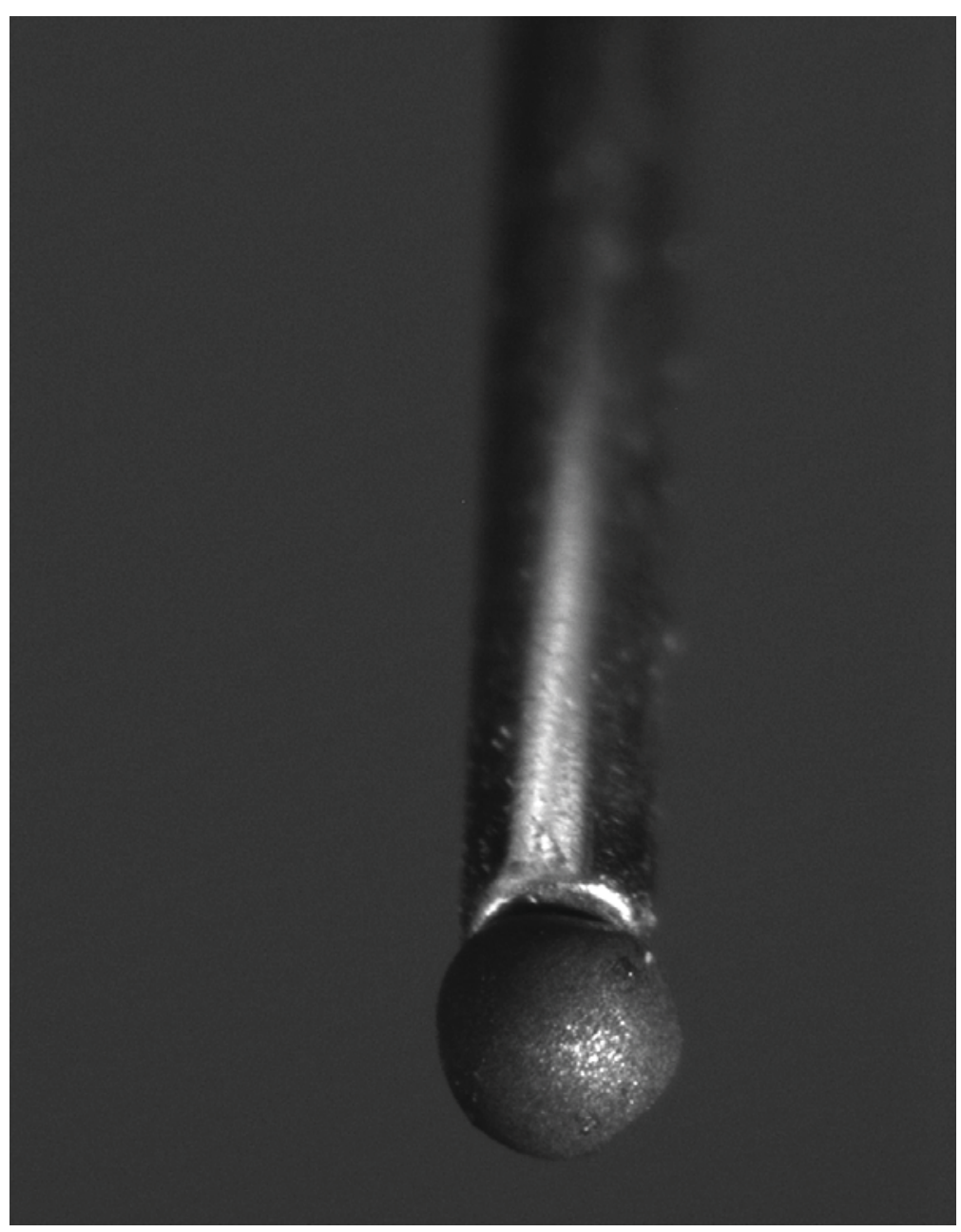

Figure 80. Single deconsolidated particle (Compact 6-3-2).

Following deconsolidation, the thimble was transferred to the Soxhlet extractor where it was leached through two 24-hour cycles, with samples taken after each leach. Time for the acid in the reflux well to overflow and siphon was approximately 2 minutes. Uranium concentrations in the leach solutions indicated no exposed kernels. Following the leach cycles, the thimble was transferred to the furnace and the burn-back was executed, maintaining the particles at $750^{\circ} \mathrm{C}$ for 72 hours. The burned-back particles were then subjected to another pair of 24-hour leach cycles in which analysis of the first step leach solution indicated approximately 220 micrograms of uranium, equivalent to the release from one particle and indicative of a failed $\mathrm{SiC}$ layer. The uranium inventory from each of the acid leach steps is given in Table 6. Analysis of fission product inventories in the solutions has not yet been completed. The particles were examined following burn-leach for apparent variations and visible defects in the exposed silicon carbide layer (Figure 81). No explicit cracks or broken coatings have been definitively identified. The particle with the defective $\mathrm{SiC}$ layer (based on post-burn leach results) was not found during visual inspection. 
Table 6. Total uranium in deconsolidation and leach-burn-leach solutions for Compact 6-3-2.

\begin{tabular}{|l|c|}
\hline \multicolumn{1}{|c|}{ Sample ID } & $\mathbf{U}_{\text {total }}(\boldsymbol{\mu g})$ \\
\hline Deconsolidation & 1.743 \\
\hline Pre-burn leach 1 & 0.327 \\
\hline Pre-burn leach 2 & 0.534 \\
\hline Pre-burn leach total & 0.861 \\
\hline Post-burn leach 1 & 221.0 \\
\hline Post-burn leach 2 & 0.136 \\
\hline Post-burn leach total & 221.1 \\
\hline Process total & 223.7 \\
\hline
\end{tabular}

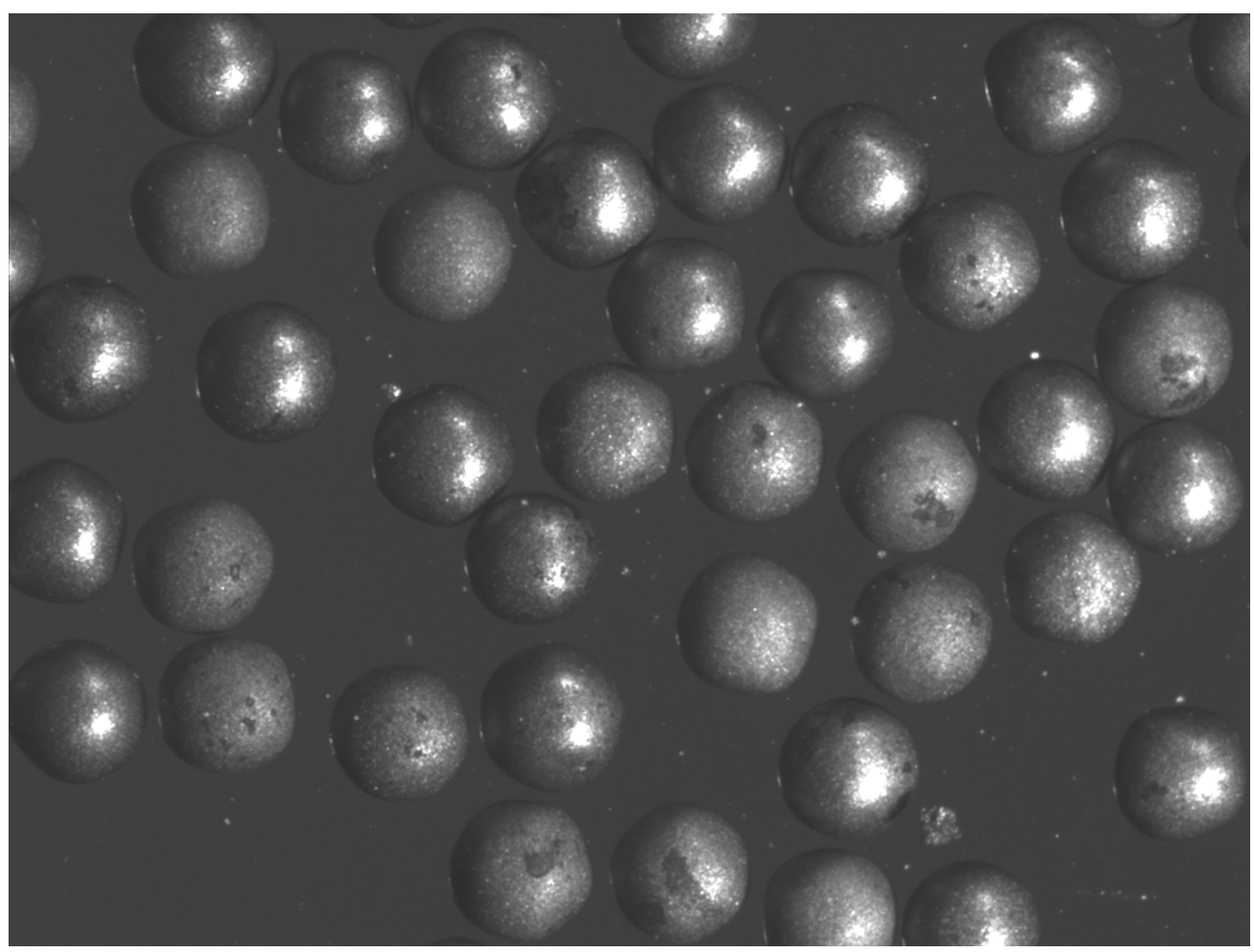

Figure 81. Post-burn-leach particles from Compact 6-3-2.

Particles from Compact 6-3-2 are currently being mounted and prepared for microscopic analysis. A small sample of particles (approximately 60) is being gamma counted to determine the inventory of various fission products of interest (e.g. Ag-110m, Cs-137) that will provide information on fission product retention during the irradiation. Results will be presented in subsequent reports. 


\section{CURRENT AND PLANNED PIE ACTIVITIES}

Additional PIE of the AGR-1 fuel compacts and capsule components is currently in progress to assess fuel performance characteristics. The details of planned PIE activities are presented in the AGR-1 PIE Plan [Demkowicz 2010]. Some of the major PIE activities include:

- Post-irradiated fission metals release analysis by measurement of fission metal inventories on metal capsule components and gamma scanning of graphite fuel holders.

- Deconsolidation of compacts to provide particles for subsequent analyses and leach-burn-leach analysis to quantify $\mathrm{SiC}$ failure fractions and evaluate fission product inventories in the compact matrices.

- Measurement of fuel compact burnup and selected fission product inventories.

- Microanalytical characterization of fuel compacts and particles using optical metallography, scanning electron microscopy, and electron probe microanalysis to investigate fuel microstructures, the condition of coatings, and fission product migration within the fuel.

- Safety testing of fuel compacts at temperatures up to $1800^{\circ} \mathrm{C}$ in pure helium to investigate release of selected fission products (including radioisotopes of silver, cesium, iodine, strontium, tellurium, and europium).

- Irradiated microsphere gamma analysis to measure fission product inventories and evaluate fission product retention for individual particles. The irradiated microsphere gamma analysis results will be correlated with microanalytical characterization of individual particles in order to determine if coating microstructure plays an important role in fission product retention.

Together, these experiments will provide the program with early data on uranium oxycarbide particle fuel performance and on the fundamental effects of irradiation and post-irradiation heating on fuel properties. The results will indicate if the program's current approach to fuel fabrication has been successful in producing high quality fuel that exhibits good irradiation and accident performance. 


\section{REFERENCES}

Demkowicz, P., 2010, “AGR-1 Post-Irradiation Examination Plan,” PLN-2828, Rev 1, March 2010.

Grover, S. B., 2010, "Completion of the First NGNP Advanced Gas Reactor Fuel Irradiation Experiment, AGR-1, in the Advanced Test Reactor," Paper \#104, Proceedings HTR-2010, Prague, Czech Republic, October 18-20, 2010.

Hunn, John D., Fred C. Montgomery, and Peter J. Pappano, 2006a, Data Compilation for AGR-1 Baseline Compact Lot LEU01-46T-Z, ORNL/TM-2006/507, August 2006.

Hunn, John D., Fred C. Montgomery, and Peter J. Pappano, 2006b, Data Compilation for AGR-1 Variant 1 Compact Lot LEU01-47T-Z, ORNL/TM-2006/508, August 2006.

Hunn, John D., Fred C. Montgomery, and Peter J. Pappano, 2006c, Data Compilation for AGR-1 Variant 2 Compact Lot LEU01-48T-Z, ORNL/TM-2006/509, August 2006.

Hunn, John D., Fred C. Montgomery, and Peter J. Pappano, 2006d, Data Compilation for AGR-1 Variant 3 Compact Lot LEU01-49T-Z, ORNL/TM-2006/510, August 2006.

Maki, J., 2009, AGR-1 Irradiation Experiment Test Plan, INL/EXT-05-00593 Rev. 3, October 2009.

Petti, D., R. Hobbins, and J. Kendall, Eds., 2010, Technical Program Plan for the Next Generation Nuclear Plant/Advanced Gas Reactor Fuel Development and Qualification Program, PLN-3636 Rev. 0, September 2010.

Ploger, Scott, 2010, “Qualification of AGR-1 Metrology System,” ECAR-900, Rev. 2, September 2010.

Pope, Michael A., 2010, AGR-1 Irradiation Test Final As-Run Report, INL/EXT-10-18097 Rev. 0, April 2010. 
Appendix A

\section{Detailed AGR-1 Metrology Results}




\section{Appendix A \\ Detailed AGR-1 Metrology Results}

Exterior diameter and length measurements were obtained during post-irradiation examination (PIE) of AGR-1 fuel compacts and their graphite holders with a custom noncontact approach. This method was based upon extracting dimensions from high-resolution camera images after carefully calibrating pixel size to images of a NIST-traceable chrome-on-glass calibration grid. Due to increasing pincushion distortion toward the telecentric lens periphery, different calibrations were developed for compact diameters, compact lengths, holder diameters, and holder lengths. Because of inadequate radiation shielding, the metrology camera had to be replaced twice over the course of the AGR-1 metrology campaign. New pixel calibration coefficients were developed on both occasions.

Inner diameters of holes in graphite holders were measured with a commercial bore gauge after fuel compacts were removed. A style with 3-point retractable probes was used to avoid gouging hole surfaces while moving along the holes. The dial indicator (0.0005-inch resolution) was read through the hot cell window via binoculars. A similar bore gauge with a larger diameter head was used to measure inner diameters of the stainless steel capsule shells. Performance of the metrology equipment was confirmed on standards before each capsule's components were measured, as well as after completion of the AGR-1 metrology campaign.

\section{A-1. AGR-1 FUEL COMPACT DIMENSIONS}

Compacts were imaged at three azimuths 120 degrees apart to allow the full external surface to be inspected. As shown by the vertical blue lines in Figure A-1, compact lengths were measured in four places along the compact center where ends were backlit by a light pipe. Thus, each length change entry in the following compact tables is an average of twelve measurements (four from each azimuth). A total of 15 diameter measurements (horizontal blue lines in Figure A-1) were spaced along the fuel-bearing length of each compact (using the red grid overlay) at each azimuth, and these were grouped into upper, middle, and lower regions where each region is approximately 0.25 -inch long. (Upper and lower regions excluded nonfueled end caps.) Consequently, each upper, middle, and lower diameter change entry in the compact tables is an average of 15 measurements (five from each azimuth). Compact diameter changes are not reported by azimuth because no ovality was detected on AGR-1 compacts during PIE. Dimensional resolution is limited by the width of a pixel in each image, which corresponds to approximately 0.00045 inch.

As-fabricated dimensions of AGR-1 fuel compacts had significant differences among variants and within variants. Consequently, analyses were conducted on relative changes in diameter and length during irradiation. As-fabricated measurements were subtracted from individual PIE measurements and each difference was then divided by the as-fabricated value. While Oak Ridge National Laboratory (ORNL) made only one length measurement on each compact, six diameter values were reported - two orthogonal measurements at top, middle, and bottom elevations. However, the ORNL vertical orientation was not necessarily maintained when AGR-1 compacts were loaded into their graphite holders, so averages of the six as-fabricated

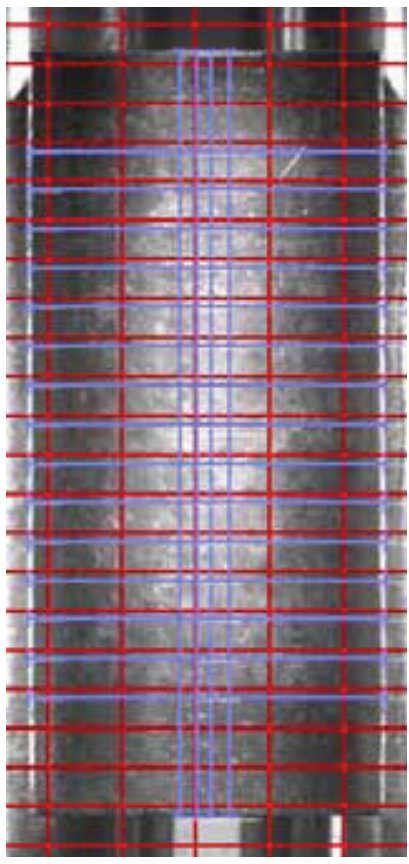

Figure A-1. Example of analyzed compact image (here Compact 5-3-3). 
diameters were used for each compact when calculating diameter changes of the irradiated compacts.

The compact dimension tables below were derived from spreadsheet reports generated by the PAX-it ${ }^{\mathrm{TM}}$ image processing software (Midwest Information Systems, Inc.) that was used to extract fuel compact dimensions. These PAX-it spreadsheets, which include high resolution versions of the unprocessed and analyzed images, are maintained as controlled records for each AGR-1 capsule on the ISASAPP Server - a designated document and records service center. These records are managed in accordance with Idaho National Laboratory (INL) PLN-2911, "NGNP Data Management and Analysis System Software Management Plan.”

Error bars in Section 4.2 of the main text have a "combined standard uncertainty" above and below data points as recommended by ANSI/NCSL Z540-2-1997, "U.S. Guide to the Expression of Uncertainty in Measurement." (No coverage factors have been applied to expand the combined uncertainty estimates into statistical confidence intervals.) Each estimate of combined uncertainty incorporates two contributing terms combined by root-sum-squaring. The first term is the standard deviation in the average dimensional change, which reflects both variability within individual compacts and, where applicable, variability among compacts in a particular group (stack, level, or entire capsule). The second term (typically smaller) is a method-related relative offset possible when extracting dimensions from images, which is computed as 0.00045 inch (one pixel width) normalized to either an as-fabricated compact diameter or length, as appropriate. One pixel width is believed to be a realistic upper bound on method-related bias for averaged AGR-1 compact dimensions because individual measurements on a standard can be high or low by up to one pixel width. Ideally, the individual offsets would cancel out in the average of a large number of measurements, although the offsets would still contribute to the standard deviation. However, small net offsets were still observed between image-based average dimensions and averaged reference measurements in the INL Engineering Calculations and Analysis Report ECAR-900, "Qualification of AGR-1 Metrology System," where measurement uncertainty was comprehensively analyzed on a carefully characterized steel standard fabricated to resemble an AGR-1 compact. Therein, net diameter offsets (relative to reference measurements) of $0.00003 \mathrm{inch}, 0.00022 \mathrm{inch}$, and $0.00037 \mathrm{inch}$ were determined from standard images taken at three azimuths, while a net offset of 0.00012 inch was found on length. For this analysis, no term was included to represent uncertainty in as-fabricated dimensions, primarily because the single length measurement on each fuel compact precluded estimating variability in as-fabricated length. 


\section{A-1.1 Capsule 1 Fuel Compacts}

Dimensional changes $(\Delta s)$ from Capsule 1 compact images are presented in Table A-1. Negative values indicate shrinkage from as-fabricated measurements made at room temperature, which are listed in the Compact column.

Table A-1. Metrology results from AGR-1 Capsule 1 fuel compacts $\left(92^{\circ} \mathrm{F}\right.$ ambient).

\begin{tabular}{|c|c|c|c|c|c|}
\hline Compact & Length $\Delta$ & $\begin{array}{c}\text { Upper } \\
\text { Diameter } \Delta\end{array}$ & $\begin{array}{c}\text { Middle } \\
\text { Diameter } \Delta\end{array}$ & $\begin{array}{c}\text { Lower } \\
\text { Diameter } \Delta\end{array}$ & $\begin{array}{c}\text { Average } \\
\text { Diameter } \Delta\end{array}$ \\
\hline $\begin{array}{l}\mathbf{1 - 1 - 1} \\
\text { len. } 0.99161 \mathrm{in.} \\
\text { dia. } 0.4858 \mathrm{in.}\end{array}$ & $\begin{array}{r}-0.0063 \text { in. } \\
(-0.64 \%) \\
\sigma=0.00035 \text { in. }\end{array}$ & $\begin{array}{r}-0.0054 \text { in. } \\
(-1.11 \%) \\
\sigma=0.00029 \text { in. }\end{array}$ & $\begin{array}{r}-0.0050 \mathrm{in} . \\
(-1.03 \%) \\
\sigma=0.00019 \mathrm{in} .\end{array}$ & $\begin{array}{r}-0.0046 \text { in. } \\
(-0.94 \%) \\
\sigma=0.00019 \mathrm{in} .\end{array}$ & $\begin{array}{r}-0.0050 \text { in. } \\
(-1.03 \%) \\
\sigma=0.00041 \mathrm{in} .\end{array}$ \\
\hline $\begin{array}{l}\mathbf{1 - 2 - 1} \\
\text { len. } 0.99417 \mathrm{in.} \\
\text { dia. } 0.4860 \mathrm{in.}\end{array}$ & $\begin{array}{r}-0.0075 \text { in. } \\
(-0.75 \%) \\
\sigma=0.00041 \text { in. }\end{array}$ & $\begin{array}{r}-0.0060 \text { in. } \\
(-1.23 \%) \\
\sigma=0.00024 \text { in. }\end{array}$ & $\begin{array}{r}-0.0059 \text { in. } \\
(-1.22 \%) \\
\sigma=0.00022 \text { in. }\end{array}$ & $\begin{array}{r}-0.0057 \mathrm{in} . \\
(-1.18 \%) \\
\sigma=0.00021 \mathrm{in} .\end{array}$ & $\begin{array}{r}-0.0059 \mathrm{in} . \\
(-1.21 \%) \\
\sigma=0.00024 \mathrm{in} .\end{array}$ \\
\hline $\begin{array}{l}\mathbf{1 - 3 - 1} \\
\text { len. } 0.99335 \mathrm{in.} \\
\text { dia. } 0.4858 \mathrm{in.}\end{array}$ & $\begin{array}{r}-0.0084 \text { in. } \\
(-0.85 \%) \\
\sigma=0.00024 \text { in. }\end{array}$ & $\begin{array}{r}-0.0062 \text { in. } \\
(-1.28 \%) \\
\sigma=0.00024 \text { in. }\end{array}$ & $\begin{array}{r}-0.0063 \text { in. } \\
(-1.30 \%) \\
\sigma=0.00021 \text { in. }\end{array}$ & $\begin{array}{r}-0.0063 \text { in. } \\
(-1.30 \%) \\
\sigma=0.00019 \mathrm{in} . \\
\end{array}$ & $\begin{array}{r}-0.0063 \text { in. } \\
(-1.29 \%) \\
\sigma=0.00022 \text { in. }\end{array}$ \\
\hline $\begin{array}{l}\text { 1-4-1 } \\
\text { len. } 0.99598 \mathrm{in.} \\
\text { dia. } 0.4858 \mathrm{in.}\end{array}$ & $\begin{array}{r}-0.0061 \text { in. } \\
(-0.62 \%) \\
\sigma=0.00075 \text { in. } \\
\end{array}$ & $\begin{array}{r}-0.0054 \text { in. } \\
(-1.12 \%) \\
\sigma=0.00016 \text { in. }\end{array}$ & $\begin{array}{r}-0.0057 \text { in. } \\
(-1.17 \%) \\
\sigma=0.00023 \text { in. }\end{array}$ & $\begin{array}{r}-0.0062 \text { in. } \\
(-1.27 \%) \\
\sigma=0.00024 \mathrm{in} .\end{array}$ & $\begin{array}{r}-0.0058 \text { in. } \\
(-1.19 \%) \\
\sigma=0.00037 \text { in. }\end{array}$ \\
\hline $\begin{array}{l}\mathbf{1 - 1 - 2} \\
\text { len. } 0.99354 \mathrm{in.} \\
\text { dia. } 0.4857 \mathrm{in.}\end{array}$ & $\begin{array}{r}-0.0072 \text { in. } \\
(-0.72 \%) \\
\sigma=0.00031 \mathrm{in} .\end{array}$ & $\begin{array}{r}-0.0053 \text { in. } \\
(-1.09 \%) \\
\sigma=0.00021 \text { in. }\end{array}$ & $\begin{array}{r}-0.0048 \text { in. } \\
(-0.99 \%) \\
\sigma=0.00023 \text { in. }\end{array}$ & $\begin{array}{r}-0.0044 \text { in. } \\
(-0.91 \%) \\
\sigma=0.00026 \text { in. }\end{array}$ & $\begin{array}{r}-0.0049 \text { in. } \\
(-1.00 \%) \\
\sigma=0.00043 \text { in. }\end{array}$ \\
\hline $\begin{array}{l}\mathbf{1 - 2 - 2} \\
\text { len. } 0.99378 \mathrm{in.} \\
\text { dia. } 0.4857 \mathrm{in.}\end{array}$ & $\begin{array}{r}-0.0080 \text { in. } \\
(-0.80 \%) \\
\sigma=0.00066 \text { in. }\end{array}$ & $\begin{array}{r}-0.0057 \text { in. } \\
(-1.18 \%) \\
\sigma=0.00029 \text { in. }\end{array}$ & $\begin{array}{r}-0.0056 \text { in. } \\
(-1.15 \%) \\
\sigma=0.00021 \text { in. }\end{array}$ & $\begin{array}{r}-0.0051 \mathrm{in} . \\
(-1.05 \%) \\
\sigma=0.00027 \mathrm{in} .\end{array}$ & $\begin{array}{r}-0.0055 \text { in. } \\
(-1.12 \%) \\
\sigma=0.00037 \text { in. }\end{array}$ \\
\hline $\begin{array}{l}\mathbf{1 - 3 - 2} \\
\text { len. } 0.99307 \text { in. } \\
\text { dia. } 0.4857 \mathrm{in.}\end{array}$ & $\begin{array}{r}-0.0 \\
(-1 \\
\sigma=0.00 \\
\end{array}$ & $\begin{array}{r}-0.0058 \text { in. } \\
(-1.20 \%) \\
\sigma=0.00016 \text { in. }\end{array}$ & $\begin{array}{r}-0.0 \\
(-1 \\
\sigma=0.00 \\
\end{array}$ & $\begin{array}{r}-0.00 \\
(-1 \\
\sigma=0.000 \\
\end{array}$ & $\begin{array}{r}-0.0 \\
(-1 \\
\sigma=0.00 \\
\end{array}$ \\
\hline $\begin{array}{l}\mathbf{1 - 4 - 2} \\
\text { len. } 0.99307 \mathrm{in.} \\
\text { dia. } 0.4857 \mathrm{in.}\end{array}$ & $\begin{array}{r}-0.0088 \text { in. } \\
(-0.89 \%) \\
\sigma=0.00039 \text { in. } \\
\end{array}$ & $\begin{array}{r}-0.0053 \text { in. } \\
(-1.09 \%) \\
\sigma=0.00022 \text { in. }\end{array}$ & $\begin{array}{r}-0.0054 \text { in. } \\
(-1.12 \%) \\
\sigma=0.00017 \mathrm{in} . \\
\end{array}$ & $\begin{array}{r}-0.0056 \text { in. } \\
(-1.15 \%) \\
\sigma=0.00022 \mathrm{in} . \\
\end{array}$ & $\begin{array}{r}-0.0054 \text { in. } \\
(-1.12 \%) \\
\sigma=0.00024 \text { in. }\end{array}$ \\
\hline $\begin{array}{l}\mathbf{1 - 1 - 3} \\
\text { len. } 0.99224 \text { in. } \\
\text { dia. } 0.4857 \mathrm{in.}\end{array}$ & $\begin{array}{r}-0.0056 \text { in. } \\
(-0.56 \%) \\
\sigma=0.00044 \text { in. }\end{array}$ & $\begin{array}{r}-0.0060 \text { in. } \\
(-1.24 \%) \\
\sigma=0.00032 \text { in. }\end{array}$ & $\begin{array}{r}-0.0055 \text { in. } \\
(-1.13 \%) \\
\sigma=0.00021 \text { in. }\end{array}$ & $\begin{array}{r}-0.0050 \text { in. } \\
(-1.03 \%) \\
\sigma=0.00012 \text { in. }\end{array}$ & $\begin{array}{r}-0.0055 \text { in. } \\
(-1.13 \%) \\
\sigma=0.00048 \text { in. }\end{array}$ \\
\hline \begin{tabular}{l}
\multicolumn{1}{c}{$\mathbf{1 - 2 - 3}$} \\
len. $0.99224 \mathrm{in.}$ \\
dia. $0.4857 \mathrm{in.}$
\end{tabular} & $\begin{array}{r}-0.0078 \text { in. } \\
(-0.78 \%) \\
\sigma=0.00024 \text { in. }\end{array}$ & $\begin{array}{r}-0.0066 \text { in. } \\
(-1.36 \%) \\
\sigma=0.00024 \text { in. }\end{array}$ & $\begin{array}{r}-0.0064 \text { in. } \\
(-1.32 \%) \\
\sigma=0.00012 \text { in. }\end{array}$ & $\begin{array}{r}-0.0061 \text { in. } \\
(-1.25 \%) \\
\sigma=0.00022 \text { in. }\end{array}$ & $\begin{array}{r}-0.0064 \text { in. } \\
(-1.31 \%) \\
\sigma=0.00030 \text { in. }\end{array}$ \\
\hline $\begin{array}{l}\mathbf{1 - 3 - 3} \\
\text { len. } 0.99343 \mathrm{in.} \\
\text { dia. } 0.4857 \mathrm{in.}\end{array}$ & $\begin{array}{r}-0.0088 \text { in. } \\
(-0.88 \%) \\
\sigma=0.00066 \text { in. }\end{array}$ & $\begin{array}{r}-0.0069 \text { in. } \\
(-1.42 \%) \\
\sigma=0.00019 \text { in. }\end{array}$ & $\begin{array}{r}-0.0068 \text { in. } \\
(-1.40 \%) \\
\sigma=0.00012 \text { in. }\end{array}$ & $\begin{array}{r}-0.0067 \mathrm{in} . \\
(-1.37 \%) \\
\sigma=0.00022 \mathrm{in} .\end{array}$ & $\begin{array}{r}-0.0068 \text { in. } \\
(-1.40 \%) \\
\sigma=0.00021 \text { in. }\end{array}$ \\
\hline $\begin{array}{l}\mathbf{1 - 4 - 3} \\
\text { len. } 0.99059 \mathrm{in.} \\
\text { dia. } 0.4857 \mathrm{in.}\end{array}$ & $\begin{array}{r}-0.0078 \text { in. } \\
(-0.79 \%) \\
\sigma=0.00027 \text { in. }\end{array}$ & $\begin{array}{r}-0.0058 \text { in. } \\
(-1.18 \%) \\
\sigma=0.00022 \text { in. }\end{array}$ & $\begin{array}{r}-0.0059 \text { in. } \\
(-1.21 \%) \\
\sigma=0.00030 \mathrm{in} .\end{array}$ & $\begin{array}{r}-0.0064 \text { in. } \\
(-1.32 \%) \\
\sigma=0.00016 \text { in. }\end{array}$ & $\begin{array}{r}-0.0060 \text { in. } \\
(-1.24 \%) \\
\sigma=0.00037 \text { in. }\end{array}$ \\
\hline
\end{tabular}




\section{A-1.2 Capsule 2 Fuel Compacts}

Length and diameter changes from images of the Capsule 2 fuel compacts are given in Table A-2. Negative values indicate shrinkage from as-fabricated room-temperature values (in Compact column).

Table A-2. Metrology results from AGR-1 Capsule 2 fuel compacts $\left(93^{\circ} \mathrm{F}\right.$ ambient).

\begin{tabular}{|c|c|c|c|c|c|}
\hline Compact & Length $\Delta$ & $\begin{array}{c}\text { Upper } \\
\text { Diameter } \Delta\end{array}$ & $\begin{array}{c}\text { Middle } \\
\text { Diameter } \Delta\end{array}$ & $\begin{array}{c}\text { Lower } \\
\text { Diameter } \Delta\end{array}$ & $\begin{array}{c}\text { Average } \\
\text { Diameter } \Delta\end{array}$ \\
\hline $\begin{array}{l}\text { 2-1-1 } \\
\text { len. } 0.98724 \text { in. } \\
\text { dia. } 0.4866 \text { in. }\end{array}$ & $\begin{array}{r}-0.0053 \text { in. } \\
(-0.53 \%) \\
\sigma=0.00050 \mathrm{in} .\end{array}$ & $\begin{array}{r}-0.0053 \mathrm{in} . \\
(-1.10 \%) \\
\sigma=0.00012 \mathrm{in} .\end{array}$ & $\begin{array}{r}-0.0050 \mathrm{in} . \\
(-1.03 \%) \\
\sigma=0.00019 \mathrm{in} .\end{array}$ & $\begin{array}{r}-0.0047 \text { in. } \\
(-0.97 \%) \\
\sigma=0.00024 \text { in. }\end{array}$ & $\begin{array}{r}-0.0050 \mathrm{in} . \\
(-1.03 \%) \\
\sigma=0.00032 \mathrm{in} .\end{array}$ \\
\hline $\begin{array}{l}\text { 2-2-1 } \\
\text { len. } 0.98736 \text { in. } \\
\text { dia. } 0.4866 \text { in. }\end{array}$ & $\begin{array}{r}-0.0060 \text { in. } \\
(-0.61 \%) \\
\sigma=0.00052 \text { in. }\end{array}$ & $\begin{array}{r}-0.0056 \text { in. } \\
(-1.14 \%) \\
\sigma=0.00023 \text { in. }\end{array}$ & $\begin{array}{r}-0.0056 \text { in. } \\
(-1.14 \%) \\
\sigma=0.00023 \text { in. }\end{array}$ & $\begin{array}{r}-0.0056 \text { in. } \\
(-1.15 \%) \\
\sigma=0.00024 \text { in. }\end{array}$ & $\begin{array}{r}-0.0056 \text { in. } \\
(-1.14 \%) \\
\sigma=0.00023 \text { in. }\end{array}$ \\
\hline $\begin{array}{l}\text { 2-3-1 } \\
\text { len. } 0.98717 \text { in. } \\
\text { dia. } 0.4866 \text { in. }\end{array}$ & $\begin{array}{r}-0.0066 \text { in. } \\
(-0.66 \%) \\
\sigma=0.00046 \text { in. }\end{array}$ & $\begin{array}{r}-0.0054 \mathrm{in} . \\
(-1.11 \%) \\
\sigma=0.00021 \mathrm{in} .\end{array}$ & $\begin{array}{r}-0.0055 \mathrm{in} . \\
(-1.13 \%) \\
\sigma=0.00021 \mathrm{in} .\end{array}$ & $\begin{array}{r}-0.0056 \text { in. } \\
(-1.15 \%) \\
\sigma=0.00024 \text { in. }\end{array}$ & $\begin{array}{r}-0.0055 \text { in. } \\
(-1.13 \%) \\
\sigma=0.00023 \text { in. }\end{array}$ \\
\hline $\begin{array}{l}\mathbf{2 - 4 - 1} \\
\text { len. } 0.98843 \mathrm{in.} \\
\text { dia. } 0.4866 \mathrm{in.}\end{array}$ & $\begin{array}{r}-0.0064 \text { in. } \\
(-0.65 \%) \\
\sigma=0.00050 \mathrm{in} .\end{array}$ & $\begin{array}{r}-0.0046 \text { in. } \\
(-0.95 \%) \\
\sigma=0.00023 \text { in. }\end{array}$ & $\begin{array}{r}-0.0051 \text { in. } \\
(-1.05 \%) \\
\sigma=0.00023 \text { in. } \\
\end{array}$ & $\begin{array}{r}-0.0056 \text { in. } \\
(-1.15 \%) \\
\sigma=0.00029 \text { in. } \\
\end{array}$ & $\begin{array}{r}-0.0051 \text { in. } \\
(-1.05 \%) \\
\sigma=0.00047 \text { in. }\end{array}$ \\
\hline \begin{tabular}{l}
\multicolumn{1}{c}{$\mathbf{2 - 1 - 2}$} \\
len. $0.98933 \mathrm{in.}$ \\
dia. $0.4865 \mathrm{in.}$
\end{tabular} & $\begin{array}{r}-0.0060 \mathrm{in} . \\
(-0.61 \%) \\
\sigma=0.00034 \mathrm{in} .\end{array}$ & $\begin{array}{r}-0.0051 \mathrm{in} . \\
(-1.04 \%) \\
\sigma=0.00024 \mathrm{in} .\end{array}$ & $\begin{array}{r}-0.0048 \text { in. } \\
(-0.99 \%) \\
\sigma=0.00021 \mathrm{in} .\end{array}$ & $\begin{array}{r}-0.0045 \text { in. } \\
(-0.93 \%) \\
\sigma=0.00022 \text { in. }\end{array}$ & $\begin{array}{r}-0.0048 \text { in. } \\
(-0.99 \%) \\
\sigma=0.00031 \text { in. }\end{array}$ \\
\hline $\begin{array}{l}\text { 2-2-2 } \\
\text { len. } 0.98803 \text { in. } \\
\text { dia. } 0.4865 \mathrm{in.}\end{array}$ & $\begin{array}{r}-0.0 \\
(-0 \\
\sigma=0.00\end{array}$ & $\begin{array}{r}-0.0052 \text { in. } \\
(-1.08 \%) \\
\sigma=0.00016 \text { in. }\end{array}$ & $\begin{array}{r}-0.0053 \mathrm{in} . \\
(-1.09 \%) \\
\sigma=0.00017 \mathrm{in} .\end{array}$ & $\begin{array}{r}-0.0051 \text { in. } \\
(-1.05 \%) \\
\sigma=0.00024 \text { in. }\end{array}$ & $\begin{array}{r}-0.0052 \text { in. } \\
(-1.07 \%) \\
\sigma=0.00021 \mathrm{in} .\end{array}$ \\
\hline $\begin{array}{l}\text { 2-3-2 } \\
\text { len. } 0.98768 \text { in. } \\
\text { dia. } 0.4865 \mathrm{in.}\end{array}$ & $\begin{array}{r}-0.0061 \text { in. } \\
(-0.62 \%) \\
\sigma=0.00043 \text { in. }\end{array}$ & $\begin{array}{r}-0.0052 \mathrm{in} . \\
(-1.08 \%) \\
\sigma=0.00016 \mathrm{in} .\end{array}$ & $\begin{array}{r}-0.0053 \text { in. } \\
(-1.10 \%) \\
\sigma=0.00021 \mathrm{in} .\end{array}$ & $\begin{array}{r}-0.0055 \text { in. } \\
(-1.13 \%) \\
\sigma=0.00024 \text { in. }\end{array}$ & $\begin{array}{r}-0.0054 \text { in. } \\
(-1.10 \%) \\
\sigma=0.00023 \text { in. }\end{array}$ \\
\hline $\begin{array}{l}\text { 2-4-2 } \\
\text { len. } 0.98634 \mathrm{in.} \\
\text { dia. } 0.4865 \mathrm{in.}\end{array}$ & $\begin{array}{r}-0.0060 \mathrm{in} . \\
(-0.60 \%) \\
\sigma=0.00057 \mathrm{in} .\end{array}$ & $\begin{array}{r}-0.0048 \mathrm{in} . \\
(-0.99 \%) \\
\sigma=0.00012 \mathrm{in} .\end{array}$ & $\begin{array}{r}-0.0050 \text { in. } \\
(-1.03 \%) \\
\sigma=0.00022 \text { in. }\end{array}$ & $\begin{array}{r}-0.0052 \text { in. } \\
(-1.08 \%) \\
\sigma=0.00024 \text { in. }\end{array}$ & $\begin{array}{r}-0.0050 \text { in. } \\
(-1.03 \%) \\
\sigma=0.00026 \text { in. }\end{array}$ \\
\hline $\begin{array}{l}\mathbf{2 - 1 - 3} \\
\text { len. } 0.98677 \text { in. } \\
\text { dia. } 0.4865 \mathrm{in.}\end{array}$ & $\begin{array}{r}-0.0054 \text { in. } \\
(-0.55 \%) \\
\sigma=0.00039 \text { in. }\end{array}$ & $\begin{array}{r}-0.0052 \mathrm{in} . \\
(-1.06 \%) \\
\sigma=0.00022 \mathrm{in} .\end{array}$ & $\begin{array}{r}-0.0048 \mathrm{in} . \\
(-0.99 \%) \\
\sigma=0.00017 \mathrm{in} .\end{array}$ & $\begin{array}{r}-0.0046 \text { in. } \\
(-0.95 \%) \\
\sigma=0.00024 \text { in. }\end{array}$ & $\begin{array}{r}-0.0049 \text { in. } \\
(-1.00 \%) \\
\sigma=0.00030 \mathrm{in.}\end{array}$ \\
\hline $\begin{array}{l}\mathbf{2 - 2 - 3} \\
\text { len. } 0.98677 \mathrm{in.} \\
\text { dia. } 0.4865 \mathrm{in.}\end{array}$ & $\begin{array}{r}-0.0054 \text { in. } \\
(-0.55 \%) \\
\sigma=0.00068 \mathrm{in} .\end{array}$ & $\begin{array}{r}-0.0052 \text { in. } \\
(-1.06 \%) \\
\sigma=0.00022 \mathrm{in.}\end{array}$ & $\begin{array}{r}-0.0054 \text { in. } \\
(-1.10 \%) \\
\sigma=0.00016 \text { in. }\end{array}$ & $\begin{array}{r}-0.0058 \text { in. } \\
(-1.18 \%) \\
\sigma=0.00017 \text { in. } \\
\end{array}$ & $\begin{array}{r}-0.0054 \text { in. } \\
(-1.11 \%) \\
\sigma=0.00032 \text { in. }\end{array}$ \\
\hline $\begin{array}{l}\text { 2-3-3 } \\
\text { len. } 0.98472 \mathrm{in.} \\
\text { dia. } 0.4865 \mathrm{in.}\end{array}$ & $\begin{array}{r}-0.0052 \mathrm{in} . \\
(-0.53 \%) \\
\sigma=0.00030 \mathrm{in} .\end{array}$ & $\begin{array}{r}-0.0053 \mathrm{in} . \\
(-1.08 \%) \\
\sigma=0.00021 \mathrm{in} .\end{array}$ & $\begin{array}{r}-0.0054 \text { in. } \\
(-1.10 \%) \\
\sigma=0.00016 \text { in. }\end{array}$ & $\begin{array}{r}-0.0057 \text { in. } \\
(-1.18 \%) \\
\sigma=0.00021 \text { in. }\end{array}$ & $\begin{array}{r}-0.0055 \text { in. } \\
(-1.12 \%) \\
\sigma=0.00028 \text { in. }\end{array}$ \\
\hline $\begin{array}{l}\mathbf{2 - 4 - 3} \\
\text { len. } 0.98650 \mathrm{in} . \\
\text { dia. } 0.4865 \mathrm{in.}\end{array}$ & $\begin{array}{r}-0.0050 \text { in. } \\
(-0.50 \%) \\
\sigma=0.00063 \text { in. }\end{array}$ & $\begin{array}{r}-0.0047 \mathrm{in} . \\
(-0.97 \%) \\
\sigma=0.00021 \mathrm{in} .\end{array}$ & $\begin{array}{r}-0.0049 \mathrm{in} . \\
(-1.01 \%) \\
\sigma=0.00019 \mathrm{in} .\end{array}$ & $\begin{array}{r}-0.0052 \text { in. } \\
(-1.08 \%) \\
\sigma=0.00029 \text { in. }\end{array}$ & $\begin{array}{r}-0.0050 \text { in. } \\
(-1.02 \%) \\
\sigma=0.00032 \mathrm{in.}\end{array}$ \\
\hline
\end{tabular}




\section{A-1.3 Capsule 3 Fuel Compacts}

Capsule 3 compact dimensional changes are shown in Table A-3, where negative values indicate shrinkage from as-fabricated measurements made at room temperature (listed in Compact column).

Table A-3. Metrology results from AGR-1 Capsule 3 fuel compacts $\left(93^{\circ} \mathrm{F}\right.$ ambient).

\begin{tabular}{|c|c|c|c|c|c|}
\hline Compact & Length $\Delta$ & $\begin{array}{c}\text { Upper } \\
\text { Diameter } \Delta\end{array}$ & $\begin{array}{c}\text { Middle } \\
\text { Diameter } \Delta\end{array}$ & $\begin{array}{c}\text { Lower } \\
\text { Diameter } \Delta\end{array}$ & $\begin{array}{c}\text { Average } \\
\text { Diameter } \Delta\end{array}$ \\
\hline $\begin{array}{l}\text { 3-1-1 } \\
\text { len. } 0.98402 \text { in. } \\
\text { dia. } 0.4869 \mathrm{in.}\end{array}$ & $\begin{array}{r}-0.0049 \text { in. } \\
(-0.50 \%) \\
\sigma=0.00051 \mathrm{in} .\end{array}$ & $\begin{array}{r}-0.0054 \mathrm{in} . \\
(-1.10 \%) \\
\sigma=0.00021 \mathrm{in} .\end{array}$ & $\begin{array}{r}-0.0052 \mathrm{in} . \\
(-1.07 \%) \\
\sigma=0.00021 \mathrm{in} .\end{array}$ & $\begin{array}{r}-0.0049 \text { in. } \\
(-1.00 \%) \\
\sigma=0.00019 \text { in. }\end{array}$ & $\begin{array}{r}-0.0052 \text { in. } \\
(-1.06 \%) \\
\sigma=0.00029 \text { in. }\end{array}$ \\
\hline $\begin{array}{l}\text { 3-2-1 } \\
\text { len. } 0.98512 \mathrm{in.} \\
\text { dia. } 0.4869 \mathrm{in.}\end{array}$ & $\begin{array}{r}-0.0039 \text { in. } \\
(-0.40 \%) \\
\sigma=0.00045 \text { in. }\end{array}$ & $\begin{array}{r}-0.0053 \text { in. } \\
(-1.08 \%) \\
\sigma=0.00027 \mathrm{in} .\end{array}$ & $\begin{array}{r}-0.0052 \text { in. } \\
(-1.08 \%) \\
\sigma=0.00000 \text { in. }\end{array}$ & $\begin{array}{r}-0.0054 \text { in. } \\
(-1.11 \%) \\
\sigma=0.00023 \text { in. }\end{array}$ & $\begin{array}{r}-0.0053 \text { in. } \\
(-1.09 \%) \\
\sigma=0.00022 \text { in. }\end{array}$ \\
\hline $\begin{array}{l}\text { 3-3-1 } \\
\text { len. } 0.99004 \text { in. } \\
\text { dia. } 0.4869 \mathrm{in.}\end{array}$ & $\begin{array}{r}-0.0058 \text { in. } \\
(-0.58 \%) \\
\sigma=0.00048 \text { in. }\end{array}$ & $\begin{array}{r}-0.0052 \mathrm{in} . \\
(-1.07 \%) \\
\sigma=0.00012 \mathrm{in} .\end{array}$ & $\begin{array}{r}-0.0053 \text { in. } \\
(-1.10 \%) \\
\sigma=0.00019 \mathrm{in} .\end{array}$ & $\begin{array}{r}-0.0054 \text { in. } \\
(-1.11 \%) \\
\sigma=0.00022 \text { in. }\end{array}$ & $\begin{array}{r}-0.0053 \text { in. } \\
(-1.09 \%) \\
\sigma=0.00020 \mathrm{in} .\end{array}$ \\
\hline $\begin{array}{l}\text { 3-4-1 } \\
\text { len. } 0.98551 \text { in. } \\
\text { dia.:0.4869 in. }\end{array}$ & $\begin{array}{r}-0.00 \\
(-C \\
\sigma=0.00\end{array}$ & $\begin{array}{r}-0.0049 \mathrm{in} . \\
(-1.00 \%) \\
\sigma=0.00019 \mathrm{in} .\end{array}$ & $\begin{array}{r}-0.0051 \text { in. } \\
(-1.04 \%) \\
\sigma=0.00022 \text { in. } \\
\end{array}$ & $\begin{array}{r}-0.0054 \text { in. } \\
(-1.10 \%) \\
\sigma=0.00021 \text { in. } \\
\end{array}$ & $\begin{array}{r}-0.0051 \text { in. } \\
(-1.05 \%) \\
\sigma=0.00029 \text { in. }\end{array}$ \\
\hline $\begin{array}{l}\text { 3-1-2 } \\
\text { len. } 0.98366 \mathrm{in.} \\
\text { dia. } 0.4869 \mathrm{in.}\end{array}$ & $\begin{array}{r}-0.0053 \text { in. } \\
(-0.54 \%) \\
\sigma=0.00058 \text { in. }\end{array}$ & $\begin{array}{r}-0.0053 \text { in. } \\
(-1.09 \%) \\
\sigma=0.00016 \text { in. }\end{array}$ & $\begin{array}{r}-0.0050 \mathrm{in} . \\
(-1.03 \%) \\
\sigma=0.00024 \mathrm{in} .\end{array}$ & $\begin{array}{r}-0.0049 \text { in. } \\
(-1.01 \%) \\
\sigma=0.00021 \text { in. }\end{array}$ & $\begin{array}{r}-0.0051 \text { in. } \\
(-1.04 \%) \\
\sigma=0.00026 \text { in. }\end{array}$ \\
\hline $\begin{array}{l}\text { 3-2-2 } \\
\text { len. } 0.98543 \text { in. } \\
\text { dia. } 0.4869 \mathrm{in.}\end{array}$ & $\begin{array}{r}-0.0070 \mathrm{in} . \\
(-0.71 \%) \\
\sigma=0.00031 \mathrm{in} .\end{array}$ & $\begin{array}{r}-0.0051 \mathrm{in} . \\
(-1.04 \%) \\
\sigma=0.00022 \mathrm{in} .\end{array}$ & $\begin{array}{r}-0.0051 \mathrm{in} . \\
(-1.04 \%) \\
\sigma=0.00022 \mathrm{in} .\end{array}$ & $\begin{array}{r}-0.0052 \text { in. } \\
(-1.07 \%) \\
\sigma=0.00021 \text { in. }\end{array}$ & $\begin{array}{r}-0.0051 \text { in. } \\
(-1.05 \%) \\
\sigma=0.00022 \mathrm{in} .\end{array}$ \\
\hline $\begin{array}{l}\text { 3-3-2 } \\
\text { len. } 0.98547 \text { in. } \\
\text { dia. } 0.4869 \mathrm{in.}\end{array}$ & $\begin{array}{r}-0.0068 \text { in. } \\
(-0.69 \%) \\
\sigma=0.00058 \text { in. }\end{array}$ & $\begin{array}{r}-0.0049 \mathrm{in} . \\
(-1.01 \%) \\
\sigma=0.00021 \mathrm{in} .\end{array}$ & $\begin{array}{r}-0.0051 \mathrm{in} . \\
(-1.04 \%) \\
\sigma=0.00023 \mathrm{in} .\end{array}$ & $\begin{array}{r}-0.0051 \text { in. } \\
(-1.04 \%) \\
\sigma=0.00022 \text { in. }\end{array}$ & $\begin{array}{r}-0.0050 \text { in. } \\
(-1.03 \%) \\
\sigma=0.00023 \text { in. }\end{array}$ \\
\hline $\begin{array}{l}\text { 3-4-2 } \\
\text { len. } 0.98532 \mathrm{in.} \\
\text { dia. } 0.4869 \mathrm{in.}\end{array}$ & $\begin{array}{r}-0.0047 \mathrm{in} . \\
(-0.48 \%) \\
\sigma=0.00057 \mathrm{in} .\end{array}$ & $\begin{array}{r}-0.0048 \mathrm{in} . \\
(-0.99 \%) \\
\sigma=0.00012 \mathrm{in} .\end{array}$ & $\begin{array}{r}-0.0048 \text { in. } \\
(-0.98 \%) \\
\sigma=0.00021 \text { in. }\end{array}$ & $\begin{array}{r}-0.0049 \text { in. } \\
(-1.00 \%) \\
\sigma=0.00026 \text { in. }\end{array}$ & $\begin{array}{r}-0.0048 \text { in. } \\
(-0.99 \%) \\
\sigma=0.00021 \mathrm{in} .\end{array}$ \\
\hline $\begin{array}{l}\text { 3-1-3 } \\
\text { len. } 0.98717 \text { in. } \\
\text { dia. } 0.4869 \mathrm{in.}\end{array}$ & $\begin{array}{r}-0.0045 \text { in. } \\
(-0.46 \%) \\
\sigma=0.00042 \text { in. }\end{array}$ & $\begin{array}{r}-0.0051 \mathrm{in} . \\
(-1.04 \%) \\
\sigma=0.00023 \mathrm{in} .\end{array}$ & $\begin{array}{r}-0.0052 \mathrm{in} . \\
(-1.08 \%) \\
\sigma=0.00017 \mathrm{in} .\end{array}$ & $\begin{array}{r}-0.0052 \text { in. } \\
(-1.06 \%) \\
\sigma=0.00016 \text { in. }\end{array}$ & $\begin{array}{r}-0.0052 \text { in. } \\
(-1.06 \%) \\
\sigma=0.00020 \text { in. }\end{array}$ \\
\hline $\begin{array}{l}\text { 3-2-3 } \\
\text { len. } 0.98681 \mathrm{in.} \\
\text { dia. } 0.4869 \mathrm{in.}\end{array}$ & $\begin{array}{r}-0.0049 \text { in. } \\
(-0.49 \%) \\
\sigma=0.00055 \text { in. }\end{array}$ & $\begin{array}{r}-0.0051 \mathrm{in} . \\
(-1.04 \%) \\
\sigma=0.00022 \mathrm{in} .\end{array}$ & $\begin{array}{r}-0.0052 \text { in. } \\
(-1.06 \%) \\
\sigma=0.00016 \text { in. }\end{array}$ & $\begin{array}{r}-0.0052 \text { in. } \\
(-1.06 \%) \\
\sigma=0.00019 \text { in. } \\
\end{array}$ & $\begin{array}{r}-0.0051 \text { in. } \\
(-1.06 \%) \\
\sigma=0.00019 \text { in. }\end{array}$ \\
\hline $\begin{array}{l}\text { 3-3-3 } \\
\text { len. } 0.98713 \mathrm{in.} \\
\text { dia. } 0.4869 \mathrm{in.}\end{array}$ & $\begin{array}{r}-0.0053 \mathrm{in} . \\
(-0.54 \%) \\
\sigma=0.00041 \mathrm{in} .\end{array}$ & $\begin{array}{r}-0.0053 \text { in. } \\
(-1.08 \%) \\
\sigma=0.00012 \mathrm{in} .\end{array}$ & $\begin{array}{r}-0.0053 \text { in. } \\
(-1.09 \%) \\
\sigma=0.00016 \text { in. }\end{array}$ & $\begin{array}{r}-0.0053 \text { in. } \\
(-1.10 \%) \\
\sigma=0.00019 \text { in. }\end{array}$ & $\begin{array}{r}-0.0053 \text { in. } \\
(-1.09 \%) \\
\sigma=0.00016 \text { in. }\end{array}$ \\
\hline $\begin{array}{l}\text { 3-4-3 } \\
\text { len. } 0.98366 \text { in. } \\
\text { dia. } 0.4869 \mathrm{in.}\end{array}$ & $\begin{array}{r}-0.0026 \text { in. } \\
(-0.26 \%) \\
\sigma=0.00047 \mathrm{in} .\end{array}$ & $\begin{array}{r}-0.0050 \mathrm{in} . \\
(-1.03 \%) \\
\sigma=0.00024 \mathrm{in} .\end{array}$ & $\begin{array}{r}-0.0053 \mathrm{in} . \\
(-1.10 \%) \\
\sigma=0.00019 \mathrm{in} .\end{array}$ & $\begin{array}{r}-0.0054 \text { in. } \\
(-1.11 \%) \\
\sigma=0.00022 \text { in. }\end{array}$ & $\begin{array}{r}-0.0052 \text { in. } \\
(-1.08 \%) \\
\sigma=0.00028 \text { in. }\end{array}$ \\
\hline
\end{tabular}




\section{A-1.4 Capsule 4 Fuel Compacts}

Length and diameter changes from images of the Capsule 4 fuel compacts are given in Table A-4. Negative values indicate shrinkage from as-fabricated room-temperature values (in Compact column).

Table A-4. Metrology results from AGR-1 Capsule 4 fuel compacts $\left(87^{\circ} \mathrm{F}\right.$ ambient).

\begin{tabular}{|c|c|c|c|c|c|}
\hline Compact & Length $\Delta$ & $\begin{array}{c}\text { Upper } \\
\text { Diameter } \Delta\end{array}$ & $\begin{array}{c}\text { Middle } \\
\text { Diameter } \Delta\end{array}$ & $\begin{array}{c}\text { Lower } \\
\text { Diameter } \Delta\end{array}$ & $\begin{array}{c}\text { Average } \\
\text { Diameter } \Delta\end{array}$ \\
\hline $\begin{array}{l}\text { 4-1-1 } \\
\text { len. } 0.99421 \mathrm{in.} \\
\text { dia. } 0.4857 \mathrm{in.}\end{array}$ & $\begin{array}{r}-0.0063 \mathrm{in} . \\
(-0.63 \%) \\
\sigma=0.00051 \mathrm{in} .\end{array}$ & $\begin{array}{r}-0.0045 \mathrm{in} . \\
(-0.93 \%) \\
\sigma=0.00032 \mathrm{in} .\end{array}$ & $\begin{array}{r}-0.0045 \text { in. } \\
(-0.92 \%) \\
\sigma=0.00028 \text { in. }\end{array}$ & $\begin{array}{r}-0.0046 \text { in. } \\
(-0.95 \%) \\
\sigma=0.00032 \text { in. }\end{array}$ & $\begin{array}{r}-0.0045 \mathrm{in} . \\
(-0.93 \%) \\
\sigma=0.00031 \mathrm{in} .\end{array}$ \\
\hline $\begin{array}{l}\text { 4-2-1 } \\
\text { len. } 0.99283 \text { in. } \\
\text { dia. } 0.4857 \mathrm{in.}\end{array}$ & $\begin{array}{r}-0.0057 \mathrm{in} . \\
(-0.58 \%) \\
\sigma=0.00020 \mathrm{in} .\end{array}$ & $\begin{array}{r}-0.0048 \text { in. } \\
(-0.98 \%) \\
\sigma=0.00021 \text { in. }\end{array}$ & $\begin{array}{r}-0.0049 \mathrm{in} . \\
(-1.00 \%) \\
\sigma=0.00029 \mathrm{in} .\end{array}$ & $\begin{array}{r}-0.0049 \mathrm{in} . \\
(-1.01 \%) \\
\sigma=0.00023 \mathrm{in} .\end{array}$ & $\begin{array}{r}-0.0048 \text { in. } \\
(-1.00 \%) \\
\sigma=0.00025 \text { in. }\end{array}$ \\
\hline $\begin{array}{l}\text { 4-3-1 } \\
\text { len. } 0.99339 \mathrm{in.} \\
\text { dia. } 0.4857 \mathrm{in.}\end{array}$ & $\begin{array}{r}-0.0068 \mathrm{in} . \\
(-0.69 \%) \\
\sigma=0.00030 \mathrm{in} .\end{array}$ & $\begin{array}{r}-0.0043 \text { in. } \\
(-0.88 \%) \\
\sigma=0.00021 \mathrm{in.}\end{array}$ & $\begin{array}{r}-0.0045 \text { in. } \\
(-0.93 \%) \\
\sigma=0.00021 \text { in. }\end{array}$ & $\begin{array}{r}-0.0047 \text { in. } \\
(-0.96 \%) \\
\sigma=0.00027 \mathrm{in} .\end{array}$ & $\begin{array}{r}-0.0045 \mathrm{in} . \\
(-0.92 \%) \\
\sigma=0.00027 \mathrm{in} .\end{array}$ \\
\hline $\begin{array}{l}\text { 4-4-1 } \\
\text { len. } 0.99343 \mathrm{in.} \\
\text { dia.:0.4857 in. }\end{array}$ & $\begin{array}{r}-0.0023 \text { in. } \\
(-0.23 \%) \\
\sigma=0.00034 \mathrm{in} .\end{array}$ & $\begin{array}{r}-0.0043 \text { in. } \\
(-0.89 \%) \\
\sigma=0.00028 \mathrm{in} .\end{array}$ & $\begin{array}{r}-0.0046 \text { in. } \\
(-0.94 \%) \\
\sigma=0.00024 \text { in. }\end{array}$ & $\begin{array}{r}-0.0046 \text { in. } \\
(-0.95 \%) \\
\sigma=0.00032 \text { in. }\end{array}$ & $\begin{array}{r}-0.0045 \mathrm{in} . \\
(-0.93 \%) \\
\sigma=0.00030 \mathrm{in} .\end{array}$ \\
\hline $\begin{array}{l}\text { 4-1-2 } \\
\text { len. } 0.99181 \mathrm{in.} \\
\text { dia. } 0.4857 \mathrm{in.} \\
\end{array}$ & $\begin{array}{r}-0.0045 \mathrm{in} . \\
(-0.45 \%) \\
\sigma=0.00032 \mathrm{in} .\end{array}$ & $\begin{array}{r}-0.0047 \mathrm{in} . \\
(-0.96 \%) \\
\sigma=0.00027 \mathrm{in} .\end{array}$ & $\begin{array}{r}-0.0045 \text { in. } \\
(-0.92 \%) \\
\sigma=0.00029 \text { in. }\end{array}$ & $\begin{array}{r}-0.0045 \text { in. } \\
(-0.92 \%) \\
\sigma=0.00029 \mathrm{in} .\end{array}$ & $\begin{array}{r}-0.0045 \text { in. } \\
(-0.93 \%) \\
\sigma=0.00029 \text { in. }\end{array}$ \\
\hline $\begin{array}{l}\text { 4-2-2 } \\
\text { len. } 0.99075 \mathrm{in.} \\
\text { dia. } 0.4857 \mathrm{in.}\end{array}$ & $\begin{array}{r}-0.0062 \mathrm{in} . \\
(-0.63 \%) \\
\sigma=0.00049 \mathrm{in} .\end{array}$ & $\begin{array}{r}-0.0 \\
(-1 \\
\sigma=0.00\end{array}$ & $\begin{array}{r}-0.0048 \text { in. } \\
(-1.00 \%) \\
\sigma=0.00029 \text { in. }\end{array}$ & $\begin{array}{r}-0.0050 \text { in. } \\
(-1.03 \%) \\
\sigma=0.00034 \text { in. }\end{array}$ & $\begin{array}{r}-0.0049 \mathrm{in} . \\
(-1.01 \%) \\
\sigma=0.00030 \mathrm{in} .\end{array}$ \\
\hline $\begin{array}{l}\text { 4-3-2 } \\
\text { len. } 0.99102 \text { in. } \\
\text { dia. } 0.4856 \text { in. }\end{array}$ & $\begin{array}{r}-0.0063 \text { in. } \\
(-0.64 \%) \\
\sigma=0.00034 \text { in. }\end{array}$ & $\begin{array}{r}-0.0042 \text { in. } \\
(-0.87 \%) \\
\sigma=0.00021 \mathrm{in} .\end{array}$ & $\begin{array}{r}-0.0044 \mathrm{in} . \\
(-0.91 \%) \\
\sigma=0.00028 \mathrm{in} .\end{array}$ & $\begin{array}{r}-0.0047 \mathrm{in} . \\
(-0.96 \%) \\
\sigma=0.00040 \mathrm{in} .\end{array}$ & $\begin{array}{r}-0.0044 \mathrm{in} . \\
(-0.91 \%) \\
\sigma=0.00036 \mathrm{in} .\end{array}$ \\
\hline $\begin{array}{l}\text { 4-4-2 } \\
\text { len. } 0.99287 \mathrm{in.} \\
\text { dia. } 0.4856 \mathrm{in.}\end{array}$ & $\begin{array}{r}-0.0038 \mathrm{in} . \\
(-0.38 \%) \\
\sigma=0.00023 \mathrm{in} .\end{array}$ & $\begin{array}{r}-0.0047 \mathrm{in} . \\
(-0.96 \%) \\
\sigma=0.00039 \mathrm{in} .\end{array}$ & $\begin{array}{r}-0.0047 \text { in. } \\
(-0.96 \%) \\
\sigma=0.00025 \text { in. }\end{array}$ & $\begin{array}{r}-0.0046 \text { in. } \\
(-0.94 \%) \\
\sigma=0.00027 \text { in. }\end{array}$ & $\begin{array}{r}-0.0046 \text { in. } \\
(-0.95 \%) \\
\sigma=0.00031 \mathrm{in} .\end{array}$ \\
\hline $\begin{array}{l}\text { 4-1-3 }\left(89^{\circ} \mathrm{F}\right)^{\mathrm{a}} \\
\text { len. } 0.99142 \mathrm{in} . \\
\text { dia. } 0.4858 \mathrm{in} .\end{array}$ & $\begin{array}{r}-0.0027 \text { in. } \\
(-0.28 \%) \\
\sigma=0.00028 \mathrm{in} .\end{array}$ & $\begin{array}{r}-0.0043 \text { in. }^{2} \\
(-0.88 \%) \\
\sigma=0.00027 \mathrm{in} .\end{array}$ & $\begin{array}{r}-0.0044 \text { in. } \\
(-0.91 \%) \\
\sigma=0.00021 \mathrm{in} .\end{array}$ & $\begin{array}{r}-0.0043 \text { in. } \\
(-0.88 \%) \\
\sigma=0.00032 \text { in. }\end{array}$ & $\begin{array}{r}-0.0042 \text { in. }^{b} \\
(-0.89 \%) \\
\sigma=0.00028 \text { in. }\end{array}$ \\
\hline $\begin{array}{l}\text { 4-2-3 } \\
\text { len. } 0.99161 \mathrm{in} . \\
\text { dia. } 0.4858 \mathrm{in.}\end{array}$ & $\begin{array}{r}-0.0059 \mathrm{in} . \\
(-0.59 \%) \\
\sigma=0.00075 \mathrm{in} .\end{array}$ & $\begin{array}{r}-0.0046 \text { in. } \\
(-0.94 \%) \\
\sigma=0.00023 \mathrm{in.}\end{array}$ & $\begin{array}{r}-0.0045 \text { in. } \\
(-0.93 \%) \\
\sigma=0.00024 \text { in. }\end{array}$ & $\begin{array}{r}-0.0049 \text { in. } \\
(-1.00 \%) \\
\sigma=0.00035 \text { in. }\end{array}$ & $\begin{array}{r}-0.0047 \mathrm{in} . \\
(-0.96 \%) \\
\sigma=0.00031 \mathrm{in} .\end{array}$ \\
\hline $\begin{array}{l}\text { 4-3-3 } \\
\text { len. } 0.99421 \mathrm{in.} \\
\text { dia. } 0.4858 \mathrm{in.}\end{array}$ & $\begin{array}{r}-0.0067 \mathrm{in} . \\
(-0.68 \%) \\
\sigma=0.00030 \mathrm{in} .\end{array}$ & $\begin{array}{r}-0.0043 \text { in. } \\
(-0.89 \%) \\
\sigma=0.00017 \text { in. }\end{array}$ & $\begin{array}{r}-0.0043 \text { in. } \\
(-0.89 \%) \\
\sigma=0.00030 \text { in. }\end{array}$ & $\begin{array}{r}-0.0045 \text { in. } \\
(-0.92 \%) \\
\sigma=0.00029 \mathrm{in} .\end{array}$ & $\begin{array}{r}-0.0044 \text { in. } \\
(-0.90 \%) \\
\sigma=0.00027 \text { in. }\end{array}$ \\
\hline $\begin{array}{l}\text { 4-4-3 } \\
\text { len. } 0.99433 \mathrm{in.} \\
\text { dia. } 0.4858 \mathrm{in.}\end{array}$ & $\begin{array}{r}-0.0036 \text { in. } \\
(-0.36 \%) \\
\sigma=0.00113 \mathrm{in} .\end{array}$ & $\begin{array}{r}-0.0043 \text { in. } \\
(-0.88 \%) \\
\sigma=0.00021 \mathrm{in} .\end{array}$ & $\begin{array}{r}-0.0044 \text { in. } \\
(-0.91 \%) \\
\sigma=0.00021 \mathrm{in} .\end{array}$ & $\begin{array}{r}-0.0045 \text { in. } \\
(-0.93 \%) \\
\sigma=0.00024 \text { in. }\end{array}$ & $\begin{array}{r}-0.0044 \mathrm{in} . \\
(-0.91 \%) \\
\sigma=0.00024 \mathrm{in} .\end{array}$ \\
\hline
\end{tabular}

a. Images captured on this compact one day later than from other Capsule 4 compacts during which the ambient in-cell temperature changed by $2^{\circ} \mathrm{F}$.

b. Diameter measurements excluded that were enlarged by the width of a crack at the top of this compact. 


\section{A-1.5 Capsule 5 Fuel Compacts}

Length and diameter changes from Capsule 5 fuel compact images are presented in Table A-5. Negative values indicate shrinkage from as-fabricated room temperature values (in Compact column).

Table A-5. Metrology results from AGR-1 Capsule 5 fuel compacts $\left(83^{\circ} \mathrm{F}\right.$ ambient).

\begin{tabular}{|c|c|c|c|c|c|}
\hline Compact & Length $\Delta$ & $\begin{array}{c}\text { Upper } \\
\text { Diameter } \Delta\end{array}$ & $\begin{array}{c}\text { Middle } \\
\text { Diameter } \Delta\end{array}$ & $\begin{array}{c}\text { Lower } \\
\text { Diameter } \Delta\end{array}$ & $\begin{array}{c}\text { Average } \\
\text { Diameter } \Delta\end{array}$ \\
\hline $\begin{array}{l}\mathbf{5 - 1 - 1} \\
\text { len. } 0.99008 \text { in. } \\
\text { dia. } 0.4867 \text { in. }\end{array}$ & $\begin{array}{r}-0.0056 \text { in. } \\
(-0.56 \%) \\
\sigma=0.00087 \mathrm{in} .\end{array}$ & $\begin{array}{r}-0.0047 \mathrm{in} . \\
(-0.96 \%) \\
\sigma=0.00019 \mathrm{in} .\end{array}$ & $\begin{array}{r}-0.0048 \mathrm{in} . \\
(-0.99 \%) \\
\sigma=0.00024 \mathrm{in} .\end{array}$ & $\begin{array}{r}-0.0048 \text { in. } \\
(-0.99 \%) \\
\sigma=0.00024 \text { in. }\end{array}$ & $\begin{array}{r}-0.0048 \text { in. } \\
(-0.98 \%) \\
\sigma=0.00023 \text { in. }\end{array}$ \\
\hline $\begin{array}{l}\quad \mathbf{5 - 2 - 1} \\
\text { len. } 0.98929 \mathrm{in.} \\
\text { dia. } 0.4866 \mathrm{in.}\end{array}$ & $\begin{array}{r}-0.0073 \text { in. } \\
(-0.74 \%) \\
\sigma=0.00031 \mathrm{in} .\end{array}$ & $\begin{array}{r}-0.0051 \mathrm{in} . \\
(-1.04 \%) \\
\sigma=0.00019 \mathrm{in} .\end{array}$ & $\begin{array}{r}-0.0052 \text { in. } \\
(-1.07 \%) \\
\sigma=0.00024 \text { in. }\end{array}$ & $\begin{array}{r}-0.0054 \text { in. } \\
(-1.11 \%) \\
\sigma=0.00021 \text { in. }\end{array}$ & $\begin{array}{r}-0.0052 \text { in. } \\
(-1.07 \%) \\
\sigma=0.00025 \text { in. }\end{array}$ \\
\hline $\begin{array}{l}\text { 5-3-1 } \\
\text { len. } 0.98744 \text { in. } \\
\text { dia. } 0.4866 \text { in. }\end{array}$ & $\begin{array}{r}-0.0057 \mathrm{in} . \\
(-0.58 \%) \\
\sigma=0.00069 \mathrm{in} .\end{array}$ & $\begin{array}{r}-0.0048 \text { in. } \\
(-0.98 \%) \\
\sigma=0.00021 \mathrm{in} .\end{array}$ & $\begin{array}{r}-0.0048 \mathrm{in} . \\
(-0.99 \%) \\
\sigma=0.00019 \mathrm{in} .\end{array}$ & $\begin{array}{r}-0.0052 \text { in. } \\
(-1.06 \%) \\
\sigma=0.00029 \text { in. }\end{array}$ & $\begin{array}{r}-0.0049 \text { in. } \\
(-1.01 \%) \\
\sigma=0.00029 \mathrm{in} .\end{array}$ \\
\hline $\begin{array}{l}\quad \mathbf{5 - 4 - 1} \\
\text { len. } 0.98835 \mathrm{in.} \\
\text { dia. } 0.4867 \mathrm{in.} \\
\end{array}$ & $\begin{array}{r}-0.0067 \text { in. } \\
(-0.67 \%) \\
\sigma=0.00046 \text { in. }\end{array}$ & $\begin{array}{r}-0.0042 \text { in. } \\
(-0.87 \%) \\
\sigma=0.00019 \mathrm{in} .\end{array}$ & $\begin{array}{r}-0.0046 \text { in. } \\
(-0.94 \%) \\
\sigma=0.00017 \text { in. } \\
\end{array}$ & $\begin{array}{r}-0.00 \\
(-1 \\
\sigma=0.000\end{array}$ & $\begin{array}{r}-0.0 \\
(- \\
\sigma=0.00 \\
\end{array}$ \\
\hline $\begin{array}{l}\mathbf{5 - 1 - 2} \\
\text { len. } 0.98909 \mathrm{in.} \\
\text { dia. } 0.4865 \mathrm{in.}\end{array}$ & $\begin{array}{r}-0.0066 \text { in. } \\
(-0.67 \%) \\
\sigma=0.00036 \text { in. }\end{array}$ & $\begin{array}{r}-0.0053 \mathrm{in} . \\
(-1.10 \%) \\
\sigma=0.00012 \mathrm{in} .\end{array}$ & $\begin{array}{r}-0.0052 \text { in. } \\
(-1.08 \%) \\
\sigma=0.00016 \text { in. }\end{array}$ & $\begin{array}{r}-0.0050 \text { in. } \\
(-1.03 \%) \\
\sigma=0.00022 \text { in. }\end{array}$ & $\begin{array}{r}-0.0052 \text { in. } \\
(-1.07 \%) \\
\sigma=0.00022 \mathrm{in} .\end{array}$ \\
\hline $\begin{array}{l}\text { 5-2-2 } \\
\text { len. } 0.98736 \text { in. } \\
\text { dia. } 0.4865 \text { in. }\end{array}$ & $\begin{array}{r}-0.00 \\
(-0 \\
\sigma=0.000 \\
\end{array}$ & $\begin{array}{r}-0.0054 \mathrm{in} . \\
(-1.11 \%) \\
\sigma=0.00021 \mathrm{in} .\end{array}$ & $\begin{array}{r}-0.0058 \mathrm{in} . \\
(-1.18 \%) \\
\sigma=0.00017 \mathrm{in} .\end{array}$ & $\begin{array}{r}-0.0059 \text { in. } \\
(-1.20 \%) \\
\sigma=0.00026 \text { in. }\end{array}$ & $\begin{array}{r}-0.0057 \text { in. } \\
(-1.17 \%) \\
\sigma=0.00028 \mathrm{in} .\end{array}$ \\
\hline $\begin{array}{l}\mathbf{5 - 3 - 2} \\
\text { len. } 0.98913 \mathrm{in.} \\
\text { dia. } 0.4865 \mathrm{in.}\end{array}$ & $\begin{array}{r}-0.0077 \text { in. } \\
(-0.78 \%) \\
\sigma=0.00018 \text { in. }\end{array}$ & $\begin{array}{r}-0.0053 \mathrm{in} . \\
(-1.09 \%) \\
\sigma=0.00025 \mathrm{in} .\end{array}$ & $\begin{array}{r}-0.0053 \text { in. } \\
(-1.10 \%) \\
\sigma=0.00012 \text { in. }\end{array}$ & $\begin{array}{r}-0.0055 \text { in. } \\
(-1.13 \%) \\
\sigma=0.00024 \text { in. }\end{array}$ & $\begin{array}{r}-0.0054 \text { in. } \\
(-1.11 \%) \\
\sigma=0.00023 \text { in. }\end{array}$ \\
\hline $\begin{array}{l}\text { 5-4-2 } \\
\text { len. } 0.98874 \mathrm{in.} \\
\text { dia. } 0.4865 \mathrm{in.}\end{array}$ & $\begin{array}{r}-0.0068 \text { in. } \\
(-0.69 \%) \\
\sigma=0.00059 \text { in. }\end{array}$ & $\begin{array}{r}-0.0044 \mathrm{in} . \\
(-0.90 \%) \\
\sigma=0.00025 \mathrm{in} .\end{array}$ & $\begin{array}{r}-0.0047 \text { in. } \\
(-0.96 \%) \\
\sigma=0.00023 \text { in. }\end{array}$ & $\begin{array}{r}-0.0052 \text { in. } \\
(-1.06 \%) \\
\sigma=0.00028 \text { in. }\end{array}$ & $\begin{array}{r}-0.0047 \text { in. } \\
(-0.97 \%) \\
\sigma=0.00041 \mathrm{in} .\end{array}$ \\
\hline $\begin{array}{l}\mathbf{5 - 1 - 3} \\
\text { len. } 0.98945 \text { in. } \\
\text { dia. } 0.4864 \text { in. }\end{array}$ & $\begin{array}{r}-0.0053 \text { in. } \\
(-0.54 \%) \\
\sigma=0.00092 \text { in. }\end{array}$ & $\begin{array}{r}-0.0048 \mathrm{in} . \\
(-1.00 \%) \\
\sigma=0.00016 \mathrm{in} .\end{array}$ & $\begin{array}{r}-0.0048 \mathrm{in} . \\
(-1.00 \%) \\
\sigma=0.00024 \mathrm{in} .\end{array}$ & $\begin{array}{r}-0.0048 \text { in. } \\
(-0.98 \%) \\
\sigma=0.00025 \text { in. }\end{array}$ & $\begin{array}{r}-0.0048 \text { in. } \\
(-0.99 \%) \\
\sigma=0.00022 \text { in. }\end{array}$ \\
\hline $\begin{array}{l}\mathbf{5 - 2 - 3} \\
\text { len. } 0.99039 \mathrm{in.} \\
\text { dia. } 0.4865 \mathrm{in.} \\
\end{array}$ & $\begin{array}{r}-0.0072 \text { in. } \\
(-0.72 \%) \\
\sigma=0.00086 \text { in. }\end{array}$ & $\begin{array}{r}-0.0054 \mathrm{in} . \\
(-1.11 \%) \\
\sigma=0.00021 \mathrm{in} .\end{array}$ & $\begin{array}{r}-0.0053 \text { in. } \\
(-1.10 \%) \\
\sigma=0.00021 \mathrm{in} . \\
\end{array}$ & $\begin{array}{r}-0.0054 \text { in. } \\
(-1.10 \%) \\
\sigma=0.00024 \text { in. } \\
\end{array}$ & $\begin{array}{r}-0.0054 \text { in. } \\
(-1.10 \%) \\
\sigma=0.00022 \text { in. }\end{array}$ \\
\hline $\begin{array}{l}\text { 5-3-3 } \\
\text { len. } 0.98902 \mathrm{in.} \\
\text { dia. } 0.4864 \mathrm{in.}\end{array}$ & $\begin{array}{r}-0.0069 \text { in. } \\
(-0.70 \%) \\
\sigma=0.00053 \mathrm{in} .\end{array}$ & $\begin{array}{r}-0.0048 \text { in. } \\
(-0.98 \%) \\
\sigma=0.00017 \mathrm{in} .\end{array}$ & $\begin{array}{r}-0.0049 \mathrm{in} . \\
(-1.01 \%) \\
\sigma=0.00022 \mathrm{in} .\end{array}$ & $\begin{array}{r}-0.0052 \text { in. } \\
(-1.07 \%) \\
\sigma=0.00021 \text { in. }\end{array}$ & $\begin{array}{r}-0.0050 \text { in. } \\
(-1.02 \%) \\
\sigma=0.00027 \mathrm{in} .\end{array}$ \\
\hline $\begin{array}{l}\mathbf{5 - 4 - 3} \\
\text { len. } 0.98969 \mathrm{in.} \\
\text { dia. } 0.4865 \mathrm{in.}\end{array}$ & $\begin{array}{r}-0.0062 \text { in. } \\
(-0.62 \%) \\
\sigma=0.00046 \text { in. }\end{array}$ & $\begin{array}{r}-0.0045 \mathrm{in} . \\
(-0.93 \%) \\
\sigma=0.00021 \mathrm{in} .\end{array}$ & $\begin{array}{r}-0.0048 \mathrm{in} . \\
(-0.99 \%) \\
\sigma=0.00021 \mathrm{in} .\end{array}$ & $\begin{array}{r}-0.0051 \text { in. } \\
(-1.05 \%) \\
\sigma=0.00023 \text { in. }\end{array}$ & $\begin{array}{r}-0.0048 \text { in. } \\
(-0.99 \%) \\
\sigma=0.00033 \text { in. }\end{array}$ \\
\hline
\end{tabular}




\section{A-1.6 Capsule 6 Fuel Compacts}

Length and diameter changes from images of the Capsule 6 fuel compacts are given in Table A-6. Negative values indicate shrinkage from as-fabricated room-temperature values (in Compact column).

Table A-6. Metrology results from AGR-1 Capsule 6 fuel compacts ( $84^{\circ} \mathrm{F}$ ambient).

\begin{tabular}{|c|c|c|c|c|c|}
\hline Compact & Length $\Delta$ & $\begin{array}{c}\text { Upper } \\
\text { Diameter } \Delta\end{array}$ & $\begin{array}{c}\text { Middle } \\
\text { Diameter } \Delta\end{array}$ & $\begin{array}{c}\text { Lower } \\
\text { Diameter } \Delta\end{array}$ & $\begin{array}{c}\text { Average } \\
\text { Diameter } \Delta\end{array}$ \\
\hline $\begin{array}{l}\text { 6-1-1 } \\
\text { len. } 0.98445 \text { in. } \\
\text { dia. } 0.4869 \text { in. }\end{array}$ & $\begin{array}{r}-0.0072 \text { in. } \\
(-0.73 \%) \\
\sigma=0.00024 \text { in. }\end{array}$ & $\begin{array}{r}-0.0054 \mathrm{in} . \\
(-1.12 \%) \\
\sigma=0.00012 \mathrm{in} .\end{array}$ & $\begin{array}{r}-0.0056 \text { in. } \\
(-1.14 \%) \\
\sigma=0.00022 \text { in. }\end{array}$ & $\begin{array}{r}-0.0054 \text { in. } \\
(-1.12 \%) \\
\sigma=0.00027 \mathrm{in} .\end{array}$ & $\begin{array}{r}-0.0055 \text { in. } \\
(-1.13 \%) \\
\sigma=0.00022 \mathrm{in} .\end{array}$ \\
\hline $\begin{array}{l}\text { 6-2-1 } \\
\text { len. } 0.98854 \mathrm{in.} \\
\text { dia. } 0.4869 \mathrm{in.}\end{array}$ & $\begin{array}{r}-0.0089 \text { in. } \\
(-0.90 \%) \\
\sigma=0.00067 \mathrm{in} .\end{array}$ & $\begin{array}{r}-0.0055 \text { in. } \\
(-1.12 \%) \\
\sigma=0.00016 \text { in. }\end{array}$ & $\begin{array}{r}-0.0058 \text { in. } \\
(-1.18 \%) \\
\sigma=0.00021 \text { in. }\end{array}$ & $\begin{array}{r}-0.0060 \text { in. } \\
(-1.23 \%) \\
\sigma=0.00021 \mathrm{in} .\end{array}$ & $\begin{array}{r}-0.0057 \text { in. } \\
(-1.18 \%) \\
\sigma=0.00029 \text { in. }\end{array}$ \\
\hline $\begin{array}{l}\text { 6-3-1 } \\
\text { len. } 0.98780 \mathrm{in.} \\
\text { dia. } 0.4869 \mathrm{in.}\end{array}$ & $\begin{array}{r}-0.0084 \text { in. } \\
(-0.85 \%) \\
\sigma=0.00023 \mathrm{in} .\end{array}$ & $\begin{array}{r}-0.0048 \text { in. } \\
(-0.98 \%) \\
\sigma=0.00023 \text { in. }\end{array}$ & $\begin{array}{r}-0.0052 \mathrm{in} . \\
(-1.07 \%) \\
\sigma=0.00023 \mathrm{in} .\end{array}$ & $\begin{array}{r}-0.0056 \text { in. } \\
(-1.14 \%) \\
\sigma=0.00022 \text { in. }\end{array}$ & $\begin{array}{r}-0.0052 \text { in. } \\
(-1.06 \%) \\
\sigma=0.00040 \text { in. }\end{array}$ \\
\hline $\begin{array}{l}\text { 6-4-1 } \\
\text { len. } 0.98512 \mathrm{in.} \\
\text { dia. } 0.4869 \mathrm{in.}\end{array}$ & $\begin{array}{r}-0.0039 \text { in. } \\
(-0.39 \%) \\
\sigma=0.00049 \text { in. }\end{array}$ & $\begin{array}{r}-0.0036 \text { in. } \\
(-0.75 \%) \\
\sigma=0.00027 \mathrm{in} .\end{array}$ & $\begin{array}{r}-0.0045 \text { in. } \\
(-0.92 \%) \\
\sigma=0.00032 \text { in. } \\
\end{array}$ & $\begin{array}{r}-0.00 \\
(-1 \\
\sigma=0.00 \\
\end{array}$ & $\begin{array}{r}-0.0044 \text { in. } \\
(-0.91 \%) \\
\sigma=0.00068 \text { in. }\end{array}$ \\
\hline $\begin{array}{l}\text { 6-1-2 } \\
\text { len. } 0.98449 \mathrm{in.} \\
\text { dia. } 0.4869 \mathrm{in.}\end{array}$ & $\begin{array}{r}-0.0062 \text { in. } \\
(-0.63 \%) \\
\sigma=0.00030 \mathrm{in} .\end{array}$ & $\begin{array}{r}-0.0054 \mathrm{in} . \\
(-1.11 \%) \\
\sigma=0.00024 \mathrm{in} .\end{array}$ & $\begin{array}{r}-0.0053 \text { in. } \\
(-1.09 \%) \\
\sigma=0.00016 \text { in. }\end{array}$ & $\begin{array}{r}-0.0052 \text { in. } \\
(-1.07 \%) \\
\sigma=0.00021 \mathrm{in} .\end{array}$ & $\begin{array}{r}-0.0053 \text { in. } \\
(-1.09 \%) \\
\sigma=0.00021 \mathrm{in} .\end{array}$ \\
\hline $\begin{array}{l}\text { 6-2-2 } \\
\text { len. } 0.98476 \text { in. } \\
\text { dia. } 0.4868 \mathrm{in.}\end{array}$ & $\begin{array}{r}-0.0087 \text { in. } \\
(-0.88 \%) \\
\sigma=0.00043 \mathrm{in} .\end{array}$ & $\begin{array}{r}-0.0053 \mathrm{in} . \\
(-1.09 \%) \\
\sigma=0.00021 \mathrm{in} .\end{array}$ & $\begin{array}{r}-0.0056 \text { in. } \\
(-1.14 \%) \\
\sigma=0.00023 \text { in. }\end{array}$ & $\begin{array}{r}-0.0058 \text { in. } \\
(-1.19 \%) \\
\sigma=0.00021 \text { in. }\end{array}$ & $\begin{array}{r}-0.0056 \text { in. } \\
(-1.14 \%) \\
\sigma=0.00028 \text { in. }\end{array}$ \\
\hline $\begin{array}{l}\text { 6-3-2 } \\
\text { len. } 0.98567 \text { in. } \\
\text { dia. } 0.4868 \mathrm{in.}\end{array}$ & $\begin{array}{r}-0.0086 \text { in. } \\
(-0.88 \%) \\
\sigma=0.00023 \text { in. }\end{array}$ & $\begin{array}{r}-0.0047 \mathrm{in.} \\
(-0.97 \%) \\
\sigma=0.00019 \mathrm{in} .\end{array}$ & $\begin{array}{r}-0.0049 \mathrm{in} . \\
(-1.00 \%) \\
\sigma=0.00029 \mathrm{in} .\end{array}$ & $\begin{array}{r}-0.0052 \text { in. } \\
(-1.07 \%) \\
\sigma=0.00023 \text { in. }\end{array}$ & $\begin{array}{r}-0.0050 \text { in. } \\
(-1.02 \%) \\
\sigma=0.00031 \text { in. }\end{array}$ \\
\hline $\begin{array}{l}\text { 6-4-2 } \\
\text { len. } 0.98413 \mathrm{in.} \\
\text { dia. } 0.4868 \mathrm{in.}\end{array}$ & $\begin{array}{r}-0.0048 \text { in. } \\
(-0.49 \%) \\
\sigma=0.00067 \mathrm{in} .\end{array}$ & $\begin{array}{r}-0.0037 \mathrm{in} . \\
(-0.76 \%) \\
\sigma=0.00034 \mathrm{in} .\end{array}$ & $\begin{array}{r}-0.0042 \text { in. } \\
(-0.87 \%) \\
\sigma=0.00022 \text { in. }\end{array}$ & $\begin{array}{r}-0.0046 \text { in. } \\
(-0.94 \%) \\
\sigma=0.00023 \text { in. }\end{array}$ & $\begin{array}{r}-0.0042 \text { in. } \\
(-0.86 \%) \\
\sigma=0.00044 \text { in. }\end{array}$ \\
\hline $\begin{array}{l}\mathbf{6 - 1 - 3} \\
\text { len. } 0.98413 \mathrm{in.} \\
\text { dia. } 0.4868 \mathrm{in.}\end{array}$ & $\begin{array}{r}-0.0071 \mathrm{in} . \\
(-0.72 \%) \\
\sigma=0.00023 \mathrm{in} .\end{array}$ & $\begin{array}{r}-0.0055 \mathrm{in} . \\
(-1.14 \%) \\
\sigma=0.00024 \mathrm{in} .\end{array}$ & $\begin{array}{r}-0.0057 \mathrm{in} . \\
(-1.17 \%) \\
\sigma=0.00012 \mathrm{in} .\end{array}$ & $\begin{array}{r}-0.0057 \text { in. } \\
(-1.17 \%) \\
\sigma=0.00021 \mathrm{in} .\end{array}$ & $\begin{array}{r}-0.0057 \text { in. } \\
(-1.16 \%) \\
\sigma=0.00021 \mathrm{in.}\end{array}$ \\
\hline $\begin{array}{l}\mathbf{6 - 2 - 3} \\
\text { len. } 0.98878 \mathrm{in.} \\
\text { dia. } 0.4868 \mathrm{in.} \\
\end{array}$ & $\begin{array}{r}-0.0083 \text { in. } \\
(-0.84 \%) \\
\sigma=0.00034 \text { in. }\end{array}$ & $\begin{array}{r}-0.0057 \mathrm{in} . \\
(-1.17 \%) \\
\sigma=0.00017 \mathrm{in} .\end{array}$ & $\begin{array}{r}-0.0058 \text { in. } \\
(-1.19 \%) \\
\sigma=0.00021 \text { in. }\end{array}$ & $\begin{array}{r}-0.0059 \text { in. } \\
(-1.21 \%) \\
\sigma=0.00023 \text { in. }\end{array}$ & $\begin{array}{r}-0.0058 \text { in. } \\
(-1.19 \%) \\
\sigma=0.00022 \text { in. }\end{array}$ \\
\hline $\begin{array}{l}\text { 6-3-3 } \\
\text { len. } 0.98807 \mathrm{in.} \\
\text { dia. } 0.4868 \mathrm{in.}\end{array}$ & $\begin{array}{r}-0.0085 \text { in. } \\
(-0.86 \%) \\
\sigma=0.00078 \mathrm{in} .\end{array}$ & $\begin{array}{r}-0.0048 \text { in. } \\
(-0.98 \%) \\
\sigma=0.00017 \mathrm{in} .\end{array}$ & $\begin{array}{r}-0.0051 \mathrm{in} . \\
(-1.05 \%) \\
\sigma=0.00019 \mathrm{in} .\end{array}$ & $\begin{array}{r}-0.0055 \text { in. } \\
(-1.13 \%) \\
\sigma=0.00029 \mathrm{in} .\end{array}$ & $\begin{array}{r}-0.0051 \text { in. } \\
(-1.05 \%) \\
\sigma=0.00037 \mathrm{in} .\end{array}$ \\
\hline $\begin{array}{l}\mathbf{6 - 4 - 3} \\
\text { len. } 0.98197 \mathrm{in.} \\
\text { dia. } 0.4869 \mathrm{in.}\end{array}$ & $\begin{array}{r}-0.0046 \text { in. } \\
(-0.46 \%) \\
\sigma=0.00088 \text { in. }\end{array}$ & $\begin{array}{r}-0.0038 \mathrm{in} . \\
(-0.77 \%) \\
\sigma=0.00028 \mathrm{in} .\end{array}$ & $\begin{array}{r}-0.0045 \mathrm{in} . \\
(-0.93 \%) \\
\sigma=0.00030 \mathrm{in} .\end{array}$ & $\begin{array}{r}-0.0051 \text { in. } \\
(-1.04 \%) \\
\sigma=0.00021 \mathrm{in} .\end{array}$ & $\begin{array}{r}-0.0045 \mathrm{in} . \\
(-0.91 \%) \\
\sigma=0.00061 \mathrm{in} .\end{array}$ \\
\hline
\end{tabular}




\section{A-1.7 Backup Contact Measurements on Compacts}

An economical backup compact metrology apparatus based on commercial contact micrometers (one for length and one for diameter) was developed in case the camera-based noncontact system became nonfunctional. Both micrometers have a resolution of 0.0001 inch and must be read through the hot cell window with binoculars. As shown in Figure A-2, the last digit must be read with the aid of a mirror. The apparatus must be calibrated to a cylindrical steel standard on a daily basis to establish offset values that are used to adjust readings for accurate compact dimensions.

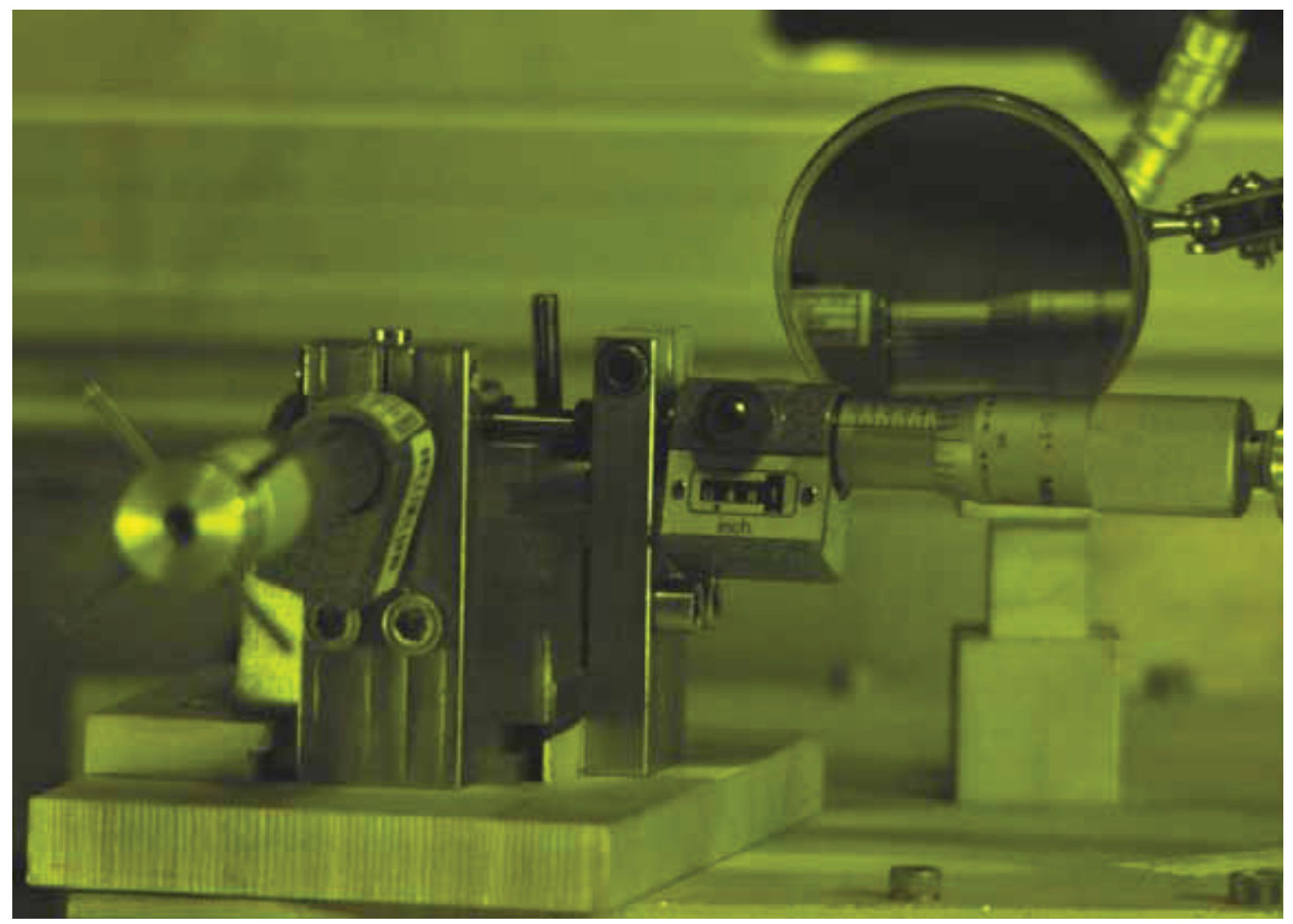

Figure A-2. Compact backup metrology apparatus in use on an irradiated AGR-1 compact.

Although the camera-based system remained in service throughout the AGR-1 metrology campaign, the backup compact apparatus was employed to spot-check diameters and lengths on three compacts from each of Capsules 1 and 4. Results of this comparison are presented in Table A-7, where image diameters are regional averages of 15 values with five from each azimuth and where image lengths are averages of the four lengths from each azimuth. Only one backup value was measured for each Table A-7 entry to limit the possibility of handling damage.

Table A-7 shows generally good agreement between the two methods on compact diameters. Diameter agreement is somewhat better on Capsule 1 compacts than on Capsule 4 compacts. This is attributed to a 0.0004-inch difference in the diameter offsets measured on a steel standard by the backup compact apparatus on the 2 days during which the two batches of AGR-1 compacts were characterized. In-cell temperatures were nearly identical over this period, so the cause of this offset shift is not obvious. In any case, the compact backup apparatus evidently is subject to bias errors of this magnitude. When combined with the 0.0045 -inch resolution limit in image dimensions, occasional differences approaching 0.001 inch between the two methods should be anticipated. 
Table A-7. Backup and image dimensions from select AGR-1 fuel compacts (in inches).

\begin{tabular}{|c|c|c|c|c|c|}
\hline Compact & $\begin{array}{c}\text { Axial } \\
\text { Region }\end{array}$ & $\begin{array}{c}\text { Backup } \\
\text { Diameter }\end{array}$ & $\begin{array}{c}\text { Image } \\
\text { Diameter } \\
\text { Averages }\end{array}$ & Backup Length & $\begin{array}{c}\text { Image Length } \\
\text { Averages by Azimuth }\end{array}$ \\
\hline \multirow{3}{*}{$1-1-1$} & Upper & 0.4807 & 0.4804 & \multirow{3}{*}{0.9845} & 0.9853 at $0^{\circ}$ \\
\hline & Middle & 0.4810 & 0.4808 & & 0.9855 at $120^{\circ}$ \\
\hline & Lower & 0.4817 & 0.4813 & & 0.9851 at $240^{\circ}$ \\
\hline \multirow{3}{*}{$1-2-2$} & Upper & 0.4801 & 0.4800 & \multirow{3}{*}{0.9850} & 0.9857 at $0^{\circ}$ \\
\hline & Middle & 0.4798 & 0.4801 & & 0.9866 at $120^{\circ}$ \\
\hline & Lower & 0.4809 & 0.4806 & & 0.9851 at $240^{\circ}$ \\
\hline \multirow{3}{*}{$1-3-3$} & Upper & 0.4788 & 0.4788 & \multirow{3}{*}{0.9843} & 0.9841 at $0^{\circ}$ \\
\hline & Middle & 0.4787 & 0.4789 & & 0.9844 at $120^{\circ}$ \\
\hline & Lower & 0.4795 & 0.4790 & & 0.9855 at $240^{\circ}$ \\
\hline \multirow{3}{*}{$4-1-1$} & Upper & 0.4803 & 0.4812 & \multirow{3}{*}{0.9859} & 0.9881 at $0^{\circ}$ \\
\hline & Middle & 0.4808 & 0.4812 & & 0.9878 at $120^{\circ}$ \\
\hline & Lower & 0.4809 & 0.4811 & & 0.9880 at $240^{\circ}$ \\
\hline \multirow{3}{*}{$4-2-2$} & Upper & 0.4805 & 0.4809 & \multirow{3}{*}{0.9832} & 0.9844 at $0^{\circ}$ \\
\hline & Middle & 0.4798 & 0.4809 & & 0.9841 at $120^{\circ}$ \\
\hline & Lower & 0.4802 & 0.4807 & & 0.9850 at $240^{\circ}$ \\
\hline \multirow{3}{*}{ 4-3-3 } & Upper & 0.4804 & 0.4815 & \multirow{3}{*}{0.9879} & 0.9873 at $0^{\circ}$ \\
\hline & Middle & 0.4810 & 0.4815 & & 0.9874 at $120^{\circ}$ \\
\hline & Lower & 0.4809 & 0.4814 & & 0.9877 at $240^{\circ}$ \\
\hline
\end{tabular}

An offset shift of 0.0005 inches in length of the steel standard was found for the backup apparatus during these 2 days. Thus, length measurements on AGR-1 compacts ideally should also have agreed within approximately 0.001 inch. However, Table A-7 reveals that several larger differences were encountered. At the 120-degree azimuth of Compact 1-2-2 and the 240-degree azimuth of Compact 1-3-3, the poor agreement is related to slanted end caps that produced anomalously high lengths in camera images taken at these particular orientations. The micrometer probe tip on the backup apparatus is flat but only 0.24-inch wide, so it cannot detect a peripheral crown when centered on the compact axis. Consistently large length discrepancies at all azimuths on Compacts 4-1-1 and 4-2-2 are not so easily explained. These compacts were on opposite sides of the fracture induced in the Capsule 4 graphite holder in order to unload the compacts. Close examination of Compact 4-1-1 and Compact 4-2-2 images shows bottom ends that are rougher than most AGR-1 compacts, suggesting an accumulation of fine debris that perhaps originated in the graphite holder. This material probably increased length measurements on these images, and it would also have increased backup length measurements if still present at the time. However, some of this debris may have been dislodged during container loading and unloading by rubbing against cushioning pads before the backup measurements were made. 


\section{A-2. AGR-1 GRAPHITE FUEL HOLDER DIMENSIONS}

Dimensions were obtained from all AGR-1 graphite holders excepting the Capsule 4 holder, which was broken into pieces during disassembly. Each AGR-1 graphite holder was imaged at three azimuths facing the camera (120 degrees apart) to allow inspecting the full external surface. Due to the limited field of view of the telecentric lens, six images were stitched into a composite image at each azimuth. As with compact images, resolution of dimensions is limited by the pixel width on the digital images (approximately 0.00045 inch). As displayed in Figure A-3, two length measurements (horizontal blue lines) were made along upper and lower sides of each composite image. Thus, each length change entry in the holder dimensional tables that follow is an average from two measurements along a given side. A total of 30 diameter measurements (vertical blue lines) were made at each azimuth within six axial regions where regional diameter locations were chosen between overlapped images to minimize effects of pincushion lens distortion. The five diameters in each region were evenly spaced (via the red grid overlay) within intervals approximately 0.25 -inch long.

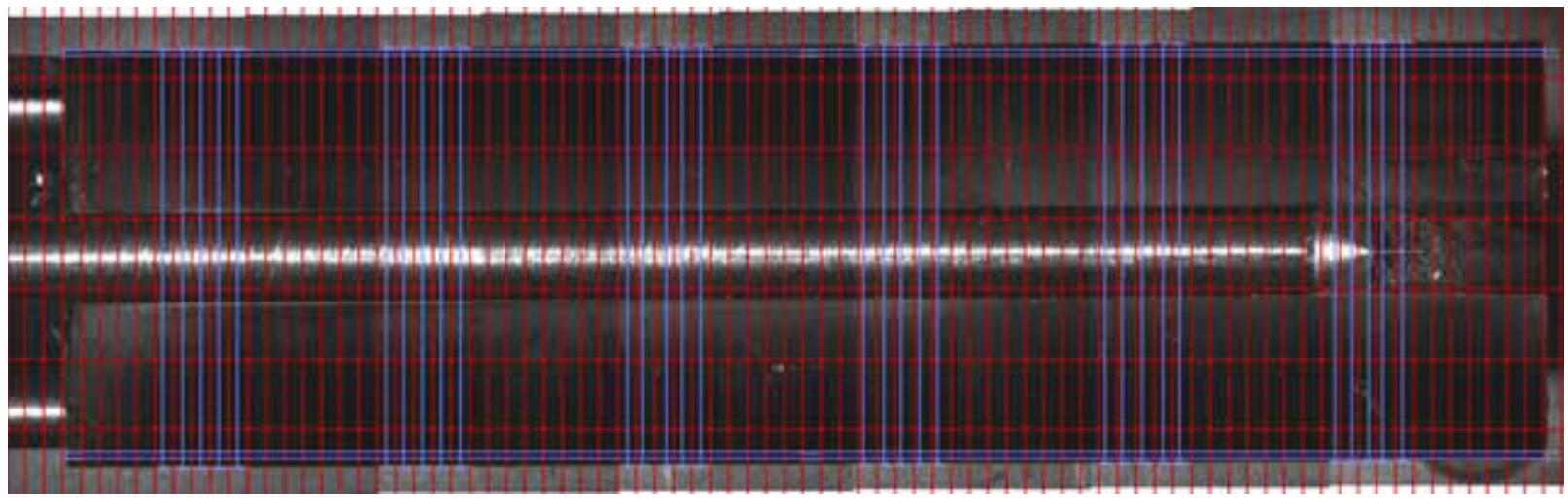

Figure A-3. Example of analyzed graphite holder composite (here Holder 6 at 0 degrees).

Holder diameter data are tabulated below in terms of absolute diameter changes and percentage changes from as-fabricated diameters. Holder length data are presented below in terms of absolute length changes and percentage changes from as-fabricated lengths. As-fabricated dimensions were extracted from the Inspection Data Traveler for SWR 98074 under which the AGR-1 graphite holders were fabricated. Only one preirradiation measurement was made of diameter and length on each holder, so it is unknown if there were any variations in as-fabricated diameter and length.

The tables of external holder dimensions below were derived from spreadsheet reports generated by the PAX-it ${ }^{\mathrm{TM}}$ image processing software (Midwest Information Systems, Inc.) that was used to extract graphite holder dimensions. These PAX-it spreadsheets, which include high resolution versions of the unprocessed and analyzed images, are maintained as controlled records on the ISASAPP Server-a designated document and records service center. These records are managed in accordance with INL PLN-2911, "NGNP Data Management and Analysis System Software Management Plan."

Error bars in Section 4.4 of the main text have a combined standard uncertainty above and below diameter change data points estimated as recommended by ANSI/NCSL Z540-2-1997, "U.S. Guide to the Expression of Uncertainty in Measurement." (No coverage factors have been applied to expand the combined uncertainty estimates into statistical confidence intervals.) Each uncertainty estimate incorporates two contributing terms combined by root-sum-squaring. The first term is the standard deviation in the regionally averaged diameter change, which reflects local variability in a graphite holder. The second smaller term is a method-related relative offset possible when extracting dimensions from images, which is computed as 0.00045 inch (one pixel width) normalized to an as-fabricated holder diameter. One pixel width is believed to be a realistic upper bound of the potential offset in each diameter 
average because individual measurements on a steel standard can be high or low by up to one pixel. Ideally the individual offsets would cancel out in the average of a large number of measurements, although the offsets would still contribute to the standard deviation. However, small net offsets were still observed between image-based average dimensions and averaged reference measurements in ECAR-900, "Qualification of AGR-1 Metrology System," where measurement uncertainty was comprehensively analyzed on a carefully characterized steel standard fabricated to resemble an AGR-1 graphite holder. Therein, net offsets (relative to reference measurements) of 0.00018 inch were determined at two azimuths and 0.00040 inch was determined at the other azimuth. For this analysis, no term was included to represent uncertainty in as-fabricated dimensions because the single diameter and length measurement precluded estimating as-fabricated variabilities.

Inner diameters of holder holes were measured after removal of fuel compacts using a commercial bore gauge with three retractable, self-centering probes. The bore gauge handle was centered in a fixture (mounted in a vise to the left beyond the field of view) as shown in Figure A-4, while each graphite holder was rigidly mounted in a separate fixture, which jointly prevented significant errors from misalignment. (The 0.4900 -inch ring gauge standard was similarly supported for calibration checks before and after each holder was characterized.) The dial indicator was read through the hot cell window with binoculars. While probes were retracted, the bore gauge was moved to different axial positions by sliding one fixture along the disassembly table rails. Depth positions inside the holder were chosen according to fiducial marks placed on the bore gauge shaft during equipment qualification. Only one reading was taken at each axial position inside each hole to reduce the possibility of gouging the interior graphite surfaces with the probe anvils. Diameter changes were calculated by comparing the bore gauge reading from the irradiated holders to similar values obtained before the irradiation. The preirradiation measurements consisted of a single inner diameter measurement for each of the three holes, and the average of the three measurements was used for the comparison.

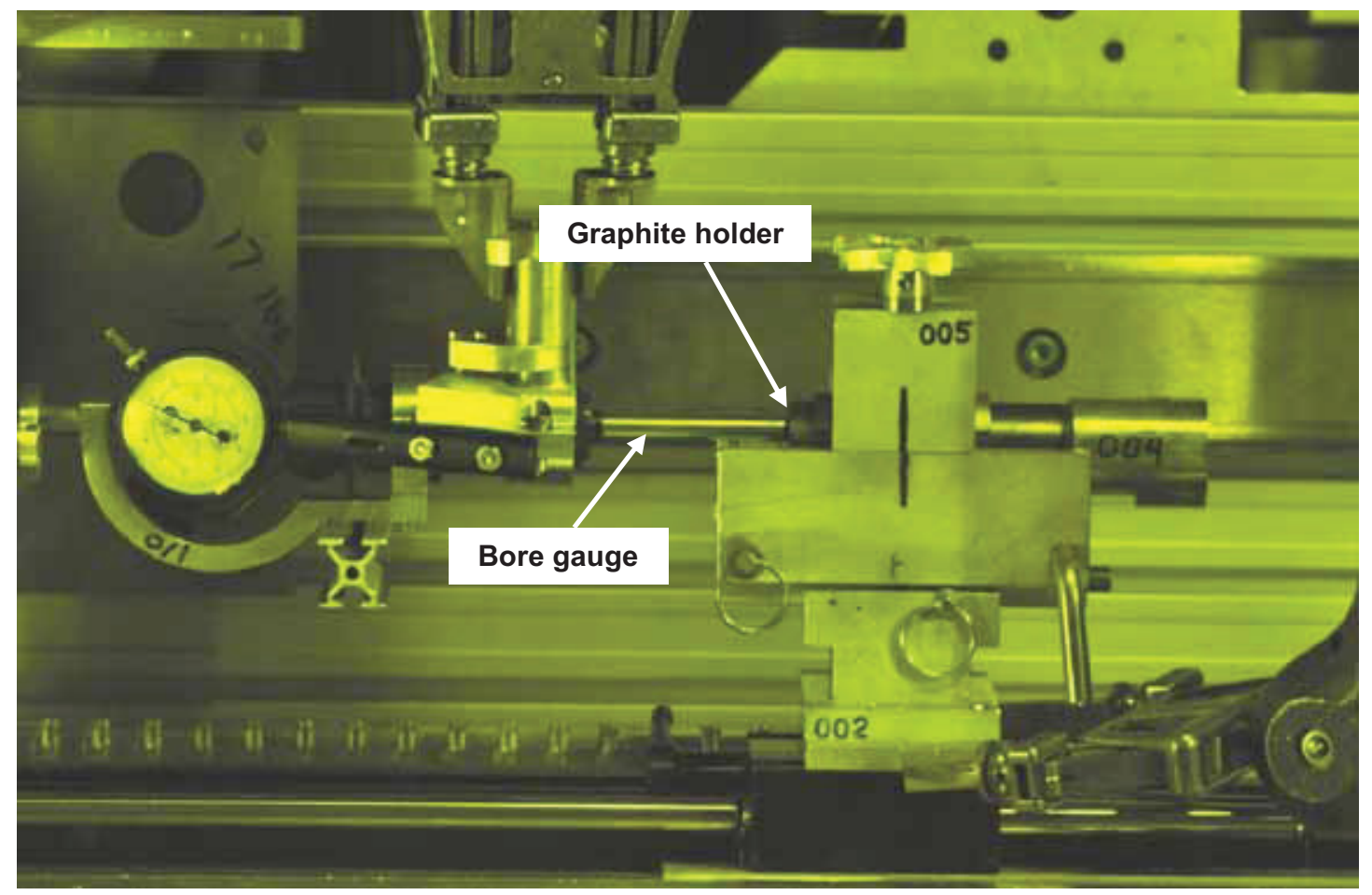

Figure A-4. Bore gauge measurements of hole diameters in the Capsule 1 graphite holder. 


\section{A-2.1 Capsule 1 Graphite Holder}

Exterior dimensional changes from Capsule 1 graphite holder images are summarized in Table A-8. Negative values indicate shrinkage from the as-fabricated measurements at room temperature (4.004-inch length and 1.219-inch diameter). At each azimuth, each regional diameter change is an average of five measurements, where the 0.25 -inch region is centered at the axial value listed. For each azimuth facing the camera, each length change is an average of two measurements made along each holder side.

Changes in hole diameters measured by bore gauge in Holder 1 are presented in Table A-9. Negative values indicate shrinkage from as-fabricated inner diameters (0.4903-inch average).

Table A-8. Exterior metrology results from AGR-1 Capsule 1 graphite holder (93 $\mathrm{F}$ ambient).

\begin{tabular}{|c|c|c|c|c|}
\hline \begin{tabular}{|c} 
Axial Region of \\
Diameters \\
(from top)
\end{tabular} & $\begin{array}{c}\Delta \text { with 0-degree } \\
\text { Azimuth Up }\end{array}$ & $\begin{array}{c}\Delta \text { with 120-degree } \\
\text { Azimuth Up }\end{array}$ & $\begin{array}{c}\Delta \text { with } 240 \text {-degree } \\
\text { Azimuth Up }\end{array}$ & $\begin{array}{c}\text { Average Dimension } \\
\text { Change (all azimuths) }\end{array}$ \\
\hline 0.4 inch & $\begin{array}{r}-0.0083 \text { inch } \\
(-0.68 \%) \\
\sigma=0.00052 \text { inch }\end{array}$ & $\begin{array}{r}-0.0084 \text { inch } \\
(-0.69 \%) \\
\sigma=0.00060 \text { inch }\end{array}$ & $\begin{array}{r}-0.0092 \text { inch } \\
(-0.75 \%) \\
\sigma=0.00052 \text { inch }\end{array}$ & $\begin{array}{r}-0.0086 \text { inch } \\
(-0.71 \%) \\
\sigma=0.00064 \text { inch }\end{array}$ \\
\hline 1.1 inches & $\begin{array}{r}-0.0057 \text { inch } \\
(-0.46 \%) \\
\sigma=0.00020 \text { inch } \\
\end{array}$ & $\begin{array}{r}-0.0058 \text { inch } \\
(-0.48 \%) \\
\sigma=0.00021 \text { inch }\end{array}$ & $\begin{array}{r}-0.0061 \text { inch } \\
(-0.50 \%) \\
\sigma=0.00021 \text { inch }\end{array}$ & $\begin{array}{r}-0.0059 \text { inch } \\
(-0.48 \%) \\
\sigma=0.00027 \text { inch }\end{array}$ \\
\hline 1.7 inches & $\begin{array}{r}-0.0056 \text { inch } \\
(-0.46 \%) \\
\sigma=0.00025 \text { inch } \\
\end{array}$ & $\begin{array}{r}-0.0056 \text { inch } \\
(-0.46 \%) \\
\sigma=0.00025 \text { inch }\end{array}$ & $\begin{array}{r}-0.0063 \text { inch } \\
(-0.52 \%) \\
\sigma=0.00021 \text { inch } \\
\end{array}$ & $\begin{array}{r}-0.0058 \text { inch } \\
(-0.48 \%) \\
\sigma=0.00042 \text { inch } \\
\end{array}$ \\
\hline 2.3 inches & $\begin{array}{r}-0.0054 \text { inch } \\
(-0.44 \%) \\
\sigma=0.00020 \text { inch } \\
\end{array}$ & $\begin{array}{r}-0.0053 \text { inch } \\
(-0.43 \%) \\
\sigma=0.00032 \text { inch } \\
\end{array}$ & $\begin{array}{r}-0.0063 \text { inch } \\
(-0.52 \%) \\
\sigma=0.00021 \mathrm{in} .\end{array}$ & $\begin{array}{r}-0.0057 \text { inch } \\
(-0.46 \%) \\
\sigma=0.00052 \text { inch } \\
\end{array}$ \\
\hline 2.9 inches & $\begin{array}{r}-0.0075 \text { inch } \\
(-0.62 \%) \\
\sigma=0.00021 \text { inch } \\
\end{array}$ & $\begin{array}{r}-0.0073 \text { inch } \\
(-0.60 \%) \\
\sigma=0.00025 \text { inch } \\
\end{array}$ & $\begin{array}{r}-0.0072 \text { inch } \\
(-0.59 \%) \\
\sigma=0.00039 \mathrm{in} .\end{array}$ & $\begin{array}{r}-0.0073 \text { inch } \\
(-0.60 \%) \\
\sigma=0.00029 \text { inch } \\
\end{array}$ \\
\hline 3.8 inches & $\begin{array}{r}-0.0113 \text { inch } \\
(-0.92 \%) \\
\sigma=0.00072 \text { inch } \\
\end{array}$ & $\begin{array}{r}-0.0108 \text { inch } \\
(-0.89 \%) \\
\sigma=0.00046 \text { inch } \\
\end{array}$ & $\begin{array}{r}-0.0104 \text { inch } \\
(-0.85 \%) \\
\sigma=0.00033 \text { inch } \\
\end{array}$ & $\begin{array}{r}-0.0108 \text { inch } \\
(-0.89 \%) \\
\sigma=0.00062 \text { inch } \\
\end{array}$ \\
\hline $\begin{array}{l}\text { Axial Length } \\
\text { Changes }\end{array}$ & $\begin{array}{r}270^{\circ}:-0.0171 \text { inch } \\
(-0.43 \%) \\
90^{\circ}:-0.0166 \text { inch } \\
(-0.42 \%) \\
\end{array}$ & $\begin{array}{r}210^{\circ}:-0.0166 \text { inch } \\
(-0.42 \%) \\
30^{\circ}:-0.0217 \text { inch } \\
(-0.54 \%) \\
\end{array}$ & $\begin{array}{r}330^{\circ}:-0.0212 \text { inch } \\
(-0.53 \%) \\
150^{\circ}:-0.0162 \text { inch } \\
(-0.40 \%) \\
\end{array}$ & $\begin{array}{r}-0.0182 \text { inch } \\
(-0.46 \%) \\
\sigma=0.00241 \text { inch }\end{array}$ \\
\hline
\end{tabular}

Table A-9. Hole diameter results from Capsule 1 graphite holder $\left(82^{\circ} \mathrm{F}\right.$ ambient).

\begin{tabular}{|l|c|r|r|}
\hline \multicolumn{1}{|c|}{$\begin{array}{c}\text { Axial Position } \\
\text { (from top) }\end{array}$} & Hole 1 & Hole 2 & Hole 3 \\
\hline $1 / 2$ inch & -0.0038 inch $(-0.78 \%)$ & -0.0038 inch $(-0.78 \%)$ & -0.0038 inch $(-0.78 \%)$ \\
\hline $1 \frac{1}{4}$ inches & -0.0028 inch $(-0.57 \%)$ & -0.0033 inch $(-0.67 \%)$ & -0.0028 inch $(-0.57 \%)$ \\
\hline 2 inches & -0.0028 inch $(-0.57 \%)$ & -0.0028 inch $(-0.57 \%)$ & -0.0028 inch $(-0.57 \%)$ \\
\hline $23 / 4$ inches & -0.0028 inch $(-0.57 \%)$ & -0.0033 inch $(-0.67 \%)$ & -0.0028 inch $(-0.57 \%)$ \\
\hline $3 \frac{1}{2}$ inches & -0.0043 inch $(-0.88 \%)$ & -0.0043 inch $(-0.88 \%)$ & -0.0038 inch $(-0.78 \%)$ \\
\hline Axial Average & -0.0033 inch $(-0.67 \%)$ & -0.0035 inch $(-0.71 \%)$ & -0.0032 inch $(-0.65 \%)$ \\
\hline
\end{tabular}




\section{A-2.2 Capsule 2 Graphite Holder}

Exterior dimensional changes from images of the Capsule 2 graphite holder are summarized in Table A-10. Positive values indicate growth relative to the as-fabricated measurements at room temperature (1.234-inch diameter and 4.007-inch length). At each azimuth, each regional diameter change is an average of five measurements, where the 0.25 -inch region is centered at the axial value listed. For each azimuth facing the camera, each length change is an average of two measurements made along each holder side.

Changes in hole diameters measured by bore gauge in Holder 2 are presented in Table A-11. Positive values indicate expansion from as-fabricated measurements ( 0.490 inch in all three holes).

Table A-10. Exterior metrology results from AGR-1 Capsule 2 graphite holder ( $86^{\circ} \mathrm{F}$ ambient).

\begin{tabular}{|c|c|c|c|c|}
\hline $\begin{array}{c}\text { Axial Region of } \\
\text { Diameters (from } \\
\text { top) }\end{array}$ & $\begin{array}{c}\Delta \text { with 0-degree } \\
\text { Azimuth Up }\end{array}$ & $\begin{array}{c}\Delta \text { with 120-degree } \\
\text { Azimuth Up }\end{array}$ & $\begin{array}{c}\Delta \text { with 240-degree } \\
\text { Azimuth Up }\end{array}$ & $\begin{array}{c}\text { Average Dimension } \\
\text { Change (all } \\
\text { azimuths) }\end{array}$ \\
\hline 0.3 inch & $\begin{array}{r}0.0181 \mathrm{inch} \\
(1.47 \%) \\
\sigma=0.00367 \mathrm{inch} \\
\end{array}$ & $\begin{array}{r}0.0197 \mathrm{inch} \\
(1.60 \%) \\
\sigma=0.00248 \mathrm{inch} \\
\end{array}$ & $\begin{array}{r}0.0177 \text { inch } \\
(1.44 \%) \\
\sigma=0.00110 \text { inch } \\
\end{array}$ & $\begin{array}{r}0.0185 \text { inch } \\
(1.50 \%) \\
\sigma=0.00260 \mathrm{inch} \\
\end{array}$ \\
\hline 1.0 inch & $\begin{array}{r}0.0119 \mathrm{inch} \\
(0.97 \%) \\
\sigma=0.00039 \mathrm{inch} \\
\end{array}$ & $\begin{array}{r}0.0143 \text { inch } \\
(1.16 \%) \\
\sigma=0.00025 \text { inch } \\
\end{array}$ & $\begin{array}{r}0.0142 \text { inch } \\
(1.15 \%) \\
\sigma=0.00060 \text { inch } \\
\end{array}$ & $\begin{array}{r}0.0135 \text { inch } \\
(1.09 \%) \\
\sigma=0.00121 \mathrm{inch} \\
\end{array}$ \\
\hline 1.7 inches & $\begin{array}{r}0.0146 \text { inch } \\
(1.18 \%) \\
\sigma=0.00046 \text { inch }\end{array}$ & $\begin{array}{r}0.0135 \text { inch } \\
(1.09 \%) \\
\sigma=0.00025 \text { inch }\end{array}$ & $\begin{array}{r}0.0140 \text { inch } \\
(1.13 \%) \\
\sigma=0.00025 \text { inch }\end{array}$ & $\begin{array}{r}0.0140 \text { inch } \\
(1.14 \%) \\
\sigma=0.00056 \text { inch }\end{array}$ \\
\hline 2.3 inches & $\begin{array}{r}0.0104 \mathrm{inch} \\
(0.84 \%) \\
\sigma=0.00135 \mathrm{inch} \\
\end{array}$ & $\begin{array}{r}0.0119 \mathrm{inch} \\
(0.96 \%) \\
\sigma=0.00073 \mathrm{inch} \\
\end{array}$ & $\begin{array}{r}0.0128 \text { inch } \\
(1.03 \%) \\
\sigma=0.00033 \text { inch } \\
\end{array}$ & $\begin{array}{r}0.0117 \mathrm{inch} \\
(0.95 \%) \\
\sigma=0.00132 \mathrm{inch} \\
\end{array}$ \\
\hline 3.0 inches & $\begin{array}{r}0.0076 \text { inch } \\
(0.62 \%) \\
\sigma=0.00099 \text { inch } \\
\end{array}$ & $\begin{array}{r}0.0093 \text { inch } \\
(0.75 \%) \\
\sigma=0.00069 \text { inch } \\
\end{array}$ & $\begin{array}{r}0.0073 \text { inch } \\
(0.59 \%) \\
\sigma=0.00056 \text { inch } \\
\end{array}$ & $\begin{array}{r}0.0081 \mathrm{inch} \\
(0.65 \%) \\
\sigma=0.00116 \mathrm{inch} \\
\end{array}$ \\
\hline 3.7 inches & $\begin{array}{r}0.0189 \text { inch } \\
(1.53 \%) \\
\sigma=0.00323 \text { in. }\end{array}$ & $\begin{array}{r}0.0177 \mathrm{inch} \\
(1.44 \%) \\
\sigma=0.00244 \mathrm{inch} \\
\end{array}$ & $\begin{array}{r}0.0172 \mathrm{inch} \\
(1.39 \%) \\
\sigma=0.00371 \mathrm{inch} \\
\end{array}$ & $\begin{array}{r}0.0179 \mathrm{inch} \\
(1.45 \%) \\
\sigma=0.00303 \mathrm{inch} \\
\end{array}$ \\
\hline $\begin{array}{l}\text { Axial Length } \\
\text { Changes }\end{array}$ & $\begin{array}{r}270^{\circ}: 0.0445 \text { inch } \\
(1.11 \%) \\
90^{\circ}: 0.0424 \text { inch } \\
(1.06 \%)\end{array}$ & $\begin{array}{r}210^{\circ}: 0.0472 \text { inch } \\
(1.18 \%) \\
30^{\circ}: 0.0406 \text { inch } \\
(1.01 \%)\end{array}$ & $\begin{array}{r}330^{\circ}: 0.0422 \text { inch } \\
(1.05 \%) \\
150^{\circ}: 0.0431 \text { inch } \\
(1.08 \%)\end{array}$ & $\begin{array}{r}0.0433 \text { inch } \\
(1.08 \%) \\
\sigma=0.00227 \text { inch } \\
\end{array}$ \\
\hline
\end{tabular}

Table A-11. Hole diameter results from AGR-1 Capsule 2 graphite holder $\left(86^{\circ} \mathrm{F}\right.$ ambient).

\begin{tabular}{|l|r|r|r|}
\hline \multicolumn{1}{|c|}{$\begin{array}{c}\text { Axial Position } \\
\text { (from top) }\end{array}$} & Hole 1 & \multicolumn{1}{c|}{ Hole 2 } & \multicolumn{1}{c|}{ Hole 3 } \\
\hline $1 / 2$ inch & 0.0050 inch $(1.02 \%)$ & 0.0030 inch $(0.61 \%)$ & 0.0035 inch $(0.71 \%)$ \\
\hline $1 \frac{1}{4}$ inches & 0.0065 inch $(1.33 \%)$ & 0.0000 inch $(0.00 \%)$ & 0.0045 inch $(0.92 \%)$ \\
\hline 2 inches & 0.0070 inch $(1.43 \%)$ & 0.0000 inch $(0.00 \%)$ & 0.0060 inch $(1.22 \%)$ \\
\hline $23 / 4$ inches & 0.0055 inch $(1.12 \%)$ & -0.0015 inch $(-0.31 \%)$ & 0.0040 inch $(0.82 \%)$ \\
\hline $3 \frac{1}{2}$ inches & 0.0050 inch $(1.02 \%)$ & 0.0020 inch $(0.41 \%)$ & 0.0045 inch $(0.92 \%)$ \\
\hline Axial Average & 0.0058 inch $(1.18 \%)$ & 0.0007 inch $(0.14 \%)$ & 0.0045 inch $(0.92 \%)$ \\
\hline
\end{tabular}




\section{A-2.3 Capsule 3 Graphite Holder}

Exterior dimensional changes from images of the Capsule 3 graphite holder are summarized in Table A-12. Positive values indicate growth relative to the as-fabricated measurements at room temperature (1.2375-inch diameter and 4.0043-inch length). At each azimuth, each regional diameter change is an average of five measurements, where the 0.25 -inch region is centered at the axial value listed. For each azimuth facing the camera, each length change is an average of two measurements made along each holder side.

Bore gauge results from Holder 3 holes after removal of fuel compacts are presented in Table A-13. Positive values indicate expansion from as-fabricated measurements ( 0.490 inch in each hole).

Table A-12. Exterior metrology results from AGR-1 Capsule 3 graphite holder ( $92^{\circ} \mathrm{F}$ ambient).

\begin{tabular}{|c|c|c|c|c|}
\hline $\begin{array}{l}\text { Axial Region of } \\
\text { Diameters } \\
\text { (from top) }\end{array}$ & $\begin{array}{l}\Delta \text { with 0-degree } \\
\text { Azimuth Up }\end{array}$ & $\begin{array}{c}\Delta \text { with 120-degree } \\
\text { Azimuth Up }\end{array}$ & $\begin{array}{c}\Delta \text { with 240-degree } \\
\text { Azimuth Up }\end{array}$ & $\begin{array}{l}\text { Average Dimension } \\
\text { Change (all azimuths) }\end{array}$ \\
\hline 0.4 inch & $\begin{array}{r}0.0162 \text { inch } \\
(1.31 \%) \\
\sigma=0.00033 \text { inch } \\
\end{array}$ & $\begin{array}{r}0.0183 \text { inch } \\
(1.48 \%) \\
\sigma=0.00025 \text { inch } \\
\end{array}$ & $\begin{array}{r}0.0152 \text { inch } \\
(1.23 \%) \\
\sigma=0.00033 \text { inch } \\
\end{array}$ & $\begin{array}{r}0.0166 \text { inch } \\
(1.34 \%) \\
\sigma=0.00134 \text { inch } \\
\end{array}$ \\
\hline $1.0 \mathrm{inch}$ & $\begin{array}{r}0.0175 \mathrm{inch} \\
(1.42 \%) \\
\sigma=0.00033 \mathrm{inch} \\
\end{array}$ & $\begin{array}{r}0.0181 \mathrm{inch} \\
(1.46 \%) \\
\sigma=0.00039 \mathrm{inch} \\
\end{array}$ & $\begin{array}{r}0.0163 \text { inch } \\
(1.31 \%) \\
\sigma=0.00021 \mathrm{inch} \\
\end{array}$ & $\begin{array}{r}0.0173 \text { inch } \\
(1.40 \%) \\
\sigma=0.00085 \text { inch } \\
\end{array}$ \\
\hline $1.7 \mathrm{in}$ & $\begin{array}{r}0.0179 \text { inch } \\
(1.45 \%) \\
\sigma=0.00050 \mathrm{inch} \\
\end{array}$ & $\begin{array}{r}0.0177 \mathrm{inch} \\
(1.43 \%) \\
\sigma=0.00025 \mathrm{inch} \\
\end{array}$ & $\begin{array}{r}0.0168 \text { inch } \\
(1.36 \%) \\
\sigma=0.00052 \text { inch } \\
\end{array}$ & $\begin{array}{r}0.0175 \text { inch } \\
(1.41 \%) \\
\sigma=0.00064 \text { inch } \\
\end{array}$ \\
\hline 2.3 inches & $\begin{array}{r}0.0167 \mathrm{inch} \\
(1.35 \%) \\
\sigma=0.00020 \mathrm{inch} \\
\end{array}$ & $\begin{array}{r}0.0177 \mathrm{inch} \\
(1.43 \%) \\
\sigma=0.00025 \mathrm{inch} \\
\end{array}$ & $\begin{array}{r}0.0186 \text { inch } \\
(1.51 \%) \\
\sigma=0.00025 \mathrm{inch} \\
\end{array}$ & $\begin{array}{r}0.0177 \mathrm{inch} \\
(1.43 \%) \\
\sigma=0.00084 \mathrm{inch} \\
\end{array}$ \\
\hline 2.9 inches & $\begin{array}{r}0.0154 \mathrm{inch} \\
(1.25 \%) \\
\sigma=0.00090 \mathrm{inch} \\
\end{array}$ & $\begin{array}{r}0.0168 \text { inch } \\
(1.36 \%) \\
\sigma=0.00025 \text { inch } \\
\end{array}$ & $\begin{array}{r}0.0163 \text { inch } \\
(1.32 \%) \\
\sigma=0.00025 \text { inch } \\
\end{array}$ & $\begin{array}{r}0.0162 \mathrm{inch} \\
(1.31 \%) \\
\sigma=0.00079 \mathrm{inch} \\
\end{array}$ \\
\hline 3.5 inches & $\begin{array}{r}0.0176 \mathrm{inch} \\
(1.42 \%) \\
\sigma=0.00143 \mathrm{inch} \\
\end{array}$ & $\begin{array}{r}0.0178 \mathrm{inch} \\
(1.44 \%) \\
\sigma=0.00095 \mathrm{inch} \\
\end{array}$ & $\begin{array}{r}0.0189 \text { inch } \\
(1.53 \%) \\
\sigma=0.00046 \text { inch } \\
\end{array}$ & $\begin{array}{r}0.0181 \mathrm{inch} \\
(1.46 \%) \\
\sigma=0.00112 \mathrm{inch} \\
\end{array}$ \\
\hline $\begin{array}{l}\text { Axial Length } \\
\text { Changes }\end{array}$ & $\begin{array}{r}315^{\circ *}: 0.0518 \mathrm{inch} \\
(1.29 \%) \\
90^{\circ}: 0.0479 \mathrm{inch} \\
(1.20 \%)\end{array}$ & $\begin{array}{r}210^{\circ}: 0.0534 \mathrm{inch} \\
(1.33 \%) \\
30^{\circ}: 0.0481 \mathrm{inch} \\
(1.20 \%) \\
\end{array}$ & $\begin{array}{r}330^{\circ}: 0.0520 \mathrm{inch} \\
(1.30 \%) \\
150^{\circ}: 0.0541 \mathrm{inch} \\
(1.35 \%) \\
\end{array}$ & $\begin{array}{r}0.0512 \text { inch } \\
(1.28 \%) \\
\sigma=0.00256 \text { inch }\end{array}$ \\
\hline
\end{tabular}

* Length measurements not possible at 270 degrees because of a missing piece broken out during disassembly. Closest available full-length azimuth was at approximately 315 degrees.

Table A-13. Hole diameter results from AGR-1 Capsule 3 graphite holder ( $92^{\circ} \mathrm{F}$ ambient).

\begin{tabular}{|l|r|r|r|}
\hline \multicolumn{1}{c|}{$\begin{array}{c}\text { Axial Position } \\
\text { (from top) }\end{array}$} & Hole 1 & Hole 2 & Hole 3 \\
\hline $1 / 2$ inch & 0.0070 inch $(1.43 \%)$ & 0.0030 inch $(0.61 \%)$ & 0.0060 inch $(1.22 \%)$ \\
\hline $1 \frac{1}{4}$ inches & 0.0070 inch $(1.43 \%)$ & 0.0020 inch $(0.41 \%)$ & 0.0075 inch $(1.53 \%)$ \\
\hline 2 inches & 0.0070 inch $(1.43 \%)$ & 0.0020 inch $(0.41 \%)$ & 0.0075 inch $(1.53 \%)$ \\
\hline $23 / 4$ inches & 0.0050 inch $(1.02 \%)$ & 0.0015 inch $(0.31 \%)$ & 0.0070 inch $(1.43 \%)$ \\
\hline $3 \frac{1}{2}$ inches & 0.0035 inch $(0.71 \%)$ & 0.0020 inch $(0.41 \%)$ & 0.0050 inch $(1.02 \%)$ \\
\hline Axial Average & 0.0059 inch $(1.20 \%)$ & 0.0021 inch $(0.43 \%)$ & 0.0066 inch $(1.35 \%)$ \\
\hline
\end{tabular}




\section{A-2.4 Capsule 5 Graphite Holder}

Exterior dimensional changes from the Capsule 5 graphite holder are given in Table A-14. Positive values show growth from preirradiation room temperature values (1.228-inch diameter and 4.002-inch length). At each azimuth, each regional diameter change is an average of five measurements, where the 0.25 -inch region is centered at the axial value listed. For each azimuth facing the camera, each length change is an average of two measurements made along each holder side.

Changes in hole diameters measured by bore gauge in Holder 5 are presented in Table A-15. Positive values indicate expansion from as-fabricated measurements ( 0.490 inch in all three holes).

Table A-14. Exterior metrology results from AGR-1 Capsule 5 graphite holder ( $90^{\circ} \mathrm{F}$ ambient).

\begin{tabular}{|c|c|c|c|c|}
\hline $\begin{array}{l}\text { Axial Region of } \\
\begin{array}{l}\text { Diameters } \\
\text { (from top) }\end{array}\end{array}$ & $\begin{array}{c}\Delta \text { with 0-degree } \\
\text { Azimuth Up }\end{array}$ & $\begin{array}{c}\Delta \text { with 120-degree } \\
\text { Azimuth Up }\end{array}$ & $\begin{array}{c}\Delta \text { with 240-degree } \\
\text { Azimuth Up }\end{array}$ & $\begin{array}{l}\text { Average Dimension } \\
\text { Change (all azimuths) }\end{array}$ \\
\hline 0.4 inch & $\begin{array}{r}0.0270 \mathrm{inch} \\
(2.20 \%) \\
\sigma=0.00195 \mathrm{inch}\end{array}$ & $\begin{array}{r}0.0260 \mathrm{inch} \\
(2.12 \%) \\
\sigma=0.00104 \mathrm{inch}\end{array}$ & $\begin{array}{r}0.0258 \text { inch } \\
(2.10 \%) \\
\sigma=0.00238 \text { inch }\end{array}$ & $\begin{array}{r}0.0263 \text { inch } \\
(2.14 \%) \\
\sigma=0.00182 \text { inch }\end{array}$ \\
\hline 1.1 inches & $\begin{array}{r}0.0224 \text { inch } \\
(1.83 \%) \\
\sigma=0.00065 \text { inch }\end{array}$ & $\begin{array}{r}0.0173 \text { inch } \\
(1.41 \%) \\
\sigma=0.00082 \text { inch }\end{array}$ & $\begin{array}{r}0.0187 \text { inch } \\
(1.52 \%) \\
\sigma=0.00110 \mathrm{inch}\end{array}$ & $\begin{array}{r}0.0195 \text { inch } \\
(1.59 \%) \\
\sigma=0.00239 \text { inch } \\
\end{array}$ \\
\hline 1.7 inches & $\begin{array}{r}0.0148 \mathrm{inch} \\
(1.21 \%) \\
\sigma=0.00041 \mathrm{inch}\end{array}$ & $\begin{array}{r}0.0151 \mathrm{inch} \\
(1.23 \%) \\
\sigma=0.00065 \mathrm{inch}\end{array}$ & $\begin{array}{r}0.0148 \mathrm{inch} \\
(1.21 \%) \\
\sigma=0.00025 \mathrm{inch}\end{array}$ & $\begin{array}{r}0.0149 \text { inch } \\
(1.21 \%) \\
\sigma=0.00045 \text { inch }\end{array}$ \\
\hline 2.4 inches & $\begin{array}{r}0.0115 \mathrm{inch} \\
(0.94 \%) \\
\sigma=0.00100 \mathrm{inch} \\
\end{array}$ & $\begin{array}{r}0.0099 \mathrm{inch} \\
(0.80 \%) \\
\sigma=0.00041 \mathrm{inch} \\
\end{array}$ & $\begin{array}{r}0.0115 \text { inch } \\
(0.94 \%) \\
\sigma=0.00060 \mathrm{inch} \\
\end{array}$ & $\begin{array}{r}0.0110 \mathrm{inch} \\
(0.89 \%) \\
\sigma=0.00104 \mathrm{inch} \\
\end{array}$ \\
\hline 3.0 inches & $\begin{array}{r}0.0070 \mathrm{inch} \\
(0.57 \%) \\
\sigma=0.00041 \mathrm{inch}\end{array}$ & $\begin{array}{r}0.0084 \mathrm{inch} \\
(0.68 \%) \\
\sigma=0.00069 \mathrm{inch}\end{array}$ & $\begin{array}{r}0.0091 \mathrm{inch} \\
(0.74 \%) \\
\sigma=0.00046 \text { inch }\end{array}$ & $\begin{array}{r}0.0082 \text { inch } \\
(0.67 \%) \\
\sigma=0.00103 \text { inch }\end{array}$ \\
\hline 3.7 inches & $\begin{array}{r}0.0146 \text { inch } \\
(1.19 \%) \\
\sigma=0.00215 \mathrm{inch}\end{array}$ & $\begin{array}{r}0.0164 \mathrm{inch} \\
(1.33 \%) \\
\sigma=0.00402 \mathrm{inch}\end{array}$ & $\begin{array}{r}0.0182 \mathrm{inch} \\
(1.48 \%) \\
\sigma=0.00286 \mathrm{inch}\end{array}$ & $\begin{array}{r}0.0164 \text { inch } \\
(1.34 \%) \\
\sigma=0.00325 \text { inch }\end{array}$ \\
\hline $\begin{array}{l}\text { Axial Length } \\
\text { Changes }\end{array}$ & $\begin{array}{r}270^{\circ}: 0.0557 \text { inch } \\
(1.39 \%) \\
90^{\circ}: 0.0502 \text { inch } \\
(1.25 \%) \\
\end{array}$ & $\begin{array}{r}210^{\circ}: 0.0463 \text { inch } \\
(1.16 \%) \\
30^{\circ}: 0.0522 \text { inch } \\
(1.30 \%)\end{array}$ & $\begin{array}{r}330^{\circ}: 0.0545 \text { inch } \\
(1.36 \%) \\
150^{\circ}: 0.0437 \text { inch } \\
(1.09 \%) \\
\end{array}$ & $\begin{array}{r}0.0504 \text { inch } \\
(1.26 \%) \\
\sigma=0.00449 \text { inch }\end{array}$ \\
\hline
\end{tabular}

Table A-15. Hole diameter results from AGR-1 Capsule 5 graphite holder $\left(92^{\circ} \mathrm{F}\right.$ ambient).

\begin{tabular}{|l|c|c|c|}
\hline \multicolumn{1}{|c|}{$\begin{array}{c}\text { Axial Position } \\
\text { (from top) }\end{array}$} & Hole 1 & Hole 2 & Hole 3 \\
\hline $1 / 2$ inch & 0.0080 inch $(1.63 \%)$ & 0.0060 inch $(1.22 \%)$ & 0.0090 inch $(1.84 \%)$ \\
\hline $1 \frac{1}{4}$ inches & 0.0080 inch $(1.63 \%)$ & 0.0010 inch $(0.20 \%)$ & 0.0080 inch $(1.63 \%)$ \\
\hline 2 inches & 0.0050 inch $(1.02 \%)$ & 0.0005 inch $(0.10 \%)$ & 0.0065 inch $(1.33 \%)$ \\
\hline $23 / 4$ inches & 0.0030 inch $(0.61 \%)$ & 0.0010 inch $(0.20 \%)$ & 0.0035 inch $(0.71 \%)$ \\
\hline $3 \frac{1}{2}$ inches & 0.0025 inch $(0.51 \%)$ & 0.0025 inch $(0.51 \%)$ & 0.0055 inch $(1.12 \%)$ \\
\hline Axial Average & 0.0053 inch $(1.08 \%)$ & 0.0022 inch $(0.45 \%)$ & 0.0065 inch $(1.33 \%)$ \\
\hline
\end{tabular}




\section{A-2.5 Capsule 6 Graphite Holder}

Exterior dimensional changes from Capsule 6 graphite holder images are summarized in Table A-16. Negative values indicate shrinkage from as-fabricated measurements at room temperature (1.119-inch diameter and 4.0014-inch length). At each azimuth, each regional diameter change is an average of five measurements, where the 0.25 -inch region is centered at the axial value listed. For each azimuth facing the camera, each length change is an average of two measurements made along each holder side.

Results of the Holder 6 bore gauge measurements are presented in Table A-17, where negative values indicate shrinkage from as-fabricated hole diameters (0.4907-inch average).

Table A-16. Exterior metrology results from AGR-1 Capsule 6 graphite holder ( $86^{\circ} \mathrm{F}$ ambient).

\begin{tabular}{|c|c|c|c|c|}
\hline $\begin{array}{c}\text { Axial Region of } \\
\text { Diameters } \\
\text { (from top) }\end{array}$ & $\begin{array}{c}\Delta \text { with 0-degree } \\
\text { Azimuth Up }\end{array}$ & $\begin{array}{c}\Delta \text { with 120-degree } \\
\text { Azimuth Up }\end{array}$ & $\begin{array}{c}\Delta \text { with 240-degree } \\
\text { Azimuth Up }\end{array}$ & $\begin{array}{c}\text { Average Dimension } \\
\text { Change (all azimuths) }\end{array}$ \\
\hline 0.4 inch & $\begin{array}{r}-0.0082 \text { inch } \\
(-0.68 \%) \\
\sigma=0.00025 \text { inch }\end{array}$ & $\begin{array}{r}-0.0078 \text { inch } \\
(-0.65 \%) \\
\sigma=0.00021 \text { inch }\end{array}$ & $\begin{array}{r}-0.0079 \text { inch } \\
(-0.66 \%) \\
\sigma=0.00032 \text { inch }\end{array}$ & $\begin{array}{r}-0.0080 \text { inch } \\
(-0.67 \%) \\
\sigma=0.00029 \text { inch }\end{array}$ \\
\hline 1.0 inch & $\begin{array}{r}-0.0049 \text { inch } \\
(-0.41 \%) \\
\sigma=0.00025 \text { inch }\end{array}$ & $\begin{array}{r}-0.0049 \text { inch } \\
(-0.41 \%) \\
\sigma=0.00025 \text { inch }\end{array}$ & $\begin{array}{r}-0.0049 \text { inch } \\
(-0.41 \%) \\
\sigma=0.00025 \text { inch }\end{array}$ & $\begin{array}{r}-0.0049 \text { inch } \\
(-0.41 \%) \\
\sigma=0.00023 \text { inch }\end{array}$ \\
\hline 1.7 inches & $\begin{array}{r}-0.0045 \text { inch } \\
(-0.37 \%) \\
\sigma=0.00025 \text { inch } \\
\end{array}$ & $\begin{array}{r}-0.0044 \text { inch } \\
(-0.37 \%) \\
\sigma=0.00038 \text { inch }\end{array}$ & $\begin{array}{r}-0.0045 \text { inch } \\
(-0.37 \%) \\
\sigma=0.00025 \text { inch } \\
\end{array}$ & $\begin{array}{r}-0.0044 \text { inch } \\
(-0.37 \%) \\
\sigma=0.00028 \text { inch } \\
\end{array}$ \\
\hline 2.4 inches & $\begin{array}{r}-0.0044 \text { inch } \\
(-0.37 \%) \\
\sigma=0.00038 \text { inch } \\
\end{array}$ & $\begin{array}{r}-0.0044 \text { inch } \\
(-0.37 \%) \\
\sigma=0.00020 \text { inch } \\
\end{array}$ & $\begin{array}{r}-0.0045 \text { inch } \\
(-0.37 \%) \\
\sigma=0.00025 \text { inch } \\
\end{array}$ & $\begin{array}{r}-0.0044 \text { inch } \\
(-0.37 \%) \\
\sigma=0.00027 \text { inch } \\
\end{array}$ \\
\hline 3.0 inches & $\begin{array}{r}-0.0047 \text { inch } \\
(-0.40 \%) \\
\sigma=0.00032 \text { inch } \\
\end{array}$ & $\begin{array}{r}-0.0044 \text { inch } \\
(-0.37 \%) \\
\sigma=0.00038 \text { inch } \\
\end{array}$ & $\begin{array}{r}-0.0046 \text { inch } \\
(-0.38 \%) \\
\sigma=0.00025 \text { inch } \\
\end{array}$ & $\begin{array}{r}-0.0046 \text { inch } \\
(-0.38 \%) \\
\sigma=0.00033 \text { inch } \\
\end{array}$ \\
\hline 3.8 inches & $\begin{array}{r}-0.0051 \text { inch } \\
(-0.43 \%) \\
\sigma=0.00038 \text { inch } \\
\end{array}$ & $\begin{array}{r}-0.0046 \text { inch } \\
(-0.38 \%) \\
\sigma=0.00025 \text { inch } \\
\end{array}$ & $\begin{array}{l}\text { Piece broken out } \\
\text { during disassembly }\end{array}$ & $\begin{array}{r}-0.0048 \text { inch } \\
(-0.40 \%) \\
\sigma=0.00042 \text { inch } \\
\end{array}$ \\
\hline $\begin{array}{l}\text { Axial Length } \\
\text { Changes }\end{array}$ & $\begin{array}{r}270^{\circ}:-0.0086 \text { inch } \\
(-0.21 \%) \\
90^{\circ}:-0.0086 \text { inch } \\
(-0.21 \%) \\
\end{array}$ & $\begin{array}{r}210^{\circ}:-0.0079 \text { inch } \\
(-0.20 \%) \\
30^{\circ}:-0.0086 \text { inch } \\
(-0.21 \%)\end{array}$ & $\begin{array}{r}330^{\circ}:-0.0088 \text { inch } \\
(-0.22 \%) \\
150^{\circ}:-0.0084 \text { inch } \\
(-0.21 \%) \\
\end{array}$ & $\begin{array}{r}-0.0085 \text { inch } \\
(-0.21 \%) \\
\sigma=0.00044 \text { inch }\end{array}$ \\
\hline
\end{tabular}

Table A-17. Hole diameter results from AGR-1 Capsule 6 graphite holder ( $88^{\circ} \mathrm{F}$ ambient).

\begin{tabular}{|l|c|r|r|}
\hline \multicolumn{1}{|c|}{$\begin{array}{c}\text { Axial Position } \\
\text { (from top) }\end{array}$} & Hole 1 & Hole 2 & Hole 3 \\
\hline $1 / 2$ inch & -0.0047 inch $(-0.96 \%)$ & -0.0042 inch $(-0.86 \%)$ & -0.0047 inch $(-0.96 \%)$ \\
\hline $1 \frac{1}{4}$ inches & -0.0032 inch $(-0.65 \%)$ & -0.0022 inch $(-0.45 \%)$ & -0.0032 inch $(-0.65 \%)$ \\
\hline 2 inches & -0.0027 inch $(-0.55 \%)$ & -0.0022 inch $(-0.45 \%)$ & -0.0027 inch $(-0.55 \%)$ \\
\hline $23 / 4$ inches & -0.0027 inch $(-0.55 \%)$ & -0.0017 inch $(-0.35 \%)$ & -0.0027 inch $(-0.55 \%)$ \\
\hline $3 \frac{1}{2}$ inches & -0.0032 inch $(-0.65 \%)$ & -0.0017 inch $(-0.35 \%)$ & -0.0022 inch $(-0.45 \% *)$ \\
\hline Axial Average & -0.0033 inch $(-0.67 \%)$ & -0.0024 inch $(-0.49 \%)$ & -0.0031 inch $(-0.63 \%)$ \\
\hline
\end{tabular}

* Measurement possibly influenced by crack formed during disassembly. 


\section{A-2.6 Backup Contact Measurements on Holders}

A backup apparatus was developed for graphite holder metrology in case the camera-based noncontact system became nonfunctional. As with the compact backup system, the backup holder apparatus was based on two commercial micrometers, one for holder length and one for diameter. Both micrometers have a resolution of 0.0001 inch and are read through the hot cell window with binoculars. As shown in Figure A-5, the last digit must be read with the aid of a mirror. The apparatus must be calibrated to steel standards on a daily basis to establish offset values that are used to adjust readings for accurate holder dimensions.

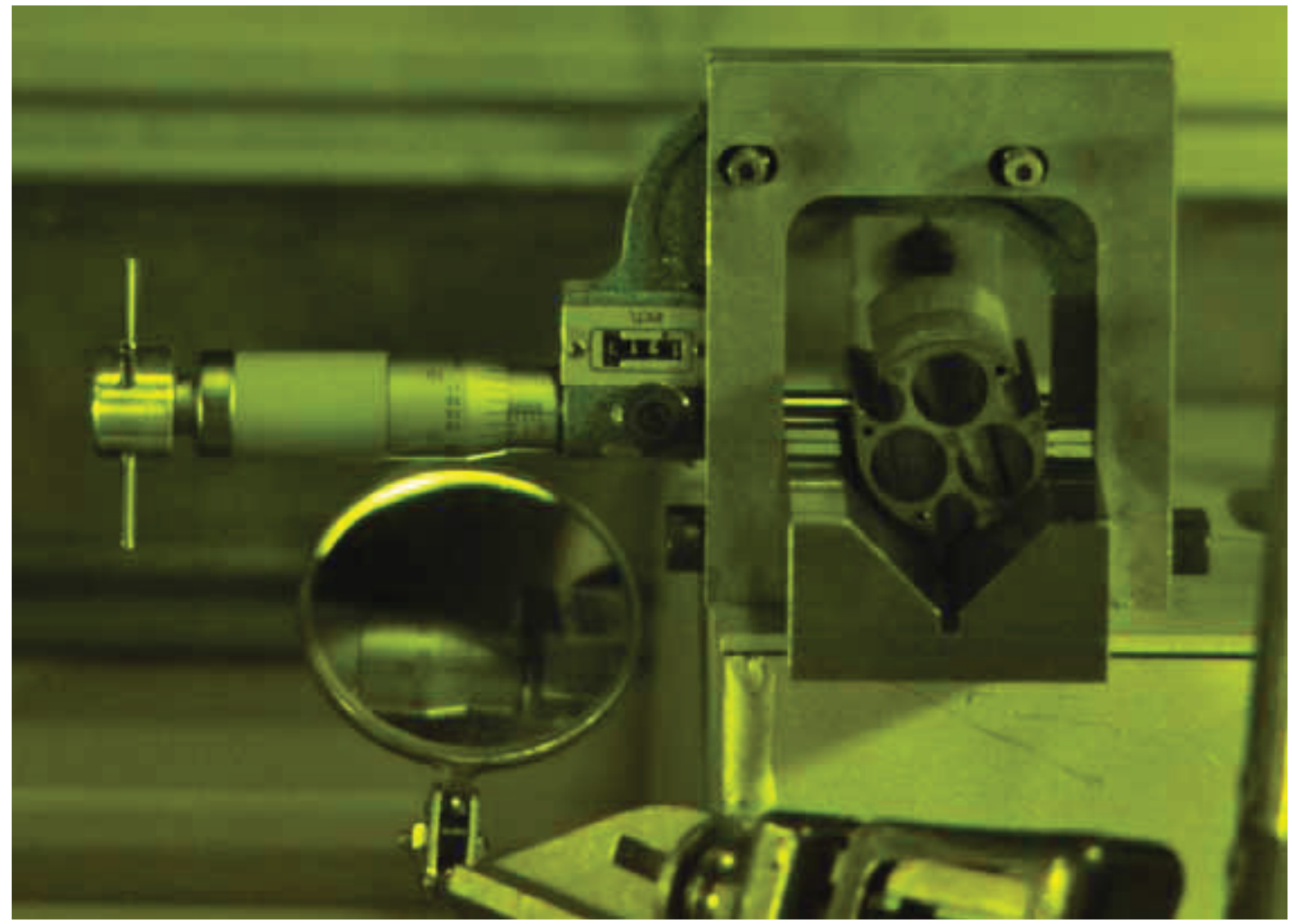

Figure A-5. Backup metrology apparatus in use on Capsule 1 graphite holder.

Although the camera-based system remained in service for the entire AGR-1 metrology campaign, this backup apparatus was employed to measure diameters and lengths on the Capsule 1 and Capsule 3 graphite holders. However, results of this effort were compromised by several problems. First, direct comparisons between the image and backup techniques were not possible at the same azimuths because of how the holder fixtures were constructed for each apparatus. As shown in Figure A-3, holders were supported with a through-tube groove facing upward during imaging. Contrariwise, Figure A-5 indicates that the backup apparatus was designed for a through-tube groove to face downward so that round sides of a holder would rest on the V-block. In addition, the backup apparatus design did not envision the substantial growth in diameters and formation of the peripheral rims found on graphite holders loaded with $7.0 \%$ boron carbide. As a consequence, the length probe was not able to engage ends of these holders at peripheral positions measured from images. Furthermore, the length probe would occasionally lift holders upward during measurements. In one case, the probe entered a compact hole. These practical difficulties prevented any meaningful comparison with image-based measurements. 